UNIVERSIDADE DE SÃO PAULO

FACULDADE DE CIÊNCIAS FARMACÊUTICAS DE RIBEIRÃO PRETO

CAMILA ALVES AREDA

Estratégia de estudo farmacoeconômico para avaliação da viabilidade de produção de medicamentos em hospital de porte especial

Ribeirão Preto 


\section{CAMILA ALVES AREDA}

Estratégia de estudo farmacoeconômico para avaliação da viabilidade de produção de medicamentos em hospital de porte especial

Tese apresentada ao Programa de Pós Graduação em Ciências Farmacêuticas da Faculdade de Ciências Farmacêuticas de Ribeirão Preto - Universidade de São Paulo para obtenção do título de Doutor em Ciências Farmacêuticas.

Área de concentração: Medicamentos e Cosméticos.

Orientador: Prof. Dr. Osvaldo de Freitas

\section{Ribeirão Preto}


AUTORIZO A REPRODUÇÃO E DIVULGAÇÃO TOTAL OU PARCIAL DESTE TRABALHO, POR QUALQUER MEIO CONVENCIONAL OU ELETRÔNICO, PARA FINS DE ESTUDO E PESQUISA, DESDE QUE CITADA A FONTE.

Areda, Camila Alves

Estratégia de estudo farmacoeconômico para avaliação da viabilidade de produção de medicamentos em hospital de porte especial. Ribeirão Preto, 2009.

177p.: il. ; $30 \mathrm{~cm}$

Tese de Doutorado, apresentada à Faculdade de Ciências Farmacêuticas de Ribeirão Preto /USP - Área de concentração: Medicamentos e Cosméticos.

Orientador: Freitas, Osvaldo de

1.Avaliação Farmacoeconômica. 2. Hospital de Porte Especial. 3. Farmácia Semi-industrial. 


\section{FOLHA DE APROVAÇÃO}

Camila Alves Areda

Estratégia de estudo farmacoeconômico para avaliação da viabilidade de produção de medicamentos em hospital de porte especial

Tese apresentada ao Programa de Pós Graduação em Ciências Farmacêuticas da Faculdade de Ciências Farmacêuticas de Ribeirão Preto - Universidade de São Paulo para obtenção do título de Doutor em Ciências Farmacêuticas.

Área de concentração: Medicamentos e Cosméticos.

Aprovado em:

Banca Examinadora

Prof. Dr.

Instituição: Assinatura:

Prof. Dr. Instituição: Assinatura:

Prof. Dr. Instituição: Assinatura:

Prof. Dr.

Instituição: Assinatura:

Prof. Dr. Instituição: Assinatura: 


\section{DEDICATÓRIA}

Aos meus pais,

Por me darem o dom da vida, Por estarem sempre presentes, Por me apoiarem durante toda minha jornada.

Obrigada por tudo

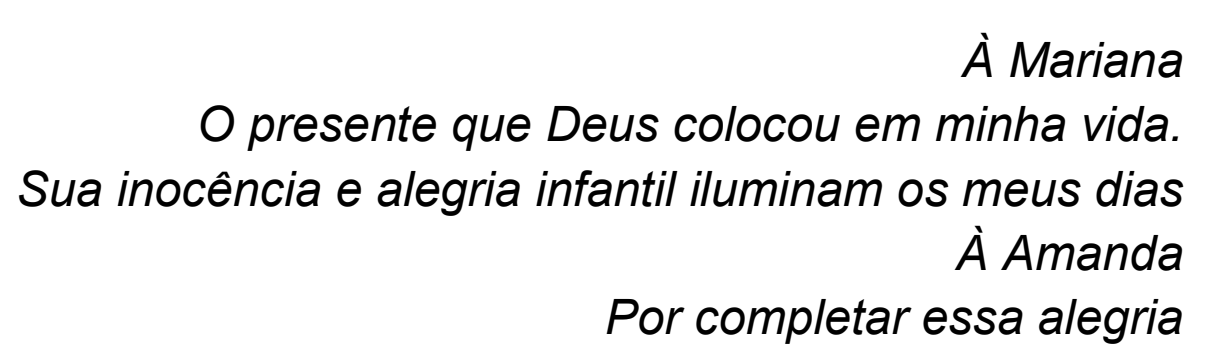

Ao Prof. Dr. Osvaldo

Por me mostrar que conhecimento é passado com gestos simples, Por me mostrar o caminho, mas deixar que eu o percorresse sozinha Por me ensinar e deixar inovar Por me orientar para vida e não para a tese, Por nunca ter desistido de acreditar em mim Não apenas um orientador, um amigo 


\section{AGRADECIMENTOS}

Deus por ser o criador de tudo.

À Clarice, obrigada pelo carinho maternal com o qual guiou minha introdução à ciência e por nos receber sempre de braços abertos.

À Camila, Priscila, Renata F., Alessandra, por tornarem fácil a divisão de um pequeno espaço, pelos momentos alegres, pela amizade que se mantém mesmo estando longe.

À Mô, por me mostrar que determinação nos leva a superar todos os obstáculos, me sinto privilegiada por ser sua amiga.

À Flavinha, amiga, sincera, forte. Aprendi e aprendo muito com você.

À Renata T. e Rafaela, obrigada pela ajuda e carinho. Não teria conseguido sem vocês.

Ao João Carlos, pelo voto de confiança que sempre deposita em mim

À Katyana, pela amizade sincera e por me mostrar que simplicidade cabe em qualquer lugar.

Marcela, Edemilson, Arony, Adriana N., Carol, Vânia, Rosiane, Rafael Zanato, Marcos Brushii, Maria Paula, Ricardo, Thais, Roberto e Renata pelo auxílio e alegre convivência durante todos os períodos de minha jornada pela ciência.

À Nath, sua luta e dedicação em prol da humanização cativa a todos.

Ao José Maria por ter me adotado e cuidado com tanto carinho durante todos os meus anos no laboratório.

À Fundação Instituto Pólo Avançado da Saúde pela oportunidade de aplicar na prática os conhecimentos adquiridos e pela compreensão, paciência e consideração no término da tese.

Aos amigos da FIPASE: Saulo, Maria Cristina, Rodrigo P., Débora, Lívia, Fabiana, Raphael, Eduardo, João Paulo, Marcelo, Juliana O, Dalton, e Renata todos vocês fazem o trabalho ser fácil e prazeroso. À Alessandra, Aline, Juliana G,. Nayara e Rodrigo E., a ajuda, o socorro de última hora e as palavras de incentivo foram essenciais.

À Geralda, Eduardo, Adriano e Ricardo, obrigada por tudo.

Ao querido amigo Alexandre, pelo apoio e carinho.

Ao grupo de professores da FEA pelas discussões sempre enriquecedoras. 
Ao grupo do SAFClin pelos trabalhos realizados juntos, pelo aprendizado, pela amizade.

Ao Prof. Dr. Hamilton por tão gentilmente dividir seu espaço comigo e pelas conversas sempre enriquecedoras.

À Josi, pela companhia sempre prazerosa e por ter me auxiliado na obtenção dos dados.

À Alessandra, Bacan e Maria Antônia pela amizade dentro da academia e fora dela.

Ao HCFMRP-USP pela autorização para realização do trabalho, ao CPD pela disponibilidade em me auxiliar na aquisição dos dados, à Profa. Dra. Ana Paula e aos residentes e enfermeiras do CTI Pediátrico.

À Divisão de Farmácia, especialmente à Alexandra, Luiz Maçao e Marlene por todas as informações passadas, pela atenção e pelas conversas esclarecedoras.

Às funcionárias da secretaria de Pós-Graduação, Ana e Rosana, sempre dispostas a me ajudar.

Aos vigias e funcionários da limpeza da FCFRP-USP pela agradável companhia nos finais de semana e nas madrugadas.

À FCFRP-USP pela excelente formação e por ter me aberto às portas para o mundo. Ao $\mathrm{CNPq}$ pelo auxílio financeiro. 
"O que interessa não é a noite em si, são os sonhos. Sonhos que o homem sonha sempre, em todos os lugares, em todas as épocas do ano, dormindo ou acordado" (William Shakespeare) 


\section{RESUMO}

Areda, C. A. Estratégia de estudo farmacoeconômico para avaliação da viabilidade de produção de medicamentos em hospital de porte especial. 2009 . 177f. Tese (Doutorado) - Faculdade de Ciências Farmacêuticas de Ribeirão Preto, Universidade de São Paulo, São Paulo, 2009.

A gestão do processo saúde/doença tem requerido somas cada vez maiores de recursos especialmente àqueles destinados à aquisição de medicamentos em hospitais de porte especial, devido à complexidade dos procedimentos, incorporação de novas tecnologias, visando não só o acesso, mas, também a qualidade de vida da população assistida. Uma das estratégias possíveis para a minimização dos custos hospitalares com a aquisição de medicamentos é instalação de farmácia semi-industrial para a produção dos mesmos, após rigoroso estudo de viabilidade econômica. Neste contexto esta investigação teve como objetivo estabelecer estratégia de estudo farmacoeconômico para avaliar a viabilidade de implantação de farmácia semi-industrial para produção de medicamentos em hospital de porte especial da rede pública. Para tanto foi realizado um estudo do consumo e dos gastos hospitalares com medicamentos nos anos 2006/2007, visando conhecer as classes que aliassem maior consumo e valor monetário e seus requisitos para a manufatura. As formas farmacêuticas que despertaram maior expectativa de produção foram os medicamentos na forma sólida (comprimidos simples e revestidos), os injetáveis de pequeno volume e os pós liofilos injetáveis. Para estes foram planejadas as instalações (área física e equipamentos), matérias-primas e recursos humanos necessários para a produção. A análise de viabilidade farmacoeconômica foi realizada considerando valores médios para as formulações, incluindo excipiente e fármaco, custos de implantação e implementação. $O$ estudo demonstrou que a produção hospitalar de medicamentos é viável sob o ponto de vista farmacoeconômico, pois o investimento se paga no primeiro mês e a partir deste passa a reduzir os gastos hospitalares com medicamentos, ou seja, começa a dar lucro e gerar benefícios para a sociedade.

Palavras-chave: Avaliação Farmacoeconômica, Hospital de Porte Especial, Farmácia Semi-industrial. 


\begin{abstract}
Areda, C. A. Pharmacoeconomics study strategy for evaluation of medicines production viability in special port hospital. 2009. 177f. Tese (Doutorado) Faculdade de Ciências Farmacêuticas de Ribeirão Preto, Universidade de São Paulo, São Paulo, 2009.

The health/sickness process management has required greater sums of resources specially those destinated to medicines acquisition in special port hospital, due to complexity of proceeding, incorporation of new technology, having in view not only the access but, also the assisted population quality of life. One of the possible strategies for hospital cost minimization with medicines acquisition is the installation of a semi industrial pharmacy, to product these medicines, after an accurate of economic viability. In this context, this investigation aimed establish pharmacoeconomics study strategy to evaluate the implantation of semi industrial pharmacy for medicine production in special port hospital of the public service. For this a study of the consumption and the hospital expenses with medicine was realized in 2006/2007, having a view to know the classes that ally a greater consumption and monetary value and its requisite for manufacture. The pharmaceutic forms that excit a greater production expectative were the solid form medicines (simple and coated tablets), the injectables of small volumes, and injectable liofile powder. For this the necessary installations (physical area and equipments), raw material and human resources were planned for the production. The pharmacoeconomics viability analysis was realized considering medium values for the formulations including excipients and drug, implantation and implementation costs. The study has showed that the medicine hospital productions is viable under the pharmacoeconomics point of view because the investment is paid in a month and after that the hospital expenses with medicines are reduced, so its begins to give profit and benefits for the society.
\end{abstract}

Key-words: Pharmacoeconomics Evaluation, Special Port Hospital, Semi Industrial Pharmacy. 


\section{LISTA DE FIGURAS}

Figura 1 - Representação esquemática do fluxo de produção de comprimidos por via úmida, respectivos equipamentos e localização na planta produtiva

Figura 2 - Representação esquemática do fluxo de produção de pós liófilos injetáveis, respectivos equipamentos e localização na planta produtiva. 68

Figura 3 - Representação esquemática do fluxo de produção de soluções estéreis com princípio ativo termoestável, respectivos equipamentos e localização na planta produtiva 69

Figura 4 - Representação esquemática do fluxo de produção de soluções estéreis com princípio ativo termolábel, respectivos equipamentos e localização na planta produtiva .70

Figura 5 - Comparação entre custos variáveis e fixos relativos à produção de medicamentos 


\section{LISTA DE TABELAS}

Tabela 1 - Distribuição dos medicamentos adquiridos pelo HCFMRP-USP no ano de 2006, em Curva $A B C$ de demanda valorizada

Tabela 2 - Distribuição dos medicamentos adquiridos pelo HCFMRP-USP no ano de 2007, em Curva ABC de demanda valorizada

Tabela 3 - Distribuição dos medicamentos adquiridos pelo HCFMRP-USP no ano de 2006, em Curva $A B C$ de demanda quantitativa

Tabela 4 - Distribuição dos medicamentos adquiridos pelo HCFMRP-USP no ano de 2007, em Curva ABC de demanda quantitativa

Tabela 5 - Distribuição dos medicamentos presentes na intersecção das regiões $\mathrm{A} e$ $B$ das curvas de demanda valorizada e demanda quantitativa referente ao ano de 2006 de acordo com sua forma farmacêutica

Tabela 6 - Distribuição dos medicamentos presentes na intersecção das regiões $\mathrm{A} e$ $B$ das curvas de demanda valorizada e demanda quantitativa referente ao ano de 2007 de acordo com sua forma farmacêutica .....

Tabela 7 - Número de especialidades farmacêuticas, quantidade total adquirida e valor total de recursos gastos dos medicamentos adquiridos no ano de 2006, selecionados para o estudo de viabilidade econômica, segundo forma farmacêutica

Tabela 8 - Número de especialidades farmacêuticas, quantidade total adquirida e valor total de recursos gastos dos medicamentos adquiridos no ano de 2007, selecionados para o estudo de viabilidade econômica, segundo forma farmacêutica

Tabela 9 - Distribuição dos medicamentos apresentados na forma de cápsula gelatinosa dura, comprimido revestido e comprimido simples de acordo com critérios da RDC n 210, ano base 2006.

Tabela 10 - Distribuição dos medicamentos apresentados na forma de pó liófilo injetável e solução injetável de acordo com critérios da RDC n² 210, ano base 2006

Tabela 11 - Distribuição dos medicamentos apresentados na forma de cápsula gelatinosa dura, comprimido revestido e comprimido simples de acordo com critérios da RDC n 210, ano base 2007.

Tabela 12 - Distribuição dos medicamentos apresentados na forma de pó liófilo injetável e solução injetável de acordo com critérios da RDC n 210, ano base 2007 
Tabela 13 - Número médio de unidades de produtos sólidos adquiridos e 58

Tabela 14 - Número médio de unidades de produtos injetáveis adquiridas e do valor total entre os anos de 2006 e 2007

Tabela 15 - Descrição seqüencial do processo de obtenção de comprimidos com prévia granulação por via úmida

Tabela 16 - Composição da formulação excipiente padrão otimista, $125 \mathrm{mg}$ de excipiente e pessimista, $250 \mathrm{mg}$ de excipiente, para comprimidos contendo $250 \mathrm{mg}$ de princípio ativo.

Tabela 17 - Distribuição das atividades e dos funcionários relativos à área de produção de medicamentos sólidos

Tabela 18 - Processos envolvidos na produção de pós liófilos

Tabela 19 - Componentes utilizados no preparo de pós liofilos e suas respectivas funções e proporções

Tabela 20 - Número de funcionários, de acordo com a etapa do processo 75

Tabela 21 - Parâmetros e equipamentos utilizados no controle físico-químico 76

Tabela 22 - Equipamentos de apoio ao controle de qualidade 76

Tabela 23 - Parâmetros e equipamentos utilizados no controle de qualidade microbiológico

Tabela 24 - Equipamentos de apoio ao controle microbiológico

Tabela 25 - Recursos humanos e atividades 80

Tabela 26 - Número médio de unidades e valor médio dos produtos sólidos e injetáveis considerados para o estudo de viabilidade

Tabela 27 - Custos variáveis mensais e anuais relativos à produção de medicamentos sólidos e injetáveis

Tabela 28 - Custos fixos relativos à produção de medicamentos sólidos e injetáveis

Tabela 29 - Custos de implantação da infra-estrutura física e de equipamentos da farmácia semi-industrial

Tabela 30 - Cálculo do VPL mensal equivalente ao primeiro ano. 86

Tabela 31 - Cálculo do VPL por ano 88 
Tabela 32 - Variações do valor médio de princípio ativo e cálculo de Valor Presente Líquido

Tabela 33 - Tipos de adequação de dose para uso pediátrico. 92

Tabela 34 - Distribuição dos medicamentos adquiridos pelo HCFMRP-USP em curva $A B C$ de demanda valorizada, 2006.

Tabela 35 - Distribuição dos medicamentos adquiridos pelo HCFMRP-USP em curva ABC de demanda valorizada, 2007.

Tabela 36 - Distribuição dos medicamentos adquiridos pelo HCFMRP-USP em curva $\mathrm{ABC}$ de demanda quantitativa, 2006.

Tabela 37 - Distribuição dos medicamentos adquiridos pelo HCFMRP-USP em Curva $A B C$ de demanda quantitativa, 2007

Tabela 38 - Testes realizados no controle de qualidade físico-químico de matériaprima

Tabela 39 - Testes realizados no controle de qualidade físico-químico de água purificada e água de qualidade injetável

Tabela 40 - Testes realizados no controle de qualidade físico-químico de produtos sólidos (comprimido simples e comprimidos revestidos).

Tabela 41 - Testes realizados no controle de qualidade físico-químico de produtos sólidos exigidos apenas para comprimidos simples

Tabela 42 - Testes realizados no controle de qualidade físico-químico de produtos injetáveis (soluções e pós liófilos injetáveis) .

Tabela 43 - Testes realizados no controle de qualidade de produtos injetáveis exigidos apenas para soluções injetáveis

Tabela 44 - Testes realizados no controle de qualidade físico-químico de produtos injetáveis exigidos apenas para pós liófilos injetáveis

Tabela 45 - Equipamentos de apoio ao setor de controle de qualidade físico-químico 145

Tabela 46 - Testes realizados no controle de qualidade microbiológico de qualidade microbiológico de matéria-prima

Tabela 47 - Testes realizados no controle de qualidade microbiológico de água purificada e água de qualidade injetável

Tabela 48 - Testes realizados no controle de qualidade microbiológico de produtos sólidos (comprimidos revestidos e comprimidos simples). 
Tabela 49 - Testes realizados no controle de qualidade microbiológico de produtos injetáveis (soluções e pós liófilos injetáveis)

Tabela 50 - Testes realizados no controle de qualidade microbiológico ambiental da área asséptica ou capela de fluxo laminar 146

Tabela 51 - Equipamentos de apoio ao setor de controle de qualidade microbiológico 146

Tabela 52 - Valores de salários e encargos referentes à mão de obra diretamente relacionada ao processo produtivo.

Tabela 53 - Valor dos princípios ativos utilizados para o cálculo do valor de matériaprima

Tabela 54 - Consumo mensal de energia elétrica dos equipamentos do setor de produtos sólidos

Tabela 55 - Consumo mensal de energia elétrica dos equipamentos do setor de produtos injetáveis 149

Tabela 56 - Valor de construção da infra-estrutura da farmácia semi-industrial para produção de medicamentos hospitalares 150

Tabela 57 - Valor dos equipamentos da unidade de produção de água purificada e água de qualidade injetável

Tabela 58 - Valor dos equipamentos da unidade de controle de qualidade físicoquímico

Tabela 59 - Valor dos equipamentos da unidade de controle de qualidade microbiológico 152

Tabela 60 - Valor dos equipamentos da unidade de produção de medicamentos sólidos

Tabela 61 - Valor dos equipamentos da unidade de produção de medicamentos injetáveis

Tabela 62 - Valor residual dos equipamentos considerando sua venda como sucata de aço 


\section{LISTA DE ABREVIATURAS E SIGLAS}

ABC - Análise Custo-Benefício

Ac - Ácido

ACE - Análise Custo-Efetividade

ACU - Análise Custo-Utilidade

AMC - Análise de Minimização de Custo

ANVISA - Agencia Nacional de Vigilância Sanitária

AVAQs - Anos de Vida Ajustados por Qualidade

BPF - Boas Práticas de Fabricação

CFP - Custos Fixos de Produção

CRF-SP - Conselho Regional de Farmácia do Estado de São Paulo

CTI - Centro de Terapia Intensiva

CVP - Custo Variável de Produção

D - Desvantagens

FGTS - Fundo de Garantia por Tempo de Serviço

GNRH - Hormônio Gonodotrófico

GV - Grande Volume

HCFMRP-USP - Hospital das Clínicas da Faculdade de Medicina de Ribeirão Preto - Universidade de São Paulo

Hum - Humano

IM -Intramuscular

INSS - Instituto Nacional de Seguridade Social

IPI -Imposto sobre Produtos Industrializados

IV - Intravenoso

LHRH - Hormônio Luteinizante

Prov. - Provisão

OPAS - Organização Pan-americana de Saúde

QALY - Quality Adjusted Life Years

QVRS - Qualidade de Vida Relacionada à Saúde

RDC - Resolução da Diretoria Colegiada

SC - Subcutâneo

SUS - Sistema Único de Saúde

V - Vantagens 
VM - Valor de Mercado

VPL - Valor Presente Líquido

WHO - World Health Organization 


\section{SUMÁRIO}

RESUMO

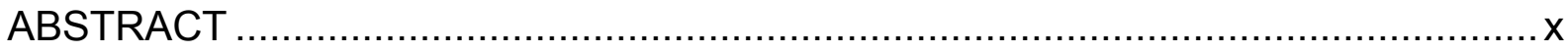

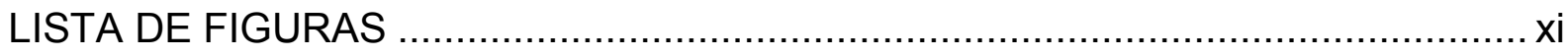

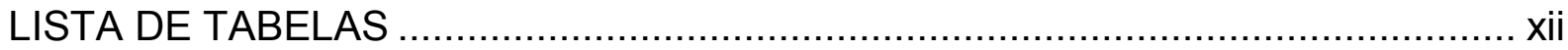

LISTA DE ABREVIATURAS E SIGLAS ........................................................... xvi

1. INTRODUÇÃO

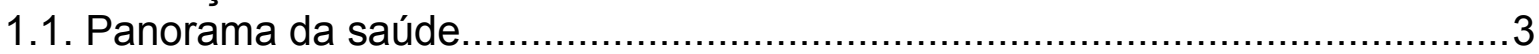

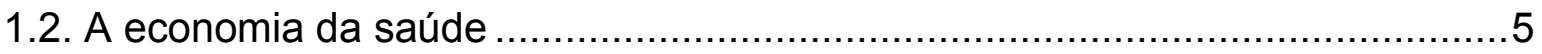

1.3. Tipos de Análises Farmacoeconômicas ………….................................

1.3.1. Análise de Minimização de Custo (AMC) ………................................

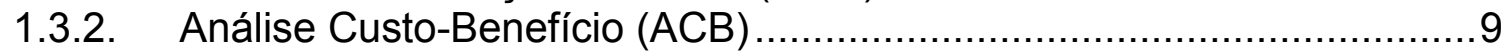

1.3.3. Análise Custo-Efetividade (ACE) ......................................................11

1.3.4. Análise Custo-Utilidade (ACU) …..................................................12

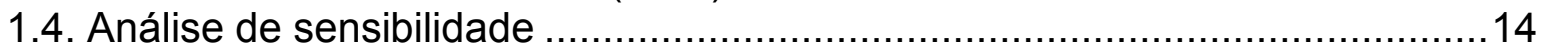

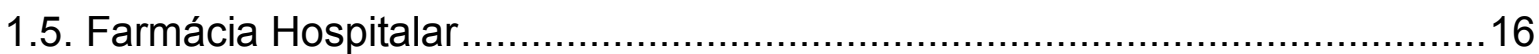

1.5.1. Funções da Farmácia Hospitalar...................................................... 17

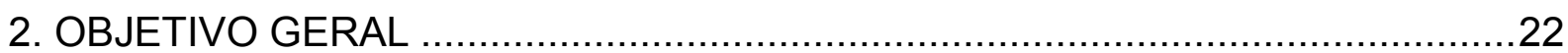

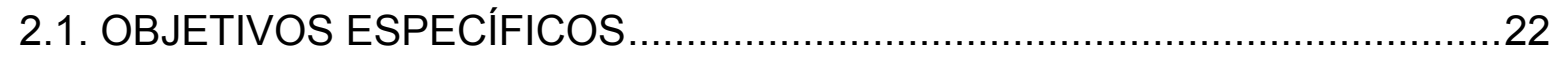

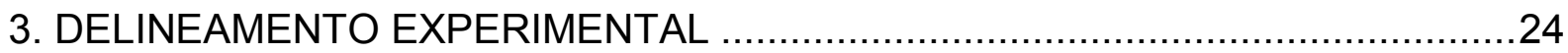

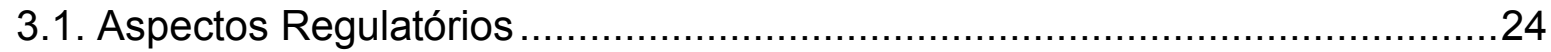

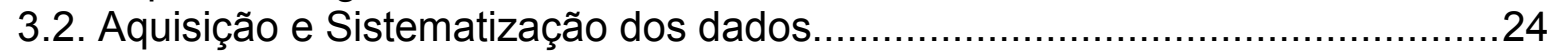

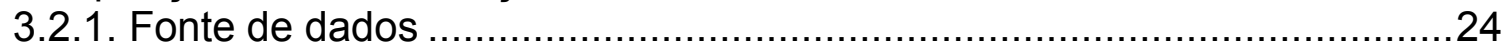

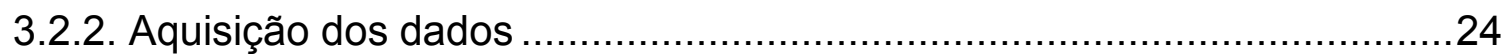

3.2.3. Identificação e Classificação dos Medicamentos ...................................25

3.2.3.1. Classificação dos medicamentos em Curva ABC de demanda

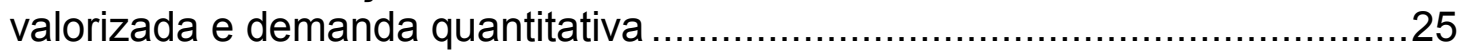

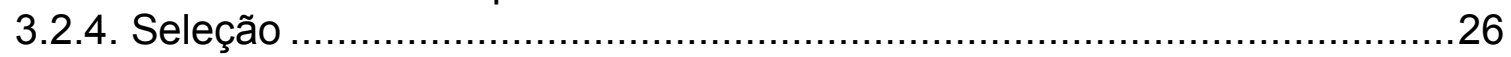

3.2.5. Classificação dos medicamentos por forma farmacêutica .....................26

3.2.6. Classificação dos medicamentos segundos critérios da RDC n' 210 ......26

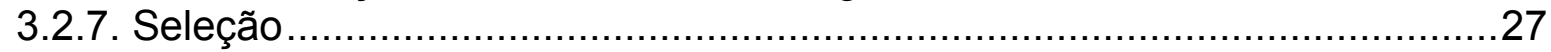

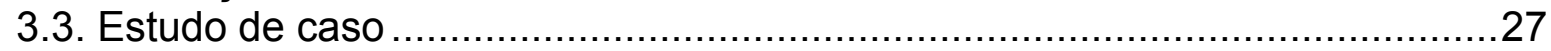

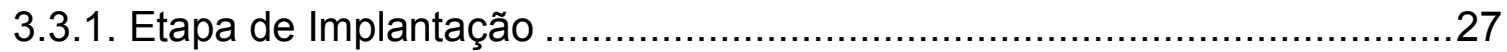

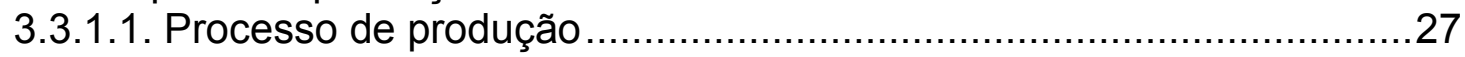

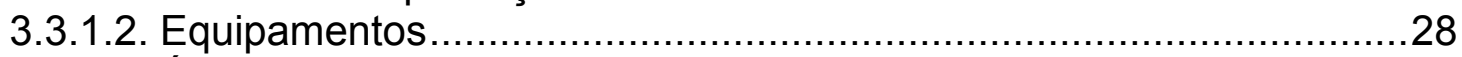

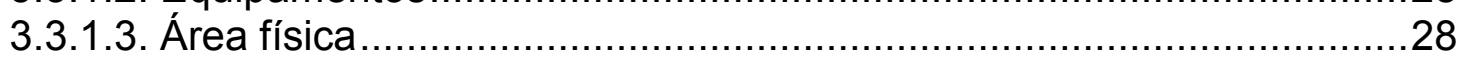

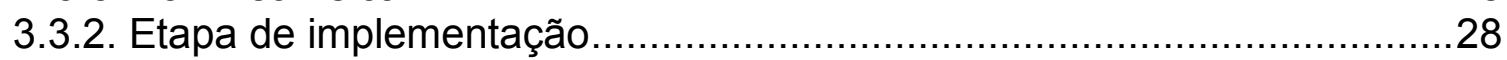

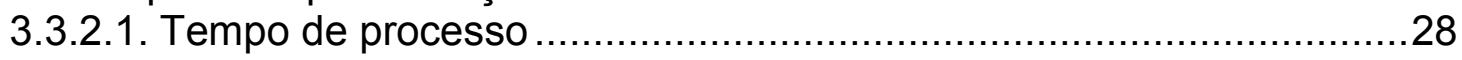

3.3.2.2. Matéria-prima e material de embalagem .....................................28

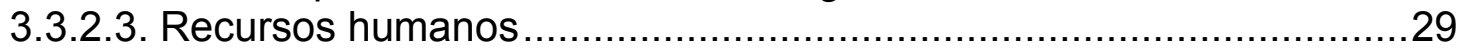


3.3.3. Atividades de Apoio: Controle de Qualidade Físico-Químico e Microbiológico, Produção de Água Purificada e de Qualidade Injetável e

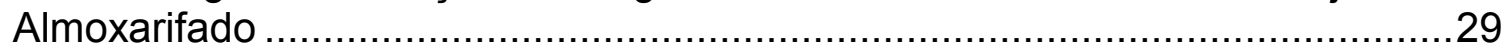

3.3.4. Estruturação da análise de viabilidade econômica ...............................30

3.3.4.1. Levantamento dos valores de mercado (VM) dos medicamentos selecionados para serem produzidos pela farmácia.....................................30

3.3.4.2. Levantamento dos custos variáveis de produção - CVP .................. 30

3.3.4.3. Obtenção da margem de contribuição de cada período .....................31

3.3.4.4. Levantamento dos custos fixos de produção - CFPs........................32

3.3.4.5. Levantamento dos custos de implantação e do valor residual ...........32

3.3.4.6. Obtenção do fluxo de economia de caixa incremental .......................33

3.3.4.7. Aplicação da técnica de Valor Presente Líquido...............................33

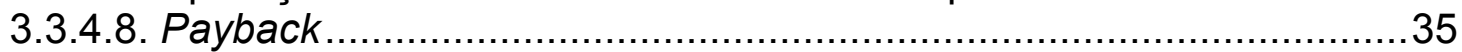

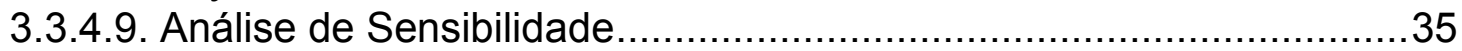

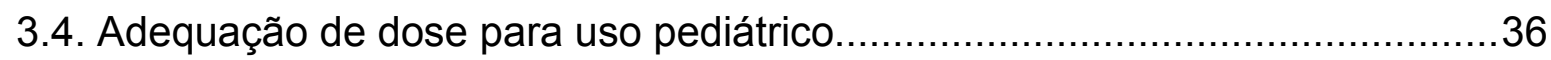

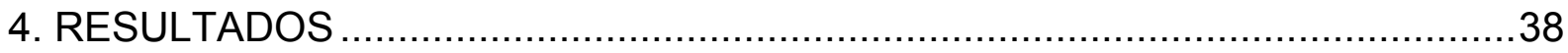

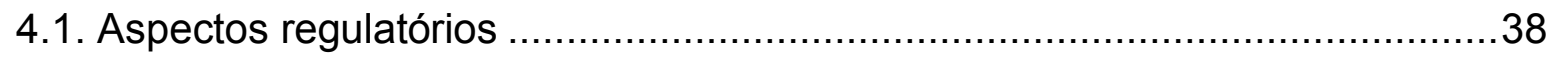

4.2. Aquisição e Sistematização dos dados.....................................................40

4.3. Classificação dos medicamentos em Curva $A B C$ de demanda valorizada e demanda quantitativa .................................................................................. 42

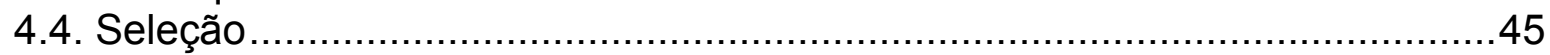

4.5. Classificação dos medicamentos por forma farmacêutica ...........................45

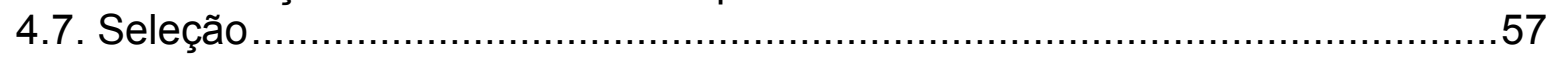

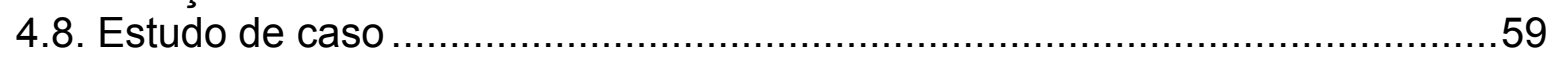

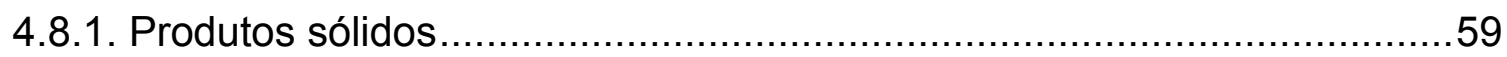

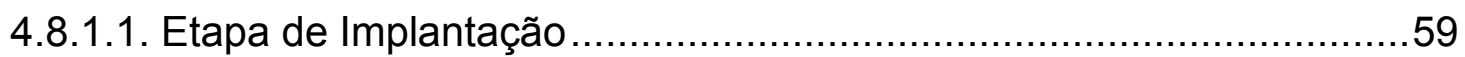

4.8.1.1.1. Processo de produção ................................................... 59

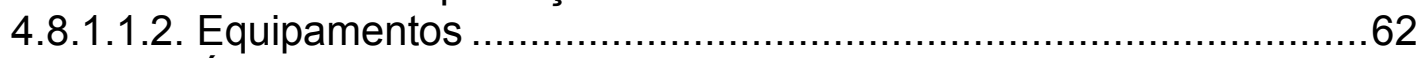

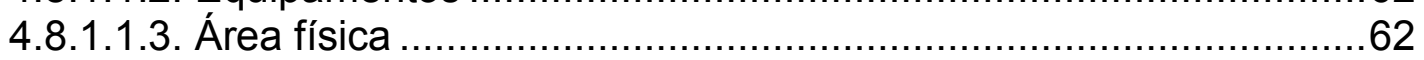

4.8.1.2. Etapa de Implementação .......................................................63

4.8.1.2.1. Tempo e capacidade dos equipamentos ...............................63

4.8.1.2.2. Matéria-prima e material de embalagem .................................64

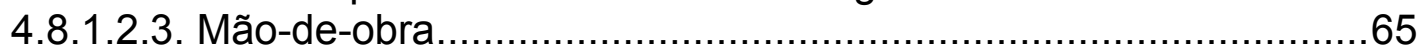

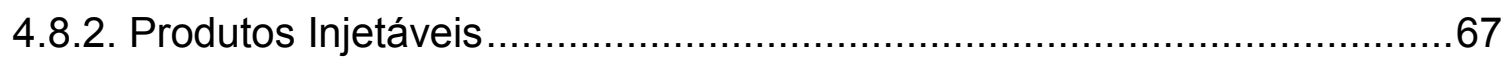

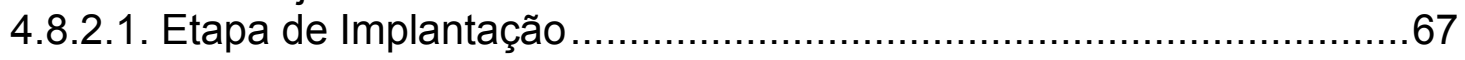

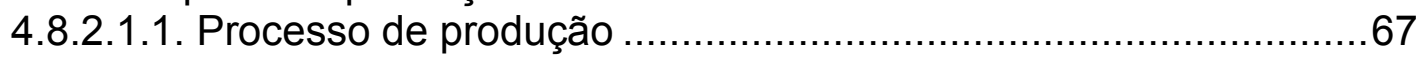

4.8.2.1.2. Equipamentos.............................................................. 71

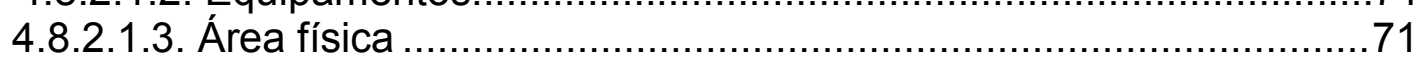

4.8.2.2. Etapa de Implementação ..................................................... 73

4.8.2.2.1. Tempo e capacidade dos equipamentos ...............................73

4.8.2.2.2. Matéria-prima e material de embalagem ..................................73

4.8.2.2.3. Mão-de-obra...................................................................... 74

4.8.3. Atividades de Apoio: Controle de Qualidade Físico-Químico e Microbiológico, Produção de Água Purificada e de Qualidade Injetável e

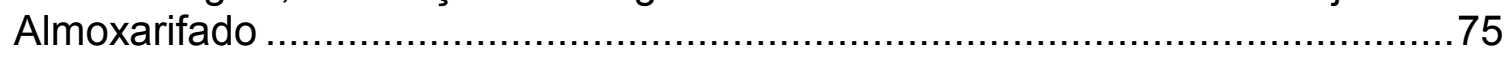

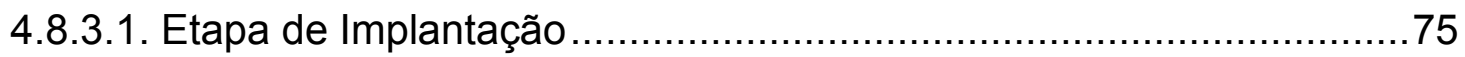

4.8.3.1.1. Processos e Equipamentos............................................. 75

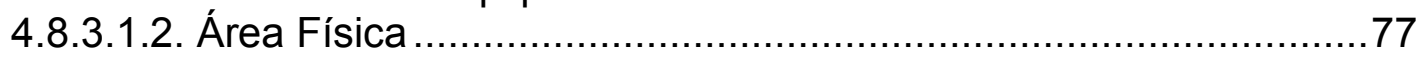

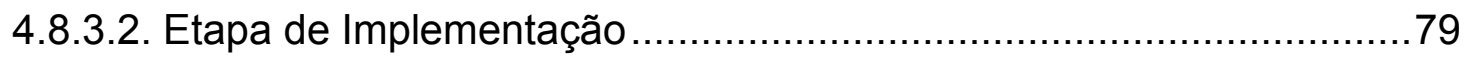




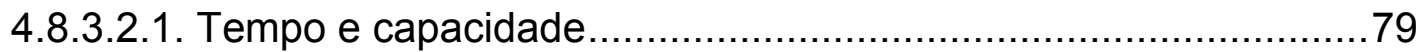

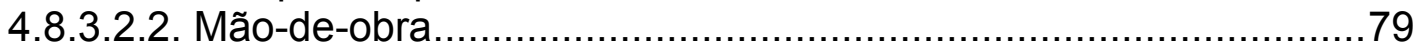

4.9. Análise de viabilidade econômica da implantação de farmácia semi-industrial

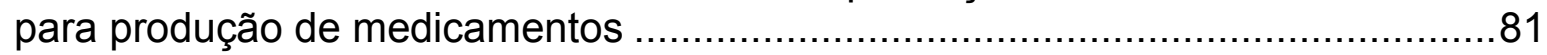

4.9.1. Levantamento dos valores de mercado (VM) e da quantidade a ser

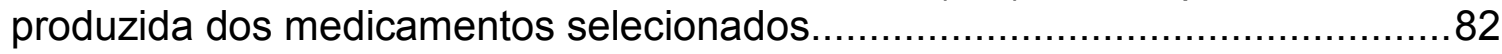

4.9.2. Levantamento dos custos variáveis de produção - CVP ........................82

4.9.3. Obtenção da margem de contribuição de cada período............................83

4.9.4. Levantamento dos custos fixos de produção - CFPs .............................83

4.9.5. Levantamento dos custos de implantação e do valor residual ..................84

4.9.6. Obtenção do fluxo de economia de caixa incremental ............................85

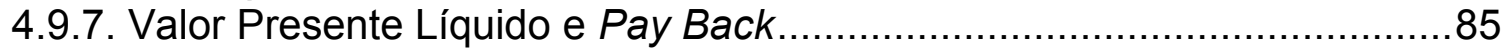

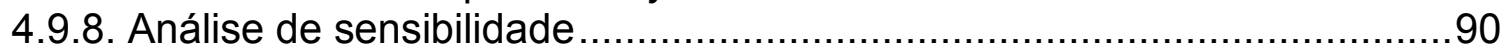

4.10. Adequação de dose para uso pediátrico ...............................................92

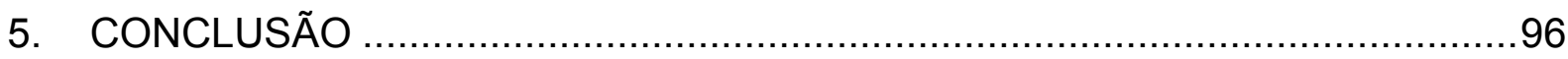

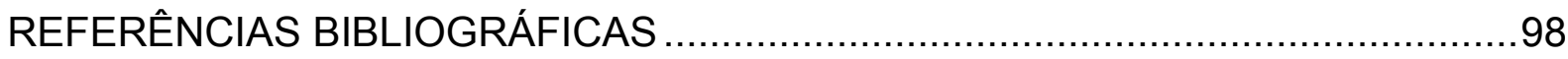

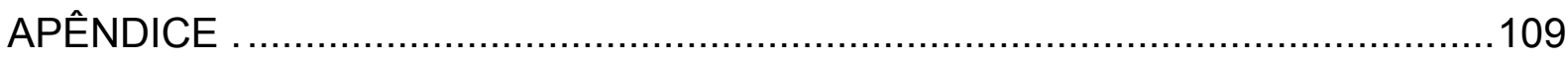

ANEXO 


\section{Introdução}




\section{INTRODUÇÃO}

A farmacoeconomia é uma sub-área da Economia em Saúde, a qual associa os conceitos clínicos de eficácia, segurança e qualidade dos diversos procedimentos da assistência à saúde com as medidas de custos econômicos. Assim, ela pode ser definida como a "aplicação da teoria econômica a farmacoterapia" ou "avaliação econômica do medicamento", ou seja, situa-se na interface entre duas grandes áreas tradicionais, a saúde e a economia (CASTILHO, 1995).

É um instrumento que ajuda a selecionar as opções mais eficientes (com boa relação custo/efeito) e pode ajudar na distribuição dos recursos sanitários de uma forma mais justa e equilibrada. Contribui para o uso racional do medicamento ao incorporar o custo aos quesitos de segurança, eficácia e qualidade das diferentes terapias medicamentosas, e a busca pela melhor relação entre custos e resultados. Embora empregando a palavra "fármaco" em sua nomenclatura, apresenta ferramentas que podem ser utilizadas igualmente na avaliação de medicamentos, programas de saúde e mesmo sistemas administrativos, desde que observadas as devidas características de cada um (ZANINI et al., 2001).

Por ser uma área de intersecção os "conflitos" são inevitáveis devido às formas diversas com que cada uma delas considera a saúde. Tradicionalmente, as profissões relacionadas à área de saúde concentram-se na ética individualista, segundo a qual a saúde não tem preço e uma vida salva justifica qualquer esforço. Por outro lado, a economia fixa-se na ética do bem comum ou ética social. A origem dessas diferenças reside nas atitudes de cada grupo sobre a utilização de recursos, porém ambas tem como visão de futuro a racionalização dos recursos e aprimoramento da assistência prestada à saúde (DEL NERO, 2002). Países que investiram na formação e especialização de recursos humanos para atuar na interface economia/saúde tem conseguido maior racionalização no processo de gestão e na qualidade do serviço de saúde. 


\subsection{Panorama da saúde}

A gestão do processo saúde/doença tem requerido somas cada vez maiores de recursos especialmente àqueles destinados à aquisição de medicamentos. Este aumento constante pode ser atribuído a diversos fatores, tais como, incorporação de novas tecnologias, envelhecimento da população e com isto o crescimento do número de portadores de doenças crônico-degenerativas, esforço para aumento do acesso aos sistemas de saúde, estratégias de promoção dos novos medicamentos tanto aquelas voltadas à classe prescritora quanto à consumidora.

$\mathrm{O}$ aumento no gasto público com medicamentos vem preocupando os governos, pois em geral é superior à inflação e ao crescimento do Produto Interno Bruto - PIB (BRUSSELS, 2006).

Nos EUA, os gastos com saúde passaram de 1,3 trilhão de dólares em 2000 para 2 trilhões de dólares em 2006, valor equivalente a 16\% do PIB. Segundo as projeções este percentual deve aumentar para 20\% até o ano 2015 (LOTTENBERG, 2007).

No Reino Unido, o crescimento dos gastos com saúde é maior que o crescimento de outros setores da economia. Entre os anos de 2001 e 2002 o gasto com saúde representou $17 \%$ dos gastos públicos, sendo o maior incremento desde o ano de 1948 (LEATHERMAN, 2003).

Os medicamentos consomem parcela considerável dos recursos, tendo forte impacto no incremento das despesas com a saúde. No Canadá, o gasto total com medicamentos aumentou $11 \%$ em 2005 , chegando a 24,8 bilhões de dólares. Foi a segunda maior despesa, ficando atrás apenas dos gastos com os hospitais e mantendo-se em patamar mais elevado que os gastos com médicos desde 2000 (CANADIAN MEDICAL ASSOCIATION JOURNAL, 2006; BUSKE, 2000; 2004).

No Brasil, segundo o Fundo Nacional de Saúde (BRASIL, 2007), os gastos com saúde estão evoluindo da mesma forma, embora não de maneira linear.

Em 2006 o gasto real do Ministério da Saúde, já deduzido o impacto da inflação, chegou a 23,6 bilhões de reais, a preços de 2001. No período entre $2002 \mathrm{e}$ 2006, a parcela do orçamento da saúde destinada à aquisição de medicamentos aumentou em $123,9 \%$, o que equivale a $11 \%$ do gasto total com saúde no ano de 2006. No mesmo período o aumento do gasto total do Ministério da Saúde foi de 9,6\% (BRASIL, 2007a). 
Face ao aumento crescente de gastos e a necessidade de pelo menos manter a qualidade do serviço prestado a saúde, os governos terão que adotar medidas para sustentar o financiamento entre outras, aumento de impostos, redução de gastos em outras áreas, onerar o usuário (BRUSSELS, 2006).

No entanto alguns países estão adotando estratégias menos danosas, como a adoção de técnicas de análises econômicas no processo de escolha das alternativas prioritárias (JOHANNESSON; LE LORIER, 1996; BRIGGS; GRAY, 1999). Essas análises podem fornecer informações que ajudem os gestores a comparar alternativas e decidir quanto à melhor opção para suas necessidades programáticas visando sempre à racionalização dos gastos aliada a eficiência clínica. A eficiência clínica objetiva a maximização da qualidade da atenção e a satisfação dos usuários com os menores custos sociais possíveis (ROBINSON, 1993a; RUSSEL et al, 1996).

A Austrália foi um dos primeiros países a incorporar estudos econômicos na elaboração de guias terapêuticos e na adoção de novas praticas em saúde. Em 1993, o governo australiano, por meio do Pharmaceutical Benefits Advisory Committee, determinou que os pedidos de inclusão de novos medicamentos na lista de produtos distribuídos gratuitamente à população deveriam ser acompanhados de uma análise econômica comparada com a alternativa terapêutica vigente (GROBLER, 1999).

A Inglaterra criou o National Institute for Clinical Excellence (NICE), este órgão é responsável pela avaliação de novas tecnologias em saúde incorporando sempre uma revisão crítica de estudos econômicos existentes (BRASIL, 2008).

Canadá, Estados Unidos e alguns países da Europa tem recomendado as análises econômicas para registro de novos produtos e nas decisões sobre as políticas a serem adotadas.

No Brasil, instituições públicas e privadas, acadêmicas ou não, fazem uso da medicina baseada em evidência para recomendar a inclusão de novos medicamentos em guias terapêuticos. Entretanto, a utilização de informações farmacoeconômicas para suporte a decisão política ainda é insipiente. 


\subsection{A economia da saúde}

Del Nero (2002, p. 19) define da economia da saúde como "o ramo do conhecimento que tem por objetivo a otimização das ações de saúde, ou seja, o estudo das condições ótimas de distribuição dos recursos disponíveis para assegurar à população a melhor assistência à saúde e o melhor estado de saúde possível, tendo em conta, meios e recursos limitados".

A Organização Mundial da Saúde a divide em Macroeconomia da Saúde e Microeconomia da Saúde; a primeira desenvolve estudos econômicos do setor saúde geral e de suas relações com os outros setores sócio-econômicos, a segunda dedica-se ao estudo dos diferentes componentes do setor saúde (OMS, 1976).

A economia da saúde explora tópicos relevantes para seu campo de aplicação: o papel dos serviços de saúde no sistema econômico; o sistema de produção e distribuição de serviços de saúde; as formas de medir o impacto de investimentos em saúde; o estudo de indicadores e níveis de saúde correlacionados a variáveis econômicas; o emprego e o salário de profissionais de saúde e a oferta de mão-de-obra; a indústria da saúde no capitalismo avançado; o comportamento do prestador de serviços e suas relações com o consumidor; a análise de custobenefício, de custo-efetividade e de custo-utilidade de serviços ou bens específicos (DEL NERO, 2002), sendo estas análises os principais componentes da farmacoeconomia.

$\mathrm{Na}$ definição estabelecida por Townsed (1987) e usualmente difundida, a farmacoeconomia representa a "descrição e análise de custos da terapia medicamentosa para os sistemas de saúde e a sociedade". Neste conceito amplo, o termo engloba todos os aspectos econômicos dos medicamentos: o seu impacto na sociedade, na indústria químico-farmacêutica, nas farmácias, nos formulários nacionais, o que significa dizer que, quase todas as áreas relacionadas a medicamentos são vinculadas a questões econômicas (SACRITÁN DEL CASTILO, 1995).

A International Society for Pharmacoeconomics and Outcomes Research ISPOR define farmacoeconomia como o "campo de estudo que avalia o comportamento de indivíduos, empresas e mercados com relação ao uso de produtos, serviços e programas farmacêuticos, e que frequentemente enfoca os custos e as consequências desta utilização" (PASHOS; KLEIN; WANKE, 1998). 
Nela está compreendida a valoração do rendimento técnico, da eficácia clínica, da segurança, da eficiência econômica, do impacto organizativo, das consequências sociais e das implicações éticas (MOSSIALOS, 1997).

A avaliação farmacoeconômica identifica, quantifica e compara os custos (recursos consumidos com produtos farmacêuticos e serviços) e as consequências (econômicas, clínicas e humanísticas) provenientes de sua utilização, podendo-se apurar o resultado de qualquer ação na área de saúde como indicador econômico de sua eficiência ou eficácia, auxiliando na otimização do uso de recursos e na tomada de decisão.

Os custos representam os investimentos financeiros em saúde. Tradicionalmente, custos em saúde tem sido classificados como diretos, indiretos e intangíveis; fixos e variáveis (DRUMMOND et al., 1997).

Custos diretos são aqueles associados diretamente com os cuidados médicos e medicamentos (ROBERTSON; LANG; HILL, 2003), e podem ser classificados em: a) sanitários ou médicos, os quais estão relacionados com medicamentos e o cuidado médico (aquisição, custo de dispensação e administração do medicamento, hospitalizações, consultas, provas diagnósticas) e, b) Não Sanitários ou não médicos, são aqueles relacionados com o fornecimento de serviços médicos, entre outros, transporte do paciente, cuidado familiar, nutrição especial (CARLOS et al., 2001).

Custos indiretos são relacionados à perda da capacidade produtiva do indivíduo ante o processo de adoecimento ou mortalidade precoce. Eles representam dias de trabalho perdidos, incapacidade de realizar as atividades profissionais, tempo gasto em viagens para receber cuidado médico e morte prematura decorrente da doença (BOMBARDIER; EISENBERG, 1985; EISENBERG, 1989; VILLAR; 1995; LEW; FORGIA; SULVETTA, 1996). Devido à dificuldade de avaliar objetivamente os custos indiretos, alguns órgãos, entre outros, o Australian Pharmaceutical Benefits Advisory Committee, estabeleceram diretrizes que excluem os custos indiretos (DEPARTMENT OF HEALTH AND AGED CARE, 1995). No entanto o The National Institute for Clinical Excellence, 2001, recomenda que estes custos sejam calculados separadamente para que possa ser avaliado o impacto de sua exclusão (NICE, 2001).

Custos intangíveis são aqueles associados à dor e ao sofrimento, são os mais difíceis de quantificar e avaliar, embora eles sejam incorporados até certo ponto nos 
serviços designados a estados doentis que refletem qualidade de vida (ROBERTSON; LANG; HILL, 2003).

Os custos também podem ser variáveis ou fixos. Os custos fixos são aqueles que não variam com a quantidade produzida de bens ou serviços, enquanto que os variáveis são aqueles que variam com a quantidade produzida. (MANKIW, 2001).

O conceito de custo de oportunidade ou custo social reflete a escassez ou a limitação de recursos. Relaciona-se a benefícios derivados da utilização de recursos em sua melhor alternativa de uso. É, portanto, uma medida do sacrifício feito pela sociedade no uso de recursos em um dado programa, uma vez que estes não estarão mais disponíveis para serem empregados em outros programas (GRIFFITHS, 1981; MILLS \& DRUMMOND, 1985).

As consequências ou benefícios, por sua vez podem ser econômicas (economia ou benefícios econômicos), clínicas, ou seja, consequências de um tratamento farmacológico ou estratégia (mortes, morbidades, e outros indicadores clínicos específicos), e humanísticas, que são as consequências da doença ou do tratamento na condição funcional do paciente ou na sua qualidade de vida através de diversas dimensões (satisfação, saúde geral, função física, função social, expectativa e qualidade de vida etc.) (VENTURINI; JOHNSON, 2002; ZANINI et al., 2001).

Os benefícios econômicos associados à melhora do estado de saúde do paciente podem ser medidos da seguinte forma (SACRISTÁN, et al, 2004):

Benefícios diretos: representam os recursos que deixaram de ser gastos em relação aos custos decorrentes da assistência médica, por exemplo, os casos de câncer de mama evitados ao se investir em um programa de prevenção.

Benefícios indiretos: são os ganhos em produtividade e para a sociedade. A recuperação da saúde e as mortes evitadas proporcionam pessoas em condições de trabalhar e produzir para a sociedade.

Para um perfeito entendimento das técnicas de avaliação econômica, é importante descrever também o conceito de eficácia, efetividade e eficiência.

Eficácia refere-se aos benefícios, consequências e resultados (outcomes) do medicamento utilizado em condições ideais, ou seja, durante sua aplicação nos ensaios clínicos, principalmente devido ao rigoroso critério de seleção de pacientes, ao acompanhamento de sua evolução clínica e do estrito cumprimento do regime terapêutico. A efetividade mede os resultados da utilização do medicamento na 
prática clínica diária, avaliando assim, as condições habituais reais. Destaca-se que a efetividade é frequentemente menor que a eficácia. Eficiência representa a relação entre os recursos financeiros (custos) e os resultados (outcomes) utilizados em determinada intervenção. (JOLICOEUR ET AL, 1992; SACRISTÁN DEL CASTILHO, 1995; BOOTMAN ET AL, 1996).

No âmbito sanitário, considera-se eficiente um programa ou tratamento que atinge o nível máximo de saúde dado um determinado recurso, isto é, quando o resultado obtido pela opção eleita é pelo menos igual ao custo de oportunidade. Também é eficiente quando, comparando-se opções que produzem o mesmo resultado, se elege a menos onerosa (SACRISTÁN, et al, 2004).

Segundo Carlos et al (2001) e Gold et al (1996) a avaliação econômica se realiza antes da tomada de decisão de sua implantação, assim os custos e efeitos de sua aplicação se produzirão no futuro. Nesses casos, quando os custos e efeitos se produzam em um período superior a um ano, será preciso transformá-los nas unidades equivalentes as do ano zero (momento em que se realiza a avaliação). Esta atualização se justifica, em parte, porque a sociedade valoriza mais os resultados sobre a saúde que se conseguem no presente do que os que se poderiam obter no futuro, e porque, em geral se prefere adiar os custos para o futuro, em vez de suportá-los no presente. Há um extensivo debate na literatura sobre uma taxa de desconto apropriada, que deve refletir as preferências dos indivíduos de negociar ganhos futuros (ou perdas) contra ganhos atuais (ou perdas). O Painel em Custo-Efetividade recomenda uma taxa de desconto de 3\% (RUSSEL et al, 1996).

$\mathrm{Na}$ avaliação farmacoeconômica várias metodologias podem ser utilizadas, desde a simples análise de minimização de custo, até as análises mais complexas de custo-benefício, custo-efetividade e custo-utilidade. As metodologias variam conforme o objetivo e a perspectiva da análise. Portanto, a análise farmacoeconômica não é decisória sobre a política de medicamentos, porém representa importante fator na tomada de decisão.

Os dados para análises farmacoeconômicas são obtidos em ensaios clínicos controlados (estudos randomizados), estudos observacionais, modelos econômicos (fontes primárias); e estudos retrospectivos, opinião de especialista clínico, avaliações de uso de medicamentos, literatura (fontes secundárias) (ZANINI et al., 2001). O uso destas fontes depende da disponibilidade de dados publicados, da 
qualidade da base de dados retrospectivos, recursos humanos e monetários e da importância relativa da decisão (ZANINI et al., 2001).

\subsection{Tipos de Análises Farmacoeconômicas}

\subsubsection{Análise de Minimização de Custo (AMC)}

A Análise de Minimização de Custo (AMC), uma das avaliações econômicas mais simples, é utilizada quando o resultado de duas ou mais intervenções são iguais em suas conseqüências clínicas. $\mathrm{Na}$ AMC somente os custos são submetidos a comparações, pois as eficácias ou efetividades das alternativas comparáveis são iguais (EISENBERG, 1989; JOLICOEUR; JONESGRIZZLE, 1992; SACRISTÁN DEL CASTILHO, 1995; BOOTMAN; TOWNSEND; MCGHAN, 1996; DRUMMOND ET AL., 1997). Esta abordagem é justificada quando as alternativas de programas ou terapias comparadas produzem resultados clínicos equivalentes, como em tomadas de decisões de guias farmacoterapêuticos (CARREIRA-HUESO, 1998; DRUMMOND, 1991). Assim, o primeiro passo crítico antes de conduzir a AMC é determinar a equivalência terapêutica das intervenções (ROBERTSON; LANG; HILL, 2003). Quando os resultados das intervenções são diferentes, não é possível proceder à análise de minimização de custos. Um exemplo de AMC é a análise dos custos da administração de um mesmo medicamento por diferentes vias de administração (PRZYBYLSKI et al., 1997).

\subsubsection{Análise Custo-Benefício (ACB)}

A Análise Custo-Benefício (ACB) faz a relação entre os custos associados ao tratamento e os benefícios financeiros gerados por ele. Todos os custos (investimentos) e benefícios (consequências) das alternativas são mensurados em termos monetários de forma que seja possível verificar se os benefícios excedem ou não as despesas para cada uma das intervenções. Entre outros aspectos, isso possibilita que o retorno proporcionado pelos recursos aplicados em saúde seja comparado com os ganhos obtidos por meio de investimentos realizados em outras 
áreas da economia (ROBINSON, 1993a). Exemplos: (i) a relação entre os custos de um tratamento e a economia de recursos proveniente da diminuição do tempo de internação dos pacientes; (ii) os custos de um programa de vacinação e os recursos produzidos pela diminuição do número de faltas ao trabalho ou do número de internações hospitalares; (iii) os custos de um programa de tratamento precoce de doenças frente ao tratamento tardio ou de suas complicações etc. (ZANINI et al., 2001).

Os resultados da análise custo-benefício são apresentados na forma de benefícios líquidos, ou seja, os benefícios da intervenção menos os custos da intervenção (BRASIL, 2008).

Este tipo de instrumento destina-se a avaliar a viabilidade econômica de projetos sociais, podendo-se aplicá-lo a um determinado programa ou a vários, alternativos, para compará-los em termo de sua "rentabilidade social". Isto pressupõe a concepção de programas na área social (saúde, educação etc.) como investimentos em capital humano, na medida em que estes programas, seja por capacitar ou por tornar a força de trabalho mais hígida, fazem com que aumente sua produtividade, elevando, assim, a produtividade do sistema econômico como um todo. Fica evidente, portanto, a fundamentação teórica deste instrumental técnico: a teoria do capital humano e a metodologia de análise econômica de investimentos (UGÁ, 2002).

Assim, estes estudos têm como vantagem teórica, facilitar escolhas entre programas de saúde e de não saúde (por ex., entre subsidiar um novo fármaco e aumentar fundos para transporte escolar) (BRINSMEAD; HILL, 2003). Fornecendo subsídios para os administradores públicos e a sociedade que permitem tomada de decisões mais embasadas e proporcionando a otimização do uso de recursos.

Este tipo de análise apresenta como inconveniente a dificuldade de atribuir valores monetários aos resultados e a vida e não permitir comparar simultaneamente produtos com mais de uma indicação. Os benefícios intangíveis, como a expressão subjetiva da sensação de saúde de cada paciente e o valor da vida humana, são obviamente muito difíceis de serem expressos em termos monetários. Além disso, a avaliação dos benefícios para pessoas que não desenvolvem uma atividade econômica fica prejudicada. Assim, esta análise tem sido muitas vezes criticada por ignorar importantes benefícios resultantes de programas de saúde e por se concentrar nos itens de fácil mensuração. Inicialmente foi a análise mais usada, mas 
devido à dificuldade de atribuir valores monetários à vida humana, atualmente a análise custo-efetividade é mais utilizada (CARREIRA-HUESO, 1998; DRUMMOND, 1991; ROBINSON, 1993b).

\subsubsection{Análise Custo-Efetividade (ACE)}

A Análise Custo-Efetividade (ACE) preocupa-se com a relação entre os custos de um tratamento, medidos em unidades monetárias e seus benefícios clínicos (efetividade) ao paciente. Os resultados são expressos em unidades não monetárias, ou seja, em termos de melhoria da saúde ou unidades naturais (prolongamento da vida, número de vidas salvas, curas clínicas, dias livres de sintomas ou dor, custo/hora do tempo da enfermagem, custo/milímetro de mercúrio alterado da pressão arterial) (DRUMMOND; JEFFERSON, 1996; HAYCOX; WALLEY, 1997; ZANINI et al., 2001). Assim, a unidade de medida selecionada dependerá do objetivo do programa ou tratamento avaliado (PINTO-PRADES; ORTÚN-RUBIO; PUIG-JUNOY, 2001).

De maneira geral a ACE é a técnica mais apropriada quando a escolha precisa ser feita entre duas ou mais opções competidoras, para as quais os ganhos esperados em saúde podem ser expressos em termos de uma medida de efeito comum (LOPERT; LANG; HILL, 2003). Portanto, a ACE é sempre comparativa e se destina à escolha da melhor estratégia para se atingir um mesmo objetivo (DETSKY; NAGLIE, 1990; DRUMMOND, 1994; UGÁ, 2002). Exemplos: relação entre os custos de tratamento com diferentes anti-hipertensivos e os respectivos graus de efetividade em diminuir a pressão arterial dos pacientes. Custos de diferentes tratamentos quimioterápicos para o câncer e seus respectivos graus de efetividade em salvar vidas ou em prolongar os anos de vida dos pacientes (ZANINI et al., 2001).

A ACE representa o tipo de análise mais utilizada na farmacoeconomia, porque possibilita o uso na prática cotidiana das mesmas unidades utilizadas nos ensaios clínicos.

O cálculo da razão de custo-efetividade expressa o custo adicional necessário para se atingir uma unidade extra do benefício clínico e é expresso pela diferença 
entre o custo de duas intervenções, dividida pela diferença entre as suas consequências em termos de saúde (efetividade) (BRASIL, 2008).

Outra unidade de medida em custo-efetividade é a qualidade de vida relacionada à saúde (QVRS). Os dois grandes tipos de QVRS são: a) as denominadas específicas, formuladas para avaliar melhoras na qualidade de vida produzidas por um tratamento específico e b) as denominadas genéricas, desenvolvidas para avaliar variações na qualidade de vida produzidas por qualquer tipo de intervenção (PINTO-PRADES; ORTÚN-RUBIO; PUIG-JUNOY, 2001).

Análise de custo-efetividade, todavia tem limitações. Como já foi notado, pode ser útil em determinar prioridades de gastos para diferentes tratamentos para a mesma condição (eficiência técnica), mas é menos aplicável para decisões envolvendo tratamentos para diferentes doenças. Não sendo possível comparação entre programas (ou mesmo com o mesmo programa) quando não há medida comum. Não se podem comparar custo-efetividades de uma terapia antihipertensiva e uma para asma, onde os efeitos do tratamento são descritos em termos de redução da pressão sanguínea na primeira e porcentagem aumentada de volume expiratório forçado para a segunda (LOPERT; LANG; HILL, 2003).

Entretanto, vários estudos que trabalham com efeitos (como o número de mortes evitadas), e não com produtos (vacinações, casas atendidas com esgoto sanitário, etc.) enquanto medida da efetividade superam essa restrição, na medida em que podem, assim, comparar estratégias de intervenção com unidades de produto totalmente distintas (ampliação do sistema de saneamento, imunizações, atenção materno-infantil, por exemplo) (UGÁ, 2002).

\subsubsection{Análise Custo-Utilidade (ACU)}

A Análise Custo-Utilidade (ACU) considera a relação entre os custos de um tratamento e seus benefícios em qualidade de vida relacionada à saúde (utilidade) do paciente, bem como os riscos de reações adversas. É o método que adiciona satisfação e preferência do paciente à análise de custo-efetividade. Trata-se de estudos destinados a comparar diferentes tratamentos destinados, fundamentalmente, a pacientes crônicos. Exemplos: relação entre os custos de diferentes tratamentos para o câncer e seus respectivos índices de qualidade de 
vida relacionada à saúde para os anos de vida que foram salvos; custo de um tratamento para artrite reumatóide e a qualidade de vida relacionada à saúde que o paciente passou a ter com a redução da dor e melhoria da mobilidade. Entretanto, não permite comparações entre diferentes setores, por exemplo, os custos com a saúde em relação com a educação, estando limitada a uma avaliação quase alocativa (WALKER, 2001).

$\mathrm{Na}$ análise Custo-Utilidade calcula-se o quanto custa para se obter um "ano de vida saudável" com diferentes tratamentos, ou seja, incorpora a quantidade e também a qualidade dos anos de vida que foram salvos por meio de um tratamento. Os resultados (outputs) são expressos como o custo pelos "anos de vida saudáveis" ou "anos de vida ajustados por qualidade" (AVAQs ou QALY - quality adjusted life years). Os AVAQs são calculados pelos anos de vida ganhos multiplicados por um índice de qualidade, aferidos por meio de questionários específicos. A medicina moderna está preocupada com a melhoria da qualidade de vida e não apenas com a quantidade de vida (DRUMMOND, 1991; ROBINSON, 1993b).

O emprego da expectativa de vida ajustada para a qualidade permite avaliar situações nas quais existe aumento de sobrevida em condições de saúde que não são perfeitas ou terapias que não alteram a sobrevida, mas melhoram a qualidade de vida (BRASIL, 2008).

A ACU é atualmente o tipo de avaliação econômica preferida dos especialistas, principalmente por permitir comparar diferentes programas ou tratamentos sem os problemas éticos incorridos na ACB por atribuir valores monetários à saúde. $\mathrm{O}$ emprego de listas de tratamentos e programas sanitários ordenados segundo seu custo por AVAQ tem auxiliado no estabelecimento de prioridades em saúde. Os tratamentos com menor custo por AVAQ devem ser implantados primeiro e os com maior custo por AVAQ devem ser considerados menos prioritários. Entretanto, apesar de útil, este não pode ser o único critério empregado no estabelecimento de prioridades em saúde (PINTO-PRADES; PUIGJUNOY; ORTÚN-RUBIO, 2001).

Assim a análise farmacoeconômica considera os fatores econômicos da utilização de medicamentos, porém, não exclui os resultados clínicos e humanísticos como objetos importantes da avaliação. O verdadeiro valor de uma intervenção ou política pode ser apurado somente se todas as dimensões do resultado são medidas 
e consideradas. Desta forma, o critério econômico não pode exercer o papel principal.

O quadro 1 ilustra resumidamente as principais características de cada tipo de análise:

\section{Quadro 1 - Tipos de Análises Farmacoeconômicas}

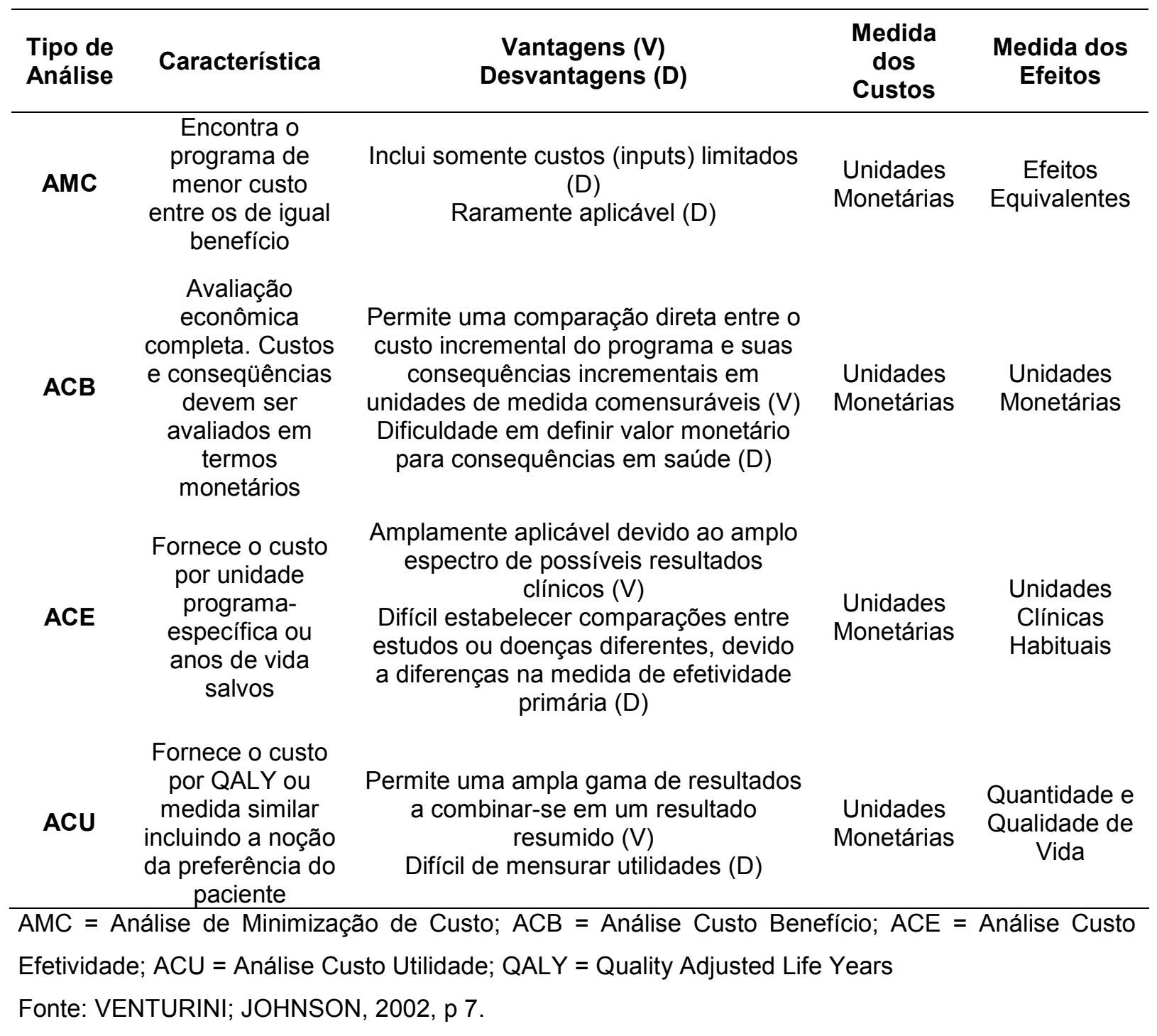

\subsection{Análise de sensibilidade}

A análise de sensibilidade leva em conta as incertezas comuns às avaliações econômicas em saúde, uma vez que os resultados encontrados na prática clínica podem variar em relação aos relatados pela literatura médica. Assim, este tipo de análise recalcula as razões obtidas na análise custo-efetividade modificando um ou 
mais parâmetros do estudo. Exemplos de variáveis são o grau de efetividade das intervenções, o curso natural da doença, os custos relacionados ao tratamento, o resultado esperado na qualidade de vida, entre outros. O Painel de Custoefetividade em saúde recomenda o emprego desta técnica nas avaliações econômicas em saúde e sugere o cálculo de todos os parâmetros ou variáveis do modelo cujas estimativas não sejam precisas ou cujos valores possam variar em cenários diferentes (BRASIL, 2008).

As análises de sensibilidade podem ser univariadas, quando modifica-se uma variável por vez ou multivariadas, quando modificam-se simultaneamente inúmeras variáveis do modelo.

Se ao variarem-se os valores para um determinado parâmetro a estratégia escolhida permanecer estável, diz-se que o modelo é insensível a esse parâmetro e a imprecisão na sua estimativa não diminui a validade das conclusões obtidas pelo modelo (SACRISTÁN, et al, 2004).

Nos países desenvolvidos, análises de custo são frequentemente empregadas para que gestores possuam informações adequadas ao definir e priorizar intervenções na área de saúde.

No Brasil, como em outros países em desenvolvimento, essa prática não tem sido adotada (MÉDICE, 1994). O desenvolvimento de estudos econômicos ainda é raro e concentrado nas instituições acadêmicas.

Arredondo e Damian, 1997, enfatizam a necessidade de se identificar e conter os custos dos serviços como um problema prioritário para a organização do sistema, portanto, é importante que governo e sistemas de saúde se preocupem com a disseminação dos conceitos e técnicas de análises econômicas; investindo na formação de recursos humanos qualificados e estimulando a produção de estudos aplicando estas ferramentas, tanto no setor público quanto no setor privado e finalmente que passem a incorporar as análises econômicas nas decisões políticas em saúde. 


\subsection{Farmácia Hospitalar}

A Farmácia Hospitalar data da época de gregos, romanos, árabes, e é certo que na Idade Média a medicina e a farmácia se desenvolviam de forma paralela sob a responsabilidade de religiosos dos conventos, nas boticas e nos hortos de plantas medicinais. No inicio do século XX predominavam nos hospitais as preparações magistrais, ou seja, os medicamentos eram preparados de acordo com as necessidades específicas de cada paciente. Com o advento das especialidades farmacêuticas (industrialização em massa dos medicamentos), a farmácia magistral entrou em obsolescência e o farmacêutico deixou de ser o manipulador de fórmulas medicamentosas e orientador quanto ao seu uso racional (BRASIL, 1994; NETO,1990).

A partir da década de 40, com o surgimento de antibióticos e sulfas, e apesar da existência do grande número de especialidades farmacêuticas, os farmacêuticos, na Europa e nos Estados Unidos da América, começaram a tomar conhecimento da necessidade de ampliação de suas áreas de atuação e iniciaram os primeiros passos em direção à Farmácia Hospitalar (BRASIL, 1994).

No Brasil, a partir de 1950 , os Serviços de Farmácia Hospitalar, representados na época pelas Santas Casas de Misericórdia e Hospital das Clínicas da Universidade de São Paulo, passaram a se desenvolver e a se modernizar (NETO, 1990).

A evolução do serviço de farmácia hospitalar fez com que, a partir da década de 80 , suas atividades antes restritas aos aspectos técnico-científicos ligados aos medicamentos se ampliassem e este setor passou a se responsabilizar também, pelas atividades administrativas ligadas à produção, ao armazenamento, ao controle, à dispensação e a distribuição de medicamentos e correlatos às unidades hospitalares e pelo uso racional dos medicamentos visando sempre à eficácia da terapêutica, além da redução dos custos (PÔRTO et al, 1985).

Atualmente a farmácia hospitalar pode ser definida como "unidade clínica, administrativa e econômica, dirigida por profissional farmacêutico, ligada hierarquicamente à direção do hospital e integrada funcionalmente com as demais unidades de assistência ao paciente" o que demonstra a ampliação das atividades para além dos limites físicos da farmácia focando sua atuação no paciente e nas 
suas necessidades e no medicamento, como instrumento e não mais como um meio (SBRAFH, 2007).

\subsubsection{Funções da Farmácia Hospitalar}

A Organização Pan-americana de Saúde - OPAS e o Ministério da Saúde do Brasil definem como funções fundamentais da farmácia hospitalar (BRASIL, 1994; OPAS, 1987):

- Seleção de Medicamentos, germicidas e correlatos necessários ao hospital, realizada pela Comissão de Farmácia e Terapêutica, associada a outras comissões quando necessário;

- Aquisição, conservação e controle dos medicamentos selecionados, permitindo que se disponha da quantidade necessária ao atendimento e evitando o armazenamento em demasia, pelo aspecto antieconômico em detrimento de outros produtos considerados essenciais;

- Manipulação, produção de medicamentos e germicidas, a farmácia pode e deve produzir medicamentos em diferentes formas farmacêuticas seja pela indisponibilidade de produtos no mercado, para atender prescrições especiais ou por motivos de viabilidade econômica. Elaborar manuais técnicos e formulários próprios;

- Estabelecimento de um sistema racional de distribuição de medicamentos capaz de assegurar que o medicamento prescrito chegue ao paciente a que está destinado, na dose correta e no momento indicado. Permitindo que a qualquer momento, os esquemas de tratamento de cada paciente hospitalizado possam ser revistos e atualizados;

- Implantação de um sistema de informação sobre medicamentos que permita otimizar a prescrição médica e a administração dos medicamentos, além de assistir aos pacientes, de forma especial, no momento da alta, orientando-os adequadamente quanto ao tratamento ambulatorial ou domiciliar prescrito. 


\subsubsection{Manipulação e Produção de Medicamentos em Farmácia Hospitalar}

Como descrita em suas funções, a farmácia hospitalar pode realizar a manipulação de fórmulas magistrais e oficinais ${ }^{1}$, o fracionamento e/ou adequação de doses e a produção de medicamentos, desde que sejam realizados em condições ambientais (estrutura física), tecnológicas (equipamentos) e de pessoal (quantitativo e capacitação) adequadas ao grau de complexidade da manipulação proposta, seja ela estéril ou não estéril e atendam às exigências da legislação (SBRAFH, 2007).

A manipulação e o fracionamento devem atender aos requisitos exigidos na RDC n 67 de 2.007 que institui as Boas Práticas de Manipulação de Medicamentos, já a produção é regida pela RDC no 210 de 2003 que regulamenta as Boas Práticas de Fabricação de Medicamentos (BRASIL, 2007b; BRASIL, 2003).

Os laboratórios de manipulação especializados permitem controlar a administração de medicamentos uma vez que são preparados exclusivamente para o paciente considerando sua idade, sexo, peso e condição orgânica ou clínica geral; atender a pacientes em condições especiais, por exemplo, no caso de pacientes com dificuldade de deglutição ou para os quais as formas farmacêuticas e/ou concentrações disponíveis no mercado não se aplicam, como pacientes neonatais e pediátricos e possibilitam a produção de medicamentos não mais comercializados e que são de interesse médico (SANTOS, 2006; GOMES; GOMES, 2003; NETO, 1990).

As especialidades médicas que mais necessitam desta atividade são a pediatria, geriatria e a dermatologia, entretanto, todas as demais áreas se beneficiam das preparações magistrais ou do fracionamento e/ou adequação de doses (NETO, 1990).

Sendo assim, tanto a produção quanto a manipulação de medicamentos deve receber atenção especial dos administradores hospitalares, pois, o medicamento manipulado, além de suas excelentes respostas terapêuticas, não tem incluído no preço final os custos de IPI, propaganda, transporte, embalagens sofisticadas e outros, o que torna essa atividade uma das molas propulsoras da economia

\footnotetext{
${ }^{1}$ Formulações magistrais são aquelas elaboradas de acordo com a patologia, dados do paciente (idade, peso etc.), além de seguir critérios médicos; enquanto as oficinais são formulações presentes nos livros oficiais de farmácia, as farmacopéias (SBRAFH, 2007).
} 
hospitalar, entretanto só deve ser viabilizada em hospitais cujo número de leitos seja expressivo a ponto de compensar o investimento. (NETO, 1990).

Na década de 90, no Brasil, a produção de medicamentos era realizada em alguns hospitais de porte especial, e chegava a atingir $60 \%$ do consumo global de medicamentos, ou seja, somente $40 \%$ de especialidades farmacêuticas eram adquiridas no mercado (NETO, 1990).

Todavia, mesmo estando entre as funções principais da farmácia hospitalar e representando uma estratégia útil na redução de custos, são pouquíssimos os hospitais brasileiros que possuem manipulação e/ou produção ativa de medicamentos, e a quase totalidade deles é formada por hospitais públicos ou por algumas santas casas de misericórdia. No geral, as atividades farmacêuticas, nos hospitais brasileiros, estão voltadas essencialmente à provisão, estocagem e distribuição e não às atividades industriais de produção e controle de medicamentos. (SANTOS, 2006; UETA et al, 2004).

Objetivando contribuir para discussões sobre o lugar da manipulação e industrialização de medicamentos em uma farmácia moderna, um estudo custoavaliação prospectivo realizado na Farmácia Central do Hospital das Clínicas da Faculdade de Medicina - USP, São Paulo, avaliou a produção física e econômica do Serviço Industrial da Farmácia Central durante um período de 12 meses $\left(1^{\circ}\right.$ de janeiro a 31 de dezembro de 1999). Para os medicamentos com similar no mercado, correspondentes a $34,4 \%$ do total, os custos industriais foram comparados com os valores de mercado e os resultados mostraram uma economia de 63,5\% (US\$3.039.953,86). Quando extrapolada para os outros dois grupos, formulações de composição exclusiva e pedidos especiais voltados para investigações clínicas, para quais não se contava com preços comerciais diretamente equivalentes, atingiu-se uma estimativa superior a US\$5.100.000,00 de economia durante um ano de operação. Mesmo considerando-se que tais contas deixam de lado muitos custos, notavelmente aqueles subordinados à comercialização e distribuição, foi lícito concluir que pelo menos parte da economia citada era verdadeira (MARIN, et al, 2001).

Apesar das atraentes economias citadas, a tomada de decisão para a implantação de um serviço de atividades farmacêuticas industriais, que atenda às necessidades hospitalares e seja economicamente viável, deve ser feita após um 
minucioso estudo farmacoeconômico, tomando como parâmetro o consumo e a participação no orçamento de todos os medicamentos disponibilizados no hospital.

A aplicação das ferramentas da economia da saúde e da farmacoeconomia em pesquisa no País ainda pode ser considerada incipiente, em especial, no tocante a produção de medicamentos em hospitais e não há disponível na literatura um modelo que permita tal avaliação.

Face a esta constatação e objetivando contribuir para a formação de recursos humanos em área ainda carente no país, este estudo se propôs a estabelecer uma estratégia para o estudo farmacoeconômico da viabilidade de produção de medicamentos em hospitais de porte especial ${ }^{2}$ da rede pública de saúde.

${ }^{2}$ São classificados como porte especial/extra hospitais com mais de 501 leitos. Alguns hospitais universitários são de porte extra. Como característica marcante destaca-se a grande variedade de serviços e a complexa gestão e controle. (SANTOS, 2006) 
Objetivos 


\section{OBJETIVO GERAL}

Estratégia de estudo farmacoeconômico para avaliar a viabilidade de implantação de farmácia semi-industrial para produção de medicamentos em hospital de porte especial da rede pública.

\subsection{OBJETIVOS ESPECÍFICOS}

a) Sistematização dos medicamentos em curva $A B C$ segundo critérios de demanda valorizada e demanda quantitativa;

b) Identificação das formas farmacêuticas, classificação segundo critérios da RDC $\mathrm{n}^{\circ} 210$ dos medicamentos constantes das regiões $A$ e $B$ de demanda valorizada e demanda quantitativa;

c) Identificação das formas farmacêuticas cuja produção é viável (técnica e economicamente);

d) Estudo de caso: identificação dos processos de produção, equipamentos necessários à produção dos itens selecionados; planejamento e avaliação do investimento em área física de acordo com as exigências da legislação pertinente; recursos humanos essenciais às atividades; matérias primas e embalagem;

e) Avaliação final técnica e econômica do projeto. 
Delineamento Experimental 


\section{DELINEAMENTO EXPERIMENTAL}

\subsection{Aspectos Regulatórios}

O desenvolvimento deste trabalho foi norteado pela Resolução da Diretoria Colegiada da Agência Nacional de Vigilância Sanitária, RDC n²10, de 04 de agosto de 2003.

\subsection{Aquisição e Sistematização dos dados}

\subsubsection{Fonte de dados}

Os dados referentes à aquisição de medicamentos foram obtidos no Hospital das Clínicas da Faculdade de Medicina de Ribeirão Preto da Universidade de São Paulo (HCFMRP-USP).

\subsubsection{Aquisição dos dados}

Os dados, relativos à quantidade e aos preços médios dos medicamentos adquiridos pelo HCFMRP-USP, foram coletados nas bases do sistema informatizado do hospital, para o período de $1^{\circ}$ de janeiro de 2006 a 31 de dezembro de 2006 e de $1^{\circ}$ de janeiro de 2007 a 31 de dezembro de 2007.

Os dados foram obtidos na forma de planilha do Microsoft Office Excel ${ }^{\odot}$ contendo as aquisições individuais de medicamentos ordenadas segundo data de incorporação.

A realização do projeto de pesquisa foi autorizada previamente pela direção do Hospital das Clínicas da Faculdade de Medicina de Ribeirão Preto (anexo 1). 


\subsubsection{Identificação e Classificação dos Medicamentos}

A nomenclatura dos medicamentos baseou-se no critério adotado pelo sistema informatizado do HCFMRP-USP que identifica os medicamentos pelo nome do princípio ativo (nome genérico). Os nomes foram acrescidos das especificações técnicas como forma, dosagem, concentração do fármaco, número de unidades de medida de peso e volume por unidade de consumo.

\subsubsection{Classificação dos medicamentos em Curva ABC de demanda valorizada e demanda quantitativa}

Para calcular, no período de um ano, a demanda quantitativa (o número de unidades totais adquiridas) e a demanda valorizada (quantidade adquirida vezes o valor unitário médio), os medicamentos foram agrupados por especialidade farmacêutica. Medicamentos que continham mesmo princípio ativo, mas concentração e/ou formas farmacêuticas diferentes foram considerados separadamente.

Também foi calculada a contribuição porcentual, que cada especialidade farmacêutica representava no gasto total com medicamentos, e do número total de unidades adquiridas para o mesmo período. Estes dados foram calculados separadamente para cada ano avaliado.

As especialidades farmacêuticas foram então classificadas em curva $A B C$ de demanda quantitativa e de valorizada.

A classificação $A B C$ visa identificar os produtos em função dos valores que eles representam e, com isso, estabelecer formas de gestão apropriadas à importância de cada item em relação ao valor total considerado (BARBIERI, MACHLINE, 2006).

A curva $A B C$ pode ser dividida em três grandes regiões ou classes: a região $A$ corresponde a um pequeno número de itens, responsáveis pela maior porcentagem acumulada dos investimentos, a região $\mathrm{B}$ corresponde a um número intermediário de itens, responsáveis por uma porcentagem acumulada também intermediária dos investimentos e a região $\mathrm{C}$ corresponde ao maior número de itens, responsáveis por pequena parte dos investimentos (MOREIRA, 2001). 
Neste trabalho foi estabelecido que a região A (maior demanda valorizada) seria composta pelos medicamentos que representasse $65 \%$ do gasto anual com medicamentos, a região $B$ (demanda valorizada intermediária) $25 \%$ e região C (menor demanda valorizada) $10 \%$ do gasto anual do hospital dom medicamentos. A mesma relação foi estabelecida para construção da curva de demanda quantitativa, porém o critério avaliado foi a quantidade adquirida.

\subsubsection{Seleção}

Os itens pertencentes à região $\mathrm{A}$ e $\mathrm{B}$ das curvas de demanda valorizada $\mathrm{e}$ demanda quantitativa foram selecionados para as próximas etapas do estudo. Medicamentos presentes tanto na curva de demanda valorizada como na curva de demanda quantitativa foram considerados uma única vez e as análises posteriores foram realizadas separadamente para os anos 2006 e 2007.

\subsubsection{Classificação dos medicamentos por forma farmacêutica}

Os medicamentos selecionados (regiões A e B de demanda valorizada e quantitativa) foram classificados quando a forma farmacêutica de acordo com a lista de medicamentos referência da ANVISA (BRASIL, 2008) e Guia Farmacoterapêutico do HCFMRP-USP (HCFMRP-USP, 2002). Quando não encontrado nas referências citadas, foi utilizada a forma farmacêutica constante da bula (BULAS.MED.BR).

\subsubsection{Classificação dos medicamentos segundos critérios da $\operatorname{RDC} \mathbf{n}^{\circ} \mathbf{2 1 0}$}

A classificação farmacológica foi realizada com base no guia farmacoterapêutico do Hospital das Clínicas da Faculdade de Medicina - USP (HCFM-USP, 2002; GOODMAN et al, 2007). Os medicamentos sujeitos a regime de controle especial foram identificados e classificados separadamente, seguindo a lista publicada pela Portaria $n^{\circ} 344$, de 12 de maio de 1998 e suas atualizações que apresenta a lista de substâncias entorpecentes, psicotrópicas, precursoras e outras 
sob regime especial (BRASIL,1999). Foram identificados aqueles de origem biotecnológica e os radioativos.

\subsubsection{Seleção}

A seleção dos medicamentos para o estudo de caso foi realizada com os medicamentos constantes das regiões $A$ e $B$, adicionado da viabilidade técnica de produção, segundo os critérios da RDC n² 210 .

\subsection{Estudo de caso}

No estudo de caso foram utilizados os medicamentos apresentados na forma farmacêutica sólida (comprimidos simples e revestidos e cápsulas gelatinosas duras) e na forma farmacêutica injetável de pequeno volume e pó liófilo, injetável. Seguindo critérios técnicos, os medicamentos apresentados na forma de cápsula gelatinosa dura foram planejados para serem produzidos na forma de comprimidos simples ou revestidos.

\subsubsection{Etapa de Implantação}

O planejamento dos recursos físicos para a implantação de uma farmácia semi-industrial para a produção de medicamentos sólidos, injetáveis de pequeno volume e pó liófilo, foram feitos de forma a atender as exigências da legislação em vigor (BRASIL, 2003).

\subsubsection{Processo de produção}

Foram utilizados meios e processos convencionais descritos nos livros textos de Farmacotécnica e Tecnologia Farmacêutica (ALDERBORN, 2005; ANSEL; POPOVICH; ALLEN Jr, 2000; BANDELIN, 1989; BILLANY, 2005; PECK et al, 1989). 


\subsubsection{Equipamentos}

Os equipamentos foram selecionados, considerando a capacidade produtiva, a expectativa de produção e a melhor relação custo-benefício. Quando uma etapa do processo de produção pode ser realizada por mais de um tipo de equipamento, optou-se por um deles.

\subsubsection{3. Área física}

Foi planejada de acordo com os processos envolvidos, expectativa de produção e porte dos equipamentos.

\subsubsection{Etapa de implementação}

Esta etapa envolve os recursos físicos, humanos e matérias primas necessárias para produção de medicamentos sólidos e injetáveis.

\subsubsection{Tempo de processo}

O tempo necessário para cada etapa do processo foi estimado com base na capacidade do equipamento, considerando as informações técnicas fornecidas pelo fabricante ou distribuidores.

\subsubsection{Matéria-prima e material de embalagem}

Os adjuvantes propostos para compor o excipiente das formas farmacêuticas sólidas ou veículo dos injetáveis, foram selecionados com base em livros texto de farmacotécnica e tecnologia farmacêutica (ALDERBORN, 2005; ANSEL; POPOVICH; ALLEN Jr, 2000; BANDELIN, 1989; BILLANY, 2005; PECK et al, 1989) e a Farmacopéia Brasileira (1996). 
As embalagens foram selecionadas de acordo com as especificações de cada produto.

\subsubsection{Recursos humanos}

A qualificação foi planejada de acordo com a atribuição em cada setor produtivo.

\subsubsection{Atividades de Apoio: Controle de Qualidade Físico-Químico e} Microbiológico, Produção de Água Purificada e de Qualidade Injetável e Almoxarifado

São atividades não diretamente relacionadas à produção, mas indispensáveis para que ela ocorra e mantenha a qualidade exigida.

Os processos envolvidos no controle de qualidade físico-químico e microbiológico e na produção de água purificada e de qualidade injetável seguiram os parâmetros determinados na Farmacopéia Brasileira (1996) e na Farmacopéia Americana - USP (1999). Foram considerados também a grande diversidade e especificidade, os reagentes, meios de cultura, padrões primários e secundários e outros componentes relativos ao controle de qualidade físico químico e microbiológico.

A infra-estrutura baseou-se na quantidade e porte dos equipamentos selecionados e no caso do almoxarifado, no volume e variedade de matéria-prima, material de embalagem e produto acabado. 


\subsubsection{Estruturação da análise de viabilidade econômica}

\subsubsection{Levantamento dos valores de mercado (VM) dos medicamentos selecionados para serem produzidos pela farmácia}

Identificou os valores pelos quais tais medicamentos foram adquiridos pelo Hospital na situação original; para efeito do estudo de viabilidade serão utilizadas as médias do número de unidades totais adquiridas e do valor total pago entre os anos de 2006 e 2007.

\subsubsection{Levantamento dos custos variáveis de produção - CVP}

Os CVP são aqueles que "mudam em proporção às mudanças no volume da produção" (MARTINS, 2006; ATKINSON, et al., 2000).

No caso desta pesquisa, foram identificados os seguintes elementos componentes do CVP:

a) mão-de-obra diretamente relacionada ao processo produtivo: o número e a qualificação dos funcionários que realizam as atividades ligadas à produção foram estabelecidos no item 3.3.2.3. As informações referentes aos salários da mão-deobra foram obtidas no Conselho Regional de Farmácia do Estado de São Paulo (CRF-SP) e representam o piso da categoria referente ao ramo de atividade hospitalar para o Estado de São Paulo referente ao ano 2007/2008 (CRF-SP, 2009). Os valores incluídos no estudo consideram os salários acrescidos de $67,79 \%$ referentes aos encargos trabalhistas.

b) matéria-prima (formulação excipiente, princípio ativo e material de embalagem): o item 3.3.2.2. estabeleceu as formulações padrão, a concentração de princípio ativo e o material de embalagem para comprimidos e injetáveis respectivamente, os componentes desta formulação e as embalagens foram cotados junto a fornecedores de matéria-prima para farmácias de manipulação e indústria farmacêutica. Como a variedade de medicamentos selecionada para produção é muito grande e conseqüentemente o número de princípios ativos diferentes também, 
optou-se por realizar a cotação de alguns itens e empregar a média dos valores encontrados como o valor do princípio ativo. Assim, obteve-se o valor equivalente a um comprimido e a uma solução injetável, estes valores foram multiplicados pela quantidade de medicamentos que se deseja produzir mensalmente e utilizados como o valor de matéria-prima.

c) material de consumo: Os filtros utilizados no processo de clarificação e esterilização dos medicamentos injetáveis devem ser trocados a cada lote de produção, portanto, foram considerados como material de consumo.

d) energia consumida pelos equipamentos durante o processo de produção: as especificações quanto ao consumo de energia elétrica de cada equipamento foram levantadas a partir da descrição adquiridas com fabricantes ou fornecedores, esse dado foi multiplicado pela quantidade de horas que cada equipamento funcionaria durante a produção de um lote de medicamentos e extrapolado para o período de um mês. Os dados encontrados foram multiplicados pelo valor do $\mathrm{MW} / \mathrm{h}$ de energia elétrica para a indústria, o resultado refere-se aos gastos mensais com energia elétrica para cada equipamento. A tarifa utilizada corresponde ao valor médio de fornecimento de energia elétrica (ANEEL, 2009).

\subsubsection{Obtenção da margem de contribuição de cada período}

Margem de contribuição é a "diferença entre a receita e o custo variável de cada produto" (MARTINS, 2006). Neste trabalho consideraremos como Receita o VM (exposto no item "a" acima), uma vez que este representa o valor total de gastos com medicamentos antes da implantação da farmácia semi-industrial e permitirá visualizar a economia causada pela implantação desta última; consideraram-se como custos variáveis (CVPs) os itens descritos acima, pois estes variam diretamente com o volume de produção. 


\subsubsection{Levantamento dos custos fixos de produção - CFPs}

Os CFPs são aqueles que "não variam conforme as mudanças no volume da produção" (MARTINS, 2006; ATKINSON, et al., 2000). Nesse trabalho foram levantados os seguintes:

a) valor da mão-de-obra indireta, ou seja, relacionada às atividades de apoio, administrativas e limpeza: os salários e encargos foram determinados seguindo os mesmos critérios para mão-de-obra diretamente relacionada à produção.

b) os custos anuais de manutenção de equipamentos, das obras civis e instalações: os custos anuais de manutenção empregados foram estimados segundo parâmetros utilizados em instituições financeiras para fins de elaboração de projetos de financiamento, para equipamentos o valor corresponde a $3 \%$ do investimento total nestes itens e para obras civis e instalações utiliza-se $1 \%$ do investimento total em infra-estrutura.

c) custos operacionais: os custos referentes às atividades do controle de qualidade e da purificação de água, ao consumo de energia elétrica e água das demais dependências da farmácia semi-industrial e a compra de materiais de escritório e limpeza foram estimados conforme experiência profissional, uma vez que não é possível prever exatamente o valor de cada uma das atividades e não há informação em literatura referente a esses valores. Esses custos são pouco representativos em relação aos custos totais do projeto e qualquer variação tem pouco impacto no estudo de viabilidade.

\subsubsection{Levantamento dos custos de implantação e do valor residual}

Os custos de implantação dizem respeito à infra-estrutura e aos equipamentos da farmácia semi-industrial considerando-se os processos produtivos e as atividades de apoio.

Os valores para a implantação da estrutura física foram pesquisados em empresas especializadas em construções para a indústria farmacêutica. 
Os equipamentos considerados foram selecionados conforme descrito no item 3.3.1.2., o custo dos equipamentos foi estimado por meio de pedido de orçamento enviado a fabricantes e fornecedores.

A fim de estimar o valor residual gerado pelos equipamentos da farmácia semi-industrial ao final de 10 anos de uso, buscou-se levantar qual seria seu valor de venda como sucata de aço.

No mercado, tal material é tratado como sucata por obsolescência e, como se trata de equipamentos pesados, são categorizados como HMS (Heavy Melt Scrap). Os valores de tal sucata tem sofrido grandes variações nestes dois últimos anos, portanto, optou-se por estimar o valor do equipamento sem nenhum tratamento para a reciclagem a partir do menor valor encontrado ${ }^{3}$, descontando-se aproximadamente $25 \%$ da preparação para a reciclagem, ou seja $R \$ 150,00$ a tonelada.

\subsubsection{Obtenção do fluxo de economia de caixa incremental}

Subtraindo da Margem de Contribuição os recursos desembolsados com os CFPs, obtém-se, por fim, o montante que será economizado pelo hospital em cada período, ou seja, a economia de caixa incremental gerada pela implantação do projeto.

\subsubsection{Aplicação da técnica de Valor Presente Líquido}

Para o cálculo do VPL foi montado o fluxo de caixa contendo os valores da receita, dos custos variáveis, da margem de contribuição, os custos fixos e o resultado (economia de caixa incremental) para os 120 meses analisados.

Descontando-se a taxa de juros encontrou-se o valor presente dos fluxos futuros de caixa. O valor presente de um fluxo futuro de caixa representa os fluxos de caixa gerados pelo projeto descontados por uma taxa de juros de mercado apropriada (ROSS; WESTERFIELD; JAFFE, 2002).

\footnotetext{
${ }^{3}$ Ressalta-se que os valores da tonelada de sucata são de difícil obtenção e considerou-se para tanto fonte retirada de reportagem do Jornal Gazeta Mercantil, de 25 de fevereiro de 2009, disponível em: http://www.gazetamercantil.com.br/GZM_News.aspx?parms=2357557,608,3,1 , acessado em 25 de fevereiro de 2009.
} 
A partir do levantamento de tais fluxos, foi aplicada a técnica de Valor Presente Líquido - VPL.

O valor presente líquido - VPL de um investimento é a soma do valor presente dos fluxos de caixa desse investimento descontados o custo inicial do investimento (ROSS; WESTERFIELD; JAFFE, 2002; BRIGHAM; GAPENSKI; EHRAHRDT, 2001).

A fórmula de cálculo do VPL segue abaixo:

$V P L=\left[\sum_{t=1}^{n} \frac{F C_{t}}{(1+K)^{t}}\right]-\left[I_{0}+\sum_{t=1}^{n} \frac{I_{t}}{(1+K)^{t}}\right]$

Onde:

$\mathrm{FC}_{\mathrm{t}}=$ fluxo (benefício) de caixa de cada período;

$\mathrm{K}$ = taxa de desconto do projeto, representada pela rentabilidade mínima requerida;

$\mathrm{I}_{0}=$ investimento processado no momento zero;

$\mathrm{I}_{\mathrm{t}}=$ valor do investimento previsto em cada período subseqüente.

Fonte: ASSAF (2003, p. 313-314)

Nesta pesquisa optou-se por utilizar como taxa de desconto a Taxa Selic ${ }^{4}$, descontando-se a inflação, medida pelo IGP-DI/FGV ${ }^{5}$, referente ao mesmo período. A inflação deve ser descontada, pois para o cálculo do VPL os valores são projetados para o futuro sem considerar a inflação, portanto, ao trazê-los para valor presente somente os juros devem ser descontados. A escolha da Taxa Selic como taxa de desconto justifica-se na medida em que os recursos a serem destinados à implantação do projeto teriam origem pública, representando de forma adequada o custo de oportunidade de tal fonte de recursos para o governo.

O VPL é a mais recomendação técnica de análise de investimentos, pois se trata de um critério simples para decidir se o investimento deve ser feito ou não (MATIAS, 2007; ROSS; WESTERFIELD; JAFFE, 2002). Pode ser interpretado como

\footnotetext{
${ }^{4}$ É a taxa apurada no Selic [Sistema Eletrônico de Liquidação e Custódia], obtida mediante o cálculo da taxa média ponderada e ajustada das operações de financiamento por um dia, lastreadas em títulos públicos federais (BCB, 2008)

${ }^{5}$ Reflete a variação dos preços em geral da economia brasileira, uma vez que cada um de seus componentes (IPA, IPC-BR e INCC) representa uma fase do processo produtivo. Tal índice "tem sido utilizado como a melhor aproximação do deflator implícito da renda" (PINHO; VASCONCELLOS, 2004, p. 360).
} 
o excesso de ganho que o projeto apresenta sobre a melhor oportunidade de investimento disponível para a aplicação do capital (SOUZA; CLEMENTE, 2002).

É considerado atraente todo investimento que apresente um valor presente líquido maior ou igual a zero, já projetos com VPL negativo devem ser rejeitados (ASSAF, 2007; BRIGHAM; GAPENSKI; EHRAHRDT, 2001). No caso desta pesquisa, um valor resultante do VPL acima de zero significa que a economia gerada pela implantação da farmácia semi-industrial é maior que os recursos investidos em sua implantação e, portanto, aceita-se como projeto viável.

\subsubsection{Payback}

Os dados obtidos permitiram calcular também o período de payback do investimento.

O período de recuperação do investimento ou payback é definido como o número esperado de anos necessários para recuperar $O$ investimento inicial (SOUZA; CLEMENTE, 2002; BRIGHAM; GAPENSKI; EHRAHRDT, 2001).

Para esta avaliação é estabelecido um período de tempo durante o qual os fluxos de caixa são somados e o investimento inicial é descontado, se o projeto tiver o período de payback dentro do prazo estabelecido deve ser aceito (ROSS; WESTERFIELD; JAFFE, 2002).

Este indicador pode ser interpretado como a medida do grau de risco do projeto, quanto maior for o payback, mais incerta será a recuperação do capital investido (SOUZA; CLEMENTE, 2002).

\subsection{4.. Análise de Sensibilidade}

Análise de sensibilidade indica quando o VPL mudará em consequência de alteração em alguma das variáveis consideradas no estudo, enquanto as outras permanecem constantes (BRIGHAM; GAPENSKI; EHRAHRDT, 2001).

Alterações no valor médio de princípio ativo empregados nas formulações sólidas e injetáveis foram realizadas a fim de se avaliar as variações do VPL. 


\subsection{Adequação de dose para uso pediátrico}

Um levantamento amostral de medicamentos que precisam de adequação de dose ou forma farmacêutica foi realizado por meio de consulta a prontuários de cinco pacientes do CTI pediátrico do HCFMRP-USP, analisando-se o número total de medicamentos administrados por dia a cada paciente, quantos precisavam de adequação de dose e/ou forma farmacêutica e qual o tipo de adequação necessária.

O período analisado correspondeu ao período de internação do paciente. 
Resultados e Discussão 


\section{RESULTADOS}

\subsection{Aspectos regulatórios}

A Resolução da Diretoria Colegiada da Agência Nacional de Vigilância Sanitária, RDC n 210, de 04 de agosto de 2003, institui o Regulamento Técnico das Boas Práticas para a Fabricação de Medicamentos a todos os estabelecimentos fabricantes destes produtos (BRASIL,2003). Este com força de lei tem como finalidade padronizar a produção de medicamentos para que seja mantida a qualidade em unidades repetitivas tanto intra quanto inter indústrias, objetivando garantir a eficácia do medicamento e a segurança do usuário.

A seguir estão relacionados alguns aspectos importantes da referida RDC.

Sanitização e higiene

"A produção de medicamentos exige um alto nível de sanitização e higiene que deve ser observado em todos os procedimentos de fabricação."

Pessoal

"Todos os funcionários em situações de responsabilidade devem ter suas atribuições específicas escritas e autoridade suficiente para desempenhá-las. Os responsáveis pela produção e Controle de Qualidade devem ser independentes um do outro."

Instalações

"As instalações devem ser localizadas, projetadas, construídas, adaptadas e mantidas de forma que sejam adequadas às operações a serem executadas. Seu projeto deve minimizar o risco de erros e possibilitar a limpeza e manutenção, de modo a evitar a contaminação cruzada, o acúmulo de poeira e sujeira ou qualquer efeito adverso que possa afetar a qualidade dos produtos. Devem estar dispostas, segundo o fluxo operacional continuo, de forma a 
permitir que a produção corresponda a sequência das operações de produção e aos níveis exigidos de limpeza."

Sanitários/vestiário

"Os sanitários não devem ter comunicação direta com as áreas de produção e armazenamento."

Áreas de armazenamento

"As áreas de armazenamento devem ter capacidade suficiente para possibilitar o estoque ordenado de várias categorias de materiais e produtos: matérias-primas; materiais de embalagem; produtos intermediários; a granel e produtos terminados, em sua condição de quarentena, aprovado, reprovado, devolvido ou recolhido."

Áreas de Controle da Qualidade

"Os laboratórios de controle de qualidade devem ser separados das áreas de produção. As áreas onde forem realizados os ensaios microbiológicos, biológicos ou com radioisótopos devem ser independentes e separadas e contar com instalações independentes, especialmente o sistema de ar."

Área de Produção

"Para minimizar a probabilidade de ocorrência de contaminação cruzada, devem existir instalações exclusivas e separadas para a produção de determinados medicamentos como preparações biológicas (microrganismos vivos), hormônios e substâncias citotóxicas. É recomendável a existência de edifícios separados para substâncias altamente sensibilizantes (penicilina, cefalosporina e seus respectivos derivados)."

Produtos terminados

"Os produtos terminados devem ser mantidos em quarentena até que sejam finalmente liberados pelo controle de qualidade. Em seguida, 
devem ser armazenados como estoque disponível, de acordo com as condições estabelecidas pelo fabricante."

\subsection{Aquisição e Sistematização dos dados}

O HCFMRP-USP foi escolhido por ter características apropriadas para a coleta dos dados necessários ao desenvolvimento do projeto, ou seja, é uma entidade autárquica, com características de hospital-escola, integrado ao Sistema Único de Saúde - SUS, em nível terciário, tendo como objetivos básicos: ensino, pesquisa e assistência. Sua estrutura organizacional e atividades obedecem aos preceitos do Decreto Estadual no 13297, de 05/03/1979.

Para o desempenho de suas atividades institucionais, dispõe de duas unidades: uma situada na área central da cidade de Ribeirão Preto, denominada Unidade de Emergência (UE) e outra situada no Campus Universitário (Unidade Campus), além do Centro Regional de Hemoterapia - Hemocentro (também no Campus). Além disso, oferece apoio profissional, financeiro, logístico e administrativo a um conjunto de unidades: Hospital-Dia de Psiquiatria, Centro Médico Social e Comunitário Vila Lobato, Centro de Saúde Escola "Joel Domingos Machado" e Centro Médico Social Comunitário Pedreira de Freitas em Cássia dos Coqueiros - SP (HCFMRP-USP, 2008).

A área de atuação do Hospital concentra-se, basicamente, no município de Ribeirão Preto, entretanto, ante as suas características de "Hospital Regional", são atendidos pacientes de várias cidades da região, chegando inclusive, a ultrapassar as divisas e/ou limites do Estado de São Paulo e até mesmo do país.

Segundo dados de 2007 o Hospital realiza diariamente cerca de 2.500 consultas, 60 cirurgias, 90 internações, 6 mil exames laboratoriais, 2 mil exames especializados e 500 exames radiológicos.

Dispõe de 850 leitos, sendo 669 na Unidade Campus e 158 na Unidade de Emergência e 23 destinados ao atendimento particular ou de convênios. Possui 35 salas cirúrgicas distribuídas entre Campus e Unidade de Emergência, duas salas de parto e uma sala de pré-parto (HCFMRP-USP, 2008).

Durante o ano de 2007 foram realizadas 598.584 consultas e procedimentos, 33.547 internações e 33.381 cirurgias (HCFMRP-USP, 2008). 
A taxa de ocupação operacional nas enfermarias para o mesmo ano foi de $76,1 \%$ sendo o censo médio diário de 577,8 pacientes/dia e a duração média de internação de 6,9 dias (HCFMRP-USP, 2008).

Quanto aos medicamentos, são dispensados no HCFMRP-USP:

\section{Medicamentos Padronizados}

A lista de medicamentos utilizados no Hospital é padronizada obedecendo a critérios definidos pela Comissão de Padronização de Medicamentos, junta deliberativa designada pelo Conselho Deliberativo do HCFMRP-USP e composta por docentes representantes dos departamentos clínicos da Faculdade de Medicina de Ribeirão Preto da Universidade de São Paulo, representantes da Divisão de Assistência Farmacêutica e da Divisão de Enfermagem do próprio hospital.

Para esta padronização são consideradas: as necessidades epidemiologias da população atendida e a seleção de produtos com evidência elevada de eficácia clínica e segurança, qualidade e melhores custos possíveis.

Por se tratar de um centro de referência e excelência, que presta assistência complexa e valoriza a otimização de resultados, o HCFMRP-USP contempla em sua padronização medicamentos adotados nacional e internacionalmente, de acordo com sua realidade, abrangendo 545 princípios ativos.

\section{Medicamentos não padronizados}

Eventualmente, devido a situações especiais, tais como, pacientes com patologias raras, ausência de resposta terapêutica e/ou intolerância aos efeitos colaterais de medicamento padronizado, pacientes em tratamento ambulatorial com fármaco não padronizado cuja substituição terapêutica não é recomendável, tornase necessária a utilização de produtos não padronizados. A estratégia mais empregada nessas situações é a justificativa da necessidade em formulário próprio, de acordo com rotina específica estabelecida pela Comissão de Padronização de Medicamentos.

\section{Medicamentos Excepcionais (Alto Custo)}

São medicamentos de elevado valor unitário, ou que, pela cronicidade do tratamento, se tornam excessivamente caros para serem suportados pela população. São abrangidos pelo Programa de Medicamentos Excepcionais, que é gerenciado pela Secretaria de Assistência à Saúde do Ministério da Saúde. 


\section{Medicamentos Especiais}

São medicamentos que fazem parte da assistência ambulatorial, como é o caso, da quimioterapia do câncer, dos medicamentos estratégicos para AIDS, tuberculose, hanseníase e diabetes.

\subsection{Classificação dos medicamentos em Curva $A B C$ de demanda valorizada e demanda quantitativa}

As tabelas contendo os medicamentos pertencentes à região $\mathrm{A}$ e $\mathrm{B}$ e os 20 primeiros itens da região $C$ da curva $A B C$ de demanda valorizada e demanda quantitativa, referente ao período do estudo são apresentadas no apêndice A.

A análise das curvas permitiu o obter informações relativas à quantidade total de unidades adquiridas, ao gasto total do hospital com medicamentos e o número de especialidades farmacêuticas diferentes nos de 2006 e 2007.

A distribuição das especialidades farmacêuticas em Curva $A B C$ de demanda valorizada possibilitou identificar quais e quantos itens foram responsáveis por maior parte do gasto hospitalar com medicamentos.

As tabelas 1 e 2 apresentam os dados obtidos pela análise das Curvas $A B C$ de demanda valorizada para o ano de 2006 e para o ano de 2007.

Tabela 1 - Distribuição dos medicamentos adquiridos pelo HCFMRP-USP no ano de 2006, em Curva ABC de demanda valorizada

\begin{tabular}{cccccc}
\hline Região & $\mathbf{n}^{\circ}$ unidades & Valor & $\begin{array}{c}\text { \% Valor } \\
\text { Total }\end{array}$ & $\begin{array}{c}\text { Valor Médio } \\
\text { Unitário }\end{array}$ & $\begin{array}{c}\mathbf{n}^{\circ} \\
\text { especialidades }\end{array}$ \\
\hline Região A & 3.541 .679 & $\mathrm{R} \$ 30.819 .884,16$ & 65,31 & $\mathrm{R} \$ 323,87$ & 58 \\
Região B & 4.232 .113 & $\mathrm{R} \$ 11.816 .595,21$ & 25,04 & $\mathrm{R} \$ 213,05$ & 143 \\
Região C & 6.713 .018 & $\mathrm{R} \$ 4.551 .632,28$ & 9,65 & $\mathrm{R} \$ 41,45$ & 875 \\
Total & $\mathbf{1 4 . 4 8 6 . 8 1 0}$ & $\mathrm{R} \$ \mathbf{4 7 . 1 8 8 . 1 1 1 , 6 5}$ & $\mathbf{1 0 0}$ & ------- & $\mathbf{1 0 7 6}$ \\
\hline
\end{tabular}

A distribuição dos medicamentos adquiridos pelo HCFMRP-USP mostra que menos de $19 \%$ do total de especialidades farmacêuticas, situadas nas regiões $A$ e $B$ da curva, consumiram, no ano de $2006,90 \%$ do total de recursos despendidos com a aquisição de medicamentos e representaram $54 \%$ do total de unidades adquiridas no mesmo período. 
Tabela 2 - Distribuição dos medicamentos adquiridos pelo HCFMRP-USP no ano de 2007, em Curva ABC de demanda valorizada

\begin{tabular}{cccccc}
\hline Região & $\mathbf{n}^{\circ}$ unidades & Valor & $\begin{array}{c}\text { \% Valor } \\
\text { Total }\end{array}$ & $\begin{array}{c}\text { Valor Médio } \\
\text { Unitário }\end{array}$ & $\begin{array}{c}\mathbf{n}^{\circ} \\
\text { especialidades }\end{array}$ \\
\hline Região A & 2.070 .969 & $\mathrm{R} \$ 19.544 .005,30$ & 65,10 & $\mathrm{R} \$ 540,48$ & 39 \\
Região B & 2.886 .084 & $\mathrm{R} \$ 7.526 .181,08$ & 25,07 & $\mathrm{R} \$ 383,34$ & 111 \\
Região C & 3.226 .312 & $\mathrm{R} \$ 2.949 .685,64$ & 9,83 & $\mathrm{R} \$ 35,35$ & 810 \\
Total & $\mathbf{8 . 1 8 3 . 3 6 5}$ & $\mathrm{R} \$ \mathbf{3 0 . 0 1 9 . 8 7 2 , 0 2}$ & $\mathbf{1 0 0}$ & $-\cdots-----$ & $\mathbf{9 6 0}$ \\
\hline
\end{tabular}

Os dados obtidos para o ano de 2007 são semelhantes aos de 2006, apesar da significativa redução no valor total gasto com medicamentos e nos outros parâmetros avaliados, as regiões A e B concentraram aproximadamente $16 \%$ do total de especialidades farmacêuticas, $61 \%$ do número de unidades e $90 \%$ do montante gasto na aquisição de medicamentos.

Rosa, 1995, demonstrou que em alguns hospitais públicos os itens da classe A representam em média de 8 a $15 \%$ dos itens consumidos e equivalem entre $75 \%$ a $85 \%$ da despesa total com medicamentos.

A concentração de grande parte dos recursos em um pequeno número de especialidades farmacêuticas, aliada a grande participação no número total de unidades adquiridas, enfatiza a importância de se desenvolver estratégias que possibilitem à redução dos gastos com medicamentos em hospitais de porte especial da rede pública.

As tabelas 3 e 4 apresentam os dados referentes as Curvas ABC de demanda quantitativa para o ano de 2006 e para o ano de 2007.

Tabela 3 - Distribuição dos medicamentos adquiridos pelo HCFMRP-USP no ano de 2006, em Curva ABC de demanda quantitativa

\begin{tabular}{cccccc}
\hline Região & $\mathbf{n}^{\circ}$ unidades & Valor & $\begin{array}{c}\text { \% Unidades } \\
\text { Totais }\end{array}$ & $\begin{array}{c}\text { Valor Médio } \\
\text { Unitário }\end{array}$ & $\begin{array}{c}\mathbf{n}^{\circ} \\
\text { especialidades }\end{array}$ \\
\hline Região A & 9.419 .202 & $\mathrm{R} \$ 11.756 .602,76$ & 65,02 & 1,25 & 64 \\
Região B & 3.626 .240 & $\mathrm{R} \$ 11.724 .417,62$ & 25,03 & 3,64 & 153 \\
Região C & 1.441 .368 & $\mathrm{R} \$ 23.707 .091,27$ & 9,95 & 97,66 & 859 \\
Total & $\mathbf{1 4 . 4 8 6 . 8 1 0}$ & $\mathbf{R} \$ \mathbf{4 7 . 1 8 8 . 1 1 1 , 6 5}$ & $\mathbf{1 0 0}$ & $-\cdots$ & $\mathbf{1 . 0 7 6}$ \\
\hline
\end{tabular}


A curva de demanda qualitativa para os medicamentos adquiridos no ano 2006 reforça a observação de que um pequeno número de especialidades farmacêuticas, $20 \%$, corresponde à maior parte do número total de unidades adquiridas, $90 \%$, e representam $50 \%$ dos recursos consumidos.

Tabela 4 - Distribuição dos medicamentos adquiridos pelo HCFMRP-USP no ano de 2007, em Curva ABC de demanda quantitativa

\begin{tabular}{cccccc}
\hline Região & $\mathbf{n}^{\circ}$ unidades & Valor & $\begin{array}{c}\text { \% Unidades } \\
\text { Totais }\end{array}$ & $\begin{array}{c}\text { Valor Médio } \\
\text { Unitário }\end{array}$ & $\begin{array}{c}\mathbf{n}^{\circ} \\
\text { especialidades }\end{array}$ \\
\hline Região A & 5.339 .025 & $\mathrm{R} \$ 4.688 .616,91$ & 65,24 & 0,96 & 47 \\
Região B & 2.046 .782 & $\mathrm{R} \$ 8.725 .909,92$ & 25,01 & 4,31 & 133 \\
Região C & 797.558 & $\mathrm{R} \$ 16.605 .345,19$ & 9,75 & 116,17 & 780 \\
Total & $\mathbf{8 . 1 8 3 . 3 6 5}$ & $\mathbf{R} \$ \mathbf{3 0 . 0 1 9 . 8 7 2 , 0 2}$ & $\mathbf{1 0 0}$ & -------- & $\mathbf{9 6 0}$ \\
\hline
\end{tabular}

Novamente, os valores obtidos demonstram que a concentração das unidades adquiridas e do valor gasto está em poucas especialidades farmacêuticas, $19 \%$, corresponde a maior parte do número total de especialidade, $90 \%$, e representam $45 \%$ dos recursos consumidos.

A comparação das curvas de demanda valorizada e demanda quantitativa no período em estudo mostra uma inversão no valor médio unitário entre as duas curvas. Nas curvas de demanda valorizada, o valor médio unitário é maior nas regiões $A$ e $B$, já na curva de demanda quantitativa este valor é maior para a região C. Este dado indica que alguns medicamentos de baixo custo situado nas regiões $A$ e B da curva de demanda quantitativa, têm participação significativa na conduta terapêutica adotada pelo hospital, assim, sua produção pode proporcionar economias ao ampliar escala. Portanto, tanto os medicamentos das regiões $\mathrm{A}$ e $\mathrm{B}$ das curvas de demanda valorizada quanto de demanda quantitativa devem ser incluídos nas análises que selecionarão os produtos viáveis de serem produzidos pela farmácia semi-industrial. 


\subsection{Seleção}

A classificação $A B C$, fornecer informações importantes para estabelecer políticas, objetivos e controles diferenciados, conforme a importância de cada item. A família de itens de maior valor deve receber atenção especial (região $A$ ), enquanto que os itens da região $\mathrm{C}$ devem receber tratamento menos rigoroso (BARBIERI; MACHLINE, 2006).

As regiões A e B das curvas de demanda valorizada e quantitativa representam $90 \%$ dos gastos com medicamentos e número de unidades adquiridas. Assim optou-se por analisar somente as regiões A e B das curvas. Os medicamentos constantes da região $C$ de demanda valorizada e demanda quantitativa foram excluídos por representar uma pequena porção do gasto anual $\mathrm{e}$ número total de unidades.

$O$ simples fato de o medicamento pertencer, nas regiões $A$ e $B$ das curvas de demanda valorizada e de demanda quantitativa não implica que sua produção seja viável, sendo necessário considerar outros parâmetros.

\subsection{Classificação dos medicamentos por forma farmacêutica}

A distribuição dos itens selecionados segundo sua forma farmacêutica permite identificar quais as formas farmacêuticas mais consumidas no hospital e que, portanto, devem ser avaliadas quanto à viabilidade de produção.

As tabelas 5 e 6 apresentam a distribuição dos medicamentos, segundo forma farmacêutica, para os anos de 2006 e 2007 respectivamente. 
Tabela 5 - Distribuição dos medicamentos presentes na intersecção das regiões $\mathrm{A}$ e $B$ das curvas de demanda valorizada e demanda quantitativa referente ao ano de 2006 de acordo com sua forma farmacêutica

\begin{tabular}{|c|c|c|c|c|c|c|}
\hline & $\begin{array}{c}n^{\circ} \text { de } \\
\text { especiali- } \\
\text { dades }\end{array}$ & $\begin{array}{c}\% \mathrm{n}^{\circ} \text { do } \\
\text { total de } \\
\text { especiali- } \\
\text { dades }^{1}\end{array}$ & $\begin{array}{l}\mathrm{n}^{\circ} \text { de } \\
\text { unidades } \\
\text { adquiridas }\end{array}$ & $\begin{array}{c}\% \text { do } \\
\text { total de } \\
\text { unidades }\end{array}$ & $\begin{array}{l}\text { Valor Gasto } \\
\text { (R\$) }\end{array}$ & $\begin{array}{l}\% \text { do } \\
\text { Valor } \\
\text { Total }^{3}\end{array}$ \\
\hline \multicolumn{7}{|l|}{ Produtos sólidos } \\
\hline Cápsula gelatinosa dura & 31 & 2,88 & 1.489 .018 & 10,28 & 2.791.172,26 & 5,91 \\
\hline Comprimido revestido & 36 & 3,35 & 2.524.115 & 17,42 & $11.699 .803,46$ & 24,79 \\
\hline Comprimido simples & 78 & 7,25 & 3.445 .976 & 23,79 & $1.559 .725,27$ & 3,31 \\
\hline Pó para inalação & 2 & 0,19 & 4.043 & 0,03 & $98.258,32$ & 0,21 \\
\hline $\begin{array}{l}\text { Pó para solução oral } \\
\text { Produtos semi-sólidos }\end{array}$ & 3 & 0,28 & 2.313 & 0,02 & $180.770,74$ & 0,38 \\
\hline $\begin{array}{l}\text { Cápsula gelatinosa } \\
\text { mole } \\
\text { Produtos líquidos }\end{array}$ & 6 & 0,56 & 800.782 & 5,53 & $1.646 .677,20$ & 3,49 \\
\hline Solução nasal & 1 & 0,09 & 1.189 & 0,01 & $118.155,65$ & 0,25 \\
\hline Solução oral & 2 & 0,19 & 12.868 & 0,09 & $114.765,67$ & 0,24 \\
\hline \multicolumn{6}{|l|}{ Produtos injetáveis } & 0,09 \\
\hline Depot & 3 & 0,28 & 3.198 & 0,02 & $712.696,25$ & 1,51 \\
\hline Emulsão injetável GV* & 1 & 0,09 & 3.634 & 0,03 & $130.707,00$ & 0,28 \\
\hline Emulsão injetável & 2 & 0,19 & 30.840 & 0,21 & $431.271,00$ & 0,91 \\
\hline Pó liófilo injetável & 50 & 4,65 & 1.125 .128 & 7,77 & $13.077 .333,61$ & 27,71 \\
\hline Solução injetável & 76 & 7,06 & 3.209 .983 & 22,16 & $9.434 .174,65$ & 19,99 \\
\hline Solução injetável GV* & 22 & 2,04 & 723.381 & 4,99 & $2.161 .141,31$ & 4,58 \\
\hline Solução para inalação & 2 & 0,19 & 1.780 & 0,01 & $105.511,45$ & 0,22 \\
\hline Solução p/ nebulização & 1 & 0,09 & 924 & 0,01 & $89.040,74$ & 0,19 \\
\hline \multicolumn{7}{|l|}{ Outros produtos } \\
\hline Pomada/gel & 2 & 0,19 & 17.360 & 0,12 & $79.203,00$ & 0,17 \\
\hline Outros & 4 & 0,37 & 27.979 & 0,19 & $347.727,80$ & 0,74 \\
\hline Total & 324 & 30,11 & 13.467 .002 & 92,96 & $44.857 .978,92$ & 94,98 \\
\hline
\end{tabular}

No ano de 2006, a maior parte dos itens, tanto em número de unidades quanto em valor gasto, concentra-se nas categorias de produtos sólidos, injetáveis e semi-sólidos. Dentre os produtos sólidos, as cápsulas gelatinosas duras, os comprimidos revestidos e os comprimidos simples juntos correspondem a $51,49 \%$ do número total de unidades adquiridas pelo hospital, o equivalente a 7,46 milhões de unidades e $34,01 \%$ do valor total. Entre os produtos injetáveis destacam-se os de pequeno volume, principalmente os pós liófilos injetáveis e as soluções injetáveis, e as soluções injetáveis de grande volume, os quais em conjunto representam 29,93\% das unidades totais adquiridas, correspondendo a 5,06 milhões de unidades e $47,7 \%$ 
do valor total gasto com medicamentos. Dentre as demais formas farmacêuticas, somente as cápsulas gelatinosas moles foram adquiridas em quantidades significantes, mais de 800 mil unidades que consumiram $3,49 \%$ dos gastos totais.

Tabela 6 - Distribuição dos medicamentos presentes na intersecção das regiões $\mathrm{A}$ e $B$ das curvas de demanda valorizada e demanda quantitativa referente ao ano de 2007 de acordo com sua forma farmacêutica

\begin{tabular}{|c|c|c|c|c|c|c|}
\hline & $\begin{array}{l}\mathrm{n}^{\circ} \text { de } \\
\text { especiali- } \\
\text { dades }\end{array}$ & $\begin{array}{c}\% \text { do } \mathrm{n}^{\circ} \\
\text { total de } \\
\text { especiali- } \\
\text { dades }^{1}\end{array}$ & $\begin{array}{c}\mathrm{n}^{\circ} \text { de } \\
\text { unidades } \\
\text { adquiridas }\end{array}$ & $\begin{array}{c}\% \text { do total } \\
\text { de } \\
\text { unidades }\end{array}$ & $\begin{array}{l}\text { Valor Gasto } \\
\text { (R\$) }\end{array}$ & $\begin{array}{l}\% \text { do } \\
\text { Valor } \\
\text { Total }\end{array}$ \\
\hline \multicolumn{7}{|l|}{ Produtos sólidos } \\
\hline Cápsula gelatinosa dura & 17 & 1,77 & 684.864 & 8,37 & $849.387,39$ & 2,83 \\
\hline Comprimido revestido & 17 & 1,77 & 1.238 .125 & 15,13 & $5.693 .981,61$ & 18,97 \\
\hline Comprimido simples & 58 & 6,04 & 1.221 .861 & 14,93 & $372.202,66$ & 1,24 \\
\hline Pó para inalação & --- & --- & --- & --- & --- & --- \\
\hline Pó para solução oral & 2 & 0,21 & 6.311 & 0,08 & $156.529,28$ & 0,52 \\
\hline \multicolumn{7}{|l|}{ Produtos semi-sólidos } \\
\hline Cápsula gelatinosa mole & 4 & 0,42 & 634.680 & 7,76 & $893.304,08$ & 2,98 \\
\hline \multicolumn{7}{|l|}{ Produtos líquidos } \\
\hline Solução nasal & 1 & 0,10 & 6.660 & 0,08 & $5.414,30$ & 0,02 \\
\hline Solução oral & 5 & 0,52 & 20.761 & 0,25 & $293.288,10$ & 0,98 \\
\hline Suspensão oral & 1 & 0,10 & 652 & 0,01 & $60.358,92$ & 0,20 \\
\hline \multicolumn{7}{|l|}{ Produtos injetáveis } \\
\hline Depot & 2 & 0,21 & 2.430 & 0,03 & $693.641,80$ & 2,31 \\
\hline Emulsão injetável GV* & 2 & 0,21 & 3.210 & 0,04 & $133.238,10$ & 0,44 \\
\hline Emulsão injetável & 2 & 0,21 & 23.130 & 0,28 & $376.300,80$ & 1,25 \\
\hline Pó liófilo injetável & 44 & 4,58 & 445.224 & 5,44 & $7.494 .912,61$ & 24,97 \\
\hline Solução injetável & 83 & 8,65 & 2.423 .969 & 29,62 & $8.420 .231,87$ & 28,05 \\
\hline Solução injetável GV* & 23 & 2,40 & 746.445 & 9,12 & $1.999 .970,66$ & 6,66 \\
\hline Solução para inalação & 2 & 0,21 & 1.247 & 0,02 & $100.511,70$ & 0,33 \\
\hline Solução p/ nebulização & --- & --- & --- & --- & --- & --- \\
\hline \multicolumn{7}{|l|}{ Outros produtos } \\
\hline Pomada/ gel & 2 & 0,21 & 16.620 & 0,20 & $74.126,48$ & 0,25 \\
\hline Outros & 3 & 0,31 & 3.072 & 0,04 & $278.344,12$ & 0,93 \\
\hline Total & 268 & 27,92 & 7.479 .261 & 91,40 & $27.895 .744,48$ & 92,92 \\
\hline
\end{tabular}

As formas farmacêuticas adquiridas, no período em estudo foram similares, porém com redução no número de unidade e consequentemente no valor gasto para o ano de 2007.

Os produtos sólidos, na forma de cápsulas gelatinosas duras, comprimidos revestidos e comprimidos simples, representam $38,43 \%$ das unidades totais adquiridas, ou seja, mais de 3,1 milhões de unidades e $23,04 \%$ do valor total gasto 
com medicamentos. Os produtos injetáveis de pequeno volume, pós liófilos injetáveis e soluções injetáveis, e as soluções injetáveis de grande volume equivalem a $44,18 \%$ do total de unidades, correspondente ao montante de 3,6 milhões de unidades e $59,68 \%$ do valor total gasto com medicamentos.

As cápsulas gelatinosas moles representam $7,76 \%$ do total de unidades adquiridas, sendo mais de 634 mil unidades e equivalentes a $2,98 \%$ do valor total despendido com medicamentos.

As diferenças no número total de unidades e no valor total gasto com medicamentos entre os dois anos enfatizam a importância de se avaliar um período superior a um ano quando se pretende estabelecer o consumo médio de medicamentos em um hospital de porte especial.

A análise conjunta das tabelas 5 e 6 mostram que as categorias farmacêuticas que mais oneram o sistema hospitalar são os produtos sólidos e os produtos injetáveis. Especialmente os comprimidos revestidos, os pós liófilos injetáveis e as soluções injetáveis, pela alta porcentagem que representam do valor total gasto na aquisição de medicamentos. Essas três formas farmacêuticas, em conjunto, foram responsáveis por mais de $70 \%$ do gasto anual total e por $64 \%$ do total em unidades adquiridas no período em 2006 e 51\% em 2007.

Os comprimidos simples e as cápsulas gelatinosas duras consomem uma parcela menor dos recursos, provavelmente por serem adquiridas em grandes quantidades, o que justifica sua inclusão nas formas farmacêuticas que serão avaliadas quanto à viabilidade de produção.

Assim, por representarem mais de $80 \%$ do valor total gasto com medicamentos e do número total de unidades adquiridas no ano de 2006 e mais de $70 \%$ dos mesmos parâmetros no ano de 2007, cápsulas gelatinosas duras, comprimidos simples e revestidos, pós liófilos injetáveis e soluções injetáveis foram as formas farmacêuticas selecionadas para o estudo de viabilidade econômica da produção de medicamentos por farmácia semi-industrial hospitalar.

Solução para nebulização e solução para inalação foram incluídas na categoria de soluções injetáveis, pois requerem os mesmos procedimentos de manufatura.

Soluções parenterais de grande volume e cápsulas gelatinosas moles, apesar de representarem parcela importante dos recursos consumidos pelo hospital nos anos analisados e ainda serem demandados em quantidade significativa, não foram 
incluídas para o estudo de viabilidade econômica. A exclusão das soluções parenterais de grande volume se deve ao fato destes itens requisitarem grande espaço para armazenagem de material de embalagem e de produto acabado o que dificulta a distribuição da área destinada à produção e estoque, principalmente por esta ser planejada para implantação em hospitais onde, normalmente, os espaços são limitados e devem ser bem aproveitados. Já as cápsulas gelatinosas moles foram excluídas por requisitarem equipamentos específicos para sua manufatura ou a necessidade de terceirização de sua produção, que só se torna viável para quantidades muito elevadas de unidades para um mesmo princípio ativo.

As tabelas 7 e 8 apresentam o número de especialidades farmacêuticas, a quantidade de unidades adquiridas e o valor total consumido de recursos, para as cinco formas farmacêuticas escolhidas para as análises posteriores do estudo de viabilidade econômica, referentes ao ano de 2006 e 2007 respectivamente.

Tabela 7 - Número de especialidades farmacêuticas, quantidade total adquirida e valor total de recursos gastos dos medicamentos adquiridos no ano de 2006, selecionados para o estudo de viabilidade econômica, segundo forma farmacêutica

\begin{tabular}{|c|c|c|c|c|c|c|}
\hline & $\begin{array}{c}n^{0} \text { de } \\
\text { especiali- } \\
\text { dades }\end{array}$ & $\begin{array}{l}\% \mathrm{n}^{\circ} \text { de } \\
\text { especiali- } \\
\text { dades }\end{array}$ & $\begin{array}{c}n^{0} \text { de } \\
\text { unidades } \\
\text { adquiridas }\end{array}$ & $\begin{array}{c}\% \text { total } \\
\text { de } \\
\text { unidades }\end{array}$ & $\begin{array}{l}\text { Valor Gasto } \\
\text { (R\$) }\end{array}$ & $\begin{array}{l}\% \text { do } \\
\text { Valor } \\
\text { Total }\end{array}$ \\
\hline \multicolumn{7}{|l|}{ Produtos sólidos } \\
\hline Cápsula gelatinosa dura & 31 & 2,88 & 1.489 .018 & 10,28 & $2.791 .172,26$ & 5,91 \\
\hline Comprimido revestido & 36 & 3,35 & 2.524 .115 & 17,42 & $11.699 .803,46$ & 24,79 \\
\hline Comprimido simples & 78 & 7,25 & 3.445 .976 & 23,79 & $1.559 .725,27$ & 3,31 \\
\hline $\begin{array}{l}\text { Total produtos sólidos } \\
\text { Produtos injetáveis }\end{array}$ & 145 & 13,48 & 7.459.109 & 51,49 & $16.050 .700,99$ & 34,01 \\
\hline Pó liófilo injetável & 50 & 4,65 & 1.125 .128 & 7,77 & $13.077 .333,61$ & 27,71 \\
\hline Solução injetável & 79 & 7,34 & 3.212 .687 & 22,18 & $9.628 .726,84$ & 20,40 \\
\hline $\begin{array}{l}\text { Total produtos } \\
\text { injetáveis }\end{array}$ & 129 & 11,99 & 4.337 .815 & 29,94 & $22.706 .060,45$ & 48,12 \\
\hline Total & 274 & 25,46 & 11.796 .924 & 81,43 & $38.756 .761,44$ & 82,13 \\
\hline
\end{tabular}


Tabela 8 - Número de especialidades farmacêuticas, quantidade total adquirida e valor total de recursos gastos dos medicamentos adquiridos no ano de 2007, selecionados para o estudo de viabilidade econômica, segundo forma farmacêutica

\begin{tabular}{|c|c|c|c|c|c|c|}
\hline & $\begin{array}{c}n^{\circ} \text { de } \\
\text { especiali- } \\
\text { dades }\end{array}$ & $\begin{array}{c}\% \mathrm{n}^{\circ} \mathrm{de} \\
\text { especiali- } \\
\text { dades }\end{array}$ & $\begin{array}{c}n^{0} \text { de } \\
\text { unidades } \\
\text { adquiridas }\end{array}$ & $\begin{array}{c}\% \text { total } \\
\text { de } \\
\text { unidades }\end{array}$ & $\begin{array}{l}\text { Valor Gasto } \\
\text { (R\$) }\end{array}$ & $\begin{array}{l}\text { \% do } \\
\text { Valor } \\
\text { Total }\end{array}$ \\
\hline \multicolumn{7}{|l|}{ Produtos sólidos } \\
\hline Cápsula gelatinosa dura & 17 & 1,77 & 684.864 & 8,37 & $849.387,39$ & 2,83 \\
\hline Comprimido revestido & 17 & 1,77 & 1.238 .125 & 15,13 & $5.693 .981,61$ & 18,97 \\
\hline Comprimido simples & 58 & 6,04 & 1.221 .861 & 14,93 & $372.202,66$ & 1,24 \\
\hline $\begin{array}{l}\text { Total produtos sólidos } \\
\text { Produtos injetáveis }\end{array}$ & 92 & 9,58 & 3.144 .850 & 38,43 & $6.915 .571,66$ & 23,04 \\
\hline Pó liófilo injetável & 44 & 4,58 & 445.224 & 5,44 & $7.494 .912,61$ & 24,97 \\
\hline Solução injetável & 85 & 8,85 & 2.425 .216 & 29,64 & $8.520 .743,57$ & 28,38 \\
\hline $\begin{array}{l}\text { Total produtos } \\
\text { injetáveis }\end{array}$ & 129 & 13,44 & 2.870 .440 & 35,08 & $16.015 .656,18$ & 53,35 \\
\hline Total & 221 & 23,02 & 6.015 .290 & 73,51 & $22.931 .227,84$ & 76,39 \\
\hline
\end{tabular}

A freqüência de utilização das formas farmacêuticas no HCFMRP-USP, no período em estudo foi similar a mundial, no qual os comprimidos correspondem a $45,8 \%$, seguidos pelos líquidos orais $(16 \%)$, injetáveis $(15 \%)$ e cápsulas $(13 \%)$ (WELLS, 2000).

\subsection{Classificação dos medicamentos segundos critérios da RDC $n^{\circ} \mathbf{2 1 0}$}

Visando atender aos critérios da RDC n²10 quanto às Boas Práticas de Fabricação, os medicamentos foram classificados de forma funcional de acordo com as exigências para a fabricação.

1. antibióticos cefalosporínicos: antibióticos beta-lactâmicos cefalosporínicos;

2. antibióticos não beta-lactâmicos: composta pelas demais classes de antibióticos, pelos antivirais, antifúngicos e antiretrovirais;

3. antibióticos penicilâmicos: compreende os antibióticos beta-lactâmicos penicilâmicos ou derivados da penicilina;

4. citostáticos: medicamentos antineoplásicos, exceto os antibióticos antineoplásicos;

5. contrastes: produtos contendo substância radioativa;

6. hormônios: contém os medicamentos de origem hormonal; 
7. medicamentos controlados: medicamentos sujeitos a regime de controle especial segundo Portaria $n^{\circ} 344$, exceto as substâncias retinóicas;

8. outros: medicamentos não pertencentes a nenhuma das outras categorias;

9. produtos biotecnológicos: medicamentos que empregam microrganismos e/ou técnicas biotecnológicas em sua produção;

10. substâncias altamente sensibilizantes: imunossupressores e retinóides.

As tabelas 9 e 10 apresentam a distribuição dos medicamentos apresentados na forma farmacêutica sólida (cápsula gelatinosa dura, comprimido revestido e comprimido simples) e injetável (pó liófilo injetável e solução injetável) respectivamente, para o ano de 2006. 
Tabela 9 - Distribuição dos medicamentos apresentados na forma de cápsula gelatinosa dura, comprimido revestido e comprimido simples de acordo com critérios da RDC $n^{\circ} 210$, ano base 2006

\begin{tabular}{|c|c|c|c|c|c|}
\hline & $\begin{array}{c}\mathrm{n}^{\circ} \text { de } \\
\text { especi } \\
\text { ali- } \\
\text { dades }\end{array}$ & $\begin{array}{c}n^{\circ} \text { de } \\
\text { unidades } \\
\text { adquiridas }\end{array}$ & $\begin{array}{c}\text { \% do total } \\
\text { de } \\
\text { unidades } \\
\text { sólidas } \\
\end{array}$ & $\begin{array}{c}\text { Valor } \\
\text { Gasto (R\$) }\end{array}$ & $\begin{array}{c}\% \text { do } \\
\text { valor total dos } \\
\text { produtos } \\
\text { sólidos } \\
\end{array}$ \\
\hline \multicolumn{6}{|l|}{ Cápsula gelatinosa dura } \\
\hline Antibióticos cefalsoporínicos & ---- & ---- & ---- & ---- & ---- \\
\hline $\begin{array}{l}\text { Antibióticos não beta- } \\
\text { lactâmicos }\end{array}$ & 11 & 562.282 & 7,54 & $817.880,57$ & 5,10 \\
\hline Antibióticos penicilâmicos & ---- & ---- & ---- & ---- & ---- \\
\hline Citostáticos & 1 & 42.000 & 0,56 & $36.828,20$ & 0,23 \\
\hline Contrates & ---- & ---- & ---- & ---- & ---- \\
\hline Hormônios & ---- & ---- & ---- & ---- & ---- \\
\hline Medicamentos controlados* & 7 & 142.342 & 1,91 & $474.258,62$ & 2,95 \\
\hline Outros & 7 & 442.134 & 5,93 & $469.772,45$ & 2,93 \\
\hline Produtos biotecnológicos & ---- & ---- & --- & ---- & --- \\
\hline Substâncias sensibilizantes & 5 & 300.260 & 4,03 & $992.432,42$ & 6,18 \\
\hline \multicolumn{6}{|l|}{ Comprimido simples } \\
\hline Antibióticos cefalsoporínicos & ---- & ---- & ---- & ---- & ---- \\
\hline $\begin{array}{l}\text { Antibióticos não beta- } \\
\text { lactâmicos }\end{array}$ & 10 & 720.330 & 9,66 & $518.086,79$ & 3,23 \\
\hline Antibióticos penicilâmicos & ---- & ---- & ---- & ---- & ---- \\
\hline Citostáticos & 2 & 193.540 & 2,59 & $77.987,02$ & 0,49 \\
\hline Contrates & ---- & ---- & --- & --- & --- \\
\hline Hormônios & 2 & 100.302 & 1,34 & $78.493,86$ & 0,49 \\
\hline Medicamentos controlados* & 21 & 867.969 & 11,64 & $565.029,61$ & 3,52 \\
\hline Outros & 41 & 1.362 .605 & 18,27 & $273.143,93$ & 1,70 \\
\hline Produtos biotecnológicos & ---- & ---- & ---- & --- & --- \\
\hline Substâncias sensibilizantes & 2 & 201.230 & 2,70 & $46.984,03$ & 0,29 \\
\hline \multicolumn{6}{|l|}{ Comprimido revestido } \\
\hline Antibióticos cefalsoporínicos & ---- & ---- & ---- & ---- & ---- \\
\hline $\begin{array}{l}\text { Antibióticos não beta- } \\
\text { lactâmicos }\end{array}$ & 7 & 999.176 & 13,40 & $3.018 .953,67$ & 18,81 \\
\hline Antibióticos penicilâmicos & ---- & ---- & --- & ---- & ---- \\
\hline Citostáticos & 5 & 75.695 & 1,01 & $1.436 .467,90$ & 8,95 \\
\hline Contrates & ---- & ---- & ---- & ---- & ---- \\
\hline Hormônios & ---- & ---- & ---- & ---- & ---- \\
\hline Medicamentos controlados* & 13 & 480.598 & 6,44 & $2.834 .041,50$ & 17,66 \\
\hline Outros & 7 & 765.246 & 10,26 & $3.266 .234,67$ & 20,35 \\
\hline Produtos biotecnológicos & ---- & ---- & ---- & --- & ---- \\
\hline Substâncias sensibilizantes & 4 & 203.400 & 2,73 & $1.144 .105,72$ & 7,13 \\
\hline Total & 145 & 7.459 .109 & 100,00 & $16.050 .700,96$ & 100,00 \\
\hline
\end{tabular}

A distribuição dos medicamentos nas classes estabelecidas demonstra que $85,03 \%$ do total de unidades e $76,24 \%$ do valor total dos produtos sólidos selecionados se concentram em apenas três classes, os antibióticos não beta- 
lactâmicos, os medicamentos controlados e os classificados como outros. As substâncias sensibilizantes e os citostáticos, mesmo correspondendo a $13,62 \%$ das unidades têm participação importante nos gastos com produtos sólidos, pois consomem $23,27 \%$ do valor total. Os hormônios representam tanto um pequeno número de unidades quanto uma reduzida porcentagem do valor total. As demais classes não foram adquiridas na forma farmacêutica sólida.

Tabela 10 - Distribuição dos medicamentos apresentados na forma de pó liófilo injetável e solução injetável de acordo com critérios da RDC n² 210, ano base 2006

\begin{tabular}{|c|c|c|c|c|c|}
\hline & $\begin{array}{l}n^{0} \text { de } \\
\text { especiali- } \\
\text { dades }\end{array}$ & $\begin{array}{c}\mathrm{n}^{\circ} \text { de } \\
\text { unidades } \\
\text { adquiridas }\end{array}$ & $\begin{array}{l}\% \text { do total } \\
\text { de unidades } \\
\text { injetáveis }\end{array}$ & $\begin{array}{c}\text { Valor } \\
\text { Gasto (R\$) }\end{array}$ & $\begin{array}{c}\% \text { valor } \\
\text { total dos } \\
\text { produtos } \\
\text { injetáveis }\end{array}$ \\
\hline \multicolumn{6}{|l|}{ Pó liófilo injetável } \\
\hline Antibióticos cefalsoporínicos & 3 & 131.700 & 3,04 & $355.189,38$ & 1,56 \\
\hline $\begin{array}{l}\text { Antibióticos não beta- } \\
\text { lactâmicos }\end{array}$ & 11 & 44.096 & 1,02 & $1.343 .483,72$ & 5,92 \\
\hline Antibióticos penicilâmicos & 5 & 111.620 & 2,57 & $1.616 .363,45$ & 7,12 \\
\hline Citostáticos & 3 & 3.890 & 0,09 & $538.146,06$ & 2,37 \\
\hline Contrates & ---- & ---- & ---- & ---- & ---- \\
\hline Hormônios & 2 & 13.260 & 0,31 & $261.935,35$ & 1,15 \\
\hline Medicamentos controlados* & 2 & 706.260 & 16,28 & $53.361,69$ & 0,24 \\
\hline Outros & 11 & 87.841 & 2,03 & $1.345 .614,12$ & 5,93 \\
\hline Produtos biotecnológicos & 12 & 25.397 & 0,59 & $7.473 .119,04$ & 32,91 \\
\hline Substâncias sensibilizantes & 1 & 1.064 & 0,02 & $90.120,80$ & 0,40 \\
\hline \multicolumn{6}{|l|}{ Solução injetável } \\
\hline Antibióticos cefalsoporínicos & ---- & ---- & ---- & ---- & ---- \\
\hline $\begin{array}{l}\text { Antibióticos não beta- } \\
\text { lactâmicos }\end{array}$ & 3 & 38.964 & 0,90 & $143.218,12$ & 0,63 \\
\hline Antibióticos penicilâmicos & ---- & ---- & ---- & ---- & ---- \\
\hline Citostáticos & 9 & 4.371 & 0,10 & $1.534 .022,55$ & 6,76 \\
\hline Contrates & 4 & 28.675 & 0,66 & $596.083,50$ & 2,63 \\
\hline Hormônios & ---- & ---- & ---- & ---- & ---- \\
\hline Medicamentos controlados* & 11 & 578.563 & 13,34 & $453.802,85$ & 2,00 \\
\hline Outros & 45 & 2.501 .240 & 57,66 & $5.381 .871,65$ & 23,70 \\
\hline Produtos biotecnológicos & 7 & 60.874 & 1,40 & $1.519 .728,17$ & 6,69 \\
\hline Substâncias sensibilizantes & ---- & ---- & ---- & ---- & ---- \\
\hline Total & 129 & 4.337.815 & 100,00 & $22.706 .060,45$ & 100,00 \\
\hline
\end{tabular}

Entre os produtos injetáveis com maior número de unidades e classificados como pós liófilos injetável, estão os antibióticos cefalosporínicos, penicilâmicos e medicamentos controlados, enquanto que para as soluções injetáveis destacam aqueles classificados como outros e os controlados, os quais representam em conjunto $92,89 \%$ do total de unidades. No entanto as maiores porcentagens em 
relação aos gastos totais, correspondem aos produtos biotecnológicos, antibióticos penicilâmicos e não beta-lactâmicos, citostáticos e aos medicamentos classificados como outros, os quais contribuem com $92,03 \%$ do gasto total. Para estes produtos, a relação entre número de unidades adquiridas e o valor pago não é direta, demonstrando que, para algumas classes, poucas unidades são adquiridas a um custo unitário alto, enquanto outras são adquiridas em grandes quantidades, mas a um custo unitário menor. Destacam-se os produtos biotecnológicos que consomem $39,61 \%$ do total de recursos e representam apenas $1,99 \%$ do total de medicamentos injetáveis selecionados.

O alto consumo de antibióticos não beta-lactâmicos na forma farmacêutica sólida também é influenciado pelos antiretrovirais que fazem parte do programa Nacional de DST/AIDS do governo federal.

As tabelas 11 e 12 apresentam a distribuição dos medicamentos adquiridos na forma farmacêutica sólida (cápsula gelatinosa dura, comprimido revestido e comprimido simples) e injetável (pó liófilo injetável e solução injetável) respectivamente, para o ano de 2007. 
Tabela 11 - Distribuição dos medicamentos apresentados na forma de cápsula gelatinosa dura, comprimido revestido e comprimido simples de acordo com critérios da RDC n²10, ano base 2007

\begin{tabular}{|c|c|c|c|c|c|}
\hline & $\begin{array}{l}n^{0} \text { de } \\
\text { especiali- } \\
\text { dades }\end{array}$ & $\begin{array}{c}n^{0} \text { de } \\
\text { unidades } \\
\text { adquiridas }\end{array}$ & $\begin{array}{c}\% \text { do total } \\
\text { de } \\
\text { unidades } \\
\text { sólidas } \\
\end{array}$ & $\begin{array}{c}\text { Valor } \\
\text { Gasto (R\$) }\end{array}$ & $\begin{array}{c}\text { \% do valor } \\
\text { total dos } \\
\text { produtos } \\
\text { sólidos } \\
\end{array}$ \\
\hline \multicolumn{6}{|l|}{ Cápsula gelatinosa dura } \\
\hline Antibióticos cefalsoporínicos & 1 & 7.208 & 0,23 & 959,62 & 0,01 \\
\hline $\begin{array}{l}\text { Antibióticos não beta- } \\
\text { lactâmicos }\end{array}$ & 10 & 508.104 & 16,16 & $785.276,04$ & 11,36 \\
\hline Antibióticos penicilâmicos & ---- & ---- & ---- & ---- & ---- \\
\hline Citostáticos & 4 & 67.912 & 2,16 & $59.664,04$ & 0,86 \\
\hline Contrates & --- & ---- & ---- & --- & --- \\
\hline Hormônios & --- & ---- & ---- & --- & ---- \\
\hline Medicamentos controlados* & ---- & ---- & ---- & ---- & ---- \\
\hline Outros & 2 & 101.640 & 3,23 & $3.487,69$ & 0,05 \\
\hline Produtos biotecnológicos & ---- & ---- & ---- & ---- & ---- \\
\hline Substâncias sensibilizantes & ---- & ---- & ---- & ---- & ---- \\
\hline \multicolumn{6}{|l|}{ Comprimido simples } \\
\hline Antibióticos cefalsoporínicos & ---- & ---- & ---- & ---- & ---- \\
\hline $\begin{array}{l}\text { Antibióticos não beta- } \\
\text { lactâmicos }\end{array}$ & 11 & 308.774 & 9,82 & $285.991,26$ & 4,14 \\
\hline Antibióticos penicilâmicos & ---- & ---- & ---- & ---- & ---- \\
\hline Citostáticos & ---- & ---- & ---- & ---- & ---- \\
\hline Contrates & ---- & ---- & ---- & ---- & ---- \\
\hline Hormônios & ---- & ---- & ---- & ---- & ---- \\
\hline Medicamentos controlados* & 10 & 211.514 & 6,73 & $13.160,60$ & 0,19 \\
\hline Outros & 37 & 701.573 & 22,31 & $73.050,80$ & 1,06 \\
\hline Produtos biotecnológicos & ---- & ---- & ---- & ---- & ---- \\
\hline Substâncias sensibilizantes & ---- & ---- & ---- & ---- & --- \\
\hline \multicolumn{6}{|l|}{ Comprimido revestido } \\
\hline Antibióticos cefalsoporínicos & ---- & ---- & ---- & ---- & ---- \\
\hline $\begin{array}{l}\text { Antibióticos não beta- } \\
\text { lactâmicos }\end{array}$ & 8 & 1.112 .506 & 35,38 & $1.790 .434,64$ & 25,89 \\
\hline Antibióticos penicilâmicos & ---- & ---- & ---- & ---- & ---- \\
\hline Citostáticos & 5 & 84.555 & 2,69 & $3.751 .085,20$ & 54,24 \\
\hline Contrates & --- & ---- & ---- & --- & ---- \\
\hline Hormônios & ---- & ---- & ---- & ---- & ---- \\
\hline Medicamentos controlados* & 1 & 6.188 & 0,20 & $66.246,32$ & 0,96 \\
\hline Outros & 2 & 23.356 & 0,74 & $10.867,81$ & 0,16 \\
\hline Produtos biotecnológicos & ---- & ---- & ---- & ---- & ---- \\
\hline Substâncias sensibilizantes & 1 & 11.520 & 0,37 & $75.347,64$ & 1,09 \\
\hline Total & 92 & 3.144 .850 & 100,00 & $6.915 .571,66$ & 100,00 \\
\hline
\end{tabular}

A participação no número de unidades totais seguiu o mesmo padrão do ano de 2006, os antibióticos não beta-lactâmicos, os medicamentos controlados e os classificados como outros concentram $94,6 \%$ do total de unidades. 
Em relação ao valor total, os citostáticos representam $55,1 \%$ deste valor e os antibióticos não beta-lactâmicos $41,39 \%$.

Substâncias sensibilizantes e antibióticos cefalosporínicos tiveram pouca participação no número de unidades e no valor total.

As demais classes não foram adquiridas na forma farmacêutica sólida.

Tabela 12 - Distribuição dos medicamentos apresentados na forma de pó liófilo injetável e solução injetável de acordo com critérios da RDC n² 210, ano base 2007

\begin{tabular}{|c|c|c|c|c|c|}
\hline & $\begin{array}{l}n^{\circ} \text { de } \\
\text { especiali- } \\
\text { dades }\end{array}$ & $\begin{array}{c}\mathrm{n}^{0} \text { de } \\
\text { unidades } \\
\text { adquiridas }\end{array}$ & $\begin{array}{l}\% \text { do total } \\
\text { de unidades } \\
\text { injetáveis }\end{array}$ & $\begin{array}{c}\text { Valor } \\
\text { Gasto (R\$) }\end{array}$ & $\begin{array}{c}\% \text { valor } \\
\text { total dos } \\
\text { produtos } \\
\text { injetáveis }\end{array}$ \\
\hline \multicolumn{6}{|l|}{ Pó liófilo injetável } \\
\hline Antibióticos cefalsoporínicos & 4 & 135.570 & 4,72 & $241.051,50$ & 1,51 \\
\hline $\begin{array}{l}\text { Antibióticos não beta- } \\
\text { lactâmicos }\end{array}$ & 10 & 90.367 & 3,15 & $1.762 .676,62$ & 11,01 \\
\hline Antibióticos penicilâmicos & 5 & 64.852 & 2,26 & $1.046 .272,94$ & 6,53 \\
\hline Citostáticos & 6 & 3.324 & 0,12 & $585.600,20$ & 3,66 \\
\hline Contrates & ---- & ---- & ---- & ---- & ---- \\
\hline Hormônios & 2 & 221 & 0,01 & $98.251,03$ & 0,61 \\
\hline Medicamentos controlados* & 1 & 2.600 & 0,09 & $194.300,00$ & 1,21 \\
\hline Outros & 10 & 145.137 & 5,06 & $653.801,82$ & 4,08 \\
\hline Produtos biotecnológicos & 6 & 3.153 & 0,11 & $2.912 .958,50$ & 18,19 \\
\hline Substâncias sensibilizantes & ---- & ---- & --- & --- & ---- \\
\hline \multicolumn{6}{|l|}{ Solução injetável } \\
\hline Antibióticos cefalsoporínicos & ---- & ---- & ---- & ---- & ---- \\
\hline $\begin{array}{l}\text { Antibióticos não beta- } \\
\text { lactâmicos }\end{array}$ & 5 & 53.420 & 1,86 & $95.898,04$ & 0,60 \\
\hline Antibióticos penicilâmicos & ---- & ---- & ---- & ---- & ---- \\
\hline Citostáticos & 8 & 4.472 & 0,16 & $1.736 .491,87$ & 10,84 \\
\hline Contrates & 4 & 28.300 & 0,99 & $1.110 .763,00$ & 6,94 \\
\hline Hormônios & 1 & 16.000 & 0,56 & $7.996,80$ & 0,05 \\
\hline Medicamentos controlados* & 12 & 196.845 & 6,86 & $386.268,82$ & 2,41 \\
\hline Outros & 48 & 2.118 .007 & 73,79 & $3.258 .651,40$ & 20,35 \\
\hline Produtos biotecnológicos & 7 & 8.172 & 0,28 & $1.924 .673,64$ & 12,02 \\
\hline Substâncias sensibilizantes & ---- & ---- & ---- & ---- & ---- \\
\hline Total & 129 & 2.870 .440 & 100,00 & $16.015 .656,18$ & 100,00 \\
\hline
\end{tabular}

O maior número de unidades de pós liófilos injetáveis, $12,93 \%$ do total, pertence a antibióticos cefalosporínicos e não beta-lactâmicos juntamente com os classificados como outros.

Para as soluções injetáveis o perfil é o mesmo que para o ano de 2006, sendo $80,68 \%$ das unidades totais medicamentos controlados e outros. 
A participação no valor total também se assemelha ao ano de $2006,87,34 \%$ das unidades totais dividem-se em produtos biotecnológicos, outros, citostáticos, antibióticos não beta-lactâmicos e penicilâmicos.

Novamente os biotecnológicos tem alta participação no valor total, $30,21 \%$, e reduzida contribuição no número total de unidades, 0,39\%.

No geral, a distribuição da participação no total de unidades adquiridas e no valor total gasto é semelhante para as diferentes formas farmacêuticas analisadas entre os anos de 2006 e 2007.

\subsection{Seleção}

A seleção foi feita com base no número médio de unidades totais adquiridas e do valor total pago entre os anos de 2006 e 2007. Esses dados foram utilizados no estudo de caso como número de unidades a serem produzidas e receita, respectivamente.

Mesmo tendo participação significativa no montante gasto com medicamentos injetáveis, os produtos biotecnológicos não foram selecionados para o estudo de caso por motivos técnicos. A maioria envolve a manipulação de microrganismos vivos exigindo rígido controle do processo produtivo, infra-estrutura para manutenção de cepas viáveis e área de produção exclusiva com equipamentos específicos. Para atender as exigências seria necessário alto investimento, não justificando sua implantação para abastecimento a demanda exclusiva de um único hospital.

Os contrastes também foram excluídos por envolverem princípios ativos radioativos que só podem ser manipulados por laboratórios especializados. 
Tabela 13 - Número médio de unidades de produtos sólidos adquiridos e do valor total entre os anos de 2006 e 2007

\begin{tabular}{|c|c|c|}
\hline & Média $n^{\circ}$ de unidades & $\begin{array}{c}\text { Média do Valor Gasto } \\
(\mathrm{R} \$)\end{array}$ \\
\hline \multicolumn{3}{|l|}{ Cápsula gelatinosa dura } \\
\hline Antibióticos cefalsoporínicos & 7.208 & 959,62 \\
\hline $\begin{array}{l}\text { Antibióticos não beta- } \\
\text { lactâmicos }\end{array}$ & 535.193 & $801.578,31$ \\
\hline Citostáticos & 54.956 & $48.246,12$ \\
\hline Medicamentos controlados* & 142.342 & $474.258,62$ \\
\hline Outros & 271.887 & $236.630,07$ \\
\hline Substâncias sensibilizantes & 300.260 & $992.432,42$ \\
\hline \multicolumn{3}{|l|}{ Comprimido simples } \\
\hline $\begin{array}{l}\text { Antibióticos não beta- } \\
\text { lactâmicos }\end{array}$ & 514.552 & $402.039,03$ \\
\hline Citostáticos & 193.540 & $77.987,02$ \\
\hline Hormônios & 100.302 & $78.493,86$ \\
\hline Medicamentos controlados* & 539.742 & $289.095,11$ \\
\hline Outros & 1.032 .089 & $173.097,37$ \\
\hline Substâncias sensibilizantes & 201.230 & $46.984,03$ \\
\hline \multicolumn{3}{|l|}{ Comprimido revestido } \\
\hline $\begin{array}{l}\text { Antibióticos não beta- } \\
\text { lactâmicos }\end{array}$ & 1.055 .841 & $2.404 .694,16$ \\
\hline Citostáticos & 80.125 & $2.593 .776,55$ \\
\hline Medicamentos controlados* & 243.393 & $1.450 .143,91$ \\
\hline Outros & 394.301 & $1.638 .551,24$ \\
\hline Substâncias sensibilizantes & 107.460 & $609.726,68$ \\
\hline Total & 5.774 .421 & $12.318 .694,10$ \\
\hline
\end{tabular}

${ }^{*}$ de acordo com definição da Portaria n 344 (BRASIL, 1999).

Tabela 14 - Número médio de unidades de produtos injetáveis adquiridas e do valor total entre os anos de 2006 e 2007

\section{Pó liófilo injetável}

Antibióticos cefalsoporínicos

Média $\mathrm{n}^{\circ}$ de unidades Média do Valor Gasto $(\mathrm{R} \$)$

Antibióticos não beta-

lactâmicos

$298.120,44$

Antibióticos penicilâmicos

67.232

$1.553 .080,17$

Citostáticos

88.236

$1.331 .318,20$

Hormônios

3.607

$561.873,13$

Medicamentos controlados*

6.741

$180.093,19$

Outros

354.430

$123.830,85$

Substâncias sensibilizantes

164.561

$363.898,51$

Solução injetável

1.064

$90.120,80$

Antibióticos não beta-

lactâmicos

46.192

$119.558,08$

Citostáticos

4.422

Hormônios

16.000

$1.635 .257,21$

387.704

$7.996,80$

Medicamentos controlados*

2.309.624

$420.035,84$

Outros

3.583.446

$4.320 .261,53$

Total

* de acordo com definição da Portaria nº 344 (BRASIL, 1999).

11.005.444,73 
Os valores contidos nas tabelas 13 e 14 foram utilizados para calcular a produção mensal dos medicamentos, a qual seria em torno de 512 mil unidades. Considerando semana de 5 dias e mês com 20 dias úteis e produção diária de aproximadamente 24,1 mil unidades de produtos sólidos e 15 mil unidades de produtos injetáveis.

O fato de apenas cinco das dez classes representarem praticamente todos os medicamentos sólidos facilita o planejamento da produção, pois reduz a variedade de princípios ativos a serem adquiridos.

\subsection{Estudo de caso}

\subsubsection{Produtos sólidos}

\subsubsection{Etapa de Implantação}

\subsection{Processo de produção}

Para deduzir o número de equipamentos, processos e área física, optou por substituir os medicamentos apresentados na forma farmacêutica cápsula gelatinosa dura pela apresentação em comprimidos simples ou revestido. Uma vez que tal substituição não prejudica as propriedades terapêuticas do principio ativo.

$\mathrm{Em}$ função das características físico-químicas do principio ativo, os comprimidos podem ser obtidos por vários métodos, ou seja, a compactação direta mistura fármaco excipiente, ou com prévia granulação da mistura, a qual pode ser realizada por via seca ou por via úmida. Os comprimidos revestidos são obtidos a partir dos comprimidos simples, sendo o processo de revestimento o diferencial entre eles.

A granulação via úmida é a que possui o maior número de etapas, porém permite a utilização de adjuvantes mais simples, portanto, mais baratos, o que a torna preferencial em relação às outras, desde que o fármaco suporte as condições do processo. O conjunto de equipamentos necessários para a obtenção de comprimidos por via úmida também podem ser utilizados para a obtenção de comprimidos pelas outras vias. Face a isto optamos pela via úmida como base de cálculo para o estudo de viabilidade de produção dos medicamentos sólidos. Por se 
tratarem de métodos rotineiramente utilizados e amplamente descritos na literatura pertinente, apresentaremos apenas o fluxo de produção. 


\section{PROTOCOLO DE PRODUCÃO DE COMPRIMIDOS VIA ÚMIDA}

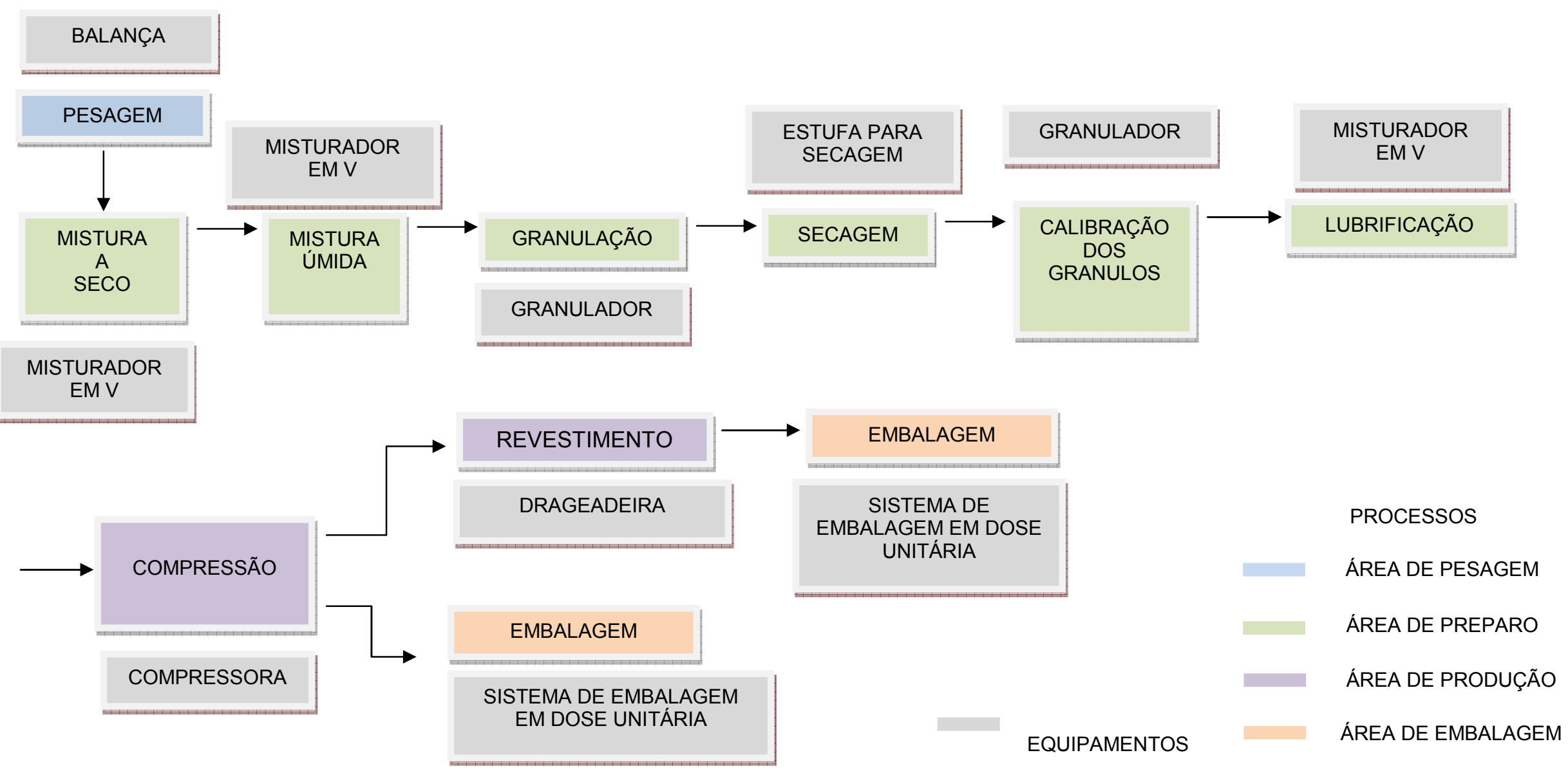

Figura 1 - Representação esquemática do fluxo de produção de comprimidos por via úmida, respectivos equipamentos e localização na planta produtiva (adaptado de ALDERBORN, 2005; ANSEL; POPOVICH; ALLEN Jr, 2000; BANDELIN, 1989; PECK et al, 1989) 


\subsection{Equipamentos}

Os equipamentos foram selecionados, com base na capacidade de produção face ao número de unidades desejadas, pois a produção é limitada pela quantidade de medicamentos consumida no hospital. A seqüência de processo e os respectivos equipamentos utilizados são mostrados na figura 1.

A maioria dos hospitais de grande porte utiliza o sistema de distribuição de medicamentos individualizado ou por dose unitária, no primeiro os medicamentos são dispensados por paciente e geralmente no período de 24horas (CODINA, 1992). O segundo é o mais apropriados para hospitais de porte especial e caracteriza-se pela distribuição ordenada dos medicamentos em formas e dosagens prontas para serem administradas a um paciente específico, de acordo com a prescrição médica, num certo período de tempo (GARRISON, 1979).

Face a isto optamos por sistema que permite a impressão, na própria embalagem, do nome genérico, forma farmacêutica, dose, número do lote de fabricação, prazo de validade e código de barras específico para cada item, minimizando a possibilidade de eventuais erros de medicação e permitindo o rastreamento do medicamento. Alem disso contribui para a implantação e otimização dos sistemas de distribuição de medicamentos por dose individualizada ou unitária.

Como os medicamentos são para o próprio consumo do hospital, a embalagens secundárias é dispensável.

\subsubsection{3. Área física}

A área física foi planejada de modo a ter o melhor proveito do espaço e de forma a permitir um fluxo racional de entrada de matéria prima e de saída do produto acabado. As características da área, como revestimento de pisos e paredes, vedação de portas e janelas, sistema de exaustão de ar, controle de temperatura e umidade, necessidade de área limpa e outros seguiram as diretrizes do órgão regulatório e, portanto, não foram descritas (BRASIL, 2003). 
Foi planejada, para a produção de sólidos, uma área de $40 \mathrm{~m}^{2}$, sub-divida em pequenos laboratórios, assim discriminados:

1. laboratório de pesagem $\left(8 \mathrm{~m}^{2}\right)$

2. laboratório de mistura, granulação e secagem (16 m²)

3. laboratório de compactação $\left(10 \mathrm{~m}^{2}\right)$

4. área de embalagem $\left(6 \mathrm{~m}^{2}\right)$

A figura 1 mostra a disposição dos equipamentos e as etapas relativas a cada laboratório.

Áreas separadas facilitam o fluxo do processo produtivo, permitindo que ao término das operações a limpeza da área seja iniciada sem que prejudique a continuidade da produção e o mais importante evita a contaminação cruzada.

Lembramos que este tipo de planejamento facilita o cumprimento das Boas Práticas de Fabricação, porém permite a fabricação de somente um produto por vez.

\subsubsection{Etapa de Implementação}

\subsection{Tempo e capacidade dos equipamentos}

O tempo de cada etapa e a capacidade dos equipamentos foram baseados nas informações fornecidas pelos fabricantes.

Na tabela 15 são descritas as etapas e o tempo de processo de obtenção de comprimidos com prévia granula por via úmida, considerando um lote de $10 \mathrm{Kg}$.

Tabela 15 - Descrição seqüencial do processo de obtenção de comprimidos com prévia granulação por via úmida

\begin{tabular}{lcc}
\hline \multicolumn{1}{c}{ Processo } & Tempo (min) & Capacidade \\
\hline Pesagem e conferencia & 60 & $10 \mathrm{Kg}$ \\
Mistura sólido/sólido & 20 & $10 \mathrm{Kg}$ \\
Mistura sólido/liquido & 20 & $10 \mathrm{Kg}$ \\
Granulação & 60 & $10 \mathrm{Kg}$ \\
Secagem & 200 & $10 \mathrm{Kg}$ \\
Calibração dos grânulos & 30 & $10 \mathrm{Kg}$ \\
Adição dos externos & 20 & $10 \mathrm{Kg}$ \\
Compressão & 90 & 25.000 comprimidos \\
Revestimento & 60 & 25.000 comprimidos \\
Embalagem & 210 & 25.000 comprimidos \\
\hline
\end{tabular}


Os tempos de cada processo foram estimados com base na expectativa de produção de aproximadamente $25 \mathrm{mil}$ unidade de comprimidos dia e capacidade dos equipamentos. No processo de compactação foi considerada uma maquina rotativa com 10 estações e 31 ciclo/minuto (310 comprimidos/minuto), e embaladora com capacidade de 120 unidades por minuto.

A secagem é a etapa limitante do processo. Utilizando a capacidade máxima da estufa o processo levaria de 8 a 10 horas, para reduzir o tempo optamos por trabalhar com $50 \%$ da capacidade máxima, o que reduz o tempo de secagem em um terço, ou seja, 200 minutos.

\subsection{Matéria-prima e material de embalagem}

Os fármacos devem ser considerados individualmente e calculada a quantidade para a produção a ser consumida no período de um ano, mais o excedente de dois meses.

$O$ apêndice $B$ apresenta uma breve descrição dos adjuvantes e das proporções que estes são adicionados às formulações de comprimidos.

A grande maioria dos comprimidos contém entre $100 \mathrm{mg}$ e $500 \mathrm{mg}$ de princípio ativo, optou-se por estabelecer a formulação para um comprimido contendo $250 \mathrm{mg}$ de princípio ativo. A composição do excipiente e, sua respectiva quantidade relativa na formulação varia de acordo com as características físico-químicas do fármaco. Em geral o excipiente representa entre $50 \%$ a $100 \%$ do peso do princípio ativo. Assim, estabeleceu-se uma formulação otimista que contém $50 \%$ do peso total do princípio ativo em excipiente, ou seja, $125 \mathrm{mg}$ e uma formulação pessimista que contém $100 \%$ do peso do princípio ativo em excipiente, ou seja, $250 \mathrm{mg}$ de excipiente.

A tabela 16 apresenta os adjuvantes selecionados, as respectivas quantidades na composição da formulação excipiente tanto para a formulação otimista quanto para a pessimista. 
Tabela 16 - Composição da formulação excipiente padrão otimista, 125mg de excipiente e pessimista, 250mg de excipiente, para comprimidos contendo 250mg de princípio ativo.

\begin{tabular}{|c|c|c|c|c|c|}
\hline \multirow{2}{*}{ Função } & \multirow{2}{*}{ Componente } & \multicolumn{2}{|c|}{$\begin{array}{c}\text { Formulação Pessimista } \\
250 \mathrm{mg}\end{array}$} & \multicolumn{2}{|c|}{$\begin{array}{c}\text { Formulação Otimista } \\
\text { 125mg }\end{array}$} \\
\hline & & $\begin{array}{c}\% \text { em relação ao } \\
\text { peso do PA }\end{array}$ & $\begin{array}{l}\text { Peso } \\
\text { (mg) }\end{array}$ & $\begin{array}{l}\text { \% em relação ao } \\
\text { peso do PA }\end{array}$ & $\begin{array}{l}\text { Peso } \\
\text { (mg) }\end{array}$ \\
\hline \multirow[t]{3}{*}{ Diluente } & celulose microcristalina & 29,05 & 72,625 & 12,6 & 31,5 \\
\hline & Amido & 29,05 & 72,625 & 12,6 & 31,5 \\
\hline & Lactose & 24,9 & 62,25 & 10,8 & 27 \\
\hline Aglutinante & Carboximetilcelulose & 10,00 & 25 & 10,00 & 25 \\
\hline Lubrificante & estearato de magnésio & 3,00 & 7,5 & 3,00 & 7,5 \\
\hline Tensoativo & $\begin{array}{l}\text { polissorbato } 80 \\
\text { Amido glicolato de }\end{array}$ & 1,00 & 2,5 & 1,00 & 2,5 \\
\hline $\begin{array}{l}\text { Desintegrante } \\
\text { Líquido de }\end{array}$ & sódio & 3,00 & 7,5 & 0,00 & 0 \\
\hline umidecimento* & água:álcool etílico & 20,00 & 100 & 20,00 & 75 \\
\hline Revestimento* & Eudragit & 1,5 & 5,65 & 1,5 & 7,5 \\
\hline
\end{tabular}

Outros adjuvantes podem ser necessários, quando o fármacos apresentar alguma incompatibilidade com os descritos na tabela 16.

\subsection{Mão-de-obra}

A qualificação e o número de funcionários foram determinados considerandose a quantidade de medicamentos que deve ser produzida e as exigências quanto à formação necessária para realizar as atividades inerentes à fabricação de medicamentos.

O responsável pela produção deve ser um profissional de nível superior, farmacêutico, este detém as responsabilidades relacionadas à supervisão e controle dos processos produtivos, monitoramento do cumprimento das Boas Práticas de Fabricação (BPFs), manutenção das instalações e equipamentos, validação dos processos, calibração e controle de equipamentos, execução dos registros, redação de relatórios e treinamento inicial e contínuo do pessoal da área produtiva (BRASIL, 2003). Como o volume de produção é relativamente pequeno apenas um profissional farmacêutico pode se responsabilizar por toda a área produtiva.

A execução das etapas de pesagem, preparo, produção e embalagem é realizada por técnico em farmácia, com formação de nível médio. Esse profissional deverá receber treinamento sobre as BPFs, de modo a compreender os objetivos e 
riscos de cada etapa. Também é de sua responsabilidade observar e relatar ao farmacêutico qualquer suspeita de não conformidade relacionada a matérias-primas, materiais de embalagem, produtos acabados e equipamentos (BRASIL, 2003; RICCI, 2008).

As atividades de limpeza e higienização da área produtiva e equipamentos e lavagem de materiais e vidrarias são executadas por um auxiliar de farmácia, com formação de nível básico e treinamento adequado (RICCl, 2003).

Tabela 17 - Distribuição das atividades e dos funcionários relativos à área de produção de medicamentos sólidos

\begin{tabular}{lc}
\hline \multicolumn{1}{c}{ Processo } & Funcionário \\
\hline Responsável Técnico & farmacêutico 1 \\
Pesagem & técnico de farmácia 1 \\
Mistura a seco & técnico de farmácia 1 \\
Mistura úmida & técnico de farmácia 1 \\
Granulação & técnico de farmácia 1 \\
Secagem & técnico de farmácia 1 \\
Calibração dos grânulos & técnico de farmácia 1 \\
Lubrificação & técnico de farmácia 1 \\
Compressão & técnico de farmácia 2 \\
Revestimento & técnico de farmácia 2 \\
Embalagem & técnico de farmácia 2 \\
Higiene e sanitização & auxiliar de farmácia 1 \\
\hline
\end{tabular}

O quadro de funcionários é enxuto, porém suficiente para a realização das atividades propostas considerando-se o volume de produção pretendido. Caso após a implantação a demanda hospitalar por medicamentos aumentar ou a farmácia decida fornecer medicamentos para outros hospitais deve ser analisada a viabilidade de se contratar novos funcionários. 


\subsubsection{Produtos Injetáveis}

\subsubsection{Etapa de Implantação}

\subsection{Processo de produção}

Para as formas farmacêuticas injetáveis de pequeno volume selecionadas foi realizado um levantamento na literatura dos diferentes processos de produção e as etapas que os constituem.

Os métodos empregados na produção de soluções injetáveis e pó liófilos injetáveis são relativamente simples, entretanto, deve ser dada atenção especial as condições de higiene e limpeza para que seja garantida a esterilidade do produto final. A diferenciação dos pós líófilos ocorre apenas na etapa final do processo, onde as soluções são submetidas a criodestilação.

A esterilização das soluções pode ser realizada por diferentes métodos. Para as soluções contendo fármacos termoestáveis o método de mais utilizado é a esterilização terminal com calor úmido, enquanto que para as soluções contendo fármacos termoinstáveis ou pó liófilo o método mais adequado é a filtração esterilizante.

Por se tratarem de métodos amplamente descritos na literatura, serão apresentados apenas os fluxos de cada processo.

Os processos produtivos estão descritos nas figuras 2, 3 e 4. 


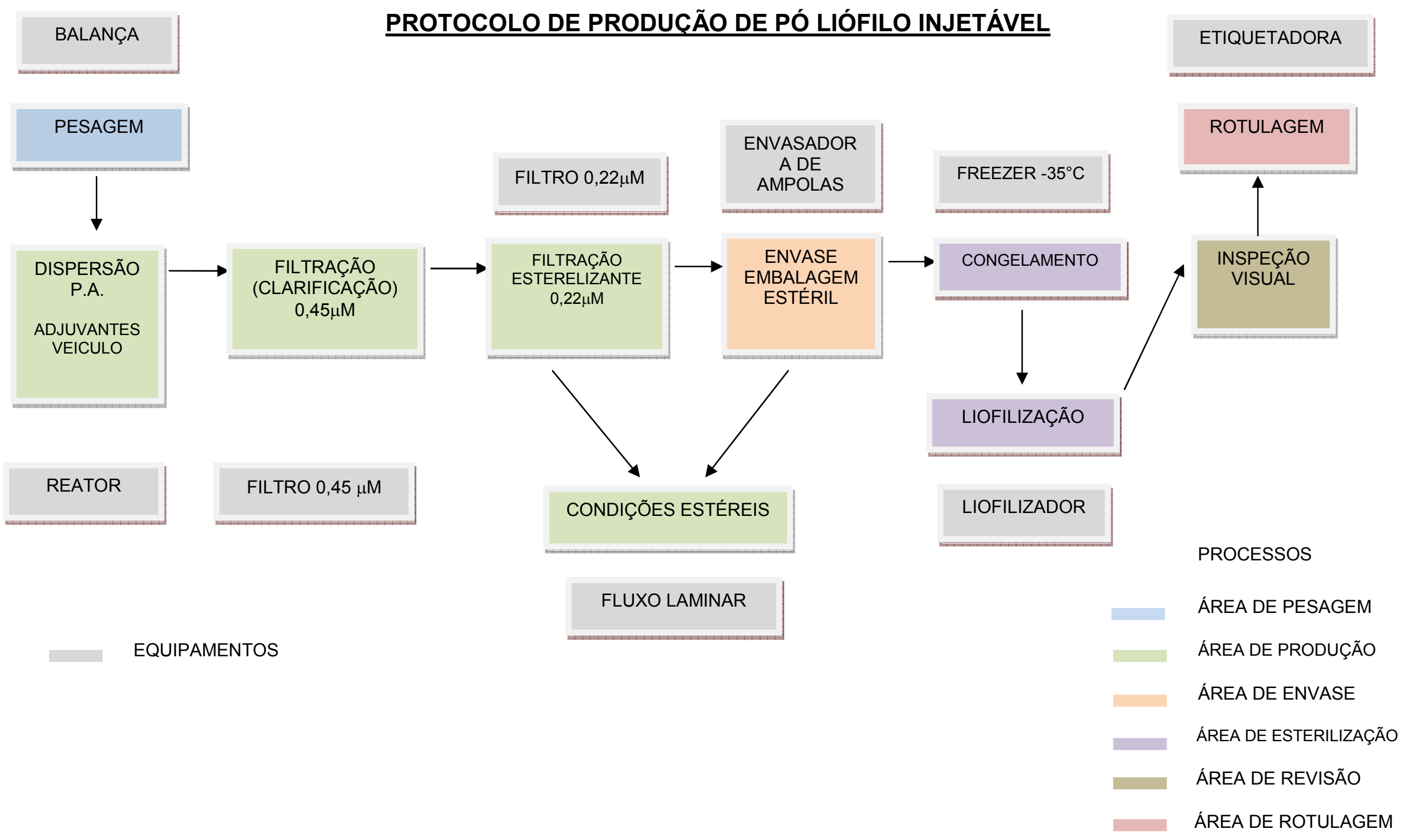

Figura 2 - Representação esquemática do fluxo de produção de pós liófilos injetáveis, respectivos equipamentos e localização na planta produtiva (ANSEL; POPOVICH; ALLEN Jr, 2000; BILLANY, 2005). 


\section{PROTOCOLO DE PRODUÇÃO DE SOLUÇÕES ESTÉREIS}

PRINCÍPIO ATIVO TERMOESTÁVEL

\section{BALANCA}

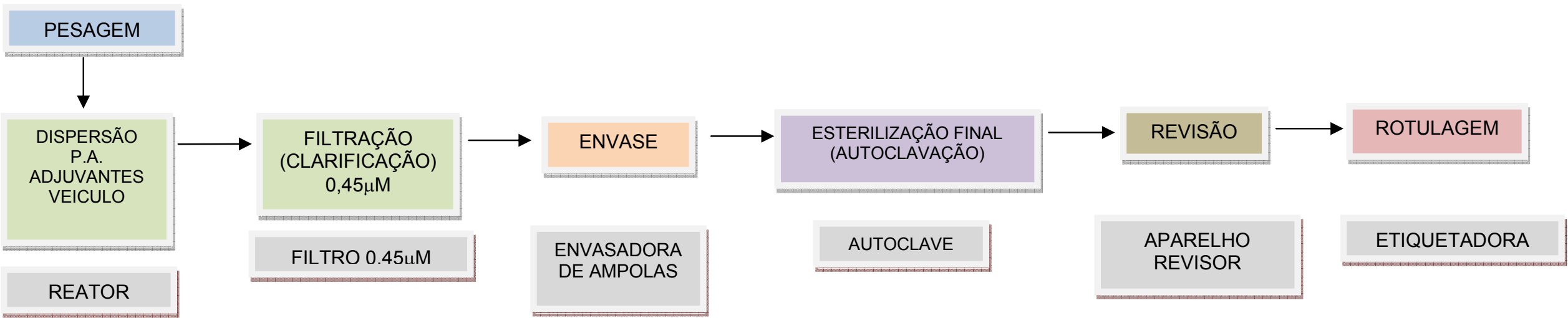

EQUIPAMENTOS

PROCESSOS

$$
\text { EQUIPAMENTOS }
$$

ÁREA DE PESAGEM

ÁREA DE PRODUÇÃO

ÁREA DE ENVASE

ÁREA DE ESTERILIZAÇÃO

ÁREA DE REVISÃo

Figura 3 - Representação esquemática do fluxo de produção de soluções estéreis com princípio ativo termoestável, respectivos equipamentos e localização na planta produtiva (ANSEL; POPOVICH; ALLEN Jr, 2000; BILLANY, 2005). 


\section{PROTOCOLO DE PRODUÇ̃̃O DE SOLUÇÕES ESTÉREIS}

PRINCÍPIO ATIVO TERMOLÁBIL

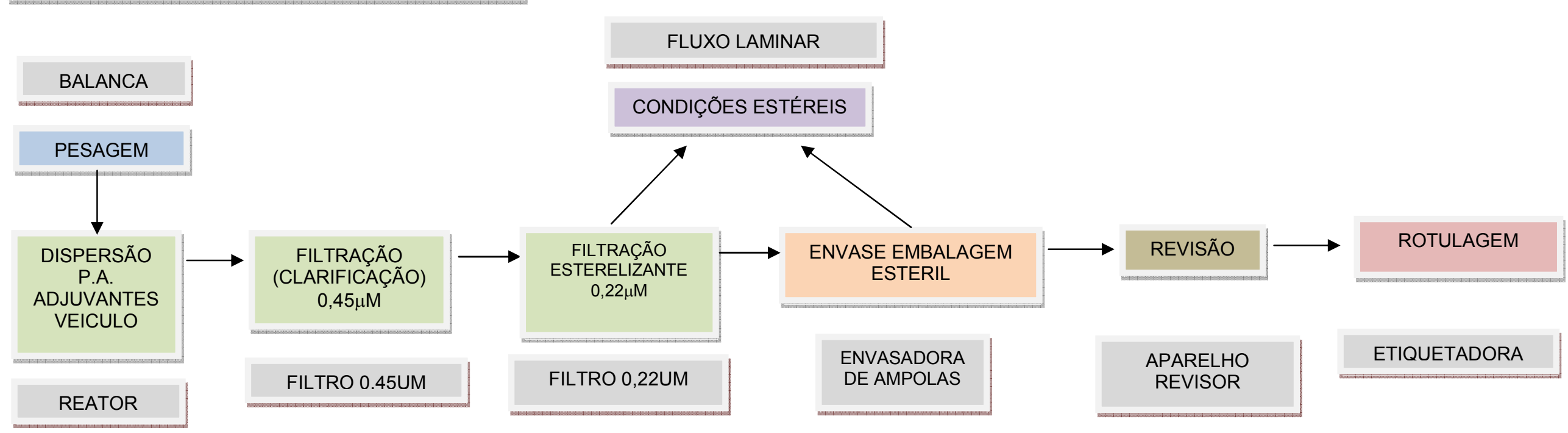

PROCESSOS

EQUIPAMENTOS

ÁREA DE PESAGEM
ÁREA DE PRODUÇÃO
ÁREA DE ENVASE
ÁREA DE ESTERILIZAÇÃO
ÁREA DE REVISÃO
ÁREA DE ROTULAGEM

Figura 4 - Representação esquemática do fluxo de produção de soluções estéreis com princípio ativo termolábel, respectivos equipamentos e localização na planta produtiva (ANSEL; POPOVICH; ALLEN Jr, 2000; BILLANY, 2005). 


\subsection{Equipamentos}

No da produção de injetáveis, os equipamentos participam uma única vez do processo produtivo e não há disponibilidade de diferentes equipamentos com mesma função e assim, o parâmetro empregado na seleção foi a capacidade produtiva estimada.

As figuras 2, 3 e 4 apresentam os equipamentos e as etapas do processo produtivo que participam.

Para a etapa de rotulagem, foi proposta uma etiquetadora que imprime o nome do princípio ativo, concentração, forma de apresentação e seu respectivo código de barras, as etiquetas identificarão as ampolas e frasco-ampolas dos produtos estéreis. Assim como para os produtos sólidos, o objetivo desta etapa é auxiliar na implantação e consolidação do sistema de distribuição de medicamentos individualizado ou por dose unitária nos hospitais.

\subsubsection{3. Área física}

O conhecimento das formas farmacêuticas e das classes que serão manufaturadas, juntamente com os processos envolvidos e o tamanho e número de equipamentos forneceram subsídios para determinação da dimensão adequada da área destinada à produção de medicamentos injetáveis.

As características do revestimento de pisos e paredes, vedação de portas e janelas, sistema de exaustão de ar, pressão positiva, controle de temperatura e umidade, necessidade de área limpa e outros seguiram o determinado na legislação em vigor (BRASIL, 2003).

Assim foi planejada uma área limpa ${ }^{6}$ de $40 \mathrm{~m}^{2}$, sub-dividida em:

1. lavagem e esterilização/despirogenização de ampolas e/ou frascos ampola 4 $\mathrm{m}^{2}$

\footnotetext{
${ }^{6}$ As áreas limpas utilizadas na fabricação de produtos estéreis são classificadas, segundo as características exigidas para a qualidade do ar, em graus A (classe 100), B (classe 1.000), C (classe 10.000) e D (classe 100.000) (WHO Technical Report Series, n902, 2002)
} 
2. área de pesagem $4 \mathrm{~m}^{2}$

3. antecâmara $3 \mathrm{~m}^{2}$

3.1. antecâmara para o ingresso de pessoal à área de preparação de produtos estéreis

3.2. antecâmara para o ingresso de materiais na área de preparação de produtos estéreis

4. área limpa $10 \mathrm{~m}^{2}$

4.1. Preparação de produtos com esterilização final ou com filtração esterilizante (grau C)

- gradiente de pressão da área de preparação asséptica para as antecâmaras e áreas adjacentes

4.2. Preparação asséptica de produtos sem esterilização final (grau B ou C)

- gradiente de pressão da área de preparação asséptica para as antecâmaras e áreas adjacentes

5. Envase $8 \mathrm{~m}^{2}$

5.1. envase de produtos com esterilização final (grau C) - área deve possuir pressão positiva em relação às áreas subjacentes

5.1.1 antecâmara para o ingresso de pessoal à área de envase de produtos estéreis

5.1.2 antecâmara para o ingresso de materiais à área de envase de produtos estéreis

5.1.3 área de esterilização final de produtos (grau C, envase soluções parenterais fluxo laminar grau A)

5.2 envase asséptico de produtos sem esterilização final (grau B ou C) - área deve possuir pressão positiva em relação às áreas subjacentes

5.2.1 antecâmara para o ingresso de pessoal à área de envase de produtos estéreis

5.2.2 antecâmara para o ingresso de materiais à área de envase de produtos estéreis

6. esterilização final de produtos $5 \mathrm{~m}^{2}$

7. inspeção visual de produtos envasados e rotulagem $6 \mathrm{~m}^{2}$

Seguindo o mesmo princípio adotado no planejamento da infra-estrutura para produtos sólidos, a área destinada aos medicamentos injetáveis não permite a 
produção simultânea de mais de um medicamento, o que reduz a probabilidade de contaminação cruzada, contaminação por partículas e troca ou mistura de produto.

\subsubsection{Etapa de Implementação}

\subsection{Tempo e capacidade dos equipamentos}

O tempo de cada etapa foi calculado com base na capacidade dos equipamentos, fornecidas pelos fabricantes.

O processo de produção das duas formas farmacêuticas selecionadas é composto por etapas similares, exceto pela inclusão do congelamento e liofilização ao final do processo para os pós liófilos injetáveis.

As descrições a seguir referem-se ao preparo de pós liófilos injetáveis

Tabela 18 - Processos envolvidos na produção de pós liófilos

\begin{tabular}{lcc}
\hline \multicolumn{1}{c}{ Processo } & Tempo $(\min )$ & Capacidade \\
\hline Pesagem & 60 & ------- \\
Dispersão & 30 & $50 \mathrm{~L}$ \\
Filtração (clarificação) $^{*}$ & 60 & $50 \mathrm{~L}$ \\
Filtração (esterilização) $^{*}$ & 120 & $50 \mathrm{~L}$ \\
Envase & 120 & $5.000 \mathrm{ampolas}$ \\
Congelamento & 30 & $5.000 \mathrm{ampolas}$ \\
Liofilização & $24^{* *}$ & $5.000 \mathrm{ampolas}$ \\
Revisão & 120 & $5.000 \mathrm{ampolas}$ \\
Rotulagem & 120 & $5.000 \mathrm{ampolas}$ \\
${ }^{*}$ pode ser realizado em um único processo & \\
${ }^{*}$ tempo em horas & &
\end{tabular}

Para as soluções, o tempo de esterilização por calor úmido é de 20 minutos a temperatura de $121^{\circ} \mathrm{C}$.

\subsection{Matéria-prima e material de embalagem}

As soluções injetáveis e os pós liófilos injetáveis possuem composição similares, uma vez que os últimos são inicialmente preparados como uma solução a qual é submetida ao processo de criodestilação para a retirada do solvente. 
Para estabelecer uma formulação padrão para soluções injetáveis e pós liófilos injetáveis considerou-se uma concentração de $250 \mathrm{mg}$ de princípio ativo e um volume final de $10 \mathrm{~mL}$.

$O$ apêndice $B$ apresenta uma breve descrição dos adjuvantes adicionados às soluções injetáveis e às soluções para preparo de pós liófilos injetáveis.

Tabela 19 - Componentes utilizados no preparo de pós liofilos e suas respectivas funções e proporções

\begin{tabular}{llcc}
\hline \multicolumn{1}{c}{ Função } & \multicolumn{1}{c}{ Componente } & $\begin{array}{c}\text { \% em relação } \\
\text { ao PA }\end{array}$ & Peso (mg) \\
\hline Solvente* $^{*}$ & Água & 100 & 10 \\
Controle do pH & ácido fosfórico & 10 & 25 \\
Controle do pH & bicarbonato de sódio & 10 & 25 \\
Tensoativo & polissorbato 80 & 1 & 2,5 \\
Diluente & Lactose & 50 & 125 \\
\hline
\end{tabular}

* porcentagem em relação ao volume total.

Salientamos que consideramos uma formulação básica para facilitar as etapas de cálculo de viabilidade econômica do projeto. No caso da fabricação destes medicamentos deve ser priorizada a apresentação já nas doses e volumes exatos para a administração, evitando a adequação de doses. Se forem produzidas outras formas farmacêuticas, as respectivas embalagens devem ser consideradas.

As embalagens para injetáveis, inclusive as tampas, não devem interagir física ou quimicamente com a preparação, o vidro é o material mais indicado, preferencialmente deve ser incolor (desde que o fármaco não seja fotossensível) para facilitar a inspeção visual do conteúdo durante o processo de revisão, no caso de substâncias sensíveis a luz pode ser empregado vidro de cor âmbar clara (ANSEL, 2000). Portanto, tanto para pós liófilos injetáveis quanto para soluções, foram selecionados ampolas e frasco ampolas de vidro.

\subsection{Mão-de-obra}

Para os funcionários que trabalham na produção de injetáveis deve ser dada ênfase ao treinamento voltado para área limpa. 
Tabela 20 - Número de funcionários, de acordo com a etapa do processo

\begin{tabular}{lc}
\hline \multicolumn{1}{c}{ Processo } & Funcionário \\
\hline Supervisão dos Processos & farmacêutico 1 \\
Pesagem & técnico de farmácia 1 \\
Dissolução & técnico de farmácia 1 \\
Filtração (clarificação) & técnico de farmácia 1 \\
Filtração (esterilização) & técnico de farmácia 1 \\
Envase & técnico de farmácia 1 \\
Freezer & técnico de farmácia 1 \\
Liofilização & técnico de farmácia 1 \\
Revisão & técnico de farmácia 2 \\
Rotulagem & técnico de farmácia 2 \\
Higiene e sanitização & auxiliar de farmácia 1 \\
\hline
\end{tabular}

4.8.3. Atividades de Apoio: Controle de Qualidade Físico-Químico e Microbiológico, Produção de Água Purificada e de Qualidade Injetável e Almoxarifado

\subsubsection{Etapa de Implantação}

\subsection{Processos e Equipamentos}

Os processos envolvidos no controle de qualidade físico-químico e microbiológico e na produção de água purificada e de qualidade injetável seguiram os parâmetros determinados na Farmacopéia Brasileira (1996) e na Farmacopéia Americana - USP (1999).

Para facilitar $O$ entendimento $O$ apêndice $C$ contém os testes relativos ao controle de qualidade físico-químico e microbiológico apresentados separadamente para matéria-prima, água purificada e de qualidade injetável, produtos sólidos, produtos injetáveis e área asséptica ou capela de fluxo laminar.

As tabelas 21 a 24 contêm os parâmetros e equipamentos relativos ao controle de qualidade físico-químico e microbiológico. 
Tabela 21 - Parâmetros e equipamentos utilizados no controle físicoquímico

\begin{tabular}{|c|c|}
\hline Teste & Equipamento (s) \\
\hline \multicolumn{2}{|l|}{ Identificação } \\
\hline Doseamento & espectrofotômetro UV/VIS \\
\hline Impurezas ou Produtos de Degradação* & HPLC \\
\hline \multicolumn{2}{|l|}{ Uniformidade de conteúdo** } \\
\hline Teste de material particulado & aparelho revisor \\
\hline Volume médio/Variação de volume & Visual \\
\hline $\mathrm{pH}$ & pHmetro \\
\hline Umidade & Balança para determinação de umidade \\
\hline Variação de peso/ Peso médio & balança analítica \\
\hline Dureza & Durômetro \\
\hline Friabilidade & Friabilômetro \\
\hline Desintegração & Desintegrador \\
\hline Teste de dissolução & Dissolutor \\
\hline Ponto de fusão & aparelho de ponto fusão \\
\hline Testes físico-quimicos da água & pHmetro, condutivímetro e teor de oxigênio \\
\hline
\end{tabular}

Tabela 22 - Equipamentos de apoio ao controle de qualidade

\begin{tabular}{ll}
\hline Teste & Equipamento (s) \\
\hline Armazenamento de água purificada & barrilete de PVC 50L \\
Armazenamento e análise dos dados & Computador \\
Conservação de substâncias e amostras & Geladeira \\
termosessíveis & termo/higrometrodigital \\
Controle de umidade e temperatura & estufa esterilização e secagem \\
Esterilização e Secagem de vidrarias & balança semi-analítica \\
Pesagem de reagentes & balança analítica \\
& sistema de água MiliQ \\
Produção de água para HPLC & Utensílios e Vidrarias \\
Outros & \\
\hline
\end{tabular}


Tabela 23 - Parâmetros e equipamentos utilizados no controle de qualidade microbiológico

\begin{tabular}{ll}
\hline Teste & Equipamento (s) \\
\hline Teste de esterilidade & \\
Teste LAL & estufa bacteriológica \\
Contagem de microganismos viáveis & fluxo laminar vertical \\
$\begin{array}{ll}\text { Contagem de microrganismos viáveis } \\
\text { Contagem de partículas }\end{array}$ & \\
\hline
\end{tabular}

Tabela 24 - Equipamentos de apoio ao controle microbiológico

\begin{tabular}{|c|c|}
\hline Teste & Equipamento (s) \\
\hline Armazenamento de água purificada & barrilete de PVC 50L \\
\hline $\begin{array}{l}\text { Armazenamento e análise dos dados } \\
\text { Conservação de substâncias e amostras } \\
\text { termosessíveis }\end{array}$ & $\begin{array}{l}\text { Computador } \\
\text { Geladeira } \\
\text { freezer }-20^{\circ} \mathrm{C}\end{array}$ \\
\hline Controle de umidade e temperatura & termo/higrometrodigital \\
\hline Esterilização e Secagem de vidrarias & estufa esterilização e secagem \\
\hline Pesagem de reagentes & $\begin{array}{l}\text { balança semi-analítica } \\
\text { balança analítica }\end{array}$ \\
\hline Preparo de meios de cultura & $\begin{array}{l}\text { Autoclave } \\
\text { agitador magnético com aquecimento }\end{array}$ \\
\hline Produção de água para HPLC & sistema de água MiliQ \\
\hline Outros & utensílios e vidrarias \\
\hline
\end{tabular}

\subsubsection{2. Área Física}

A infra-estrutura baseou-se na quantidade e porte dos equipamentos selecionados e no caso do almoxarifado, no volume e variedade de matéria-prima, material de embalagem e produto acabado.

Área destinada a produção de água $8 \mathrm{~m}^{2}$

1. água potável

2. água purificada

3. água de qualidade injetável 
Área destinada ao Controle de qualidade $20 \mathrm{~m}^{2}$, sendo:

1. controle de qualidade físico-químico $10 \mathrm{~m}^{2}$

2. controle de qualidade microbiológico $10 \mathrm{~m}^{2}$

Almoxarifado matéria-prima (armazenagem) $40 \mathrm{~m}^{2}$, subdividido em:

1. matérias-primas, produtos intermediários, produtos a granel e material de embalagem

1.1 produtos em quarentena

1.2 produtos aprovados

1.3 produtos reprovados

1.4 local exclusivo para guarda de substâncias e produtos sujeitos ao regime de controle especial

2. recepção de matéria-prima e material de embalagem

3. área específica para amostragem de matéria-prima.

4. área para armazenamentos de materiais e/ou produtos vencidos enquanto aguardam seu destino final

Almoxarifado produto acabado $15 \mathrm{~m}^{2}$, subdividido em:

1. produtos terminados

1.1 produtos aprovados

1.2 produtos em quarentena

1.3 produtos reprovados

1.4 local exclusivo para guarda de substâncias e produtos sujeitos ao regime de controle especial

Sanitários $8 \mathrm{~m}^{2}$

Para facilitar a logística da área produtiva optou-se pelo planejamento de duas áreas de armazenamento, uma destinada á recebimento e armazenagem de matéria-prima, material de embalagem, produtos intermediários e a granel, localizada na entrada da área produtiva, assim, os produtos são recebidos e seguem em seqüência linear para a área de produção; e outra destinada a produtos acabados, localizada próximo a saída da área produtiva, fazendo com que os medicamentos finalizados saiam da produção direto para o armazenamento. 
A dimensão da área de armazenamento é relativamente pequena, pois levouse em consideração o pequeno espaço ocupado pelo material de embalagem (ampolas, frasco ampolas, filme de pvc) e a proximidade de fornecedores facilitando a aquisição e entrega de matéria-prima em um curto período de tempo, reduzindo a quantidade que deve ser estocada. Caso a instalação seja feita em áreas distante dos centros fornecedores, a capacidade deve ser aumentada para possibilitar estocagem.

\subsubsection{Etapa de Implementação}

\subsection{Tempo e capacidade}

O ideal é que a produção de água seja dinâmica, ou seja, deve ser programada para ocorrer imediatamente antes de sua utilização na produção, evitando assim que haja estoques. Este procedimento reduz o investimento em reservatórios de água e o mais importante, reduz a probabilidade de contaminação. È conveniente que antes de ser empregada na produção a água purificada e de qualidade injetável tenha laudo do controle de qualidade.

\subsection{Mão-de-obra}

Os responsáveis pela produção, Controle e Garantia da Qualidade devem exercer em conjunto, determinadas atividades relativas à qualidade, tais como:

(a) autorização dos procedimentos e documentos, inclusive suas atualizações;

(b) monitoramento e o controle do ambiente de fabricação;

(c) higiene;

(d) validação de processo e a calibração de instrumentos analíticos;

(e) treinamento, incluindo a aplicação dos princípios de garantia da qualidade;

(f) aprovação e o monitoramento de fornecedores de materiais;

(g) aprovação e o monitoramento dos fabricantes contratados;

(h) especificações e o monitoramento das condições de armazenamento de matérias primas e produtos acabados;

(i) arquivo de documentos/ registros; 
(j) monitoramento do cumprimento das BPF;

(k) inspeção, investigação e amostragem, de modo a monitorar fatores que possam afetar a qualidade do produto.

O responsável pelo Controle de qualidade possui as seguintes responsabilidades:

(a) aprovar ou rejeitar as matérias-primas, os materiais de embalagem e os produtos intermediários, a granel e terminados;

(b) avaliar os registros dos lotes;

(c) assegurar que sejam realizados todos os ensaios necessários;

(d) aprovar as instruções para amostragem, as especificações, os métodos de ensaio e os procedimentos de controle de qualidade;

(e) aprovar e monitorar as análises realizadas, previstas em contrato;

(f) verificar a manutenção das instalações e dos equipamentos;

(g) assegurar que sejam feitas as validações necessárias, inclusive a validação dos procedimentos analíticos e calibração dos equipamentos de controle;

(h) assegurar que sejam realizados treinamentos iniciais e contínuos do pessoal da área de Controle de qualidade, de acordo com as necessidades do setor.

Tabela 25 - Recursos humanos e atividades

\begin{tabular}{lc}
\hline \multicolumn{1}{c}{ Processo } & Funcionário \\
\hline Supervisão/Execução dos Processos & farmacêutico 2 \\
Controle de qualidade físico-químico & técnico de farmácia 3 \\
Controle de qualidade microbiológico & técnico de farmácia 3 \\
Produção de água purificada/injetável & técnico de farmácia 3 \\
Higiene e sanitização & auxiliar de limpeza 2 \\
\hline
\end{tabular}

Obs: É vedado ao profissional farmacêutico ser responsável pela área de Produção e Controle de Qualidade. 


\subsection{Análise de viabilidade econômica da implantação de farmácia semi- industrial para produção de medicamentos}

Para produzir diferentes classes de medicamentos em pequenas quantidades, a solução mais viável é produzi-los em uma única área em tempos distintos. Para isto é necessário rigoroso controle e validação de processos de higienização e limpeza entre a produção de uma classe e outra. Também é necessário o planejamento rigoroso da utilização da área para que não coincida a produção de diferentes classes no mesmo período. O cálculo da quantidade a ser produzida também deve ser bem elaborado para evitar falha no abastecimento dos medicamentos, já que produções emergenciais ficam impossibilitadas nesta organização.

Posteriormente, deve-se calcular o período de tempo para produzir cada uma das especialidades farmacêuticas que compõem uma mesma categoria, levando-se em consideração a capacidade produtiva dos equipamentos, o número de horas de funcionamento da área produtiva por dia, o tempo de preparo da área, incluindo manutenção dos equipamentos e sanitização e higiene entre uma produção e outra.

Ao terminar a produção de uma determinada categoria e antes de iniciar a próxima é aconselhável a paralisação da estrutura produtiva por alguns dias visando apurada limpeza e manutenção de acordo com rígidos critérios estabelecidos nas BPF para eliminar a possibilidade de contaminação cruzada.

Neste estudo, para agrupamento das diferentes categorias em uma mesma área produtiva levou-se em consideração a análise das quantidades adquiridas ao longo de um ano para cada categoria e as exigências da RDC210 quanto à área produtiva. Assim, foi estabelecido um cenário onde foram projetadas uma área de produção para sólidos e uma para medicamentos estéreis. Esta divisão considerou as maiores exigências da legislação em relação a produção de antibióticos penicilâmicos e cefalosporínicos. Portanto, considera-se que as demais categorias serão produzidas nestas mesmas condições o que acarreta em maior segurança, para o paciente, para os funcionários envolvidos na manipulação e para o meio ambiente. 


\subsubsection{Levantamento dos valores de mercado (VM) e da quantidade a ser produzida dos medicamentos selecionados}

Os valores referentes à média do número de unidades adquiridas e do valor total pago entre os anos de 2006 e 2007 foram considerados como parâmetros da quantidade de itens que devem ser produzidos pela farmácia e do valor de mercado dos medicamentos.

Tabela 26 - Número médio de unidades e valor médio dos produtos sólidos e injetáveis considerados para o estudo de viabilidade

\begin{tabular}{lcc}
\hline & Média de unidades & Média do Valor Gasto $(\mathbf{R} \mathbf{)}$ \\
\hline Produtos sólidos & 5.774 .421 & $12.318 .694,10$ \\
Produtos injetáveis & 3.583 .446 & $11.005 .444,73$ \\
Total & $\mathbf{9 . 3 5 7 . 8 6 7}$ & $\mathbf{2 3 . 3 2 4 . 1 3 8 , 8 2}$ \\
\hline
\end{tabular}

O número médio de unidades para os anos de 2006 e 2007 permite estimar uma produção mensal de 482 mil unidades sólidas e 299 mil unidades injetáveis. Considerando que a estrutura produtiva funcionará de segunda a sexta, por mês, serão 20 dias de trabalho, resultando na produção diária de 24,1 mil unidades sólidas e 15 mil unidades injetáveis. O valor gasto médio equivale ao VM.

\subsubsection{Levantamento dos custos variáveis de produção - CVP}

A tabela 27 apresenta os custos variáveis mensais e anuais relativos à produção de medicamentos sólidos e injetáveis. A demonstração detalhada dos custos variáveis está apresentada no apêndice $D$.

Tabela 27 - Custos variáveis mensais e anuais relativos à produção de medicamentos sólidos e injetáveis

\begin{tabular}{lcc}
\hline Custos Variáveis & Custo Mensal (R\$) & Custo Anual (R\$) \\
\hline Matéria-Prima & $408.515,97$ & $4.902 .191,69$ \\
Materiais de consumo (filtros) & $19.293,00$ & $231.516,00$ \\
Mão-de-obra & $6.128,83$ & $73.545,96$ \\
Energia Elétrica & 431,11 & $5.173,34$ \\
Total & $\mathbf{4 3 4 . 3 6 8 , 9 2}$ & $\mathbf{5 . 2 1 2 . 4 2 6 , 9 9}$ \\
\hline
\end{tabular}


O custo com matéria-prima é o mais representativo dos custos variáveis. $\mathrm{O}$ valor de energia elétrica é baixo, pois, principalmente no caso de produtos sólidos, os equipamentos não funcionam durante todo o processo produtivo, como demonstrado na tabela 27.

\subsubsection{Obtenção da margem de contribuição de cada período}

A produção de medicamentos visa atender as necessidades hospitalares a um custo menor que os valores de mercado, portanto, não há lucro, mas sim economia de recursos, assim, considerou-se receita o VM dos medicamentos selecionados.

A diferença entre a receita e o custo variável de produção resultou na margem de contribuição, os valores estão apresentados juntamente com o cálculo do VPL.

\subsubsection{Levantamento dos custos fixos de produção - CFPs}

A tabela 28 apresenta os custos fixos mensais e anuais relativos à produção de medicamentos sólidos e injetáveis. Os valores de salários e encargos para mãode-obra indireta são os mesmos descritos para mão-de-obra direta. As taxas anuais de manutenção de infra-estrutura (1\%) e equipamentos (3\%) correspondem às utilizadas em instituições financeiras para fins de elaboração de projetos de financiamento. Os demais valores foram estimados.

Tabela 28 - Custos fixos relativos à produção de medicamentos sólidos e injetáveis

\begin{tabular}{lcc}
\hline Custos Fixos & Custo Mensal (R\$) & Custo Anual (R\$) \\
\hline Mão-de-obra Indireta & $6.128,83$ & $73.545,96$ \\
Energia Elétrica & 500,00 & $6.000,00$ \\
Água & $1.000,00$ & $12.000,00$ \\
Material Escritório das Atividades de Apoio & 600,00 & $7.200,00$ \\
Custos de Controle de Qualidade & $2.000,00$ & $24.000,00$ \\
Custos de Manutenção Infra-Estrutura & 558,13 & $6.697,60$ \\
Custos de Manutenção Equipamentos & $1.790,33$ & $21.483,96$ \\
Total & $\mathbf{1 2 . 5 7 7 , 2 9}$ & $\mathbf{1 5 0 . 9 2 7 , 5 2}$ \\
\hline
\end{tabular}


Nos custos fixos o mais relevantes é o custo com mão-de-obra.

A figura 5 apresenta a comparação entre custos variáveis e fixos.

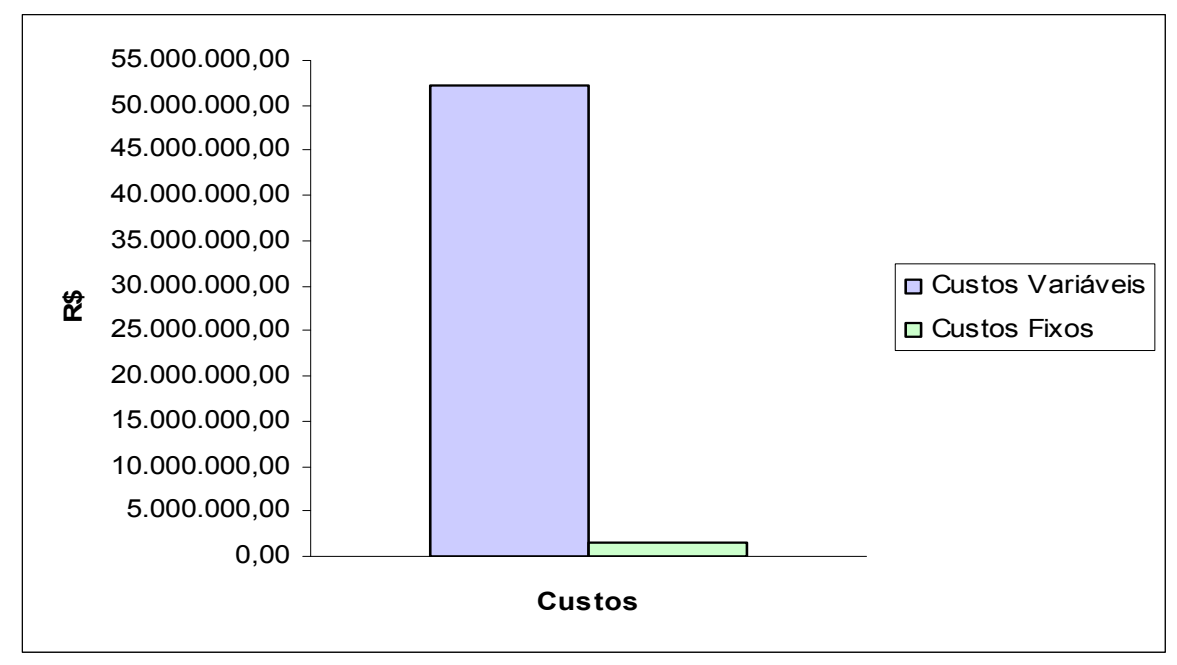

Figura 5 - Comparação entre custos variáveis e fixos relativos à produção de medicamentos

É possivel observar que o maior impacto no custo total são os custos variáveis, comprovando que a não exatidão dos valores referentes à energia elétrica, água, material de escritório e manutenção do controle de qualidade não interfere significativamente no cálculo do VPL. No caso de um estudo em condições reais de implantação é aconselhável a obtenção de valores reais.

\subsubsection{Levantamento dos custos de implantação e do valor residual}

Os custos de implantação estão resumidos na tabela abaixo, os detalhes estão no apêndice $D$.

Tabela 29 - Custos de implantação da infra-estrutura física e de equipamentos da farmácia semi-industrial

\begin{tabular}{lc}
\hline & Valor (R\$) \\
\hline Infra-estrutura & $669.760,00$ \\
Controle de qualidade físico químico & $276.311,13$ \\
Controle de qualidade microbiológico & $56.975,57$ \\
Produção de água purificada & $3.866,65$ \\
Produção de água injetável & $18.001,65$ \\
Produção de Sólidos & $214.775,00$ \\
Produção de Injetáveis & $63.388,00$ \\
Total & $\mathbf{1 . 3 0 3 . 0 7 8 , 0 0}$ \\
\hline
\end{tabular}


O valor total dos equipamentos como sucata, considerando-se o quilo do aço a $R \$ 0,16$ é $R \$ 229,32$. Os cálculos estão no apêndice $D$.

\subsubsection{Obtenção do fluxo de economia de caixa incremental}

Subtraindo da Margem de Contribuição os recursos desembolsados com os CFPs, obtém-se, por fim, o montante que será economizado pelo hospital em cada período, ou seja, a economia de caixa incremental gerada pela implantação do projeto. Os valores estão apresentados nas tabelas 30 e 31 .

\subsubsection{Valor Presente Líquido e Pay Back}

Para o cálculo do VPL foi montado o fluxo de caixa contendo os valores da receita, dos custos variáveis, da margem de contribuição, os custos fixos e o resultado (economia de caixa incremental) para os 120 meses analisados.

Descontando-se a taxa de juros encontrou-se o valor presente dos fluxos futuros de caixa.

O VPL foi obtido pela soma do valor presente dos fluxos de caixa descontados o custo inicial do investimento.

As tabelas 30 e 31 apresenta o cálculo mensal do VPL para o ano 1 e os investimentos para implantação da farmácia semi-industrial ocorridos no ano zero, nos demais anos os valores se repetem. 
Tabela 30 - Cálculo do VPL mensal equivalente ao primeiro ano

\begin{tabular}{|c|c|c|c|c|c|c|c|c|c|c|c|c|c|}
\hline & Ano 0 & & & & & & & Ano 1 & & & & & \\
\hline Mês & 0 & 1 & 2 & 3 & 4 & 5 & 6 & 7 & 8 & 9 & 10 & 11 & 12 \\
\hline Receita & & $1.943 .678,24$ & $1.943 .678,24$ & $1.943 .678,24$ & $1.943 .678,24$ & $1.943 .678,24$ & $1.943 .678,24$ & $1.943 .678,24$ & $1.943 .678,24$ & $1.943 .678,24$ & $1.943 .678,24$ & $1.943 .678,24$ & $1.943 .678,24$ \\
\hline Custos Variáveis & & $434.368,92$ & $434.368,92$ & $434.368,92$ & $434.368,92$ & $434.368,92$ & $434.368,92$ & $434.368,92$ & $434.368,92$ & $434.368,92$ & $434.368,92$ & $434.368,92$ & $434.368,92$ \\
\hline $\begin{array}{l}\text { Matéria-Prima } \\
\text { Materiais de consumo }\end{array}$ & & $408.515,97$ & $408.515,97$ & $408.515,97$ & $408.515,97$ & $408.515,97$ & $408.515,97$ & $408.515,97$ & $408.515,97$ & $408.515,97$ & $408.515,97$ & $408.515,97$ & $408.515,97$ \\
\hline (filtros) & & $19.293,00$ & $19.293,00$ & $19.293,00$ & $19.293,00$ & $19.293,00$ & $19.293,00$ & $19.293,00$ & $19.293,00$ & $19.293,00$ & $19.293,00$ & $19.293,00$ & $19.293,00$ \\
\hline Mão-de-obra & & $6.128,83$ & $6.128,83$ & $6.128,83$ & $6.128,83$ & $6.128,83$ & $6.128,83$ & $6.128,83$ & $6.128,83$ & $6.128,83$ & $6.128,83$ & $6.128,83$ & $6.128,83$ \\
\hline Energia Elétrica & & 431,11 & 431,11 & 431,11 & 431,11 & 431,11 & 431,11 & 431,11 & 431,11 & 431,11 & 431,11 & 431,11 & 431,11 \\
\hline Margem de Contribuição & & $1.509 .309,32$ & $1.509 .309,32$ & $1.509 .309,32$ & $1.509 .309,32$ & $1.509 .309,32$ & $1.509 .309,32$ & $1.509 .309,32$ & $1.509 .309,32$ & $1.509 .309,32$ & $1.509 .309,32$ & $1.509 .309,32$ & $1.509 .309,32$ \\
\hline Custos Fixos & & $12.577,29$ & $12.577,29$ & $12.577,29$ & $12.577,29$ & $12.577,29$ & $12.577,29$ & $12.577,29$ & $12.577,29$ & $12.577,29$ & $12.577,29$ & $12.577,29$ & $12.577,29$ \\
\hline Mão-de-obra Indireta & & $6.128,83$ & $6.128,83$ & $6.128,83$ & $6.128,83$ & $6.128,83$ & $6.128,83$ & $6.128,83$ & $6.128,83$ & $6.128,83$ & $6.128,83$ & $6.128,83$ & $6.128,83$ \\
\hline Outros Custos & & $6.448,46$ & $6.448,46$ & $6.448,46$ & $6.448,46$ & $6.448,46$ & $6.448,46$ & $6.448,46$ & $6.448,46$ & $6.448,46$ & $6.448,46$ & $6.448,46$ & $6.448,46$ \\
\hline Energia Elétrica & & 500,00 & 500,00 & 500,00 & 500,00 & 500,00 & 500,00 & 500,00 & 500,00 & 500,00 & 500,00 & 500,00 & 500,00 \\
\hline $\begin{array}{l}\text { Água } \\
\text { Material Escritório } \\
\text { das Ativ. Apoio }\end{array}$ & & $1.000,00$ & $1.000,00$ & $1.000,00$ & $1.000,00$ & $1.000,00$ & $1.000,00$ & $1.000,00$ & $1.000,00$ & $1.000,00$ & $1.000,00$ & $1.000,00$ & $1.000,00$ \\
\hline $\begin{array}{l}\text { Custos de CQ } \\
\text { Custos de Manut. } \\
\text { Infra Estrutura } \\
\text { Custos de Manut. } \\
\text { Equipamentos }\end{array}$ & & $2.000,00$ & $2.000,00$ & $2.000,00$ & $2.000,00$ & $2.000,00$ & $2.000,00$ & $2.000,00$ & $2.000,00$ & $2.000,00$ & $2.000,00$ & $2.000,00$ & $2.000,00$ \\
\hline Infra Estrutura & $669.760,00$ & & & & & & & & & & & & \\
\hline Equipamentos & $716.132,00$ & & & & & & & & & & & & \\
\hline Venda equipamentos & & & & & & & & & & & & & \\
\hline Resultado do Período & $-1.385 .892,00$ & $1.496 .732,03$ & $1.496 .732,03$ & $1.496 .732,03$ & $1.496 .732,03$ & $1.496 .732,03$ & $1.496 .732,03$ & $1.496 .732,03$ & $1.496 .732,03$ & $1.496 .732,03$ & $1.496 .732,03$ & $1.496 .732,03$ & $1.496 .732,03$ \\
\hline Valor Presente & $-1.385 .892,00$ & $1.492 .876,06$ & $1.489 .030,03$ & $1.485 .193,91$ & $1.481 .367,67$ & $1.477 .551,29$ & $1.473 .744,74$ & $1.469 .947,99$ & $1.466 .161,03$ & $1.462 .383,83$ & $1.458 .616,35$ & $1.454 .858,58$ & $1.451 .110,50$ \\
\hline Valor Presente Acumulado & $-1.385 .892,00$ & $106.984,06$ & $1.596 .014,09$ & $3.081 .208,00$ & $4.562 .575,67$ & $6.040 .126,96$ & $7.513 .871,70$ & $8.983 .819,69$ & $10.449 .980,72$ & $11.912 .364,55$ & $13.370 .980,90$ & $14.825 .839,49$ & $16.276 .949,98$ \\
\hline Mês & 0 & 1 & 2 & 3 & 4 & 5 & 6 & 7 & 8 & 9 & 10 & 11 & 12 \\
\hline Juros SELIC (mensal) & 1,0025829100 & & & & & & & & & & & & \\
\hline Payback: & Mês 1 & & & & & & & & & & & & \\
\hline
\end{tabular}


O empreendimento recupera o investimento quando $\mathrm{O}$ valor presente acumulado, apresentado na tabela do cálculo mensal para o VPL no primeiro ano, passa a ser positivo. No caso, o retorno do investimento ocorre logo no primeiro mês. Este indicador é interpretado como a medida do grau de risco do projeto, quanto maior o payback, mais incerta será a recuperação do capital investido. Portanto, segundo os parâmetros analisados, trata-se de um projeto de baixo risco.

O cálculo anual do VPL para o período de 10 anos está na tabela 31. 
Tabela 31 - Cálculo do VPL por ano

\begin{tabular}{|c|c|c|c|c|c|c|c|c|c|c|c|c|}
\hline ANO & Ano 0 & Ano 1 & Ano 2 & Ano 3 & Ano 4 & Ano 5 & Ano 6 & Ano 7 & Ano 8 & Ano 9 & Ano 10 & TOTAL \\
\hline Receita & & 23.324.138,82 & $23.324 .138,82$ & 23.324.138,82 & $23.324 .138,82$ & $23.324 .138,82$ & $23.324 .138,82$ & 23.324.138,82 & $23.324 .138,82$ & 23.324.138,82 & 23.324.138,82 & $233.241 .388,21$ \\
\hline $\begin{array}{l}\text { Custos } \\
\text { Variáveis }\end{array}$ & & $5.212 .426,99$ & $5.212 .426,99$ & $5.212 .426,99$ & $5.212 .426,99$ & $5.212 .426,99$ & $5.212 .426,99$ & $5.212 .426,99$ & $5.212 .426,99$ & $5.212 .426,99$ & $5.212 .426,99$ & $52.124 .269,87$ \\
\hline Matéria-Prima & & $4.902 .191,69$ & $4.902 .191,69$ & $4.902 .191,69$ & $4.902 .191,69$ & $4.902 .191,69$ & $4.902 .191,69$ & $4.902 .191,69$ & $4.902 .191,69$ & $4.902 .191,69$ & $4.902 .191,69$ & $49.021 .916,87$ \\
\hline $\begin{array}{l}\text { Material de } \\
\text { consumo }\end{array}$ & & $231.516,00$ & $231.516,00$ & $231.516,00$ & $231.516,00$ & $231.516,00$ & $231.516,00$ & $231.516,00$ & $231.516,00$ & $231.516,00$ & $231.516,00$ & $2.315 .160,00$ \\
\hline Mão-de-obra & & $73.545,96$ & $73.545,96$ & $73.545,96$ & $73.545,96$ & $73.545,96$ & $73.545,96$ & $73.545,96$ & $73.545,96$ & $73.545,96$ & $73.545,96$ & $735.459,60$ \\
\hline $\begin{array}{l}\text { Energia Elétrica } \\
\text { Maraem de }\end{array}$ & & $5.173,34$ & $5.173,34$ & $5.173,34$ & $5.173,34$ & $5.173,34$ & $5.173,34$ & $5.173,34$ & $5.173,34$ & $5.173,34$ & $5.173,34$ & $51.733,40$ \\
\hline $\begin{array}{l}\text { Margem de } \\
\text { Contribuição }\end{array}$ & & 18.111.711,83 & $18.111 .711,83$ & $18.111 .711,83$ & $18.111 .711,83$ & $18.111 .711,83$ & $18.111 .711,83$ & $18.111 .711,83$ & 18.111.711,83 & $18.111 .711,83$ & 18.111.711,83 & 181.117.118,34 \\
\hline Custos Fixos & & $150.927,52$ & $150.927,52$ & $150.927,52$ & $150.927,52$ & $150.927,52$ & $150.927,52$ & $150.927,52$ & $150.927,52$ & $150.927,52$ & $150.927,52$ & $1.509 .275,20$ \\
\hline $\begin{array}{l}\text { Mão-de-obra } \\
\text { Indireta }\end{array}$ & & $73.545,96$ & $73.545,96$ & $73.545,96$ & $73.545,96$ & $73.545,96$ & $73.545,96$ & $73.545,96$ & $73.545,96$ & $73.545,96$ & $73.545,96$ & $735.459,60$ \\
\hline Outros Custos & & $77.381,56$ & $77.381,56$ & $77.381,56$ & $77.381,56$ & $77.381,56$ & $77.381,56$ & $77.381,56$ & $77.381,56$ & $77.381,56$ & $77.381,56$ & $773.815,60$ \\
\hline Energia Elétrica & & $6.000,00$ & $6.000,00$ & $6.000,00$ & $6.000,00$ & $6.000,00$ & $6.000,00$ & $6.000,00$ & $6.000,00$ & $6.000,00$ & $6.000,00$ & $60.000,00$ \\
\hline Água & & $12.000,00$ & $12.000,00$ & $12.000,00$ & $12.000,00$ & $12.000,00$ & $12.000,00$ & $12.000,00$ & $12.000,00$ & $12.000,00$ & $12.000,00$ & $120.000,00$ \\
\hline $\begin{array}{l}\text { Material } \\
\text { Escritório das } \\
\text { Ativ. Apoio }\end{array}$ & & $7.200,00$ & $7.200,00$ & $7.200,00$ & $7.200,00$ & $7.200,00$ & $7.200,00$ & $7.200,00$ & $7.200,00$ & $7.200,00$ & $7.200,00$ & $72.000,00$ \\
\hline $\begin{array}{l}\text { Custos de CQ } \\
\text { Custos de } \\
\text { Manut. Infra }\end{array}$ & & $24.000,00$ & $24.000,00$ & $24.000,00$ & $24.000,00$ & $24.000,00$ & $24.000,00$ & $24.000,00$ & $24.000,00$ & $24.000,00$ & $24.000,00$ & $240.000,00$ \\
\hline $\begin{array}{l}\text { Estrutura } \\
\text { Custos de } \\
\text { Manut. }\end{array}$ & & $6.697,60$ & $6.697,60$ & $6.697,60$ & $6.697,60$ & $6.697,60$ & $6.697,60$ & $6.697,60$ & $6.697,60$ & $6.697,60$ & $6.697,60$ & $66.976,00$ \\
\hline Equipamentos & & $21.483,96$ & $21.483,96$ & $21.483,96$ & $21.483,96$ & $21.483,96$ & $21.483,96$ & $21.483,96$ & $21.483,96$ & $21.483,96$ & $21.483,96$ & $214.839,60$ \\
\hline Infra Estrutura & $-669.760,00$ & 0,00 & 0,00 & 0,00 & 0,00 & 0,00 & 0,00 & 0,00 & 0,00 & 0,00 & 0,00 & $-669.760,00$ \\
\hline Equipamentos & $-716.132,00$ & 0,00 & 0,00 & 0,00 & 0,00 & 0,00 & 0,00 & 0,00 & 0,00 & 0,00 & 0,00 & $-716.132,00$ \\
\hline $\begin{array}{l}\text { Resultado do } \\
\text { Respamento }\end{array}$ & & 0,00 & 0,00 & 0,00 & 0,00 & 0,00 & 0,00 & 0,00 & 0,00 & 0,00 & 229,32 & 229,32 \\
\hline Período & $-1.385 .892,00$ & $17.960 .784,31$ & $17.960 .784,31$ & $17.960 .784,31$ & $17.960 .784,31$ & $17.960 .784,31$ & $17.960 .784,31$ & $17.960 .784,31$ & $17.960 .784,31$ & $17.960 .784,31$ & $17.960 .784,31$ & $178.221 .951,14$ \\
\hline Valor Presente & $-1.385 .892,00$ & $17.662 .841,98$ & $17.124 .465,12$ & $16.602 .498,40$ & $16.096 .441,62$ & $15.605 .809,83$ & $15.130 .132,88$ & $14.668 .954,92$ & $14.221 .834,01$ & $13.788 .341,70$ & $13.368 .062,55$ & $152.883 .491,01$ \\
\hline
\end{tabular}


Com base na tabela é possível constatar que a margem de contribuição é positiva, em todos os períodos analisados, o que retrata que a receita é superior aos custos variáveis. Depois de descontado os custos fixos da margem de contribuição o resultado se mantém positivo em todos os períodos.

Nota-se que o VPL é negativo apenas no início do período analisado, ano zero, quando são feitos os investimentos em infra-estrutura e equipamentos, a partir do início da produção, o VPL é positivo, sendo a soma total dos 10 anos de $\mathrm{R} \$ 152.883 .491,01$.

Este resultado demonstra que a economia gerada pela farmácia semiindustrial é maior que os recursos investidos em sua implantação e, portanto, o projeto é considerado viável, evidenciando os benefícios financeiros obtidos com a produção de medicamentos em farmácia semi-industrial hospitalar.

Diferente de projetos desenvolvidos pelo setor privado, cujo objetivo principal é gerar retorno ao capital investido, os projetos públicos não visam o lucro e sim um saldo de benefícios sobre custos para a sociedade (CLEMENTE, 2002).

Assim, a produção de medicamentos pelo próprio hospital resulta em melhor aproveitamento dos recursos públicos, sendo que os valores economizados podem ser aplicados no setor saúde ou mesmo em outros setores retornando à sociedade na forma de benefícios.

O valor do VPL nesse projeto é bem expressivo, visto que os medicamentos produzidos pelo hospital são para consumo interno, não estão embutidos os gastos com pesquisa e desenvolvimento, embalagem secundária, propaganda, distribuição, bonificações e comissões a vendedores e o lucro da indústria farmacêutica, que representam cerca de $40 \%$ do valor do medicamento.

Segundo a revista Fortune (2008), doze grandes companhias farmacêuticas estão entre as quinhentas empresas mais lucrativas do mundo. O balanço divulgado por onze empresas para o ano de 2007 mostra que a arrecadação total foi de 376 bilhões, sendo o lucro líquido total de 70,51 bilhões de dólares, ou $18,8 \%$. O investimento total em pesquisa e desenvolvimento foi de aproximadamente 55,28 bilhões de dólares, equivalente a $14,72 \%$ da arrecadação total.

No entanto, ao analisarmos os gastos na divulgação dos produtos vemos que os valores são pelo menos iguais aos aplicados na pesquisa e desenvolvimento. No mesmo período, os valores despendidos com toda a parte de divulgação (marketing, viagens, bonificações, comissões etc.) somaram aproximadamente 116,22 bilhões 
de dólares, contudo deve-se enfatizar que esse valor engloba todos os recursos gastos com a divulgação dos produtos e a folha de pagamento dos funcionários. Esta é uma estratégia encontrada pelas empresas para encobrir parcialmente os gastos voltados para o marketing dos seus produtos, entretanto estima-se que pelo menos metade desse valor seja gasto somente com a divulgação dos medicamentos, ou seja, valor igual ou superior ao gasto em pesquisa e desenvolvimento de novos produtos. Assim, podemos inferir que os gastos com pesquisa e desenvolvimento não são os maiores responsáveis pelos altos preços dos medicamentos como alegam as grandes empresas farmacêuticas e que é inegável a substancial contribuição dos gastos com toda a divulgação no preço final de cada produto (FORTUNE, 2008).

\subsubsection{Análise de sensibilidade}

Para avaliar até que ponto alterações nos valores de matéria-prima resultam em VPL positivo, foram calculados três diferentes valores médios de princípios ativos e considerou-se $30 \%, 50 \%$ e $100 \%$ das formulações injetáveis e sólidas sendo produzidas com esses princípios ativos. O apêndice D contém os valores de todos os princípios ativos e o cálculo das médias.

Tabela 32 - Variações do valor médio de princípio ativo e cálculo de Valor Presente Líquido

\begin{tabular}{cccc}
\hline & \multicolumn{3}{c}{ VPL } \\
\hline Valor Médio/Kg (R\$) & $\mathbf{3 0 \%}$ & $\mathbf{5 0 \%}$ & $\mathbf{1 0 0 \%}$ \\
$14.819,33$ & $102.637 .519,79$ & $43.942 .965,45$ & $-102.793 .420,41$ \\
$49.393,13$ & $-105.782 .617,54$ & $-303.423 .930,11$ & $-797.527 .211,53$ \\
$131.000,00$ & $-597.730 .712,72$ & $-1.123 .337 .422,08$ & $-2.437 .354 .195,46$ \\
\hline
\end{tabular}

As variações demonstram que a produção de medicamentos só é viável quando se considera $30 \%$ e $50 \%$ dos medicamentos sólidos e injetáveis contendo o valor médio de princípio ativo de $\mathrm{R} \$ 14.819,33$. Nos demais casos o VPL é negativo, ou seja, o projeto não é viável.

Normalmente, os princípios ativos de maior valor por quilo são empregados em baixas concentrações nas formulações farmacêuticas (microgramas), e no caso padronizado, foi considerado 250mg. Assim, mesmo tendo um alto valor por quilo, o 
custo por unidade não seria tão elevado e a produção não se torna inviável. Mas, neste caso, deve ser calculada a viabilidade para cada princípio ativo individualmente, só assim, é possível afirmar com certeza se os custos de produção são inferiores ao seu valor de mercado.

Os passos descritos servem de referência para a aplicação de estudos de viabilidade econômica da produção de medicamentos em hospitais de porte extra ou mesmo de grande porte, mas a variedade e quantidade de especialidades farmacêuticas avaliadas e o valor de mercado devem refletir a realidade específica de cada instituição. Todos os custos considerados no estudo de viabilidade econômica devem ser atualizados, pois datam de janeiro de 2009.

Como limitações para o desenvolvimento deste trabalho podem ser destacadas:

a) inexistência de uma formulação padrão de excipiente na literatura, uma vez que cada princípio ativo deve ser avaliado individualmente quanto à variedade e quantidade de adjuvantes e possíveis incompatibilidades, neste caso, a opinião de especialistas é de grande valia, mas não exclui a necessidade de testes entre princípio ativo e adjuvante;

b) ainda referente à formulação padrão é necessário realizar testes in vitro (dissolução) para avaliação da liberação do fármaco a partir da forma farmacêutica e testes de biodisponibilidade in vivo para comprovar a eficácia do medicamento. Grande parte dos hospitais de porte especial está associada a universidades, portanto, os testes de dissolução podem ser realizados em parceria com estas instituições. Os testes de biodisponibilidade podem ser conduzidos na própria estrutura do hospital;

c) a dificuldade de se obter os valores de infra-estrutura, equipamentos e matériaprima com fornecedores e/ou distribuidores, pois, como não há possibilidade de compra, poucas se interessam em enviar as cotações e especificações. No caso da cotação realizada pelos hospitais, esta barreira é superada, uma vez que pode ocorrer a compra;

d) não exatidão dos custos relativos a consumo de energia elétrica, água, custos de manutenção do controle de qualidade e outros. Esses dados podem ser baseados no consumo e tarifas usuais do hospital, permitindo a obtenção de valores mais reais. 


\subsection{Adequação de dose para uso pediátrico}

Tabela 33 - Tipos de adequação de dose para uso pediátrico

\begin{tabular}{|c|c|c|c|c|}
\hline \multirow[b]{2}{*}{ Paciente } & \multicolumn{3}{|c|}{ Especialidades farmacêuticas } & \multirow[b]{2}{*}{ Tipo de adequações (\%) } \\
\hline & $\begin{array}{l}\mathrm{n}^{\circ} \text { de dias } \\
\text { de } \\
\text { internação }\end{array}$ & $\begin{array}{l}n^{\circ} \text { total de } \\
\text { especialidades } \\
\text { diferentes }\end{array}$ & $\begin{array}{c}\mathrm{n}^{\circ} \text { e \% de } \\
\text { adequações de } \\
\text { forma elou } \\
\text { dosagem }\end{array}$ & \\
\hline 1 & 7 & 23 & $13(56,50 \%)$ & $\begin{array}{c}\text { Diluição }(69,2 \%) \\
\text { Forma farmacêutica } \\
\text { inadequada }(15,4 \%) \\
\text { Quantidade superior à } \\
\text { utilizada }(15,4 \%)\end{array}$ \\
\hline 2 & 10 & 17 & $13(76,50 \%)$ & $\begin{array}{c}\text { Diluição }(61,5 \%) \\
\text { Forma farmacêutica } \\
\text { inadequada }(0 \%) \\
\text { Quantidade superior à } \\
\text { utilizada }(38,5 \%)\end{array}$ \\
\hline 3 & 30 & 33 & $24(72,70 \%)$ & $\begin{array}{c}\text { Diluição }(50 \%) \\
\text { Forma farmacêutica } \\
\text { inadequada }(8,3 \%) \\
\text { Quantidade superior à } \\
\text { utilizada }(41,7 \%)\end{array}$ \\
\hline 4 & 20 & 28 & $24(85,70 \%)$ & $\begin{array}{c}\text { Diluição }(41,7 \%) \\
\text { Forma farmacêutica } \\
\text { inadequada }(12,5 \%) \\
\text { Quantidade superior à } \\
\text { utilizada }(45,8 \%)\end{array}$ \\
\hline 5 & 17 & 24 & $16(66,70 \%)$ & $\begin{array}{c}\text { Diluição }(37,5 \%) \\
\text { Forma farmacêutica } \\
\text { inadequada }(0 \%) \\
\text { Quantidade superior à } \\
\text { utilizada }(62,5 \%)\end{array}$ \\
\hline Média & 16,8 & 25 & 18 (72\%) & \\
\hline
\end{tabular}

De maneira geral dos medicamentos são padronizados e produzidos para serem utilizados em indivíduos adultos. Porém quando estes são utilizados em pacientes pediátricos quase sempre é necessária a adequação de dose, para atender as necessidades específicas de um usuário. Em nosso estudo a média de adequação de doses para os pacientes do CTI pediátrico, foi de $72 \%$. Valores que são superiores aos relatados por Nunn, 2003, que analisou os resultados de estudos sobre o uso de medicamentos off label ou não licenciados na Grã-Bretanha e encontrou sua aplicação em $11 \%$ dos medicamentos prescritos para crianças em 
ambulatórios e consultórios, $25 \%$ em enfermarias de hospital, $40 \%$ em unidades de terapia intensiva e $80 \%$ em neonatologia.

Este mesmo autor relata que fármacos disponíveis em formas pediátricas destinam-se a problemas comuns, como infecções, mas são raros ou inexistentes os destinados a patologias menos comuns como hipertensão (NUNN,2003).

A adequação de doses realizadas na própria enfermaria pode levar a doses inadequadas. Erros de dosagem são principal fator de erros de medicação em crianças (WONG et al., 2004).

O levantamento das prescrições, apesar de se restringir a análise do prontuário de cinco pacientes apenas, mostra que a freqüência de adequação de dose ou forma farmacêutica para pacientes pediátricos foi alta, e realizada em condições impróprias, já que acontece nas enfermarias e não na farmácia do hospital.

O ajuste da dose de comprimidos, injetáveis e cápsulas requer manipulação específica que não pode ser executada em outro local a não ser no laboratório de manipulação e por pessoa treinada (GOMES; GOMES, 2003).

Para medicamentos que são consumidos em grandes quantidades em concentrações e/ou formas farmacêuticas não disponíveis no mercado, a produção é possível de ser realizada pela farmácia semi-industrial. Para os itens cuja dose é geralmente prescrita em relação ao peso corporal do paciente não é factível padronizar a produção. Para estes deve ser planejada a implantação de uma área para a manipulação de medicamentos, fracionamento e adequação de dosagens, a chamada Farmacotécnica Hospitalar. Esta pode estar ligada à farmácia semiindustrial ou ser independente.

Este setor é de fundamental importância em hospitais de porte especial, principalmente para atender às necessidades de pacientes neonatais e pediátricos,

Por não produzir e sim manipular e realizar a adequação de doses, esta área deve seguir os critérios da RDC $n^{\circ} 67$, de 08 de outubro de 2007 que aprova o Regulamento Técnico sobre as Boas Práticas de Manipulação de Medicamentos em Farmácias e seus anexos.

A área destinada à Farmacotécnica deve contemplar um laboratório para formas farmacêuticas não estéreis e um laboratório para formas farmacêuticas estéreis, este último deve seguir os requisitos de área limpa. Não pode ser o mesmo que prepara nutrições parenterais, quimioterápicos. 
A legislação brasileira não normatiza a dimensão da área física destinada ao setor de Farmacotécnica Hospitalar. A Sociedad Española de Farmácia Hospitalaria, 2003, recomenda que as dimensões sejam proporcionais ao número de leitos, $20 \mathrm{~m}^{2}$ para hospitais de 250 leitos; $30 \mathrm{~m}^{2}$ para hospitais de 600 leitos e $45 \mathrm{~m}^{2}$ para hospitais de 1.000 leitos. Deve ter pelo menos um farmacêutico e um auxiliar técnico e contar com os equipamentos necessários.

A grande maioria dos hospitais brasileiros não possui área dedicada ao preparo de misturas intravenosas e sua manipulação ocorre nos postos de enfermagem, em condições inadequadas. O preparo na farmácia eleva a segurança dos medicamentos administrados ao paciente e disponibiliza a equipe de enfermagem para dedicar-se à assistência ao paciente (FRANÇA, 2008).

A incidência de erros de medicação associados a dano graves em pacientes pediátricos é três vezes superior àquela observada em adultos, sendo 1 erro a cada 6,4 prescrições (AMERICAN ACADEMY OF PEDIATRICS, 2003).

Contribuem para essa elevada incidência a falta de informações sobre posologias pediátricas e indicações; fatores como a necessidade de individualização dos cálculos de dose por peso, idade, superfície corpórea e condições clínicas; prescrição por médicos residentes; a necessidade de utilização de preparações extemporâneas; a falta de apresentações de medicamentos em concentrações adequadas para o fracionamento de doses pediátricas, incluindo injetáveis (GHALEB et al., 2006; ROWE; KOREN; KOREN, 1998). 
Conclusão 


\section{CONCLUSÃO}

Este trabalho representa um passo inicial, porém necessário no sentido de estimular estudos nesta área, cujos resultados podem ser aplicados em prazos curtos e com benefícios imediatos. Mostrou também que soma substancial de trabalho ainda é necessário para seu aprimoramento, dada a complexidade do assunto, pois é necessária a interação de diversas áreas do conhecimento, tais como legislação em vigor, meios e processos de produção, equipamentos mais adequados e finalidade desejada, técnicas econômicas e contábeis.

De acordo com os resultados a instalação de farmácia semi-industrial em hospital de porte especial e a produção de medicamentos, representam substancial economia de recursos para a instituição. 
Referências 


\section{REFERÊNCIAS BIBLIOGRÁFICAS*}

Agência Nacional de Energia Elétrica. Consumidores, Consumo, Receita, Tarifa Média - por classe consumo. Disponível em: <http://www.aneel.gov.br/area.cfm?idArea=493\&idPerfil=4>. Acesso 12 jan. 2009.

ALDERBORN, G. Comprimidos e compressão. In: AULTON, M. E. Delineamento de Formas Farmacêuticas. $2^{\mathrm{a}}$ ed. Tradução George G. Ortega, et al. Porto Alegre: Artmed, 2005, p. 402-443.

AMERICAN ACADEMY OF PEDIATRICS. Committee on Drugs and Committee on Hospital Care. Policy Statement: Prevention of medication errors in the pediatric inpatient setting, 2003. Pediatrics:Elk Grove Village, v. 112, n. 2, p. 431-436, 2003.

ANSEL, H. C; POPOVICH, N. G.; ALLEN Jr, L. V. Farmacotécnica: formas farmacêuticas e sistemas de liberação de fármacos. Tradução T Oppido. $6^{a}$ ed.São Paulo:Premier, 2000, 568 p.

ARREDONDO, A.; DAMIÁN, T. Costos económicos en la producción de servicios de salud: del costo de los insumos al costo de manejo de caso. Salud Pública de México, Morelos, v. 39, n. 2, p. 117-124, 1997.

ASSAF NETO, A. Finanças corporativas e valor. $3^{a}$ ed. São Paulo: Atlas, 2007, $609 \mathrm{p}$.

ATKINSON, A. A.; et al. Contabilidade Gerencial. Tradução André O. M. Du Chenoy Castro. $1^{\text {a }}$ ed. São Paulo: Atlas, 2000, 812p.

BANDELIN, F. J. Compressed Tablets by Wet Granulation. In: LIEBERMAN, H. A.; LACHMAN, L.; SCHWARTZ, J.B. Pharmaceutical dosage forms - tablets. $2^{\mathrm{a}}$ ed New York:Dekker, 1989, p. 131-193.

BARBIERI, J. C.; MACHLINE, C. Logística Hospitalar: teoria e prática. $1^{\text {a }}$ ed. São Paulo:Saraiva, 2006, 325p.

Banco Central do Brasil. Taxa Selic - Descrição. 2008. Disponível em: http://www.bcb.gov.br/?SELICDESCRICAO. Acesso em: 20/02/2009.

BILLANY, M. Soluções. In: AULTON, M. E. Delineamento de Formas Farmacêuticas. $2^{\mathrm{a}}$ ed. Tradução George G. Ortega, et al. Porto Alegre:Artmed, 2005, p. 318-329. 
BOMBARDIER, C., EISENBERG, J. M., Looking into the crystal ball: can we estimate the lifetime cost of rheumatoid arthritis? Journal of Rheumatology, v. 122, n. 2, p. 201-204, 1985.

BOOTMAN, J. L., TOWNSEND, R. J., MCGHAN, W. F., Principles of pharmacoeconomics. $2^{\mathrm{a}}$ ed., Cincinnati: Harvey Whitney, 1996.

BRASIL. Agência Nacional de Vigilância Sanitária. Lista de Medicamentos Referência, 2008. Atualizada em 12/08/2008. Disponível em: <http://www.anvisa.gov.br/medicamentos/referencia/lista.pdf>

BRASIL. Agência Nacional de Vigilância Sanitária. Resolução da Diretoria Colegiada, RDC $n^{\circ}$ 210, de 04 de agosto de 2003. Institui o Regulamento Técnico das Boas Práticas para a Fabricação de Medicamentos. Diário Oficial da União; Poder Executivo, Brasília, DF, de 14 de agosto de 2003.

BRASIL. Agência Nacional de Vigilância Sanitária. Resolução da Diretoria Colegiada, RDC n 67, de 08 de outubro de 2007. Dispõe sobre Boas Práticas de Manipulação Magistrais e Oficinais para Uso Humano em farmácias. Diário Oficial da União; Poder Executivo, Brasília, DF, de 09 de outubro de 2007b.

BRASIL. Ministério da Saúde. Agência Nacional de Vigilância Sanitária. Resolução $n^{\circ} 391$ de agosto de 1999. Diário Oficial de Brasília, Poder Executivo, Brasília, DF, 10 de agosto de 1999. Seção 1 pp. 62-69.

BRASIL. Ministério da Saúde. Coordenação de Controle de Infecção Hospitalar (Editores). Guia Básico para a Farmácia Hospitalar. Brasília, 1994. 174 p.

BRASIL. Ministério da Saúde. Secretaria de Vigilância Sanitária. Portaria $n^{\circ} 344$, de 12 de maio de 1998 (Versão Republicada 01-02-1999). Aprova o Regulamento Técnico sobre substâncias e medicamentos sujeitos a controle especial. Diário Oficial da União; Poder Executivo, Brasília, DF, de 01 de fevereiro de 1999.

BRASIL. Ministério da Saúde. Secretaria Executiva. Área de Economia da Saúde e Desenvolvimento. Núcleo Nacional de Economia da Saúde. Evolução dos Gastos do Ministério da Saúde com Medicamentos. VIEIRA, F. S.; MENDES, A. C. R. Brasília: Editora do Ministério da Saúde, 2007a, 33p.

BRASIL. Ministério da Saúde. Secretaria Executiva. Área de Economia da Saúde e Desenvolvimento. Avaliação Econômica em Saúde: desafios para gestão no Sistema Único de Saúde. Brasília:Editora do Ministério da Saúde, 2008, 104p.

BRIGHAM, E. F.; GAPENSKI, L. C.; EHRAHRDT, M. C. Administração Financeira: teoria e prática. Tradução Alexandre L. G. Alcântara, José N. A. Salazar. 9a ed. São Paulo: Atlas, 2001, 1113 p. 
BRIGSS A. H.; GRAY, A. M. Handling uncertainty in economic evaluations of healthcare interventions. British Medical Journal, London, v. 319, p 635-638, 1999.

BRIMAN, A. Research method and organization studies. London:Unwin Hyman, 1989.

BRINSMEAD, R.; HILL, S. Use of Pharmacoeconomics in prescribing research. Part 4: cost-utility analysis a useful tool? Journal of Clinical Pharmacy And Therapeutics, v. 28, p. 339-346, 2003.

BRUSSELS, RW. Health spending rising faster than GDP in most rich countries. BMJ, British Medical Journal, London , 2006.

BULAS.MED.BR. Bulas de medicamentos na internet disponível em $<$ www.bulas.med.br>. Acesso em: set 2008.

BUSKE, L. Health care spending rises $4,6 \%$ in 2003. Canadian Medical Association Journal; v. 170, n.3 :325, 2004.

BUSKE, L. Drug costs surpass spending on physicians. Canadian Medical Association Journal; v. 162, n. $3: 405,2000$.

CANADIAN MEDICAL ASSOCIATION JOURNAL. Drug spending hits \$24.8 billion. Canadian Medical Association Journal, 2006.

CARLOS, I. C. C.; SIQUEIRA, R. L. C. L.; PESSOA, M. T. F. C.; ALMEIDA, R. F. C. Farmacoeconomia: guia breve, Ceará: Secretaria da Saúde do Estado do Ceará, 2001, 56 p.

CARREIRA-HUESO, F. J. Aplicación de los estudios farmacoeconômicos em el hospital. Medicina Clínica, v. 111, n. 9, p. 347-353, 1998.

CASTILHO, J. A. S. Farmacoeconomía y evaluación econômica de medicamentos. Introducción. In: Castilho, J. A. S., Llach, X. B., Forns, J. r., eds. Farmacoeconomía: evaluación econômica de medicamentos, Madrid: editores medicos, cap 1, p 19-30, 1995.

CLEMENTE, A.; FERNANDES, E. Planejamento e Projetos. In: CLEMENTE, A. (organizador). Projetos Empresariais e Públicos. 2a ed, São Paulo:Altas, 2002, $p$ 21-27.

CODINA, C.; RIBEIRO, J.; ROCA, M. Dispensacion y distribuicion de medicamentos. In: DOMINGUES-GIL, H.; FALGAS, J. B. Farmacia Hospitalaria. Sociedad Española de Farmacéuticos Hospitalarios, Madrid:EMISA, 1992, p. 370-395. 
CONSELHO REGIONAL DE FARMÁCIA DO ESTADO DE SÃO PAULO. Piso profissional por área de atuação. Disponível em <http://www.crfsp.org.br/joomla/index.php?option=com_content\&view=article\&id=315 \&ltemid=96>. Acesso em: 23 de jan. 2009.

DEL NERO, C. R.; O que é Economia da Saúde. In: PIOLA, S. F.; VIANNA, S. M. (Organizadores); Economia da Saúde: conceito e contribuição para a gestão da saúde. $3^{a}$ ed. Brasília: IPEA, 2002, cap. 1, p. 5-21.

DEPARTMENT OF HEALTH AND AGED CARE, Guidelines for the pharmaceutical industry on preparation of submissions to the Pharmaceutical Benefits Advisory Committee: including major submissions involving economic analyses, $1995 . \quad$ Disponível em <http://www.health.gov.au/pbs/pubs/pharmpac/gusubpac.htm> Acesso em: 12 fev. 2004.

DETSKY, A. S., NAGLIE, I. G., A clinician's guide to cost-effectiveness analysis. Annals of Internal Medicine, v .113, n. 2, p. 147-154, 1990.

DRUMMOND, M. F. Guidelines for pharmacoeconomics studies: the ways forward. Pharmacoeconomics, v. 6, n. 6, p. 493-497, 1994.

DRUMMOND, M. F. Introducing economic and quality of life measurements into clinical studies. Annals of Medicine, v. 33, n. 5, p. 339-344, 1991.

DRUMMOND, M. F. O'BRIEN, B.; STODDART, G. L; TORRANCE, G. W. Methods for the economic evaluation of health care programmes. $2^{a}$ ed. New York: Oxford University Press, 1997. 181p.

DRUMMOND, M. F.; JEFFERSON, T. O. Guidelines for authors and peer reviewers of economic submissions to the BMJ. British Medical Journal, London, v. 313, p. 275-283, 1996.

EISENBERG, J. M. Clinical economics: a guide to economic analysis of clinical practices. Journal of the American Medical Association, v. 262, n. 20, p. 28792886, 1989.

Farmacopéia Brasileira. 4ª ed. São Paulo:Atheneu, 1988-1996.

FRANÇA, G.G. Formas farmacêuticas estéreis: central de misturas intravenosas. In: STORPIRTIS, S.; et al. Farmácia Clínica e Atenção Farmacêutica. Rio de Janeiro: Guanabara Koogan, 2008, p 182-190. 
FORTUNE. Global 500 industries. Jul. 2008. Disponível em <http://money.cnn.com/magazines/fortune/global500/2008/industries/21/index.html.> acesso em 22 fev. 2009.

GARRISON, T. J. Medication distribution Systems. In: SMITH, M. C.; BROWN, T. Handbook of Institucional Pharmacy Practice. London:Willians \& Wilkins, 1979, C. 4.

GHALEB, M. A. et al. Systematic review of medications errors in pediatric patients. Annals of Pharmacotherapy, Cincinnati, v. 40, n. 10, p. 1766-1776, 2006.

GOLD, M. R.; SIEGEL, J. E.; RUSSLE, L. B.; WEINSTEING, M. C. Costeffectiveness in health and medicine. New York: Oxford University Press, 1996.

GOMES, E. J. M.; GOMES, M. J. V. M. Manipulação de medicamentos estéreis e não estéreis em farmácia hospitalar. In: GOMES, M. J. V. M; REIS, A. M. M. (organizadores). Ciências Farmacêuticas: uma abordagem em Farmácia hospitalar. $1^{\mathrm{a}}$ ed. São Paulo:Atheneu, 2003, p. 387-405.

GOODMAN, G.A.; et al - As Bases Farmacológicas da Terapêutica. 11ª . Ed., Rio de Janeiro: Mcgraw Hill, 2007.

GRIFFITHS, D.A.T. Economic evaluation of health services. Rev Epidém et Santé Publ, v. 29, p.85-101, 1981.

GROBLER, M. Economic analysis: is it working? Aust. Prescr., v. 22, p. 50-1, 1999.

HAYCOX, A.; WALLEY, T. Pharmacoeconomics: basic concepts and terminology. Br J Clin Pharmacol, v. 43, p. 343-348, 1997.

HOGAN, J. Revestimento de comprimidos e multiparticulados. Delineamento de Formas Farmacêuticas. $2^{a}$ ed. Tradução George G. Ortega, et al. Porto Alegre:Artmed, 2005, p. 402-443.

HOSPITAL DAS CLÍNICAS DA FACULDADE DE MEDICINA DA UNIVERSIDADE DE SÃO PAULO. Guia Farmacoterapêutico HC. Hospital das Clínicas da Faculdade de Medicina da Universidade de São Paulo. Câmara de Fármacos e Medicamentos da Subcomissão de Avaliação Terapêutica da Comissão de Avaliação Tecnológica em Saúde da Diretoria Clínica e Divisão de Farmácia. Divisão de Farmácia, São Paulo, 2002, 300p.

HOSPITAL DAS CLÍNICAS DA FACULDADE DE MEDICINA DE RIBEIRÃO PRETO DA UNIVERSIDADE DE SÃO PAULO, Indicadores de Produção 2007, Ribeirão Preto, 2008. Disponível em <http://www.hcrp.fmrp.usp.br> Acesso em: 21 nov. 2008. 
JOHANNESSON, M.; LE LORIER, J. How to assess the economics of hypertension control programmes. J. Hum. Hypertens, v. 10 supl. 1, 893-894, 1996.

JOLICOEUR, L. M., JONES-GRIZZLE, A. J., BOYER, J. G., Guidelines for performing a pharmacoeconomic analysis. American Journal of Hospital Pharmacy, v. 49, n. 7, p. 1741-1747, 1992.

LEATHERMAN S, BERWICK D, ILES D et al. The business case for quality: Case studies and an analysis. Health Aff 2003; 22:17-30.

LEW M. A., FORGIA, G. M., SULVETTA, M. B., Mensuring public hospital costs: empirical evidence from Dominican Republic. Social Science and Medicine, v. 43, n. 2, p. 221-234, 1996.

LIMA, C. R.; SILVA, M. D. G.; REIS, V. L. S. Sistemas de distribuição de medicamentos em farmácia hospitalar. In: GOMES, M. J. V. M; REIS, A. M. M. (organizadores). Ciências Farmacêuticas: uma abordagem em farmácia hospitalar. $1^{\mathrm{a}}$ ed. São Paulo: Atheneu, 2001, p. 347-363.

LOPERT, R.; LANG, D. L., HILL, S. R. Use of Pharmacoeconomics in prescribing research. Part 3: cost-effectiveness analysis - a technique for decision making at the margin. Journal of Clinical Pharmacy And Therapeutics, v. 28, p. 243-249, 2003.

LOTTENBERG, C. A saúde brasileira pode dar certo: os caminhos para garantir um atendimento de qualidade, sustentável e acessível para toda a população. São Paulo: Atheneu, 2007, 111 p.

MANKIW, G. N. Introdução à Economia: princípios de micro e macroeconomia. Tradução Maria José Cyhlar Monteiro. $2^{a}$ ed. Rio de Janeiro: Elsevier, 2001. 831 p.

MARIN, M. L. M.; CHAVES, C. E.; ZANINI, A. C.; FAINTUCH, J.; FAINTUCH, D.; CIPRIANO, S. L. Cost of drugs manufactured by the University Hospital: role of the central pharmacy. Revista do Hospital das Clínicas da Faculdade de Medicina, São Paulo, v. 56, n. 2, p. 41-46, 2001.

MARTINS, E. Contabilidade de Custos. $8^{a}$ ed. São Paulo: Atlas, 2006.

MATIAS, A.B. Finanças corporativas de longo prazo. São Paulo: Atlas, 2007.

MÉDICI, A. C. Economia e Financiamento do Setor Saúde no Brasil. São Paulo, Faculdade de Saúde Pública - USP, 1994.

MILLS, A.; DRUMMOND, M. F. Economic evaluation of health programmes: a glossary of terms. World Heath Stat, 38(34), p 432-4, 1985. 
MOREIRA, D. A., Administração da Produção e Operações. São Paulo: Pioneira Thomson Learning, 2001.

MOSSIALOS, E. Citizens' views on health care systems in the 15 member states of the European Union. Health Economics, v. 6, p. 109-116, 1997.

NATIONAL INSTITUTE FOR CLINICAL EXCELLENCE. Guidance for manufacturers and sponsors, 2001. Disponível em $<\mathrm{http}: / / w w w . n i c e . o r g . u k / p d f / t e c h n i c a l g u i d a n c e f o r m a n u f a c t u r e r s t a n d s p o n s r s . p d f>$ Acesso 12 Fev. 2004.

NETO, J. F. M. Farmácia Hospitalar: um enfoque sistêmico. Brasília: Thesaurus, 1990, 123p.

NUNN, A. J. Making medicines that children can take. Arch. Dis. Child., London, v.88, p. 369-371, 2003.

ORGANIZAÇÃO PAN-AMERICANA DA SAÚDE. Bases para El desarrollo y aprovechamiento sanitário de la farmacia hospitalaria. Washington, OPAS, p 1-36, 1987.

ORGANIZACIÓN MUNDIAL DE LA SALUD (OMS). Economía aplicada a la sanidad. Cuadernos de Salud Publica, Genebra: OMS, 1976, 53 p.

ORGANIZACIÓN PANAMERICAMA DE LA SALUD. Bases para el desarollo y aprovechamiento sanitário de la farmacia hospitalaria. Bogatá, 1987, p37.

PASHOS, C. L.; KLEIN, E. G.; WANKE, L. A. ISPOR Lexicon, Princeton: International Society for Pharmacoeconomic and Outcomes Research, 1998.

PECK, G., E.; BALEY, G. J.; MCCURDY, V. E.; BANKER, G. S. Tablet Formulation and Design. In: LIEBERMAN, H. A.; LACHMAN, L.; SCHWARTZ, J.B. Pharmaceutical dosage forms - tablets. $2^{\mathrm{a}}$ ed. Nova York:Dekker, 1989.

PINHO, D. B.; VASCONCELLOS, M. A. S. Manual de Economia. $5^{a}$ ed. São Paulo: Saraiva, 2004.

PINTO-PRADES, J. L.; ORTÚN-RUBIO, V; PUIG-JUNOY, J. El Análisis costeefectividad en sanidad. Atención Primaria, v.27, n 4, março, 2001.

PINTO-PRADES, J. L.; PUIG-JUNOY, J.; ORTÚN-RUBIO, V. Análisis coste-utilidad. Atención Primaria, v.27, n 8, maio 2001. 
PÔRTO, B. S.; et al. Termo de referência para implantação ou reestruturação de farmácias de hospitais universitários. Rio de Janeiro, UFRJ, 1985, 75p.

PRZYBYLSKI, K. G. et al. A pharmacist-initiated program of intravenous to oral antibiotic conversion. Pharmacotherapy, v. 17, n. 2, p. 271-276, 1997.

RICCI, M. C. S. Farmacotécnica Hospitalar: formas farmacêuticas não estéreis. In: STORPIRTIS, S.; et al. Farmácia Clínica e Atenção Farmacêutica. Rio de Janeiro, Guanabara Koogan, 2008, p 171-181.

ROBERTSON, J.; LANG, D., HILL, S. Use of Pharmacoeconomics in prescribing research. Part 1: costs-moving beyond the acquisition price for drugs. Journal of Clinical Pharmacy And Therapeutics, v. 28, p. 73-79, 2003.

ROBINSON, R. Cost-benefit analysis. British Medical Journal, London, v. 307, p 924-926, 1993a.

ROBINSON, R. Economic Evaluation and Health Care: what does it means? British Medical Journal, v. 307, p. 670-673, 1993 b.

ROSA, M. B. A utilização da classificação $A B C$ do gasto com medicamentos como importante ferramenta no gerenciamento da farmácia hospitalar. In: $1^{\circ}$ Seminário Internacional de Farmacêuticos, $4^{\circ}$ Congresso Brasileiro de Produtos Farmacêuticos, Cosméticos e Afins, $9^{\circ}$ Congresso Paulista de Farmacêuticos, São Paulo,1995.

ROSS, S. A.; WESTERFIELD, R. W.; JAFFE, J. F. Administração Financeira. Tradução SANVICENTE, A. Z. São Paulo, Atlas, 2002.

ROWE, C.; KOREN, T.; KOREN, G. Errors by paediatric residents in calculating drug doses. Arch. Dis. Child., London, v 79, p 56-58, jul. 1998.

RUSSEL L. B., GOLD M. R.; SIEGEL J. E.; DANIELS N.; WEINSTEIN, M. C. For the Panel on Cost-Effectiveness in Health and Medicine. The role of Cost-effectiveness analysis in health and medicine. JAMA, v. 276, n. 14, p. 1172-1177, 1996.

SACRISTÁN, J. A.; ORTÚN, V.; ROVIRA, J.; PRIETO, L.; GARCÍA-ALONSO, F. Evaluación económica en medicina. Med Clin, v. 122, n. 10, p. 379-82, 2004.

SACRITÁN DEL CASTILHO, J. A., Farmacoeconomia y evaluación económica de medicamentos: introducción. In Sacristán Del Castilho J. A., Llach, X. B., Farmacoeconomia: evaluación económica de medicamentos, Madrid: Editores Médicos, p 19-29, 1995. 302p.

SANTOS, G. A. A dos. Gestão de farmácia hospitalar. SENAC, São Paulo, 2006. 
SOCIEDAD ESPAÑOLA DE FARMACIA HOSPITALARIA. Recomendaciones para la elaboración de medicamentos en el hospital SEFH: normas de correcta elaboración y control de calidad de las fórmula magistrales y preparados oficinales: adaptación del real decreto 175/2001 de 23 de febrero. Madrid, 2003. Disponível em: <http://www.sefh.es/normas/elaboracion.pdf>. Acesso em: 16 out. 2008.

SOCIEDADE BRASILEIRA DE FARMÁCIA HOSPITALAR - SBRAFH. Padrões Mínimos para Farmácia Hospitalar. SBRAFH, Goiânia, 20 p, 2007.

SOUZA, A.; CLEMENTE, A. Análise econômico financeira de projetos. In: CLEMENTE, A. (organizador) Projetos empresariais e públicos. São Paulo, Atlas, 2002, p 144-180.

THE UNITED STATES PHARMACOPEIA The National Formulary - USP 24. Rockville: The United States Pharmacopeial Convention, 1999.

TOWNSEND, R. J. Post-marketing drug research and development. Drug Intelligence \& Clinical Pharmacy, v. 21, n. 1, p. 134-136, 1987.

UETA, J.; MALUVAYSHI, C. H.; SHUHAMA, I. K.; FREITAS, O.; SANTOS, J. A. F. Plano de gestão para a farmácia de um hospital escola. In, CASSIANI, S. H. B. A segurança dos pacientes na utilização de medicação. $1^{\text {a }}$ ed. São Paulo: Artes Médicas, 2004, cap. 7, p. 63-72.

UGÁ, M. A. D.; Instrumentos de Avaliação Econômica dos Serviços de Saúde: alcances e limitações. In: PIOLA, S. F.; VIANNA, S. M. (Organizadores) Economia da Saúde: conceito e contribuição para a gestão da saúde, $3^{a}$ ed., Brasília: IPEA, 2002, cap. 9, p. 209-226.

VENTURINI, F.; JOHNSON, K. A. Introduction to Pharmacoeconomic Principles and Application in Pharmacy Practice. California Journal of Health-System Pharmacy, jan/fev, 2002.

VILLAR, F. A., Evaluación económica aplicada a los medicamentos: características y metodologia. In SACRISTÁN DEL CASTILHO, J. A., LLACH, X. B., Farmacoeconomia: evaluación económica de medicamentos, Madrid: Editores Médicos, 1995, p. 31-50. 302p.

WALKER, D. Cost and cost-effectiveness guidelines: which one to use? Health policy Plan, v. 16, n. 1, p. 113-121, 2001.

Wells, Jl. - Pharmaceutical preformulation, 1988. Sastry, et al. Recent technological advances in oral drug delivery. A review. Pharm. Sci. Technol. Today, v. 3., p.138145, 2000. 
WONG, I. C. K.; GHALEB, M. A.; FRANKLIN, B. D.; BARBER, N. Incidence and nature of dosing errors in paediatric medications - a systematic review. Drug Saf. 27, 661-670, 2004.

ZANINI, A. C.; FARHAT, F. C. L. G.; RIBEIRO, E.; FOLLADOR, W. Farmacoeconomia: conceitos e aspectos operacionais. Ver. Brás. de Ciências Farmacêuticas, v. 37, n. 3, p. 225-237, set/dez. 2001.

*De acordo com: ASSOCIAÇÃO BRASILEIRA DE NORMAS TÉCNICAS. NBR 6023: informação e documentação: referências: elaboração. Rio de Janeiro, 2002. 
Apêndices 
APÊNDICE A - Distribuição dos medicamentos adquiridos pelo HCFMRP-USP em Curva ABC de demanda valorizada e demanda quantitativa nos anos 2006 e 2007.

Tabela 34 - Distribuição dos medicamentos adquiridos pelo HCFMRP-USP em curva ABC de demanda valorizada, 2006

\begin{tabular}{|c|c|c|c|c|c|}
\hline Nome do Medicamento & Forma Farmacêutica & Concentração & $\begin{array}{c}\text { Quantidade } \\
\text { Recebida (unidades) }\end{array}$ & $\begin{array}{c}\text { Valor } \\
\text { Total (R\$) }\end{array}$ & $\begin{array}{r}\% \text { do } \\
\text { Gasto To }\end{array}$ \\
\hline \multicolumn{6}{|l|}{ Curva A } \\
\hline Interferon alfa peguilado & pó liófilo injetável & ----- & 5.609 & $3.012 .622,00$ & 6,38 \\
\hline Sevelamer & comprimido revestido & $800 \mathrm{mg}$ & 566.640 & $2.611 .077,30$ & 5,53 \\
\hline Infliximab & pó liófilo injetável & $100 \mathrm{mg}$ & 1.284 & $1.420 .801,33$ & 3,01 \\
\hline Olanzapina & comprimido revestido & $10 \mathrm{mg}$ & 124.404 & $1.265 .048,40$ & 2,68 \\
\hline Lopinavir + ritonavir & cápsula gelatinosa mole & $133,3 \mathrm{mg}+33,3 \mathrm{mg}$ & 461.340 & $1.065 .030,85$ & 2,26 \\
\hline Dornase alfa & solução injetável & $2,5 \mathrm{mg}$ & 13.620 & $960.482,40$ & 2,04 \\
\hline Imatinib & comprimido revestido & $100 \mathrm{mg}$ & 24.300 & $923.400,00$ & 1,96 \\
\hline Imunoglobulina humana endovenosa & pó liófilo injetável & $5 \mathrm{~g}$ & 3.467 & $907.168,72$ & 1,92 \\
\hline Imipenema + cilastatina & pó liófilo injetável & $500 \mathrm{mg}$ & 26.990 & $883.135,00$ & 1,87 \\
\hline Ácido zoledrônico & solução injetável & $4 \mathrm{mg}$ & 890 & $807.530,00$ & 1,71 \\
\hline Tenofovir & comprimido revestido & $300 \mathrm{mg}$ & 63.780 & $777.251,89$ & 1,65 \\
\hline Zidovudina + lamivudina & comprimido revestido & $300 \mathrm{mg}+150 \mathrm{mg}$ & 507.480 & $642.977,17$ & 1,36 \\
\hline Efavirenz & comprimido revestido & $600 \mathrm{mg}$ & 178.350 & $635.457,72$ & 1,35 \\
\hline Voriconazol & comprimido revestido & $200 \mathrm{mg}$ & 3.346 & $617.413,76$ & 1,31 \\
\hline Tacrolimus & cápsula gelatinosa dura & $1 \mathrm{mg}$ & 119.400 & $534.050,00$ & 1,13 \\
\hline Paclitaxel semi-sintético & solução injetável & $300 \mathrm{mg}$ & 236 & $516.154,00$ & 1,09 \\
\hline Goserelina & depot & $3,6 \mathrm{mg}$ & 2.111 & $513.661,63$ & 1,09 \\
\hline Meropenem & pó liófilo injetável & $500 \mathrm{mg}$ & 19.130 & $497.270,00$ & 1,05 \\
\hline Interferon beta & pó liófilo injetável & $12000000 \mathrm{UI}$ & 1.296 & $484.122,72$ & 1,03 \\
\hline Docetaxel triidratado & solução injetável & $80 \mathrm{mg}$ & 335 & $483.950,00$ & 1,03 \\
\hline Toxina botulínica & solução injetável & $500 \mathrm{UI}$ & 491 & $440.067,27$ & 0,93 \\
\hline Cloridrato de gencitabina & pó liófilo injetável & $1 \mathrm{~g}$ & 810 & $422.985,90$ & 0,90 \\
\hline Interferon beta SC & pó liófilo injetável & $6.000 .000 \mathrm{UI}$ & 1.212 & $420.024,24$ & 0,89 \\
\hline Interferon beta IM & pó liófilo injetável & $6.000 .000 \mathrm{UI}$ & 664 & $415.448,00$ & 0,88 \\
\hline
\end{tabular}


Continuação

\begin{tabular}{|c|c|c|c|c|c|}
\hline Nome do Medicamento & Forma Farmacêutica & Concentração & $\begin{array}{c}\text { Quantidade } \\
\text { Recebida (unidades) }\end{array}$ & $\begin{array}{c}\text { Valor } \\
\text { Total (R\$) }\end{array}$ & $\begin{array}{c}\% \text { do } \\
\text { Gasto Total }\end{array}$ \\
\hline Nelfinavir & comprimido simples & $250 \mathrm{mg}$ & 375.030 & $390.152,47$ & 0,83 \\
\hline Albumina humana sérica $20 \%$ & solução injetável & $50 \mathrm{~mL}$ & 5.585 & $384.022,00$ & 0,81 \\
\hline Micofenolato mofetil & comprimido revestido & $500 \mathrm{mg}$ & 130.800 & $383.824,00$ & 0,81 \\
\hline Anfotericina B coloidal & pó liófilo injetável & $50 \mathrm{mg}$ & 750 & $379.440,00$ & 0,80 \\
\hline Sirolimus & comprimido revestido & $1 \mathrm{mg}$ & 24.360 & $367.227,00$ & 0,78 \\
\hline Deferoxamina mesilato & pó liófilo injetável & $500 \mathrm{mg}$ & 15.920 & $366.734,34$ & 0,78 \\
\hline Enoxaparina & solução injetável & $40 \mathrm{mg}$ & 20.900 & $364.832,60$ & 0,77 \\
\hline Atazanavir & cápsula gelatinosa dura & $150 \mathrm{mg}$ & 51.600 & $349.547,40$ & 0,74 \\
\hline Propofol p f s $1 \%$ & emulsão injetável & $50 \mathrm{~mL}$ & 3.670 & $346.400,00$ & 0,73 \\
\hline Contraste $p /$ angiografia cerebral & solução injetável & $50 \mathrm{~mL}$ & 11.100 & $345.380,00$ & 0,73 \\
\hline Interferon beta & solução injetável & $9600000 \mathrm{UI}$ & 1.755 & $329.062,50$ & 0,70 \\
\hline Hidroxietilamida solução $6 \%$ & solução injetável GV & $500 \mathrm{~mL}$ & 9.800 & $327.896,00$ & 0,69 \\
\hline Imunoglobulina de coelho anti-timocitos hum. & pó liófilo injetável & $25 \mathrm{mg}$ & 9.820 & $286.675,00$ & 0,61 \\
\hline Solução fisiológica isotônica & solução injetável GV & $100 \mathrm{~mL}$ & 216.940 & $285.791,80$ & 0,61 \\
\hline Tacrolimus & cápsula gelatinosa dura & $5 \mathrm{mg}$ & 12.650 & $282.262,50$ & 0,60 \\
\hline Micofenolato sódico & comprimido revestido & $360 \mathrm{mg}$ & 44.640 & $280.014,72$ & 0,59 \\
\hline Topiramato & comprimido revestido & $100 \mathrm{mg}$ & 101.460 & $274.226,60$ & 0,58 \\
\hline Basiliximab & pó liófilo injetável & $20 \mathrm{mg}$ & 92 & $259.145,46$ & 0,55 \\
\hline Quetiapina & comprimido revestido & $200 \mathrm{mg}$ & 30.716 & $254.119,60$ & 0,54 \\
\hline Atorvastatina & comprimido revestido & $20 \mathrm{mg}$ & 54.960 & $238.860,56$ & 0,51 \\
\hline Cefepime & pó liófilo injetável & $1 \mathrm{~g}$ & 38.850 & $238.170,68$ & 0,50 \\
\hline Enfuvirtida & pó liófilo injetável & $90 \mathrm{mg} / \mathrm{mL}$ & 74 & $234.572,52$ & 0,50 \\
\hline Octreotida & solução injetável & $0,1 \mathrm{mg}$ & 7.030 & $231.615,00$ & 0,49 \\
\hline Aminoácidos $10 \%$ + solução de glicose $50 \%$ & solução injetável GV & ----- & 6.486 & $229.033,92$ & 0,49 \\
\hline Donepezil & comprimido revestido & $10 \mathrm{mg}$ & 20.972 & $223.482,84$ & 0,47 \\
\hline Enoxaparina & solução injetável & $60 \mathrm{mg}$ & 8.792 & $222.572,56$ & 0,47 \\
\hline Cloridrato de epirrubicina & solução injetável GV & $200 \mathrm{mg}$ & 285 & $220.950,00$ & 0,47 \\
\hline Eritropoetina humana recombinante & solução injetável & $4000 \mathrm{UI}$ & 42.026 & $216.433,71$ & 0,46 \\
\hline Atorvastatina & comprimido revestido & $10 \mathrm{mg}$ & 87.610 & $212.906,14$ & 0,45 \\
\hline
\end{tabular}




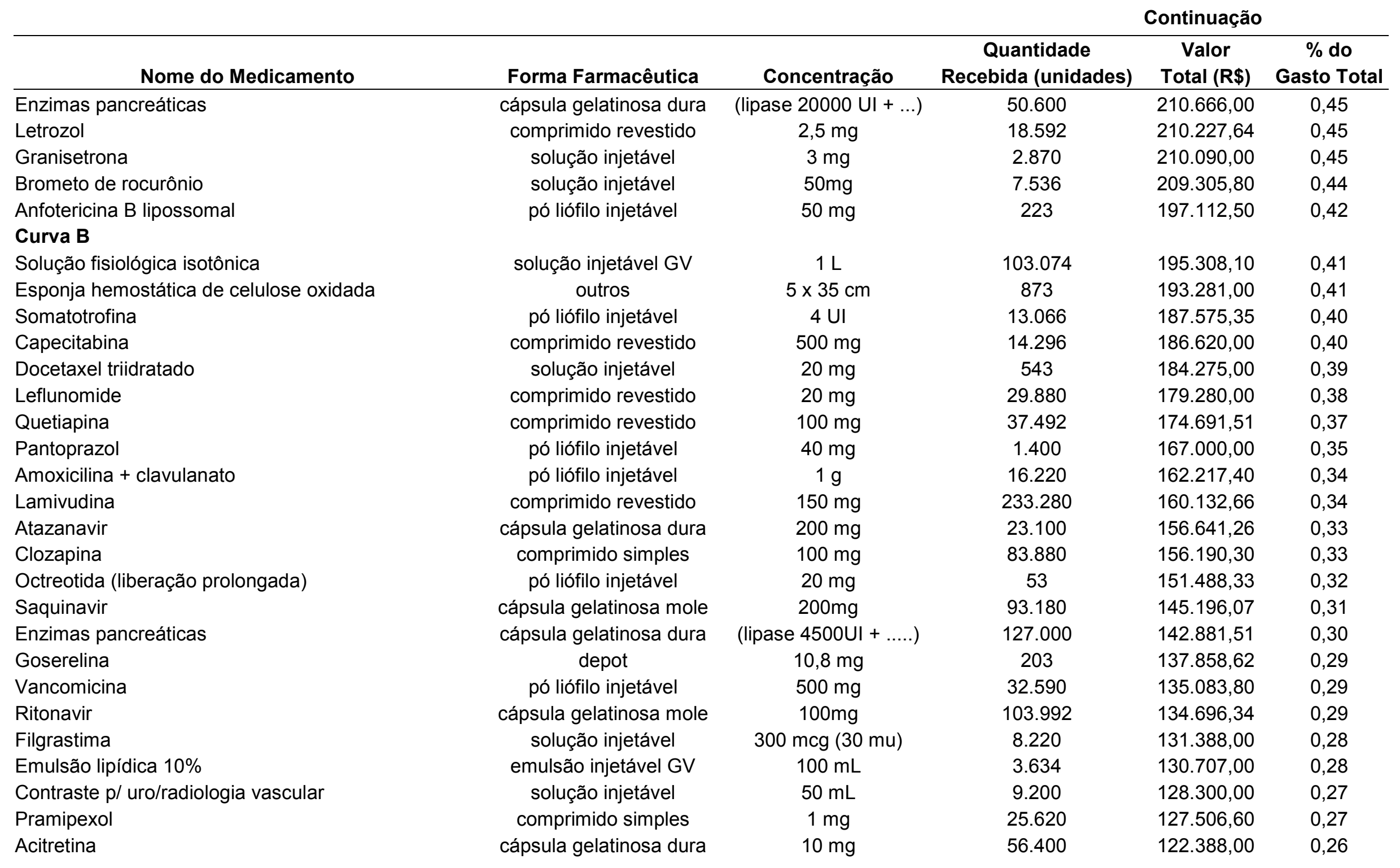




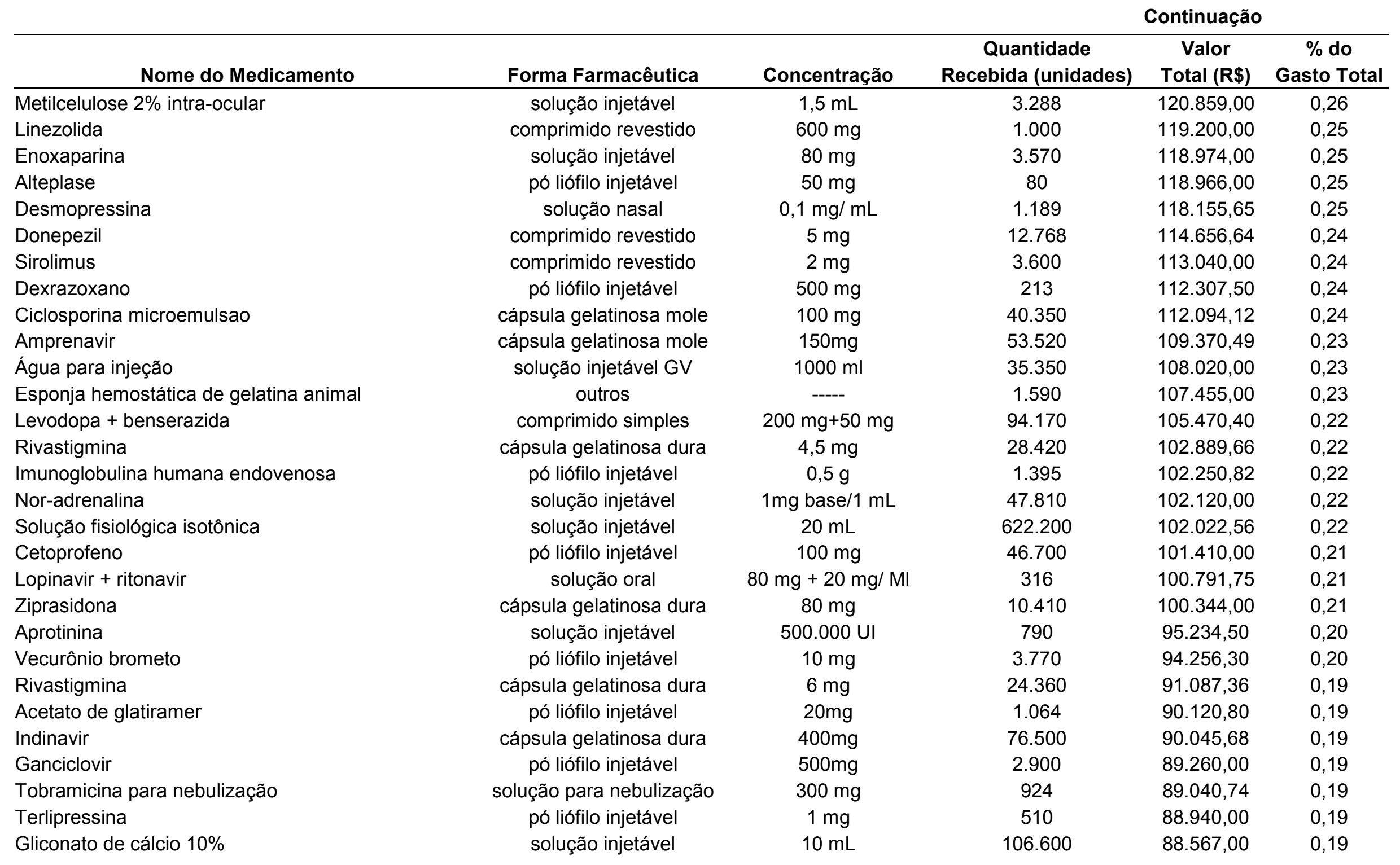




\begin{tabular}{|c|c|c|c|c|c|}
\hline \multirow[b]{2}{*}{ Nome do Medicamento } & \multirow[b]{2}{*}{ Forma Farmacêutica } & \multirow[b]{2}{*}{ Concentração } & \multicolumn{3}{|c|}{ Continuação } \\
\hline & & & $\begin{array}{c}\text { Quantidade } \\
\text { Recebida (unidades) }\end{array}$ & $\begin{array}{c}\text { Valor } \\
\text { Total (R\$) }\end{array}$ & $\begin{array}{c}\% \text { do } \\
\text { Gasto Total }\end{array}$ \\
\hline Midazolam & solução injetável & $50 \mathrm{mg}$ & 44.830 & $87.825,64$ & 0,19 \\
\hline Propofol & emulsão injetável & $200 \mathrm{mg}$ & 27.170 & $84.871,00$ & 0,18 \\
\hline Contraste paramagnetico & solução injetável & $10 \mathrm{~mL}$ & 3.715 & $84.860,50$ & 0,18 \\
\hline Citarabina & solução injetável & $1 \mathrm{~g}$ & 1.010 & $83.499,80$ & 0,18 \\
\hline Cefalotina & pó liófilo injetável & $1 \mathrm{~g}$ & 67.250 & $81.938,30$ & 0,17 \\
\hline Ciclosporina microemulsao & cápsula gelatinosa mole & $50 \mathrm{mg}$ & 48.400 & $80.289,33$ & 0,17 \\
\hline Entacapone & comprimido revestido & $200 \mathrm{mg}$ & 31.080 & $80.186,40$ & 0,17 \\
\hline Rivastigmina & cápsula gelatinosa dura & $3 \mathrm{mg}$ & 25.424 & $79.934,66$ & 0,17 \\
\hline Octreotida liberação prolongada & pó liófilo injetável & $30 \mathrm{mg}$ & 20 & $79.786,90$ & 0,17 \\
\hline Risendronato sódico & comprimido revestido & $35 \mathrm{mg}$ & 2.744 & $79.634,08$ & 0,17 \\
\hline Alemtuzumab & solução injetável & $30 \mathrm{mg}$ & 29 & $78.971,93$ & 0,17 \\
\hline Olanzapina & comprimido revestido & $5 \mathrm{mg}$ & 14.392 & $73.750,60$ & 0,16 \\
\hline Riluzol & comprimido revestido & $50 \mathrm{mg}$ & 4.424 & $72.509,36$ & 0,15 \\
\hline Pramipexol & comprimido simples & $0,25 \mathrm{mg}$ & 43.980 & $71.664,00$ & 0,15 \\
\hline Solução fisiológica isotônica & solução injetável GV & $500 \mathrm{Ml}$ & 45.630 & $69.574,36$ & 0,15 \\
\hline Vigabatrina & comprimido simples & $500 \mathrm{mg}$ & 42.240 & $69.375,60$ & 0,15 \\
\hline Ac. Mucopolissacarideo polissulfurico & pomada & $40 \mathrm{~g}$ & 6.950 & $69.331,50$ & 0,15 \\
\hline Caspofungina & pó liófilo injetável & $50 \mathrm{mg}$ & 46 & $69.224,00$ & 0,15 \\
\hline Solução de glicose $5 \%$ & solução injetável GV & $1 \mathrm{~L}$ & 32.144 & $68.273,20$ & 0,14 \\
\hline Fentanila & solução injetável & $0,50 \mathrm{mg}$ & 36.050 & $67.707,20$ & 0,14 \\
\hline Abacavir & comprimido revestido & $300 \mathrm{mg}$ & 11.940 & $66.520,47$ & 0,14 \\
\hline Solução fisiológica isotônica & solução injetável GV & $250 \mathrm{~mL}$ & 54.850 & $65.989,50$ & 0,14 \\
\hline
\end{tabular}




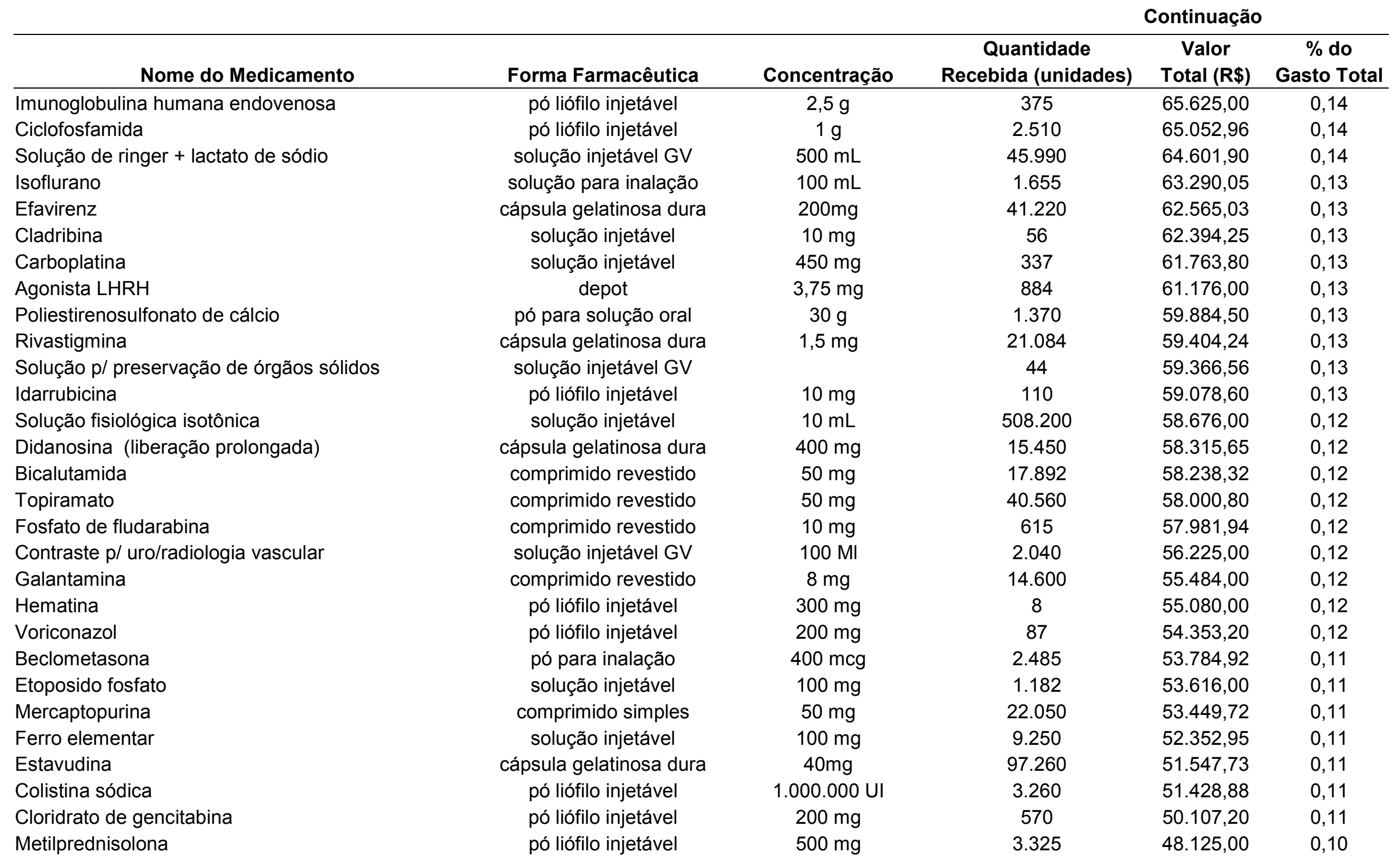




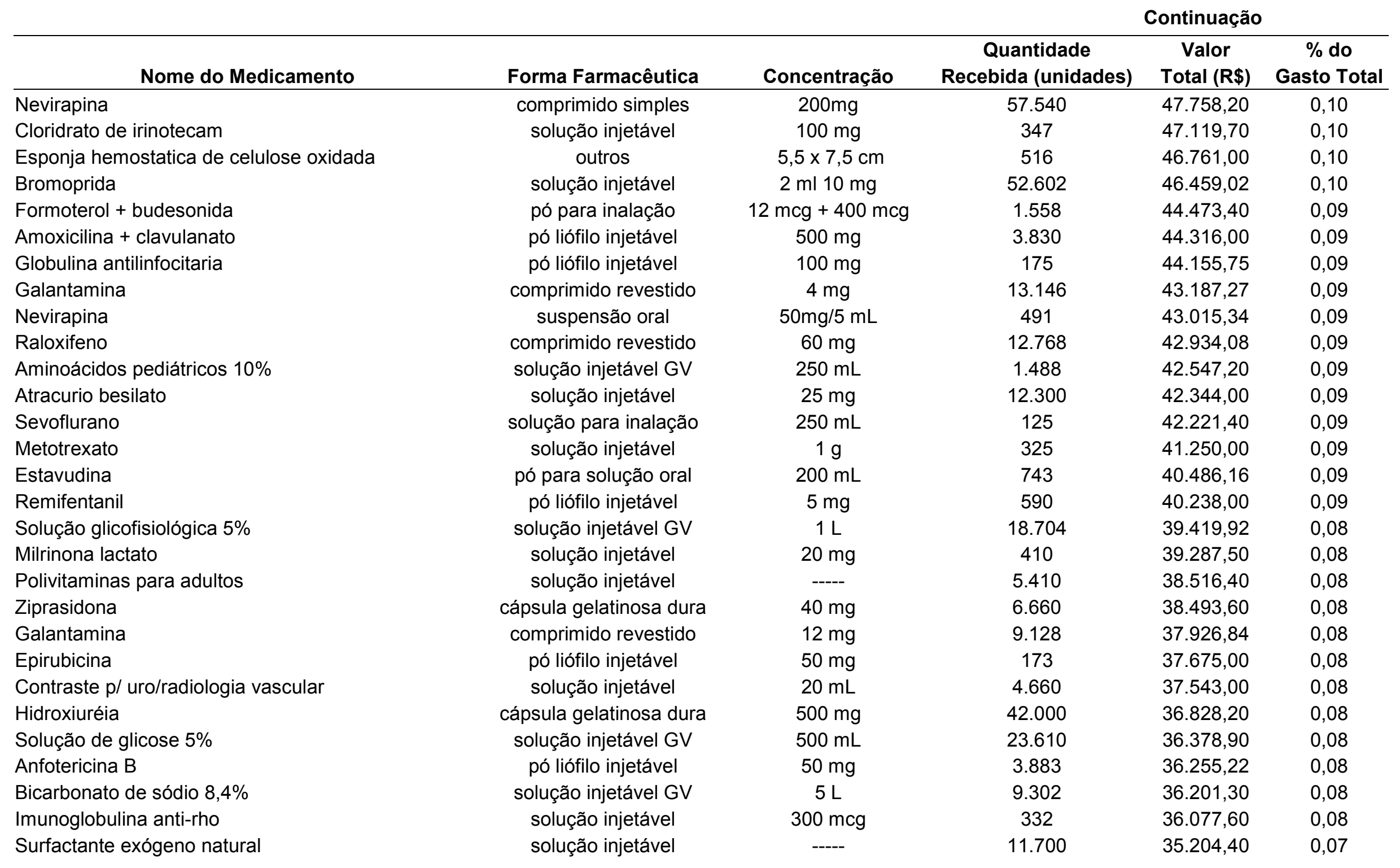




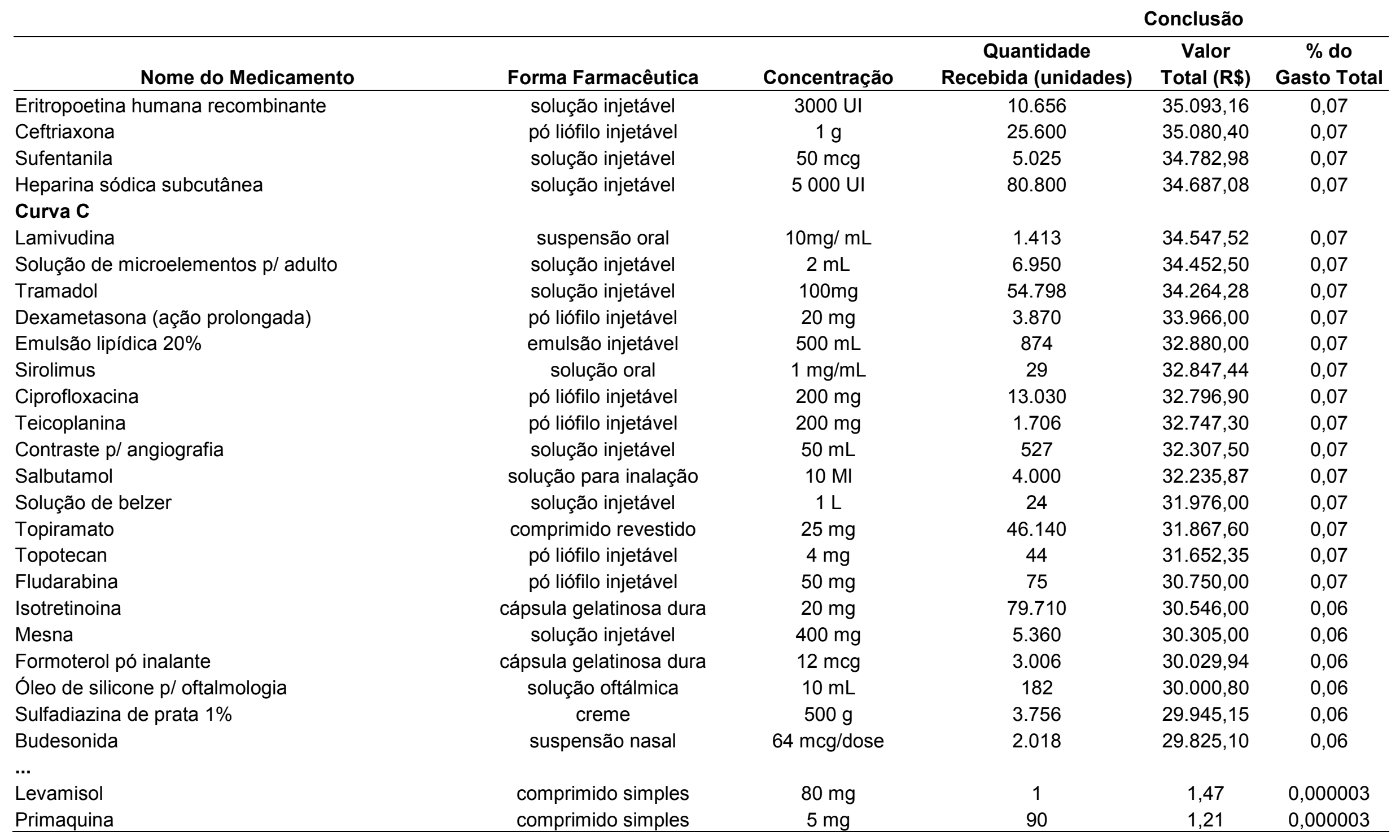


Tabela 35 - Distribuição dos medicamentos adquiridos pelo HCFMRP-USP em curva ABC de demanda valorizada, 2007

\section{Nome do Medicamento \\ Curva A}

Imatinib

Imunoglobulina humana endovenosa

Ácido zoledrônico

Contraste $\mathrm{p} /$ angiografia cerebral

Paclitaxel semi-sintético

Rituximab

Albumina humana serica $20 \%$

Zidovudina + lamivudina

Anfotericina B lipossomal

Lopinavir + ritonavir

Goserelina

Imipenema + cilastatina

Anfotericina B coloidal

\section{Efavirenz}

Docetaxel triidratado

Atazanavir

Enoxaparina

Meropenem

Propofol p f s $1 \%$

Cloridrato de gencitabina

Capecitabina

Docetaxel triidratado

Cloridrato de epirrubicina

Letrozol

Hidroxietilamida solução $6 \%$

Enfuvirtida

Quantidade

Valor

$\%$ do

Forma Farmacêutica

Concentração

Recebida (unidades) Total (R\$) Gasto Total

comprimido revestido

pó liófilo injetável

solução injetável

solução injetável

solução injetável

solução injetável

solução injetável

comprimido revestido

pó liófilo injetável

cápsula gelatinosa mole depot

pó liófilo injetável

pó liófilo injetável

comprimido revestido

solução injetável

cápsula gelatinosa dura

solução injetável

pó liófilo injetável

emulsão injetável

pó liófilo injetável

comprimido revestido

solução injetável

solução injetável GV

comprimido revestido

solução injetável GV

pó liófilo injetável
$400 \mathrm{mg}$

$5 \mathrm{~g}$

$4 \mathrm{mg}$

$50 \mathrm{~mL}$

$300 \mathrm{mg}$

$500 \mathrm{mg}$

$50 \mathrm{~mL}$

$300 m g+150 m g$

$50 \mathrm{mg}$

$133,3 \mathrm{mg}+33,3 \mathrm{mg}$

$3,6 \mathrm{mg}$

$500 \mathrm{mg}$

$50 \mathrm{mg}$

$600 \mathrm{mg}$

$80 \mathrm{mg}$

$150 \mathrm{mg}$

$40 \mathrm{mg}$

$500 \mathrm{mg}$

$50 \mathrm{~mL}$

$1 \mathrm{~g}$

$500 \mathrm{mg}$

$20 \mathrm{mg}$

$200 \mathrm{mg}$

$2,5 \mathrm{mg}$

$500 \mathrm{~mL}$

$90 \mathrm{mg} / \mathrm{mL}$

18.840
2.424
960
15.150
363
139
7.575
468.480
954
439.920
2.250
27.560
1.110
183.570
352
73.140
21.850
20.500
4.500
525
20.804
905
332
22.456
7.379
88

3.103.500,00 10,34

2.378.461,62 7,92

$812.130,90 \quad 2,71$

$806.250,00 \quad 2,69$

$753.960,00 \quad 2,51$

$733.572,00 \quad 2,44$

$692.403,00 \quad 2,31$

$637.805,06 \quad 2,12$

$606.415,76 \quad 2,02$

$599.911,18 \quad 2,00$

$559.423,00 \quad 1,86$

$551.214,50 \quad 1,84$

$541.500,00 \quad 1,80$

$506.448,27 \quad 1,69$

$457.600,00 \quad 1,52$

$419.835,59 \quad 1,40$

404.896,00 $\quad 1,35$

$377.900,00 \quad 1,26$

$339.227,10 \quad 1,13$

$279.270,00 \quad 0,93$

$275.294,40 \quad 0,92$

$270.200,00 \quad 0,90$

$265.400,00 \quad 0,88$

$259.434,00 \quad 0,86$

$245.481,50 \quad 0,82$

243.893,90 0,81

Continua 
Continuação

\begin{tabular}{|c|c|c|c|c|c|}
\hline Nome do Medicamento & Forma Farmacêutica & Concentração & $\begin{array}{c}\text { Quantidade } \\
\text { Recebida (unidades) }\end{array}$ & $\begin{array}{c}\text { Valor } \\
\text { Total (R\$) }\end{array}$ & $\begin{array}{c}\% \text { do } \\
\text { Gasto Total }\end{array}$ \\
\hline Voriconazol & comprimido revestido & $200 \mathrm{mg}$ & 1.316 & $242.144,00$ & 0,81 \\
\hline Solução fisiológica isotônica & solução injetável GV & $1 \mathrm{~L}$ & 111.854 & $206.684,58$ & 0,69 \\
\hline Solução fisiológica isotônica & solução injetável GV & $100 \mathrm{Ml}$ & 186.410 & $198.629,90$ & 0,66 \\
\hline Remifentanil & pó liófilo injetável & $5 \mathrm{mg}$ & 2.600 & $194.300,00$ & 0,65 \\
\hline Enoxaparina & solução injetável & $60 \mathrm{mg}$ & 7.220 & $190.749,50$ & 0,64 \\
\hline Toxina botulínica & solução injetável & $500 \mathrm{UI}$ & 205 & $189.625,00$ & 0,63 \\
\hline Metilcelulose $2 \%$ intra-ocular & solução injetável & $1,5 \mathrm{~mL}$ & 3.905 & $187.750,80$ & 0,63 \\
\hline Rituximab & solução injetável & $100 \mathrm{mg}$ & 174 & $183.538,00$ & 0,61 \\
\hline Lamivudina & comprimido revestido & $150 \mathrm{mg}$ & 259.860 & $179.019,41$ & 0,60 \\
\hline Alteplase & pó liófilo injetável & $50 \mathrm{mg}$ & 114 & $173.978,80$ & 0,58 \\
\hline Imunoglobulina de coelho anti-timocitos hum. & pó liófilo injetável & $25 \mathrm{mg}$ & 385 & $170.955,60$ & 0,57 \\
\hline Contraste $\mathrm{p} /$ uro/radiologia vascular & solução injetável & $50 \mathrm{~mL}$ & 6.300 & $155.300,00$ & 0,52 \\
\hline Nelfinavir & comprimido simples & $250 \mathrm{mg}$ & 148.500 & $149.901,93$ & 0,50 \\
\hline \multicolumn{6}{|l|}{ Curva B } \\
\hline Lopinavir + ritonavir & solução oral & $80 \mathrm{mg}+20 \mathrm{mg} / \mathrm{mL}$ & 468 & $141.730,13$ & 0,47 \\
\hline Trastuzumab & pó liófilo injetável & $440 \mathrm{mg}$ & 18 & $139.764,88$ & 0,47 \\
\hline Esponja hemostática de celulose oxidada & outros & $5 \times 35 \mathrm{~cm}$ & 588 & $138.110,52$ & 0,46 \\
\hline Cefepime & pó liófilo injetável & $1 \mathrm{~g}$ & 37.210 & $136.406,80$ & 0,45 \\
\hline Atazanavir & cápsula gelatinosa dura & $200 \mathrm{mg}$ & 21.720 & $134.960,83$ & 0,45 \\
\hline Goserelina & depot & $10,8 \mathrm{mg}$ & 180 & $134.218,80$ & 0,45 \\
\hline Brometo de rocurônio & solução injetável & $50 \mathrm{mg}$ & 4.500 & $129.598,54$ & 0,43 \\
\hline Água para injeção & solução injetável GV & $1 \mathrm{~L}$ & 38.790 & $128.223,00$ & 0,43 \\
\hline Saquinavir & cápsula gelatinosa mole & $200 \mathrm{mg}$ & 82.260 & $124.638,57$ & 0,42 \\
\hline Octreotida & solução injetável & $0,1 \mathrm{mg}$ & 4.075 & $123.269,50$ & 0,41 \\
\hline Basiliximab & pó liófilo injetável & $20 \mathrm{mg}$ & 42 & $120.960,00$ & 0,40 \\
\hline Enoxaparina & solução injetável & $80 \mathrm{mg}$ & 3.410 & $119.644,60$ & 0,40 \\
\hline Ganciclovir & pó liófilo injetável & $500 \mathrm{mg}$ & 3.700 & $118.572,00$ & 0,39 \\
\hline Nalbufina & solução injetável & $10 \mathrm{mg}$ & 14.800 & $117.801,92$ & 0,39 \\
\hline Aminoácidos $10 \%$ + solução de glicose $50 \%$ & solução injetável & ------ & 3.222 & $111.120,00$ & 0,37 \\
\hline
\end{tabular}




\begin{tabular}{|c|c|c|c|c|c|}
\hline & & & \multicolumn{3}{|c|}{ Continuação } \\
\hline Nome do Medicamento & Forma Farmacêutica & Concentração & $\begin{array}{c}\text { Quantidade } \\
\text { Recebida (unidades) }\end{array}$ & $\begin{array}{c}\text { Valor } \\
\text { Total (R\$) }\end{array}$ & $\begin{array}{c}\% \text { do } \\
\text { Gasto Total }\end{array}$ \\
\hline Lopinavir + ritonavir & comprimido revestido & $200 \mathrm{mg}+50 \mathrm{mg}$ & 64.800 & $110.373,96$ & 0,37 \\
\hline Ritonavir & cápsula gelatinosa mole & $100 \mathrm{mg}$ & 82.740 & $107.746,33$ & 0,36 \\
\hline Brometo de vecuronio & pó liófilo injetável & $10 \mathrm{mg}$ & 3.650 & $104.869,30$ & 0,35 \\
\hline Contraste paramagnetico & solução injetável & $10 \mathrm{~mL}$ & 2.800 & $101.848,00$ & 0,34 \\
\hline Dexrazoxano & pó liófilo injetável & $500 \mathrm{mg}$ & 159 & $100.455,00$ & 0,33 \\
\hline Vancomicina & pó liófilo injetável & $500 \mathrm{mg}$ & 29.225 & $95.622,25$ & 0,32 \\
\hline Estavudina & pó para solução oral & $200 \mathrm{~mL}$ & 1.671 & $94.358,68$ & 0,31 \\
\hline Solução fisiológica isotônica & solução injetável GV & $250 \mathrm{~mL}$ & 69.692 & $92.715,61$ & 0,31 \\
\hline Solução de ringer + lactato de sódio & solução injetável GV & $500 \mathrm{~mL}$ & 61.610 & $89.813,10$ & 0,30 \\
\hline Bortezomibe & pó liófilo injetável & $3,5 \mathrm{mg}$ & 32 & $89.452,48$ & 0,30 \\
\hline Alprostadil & solução injetável & $500 \mathrm{mcg}$ & 110 & $87.714,00$ & 0,29 \\
\hline Esponja hemostática de gelatina animal & outros & ------ & 1.920 & $87.060,00$ & 0,29 \\
\hline Emulsão lipídica $10 \%$ & emulsão injetável GV & $100 \mathrm{~mL}$ & 2.230 & $85.298,10$ & 0,28 \\
\hline Solução fisiológica isotônica & solução injetável GV & $500 \mathrm{~mL}$ & 64.210 & $83.995,05$ & 0,28 \\
\hline Solução fisiológica isotônica & solução injetável & $20 \mathrm{~mL}$ & 467.900 & $83.727,00$ & 0,28 \\
\hline Filgrastima & solução injetável & $300 \mathrm{mcg}(30 \mathrm{mu})$ & 6.024 & $83.131,20$ & 0,28 \\
\hline Contraste $\mathrm{p} /$ uro/radiologia vascular & solução injetável GV & $100 \mathrm{~mL}$ & 1.580 & $80.320,00$ & 0,27 \\
\hline Levosimedan & solução injetável & $2,5 \mathrm{mg} / \mathrm{mL}$ & 25 & $77.632,00$ & 0,26 \\
\hline Solução salina balanceada p/ oftalmologia & solução injetável GV & $500 \mathrm{Ml}$ & 1.850 & $77.627,60$ & 0,26 \\
\hline Bicarbonato de sódio $8,4 \%$ & solução injetável & $5 \mathrm{~L}$ & 16.075 & $76.169,43$ & 0,25 \\
\hline Aminoácidos pediátricos 10\% & solução injetável GV & $250 \mathrm{~mL}$ & 2.148 & $75.415,20$ & 0,25 \\
\hline Micofenolato sódico & comprimido revestido & $360 \mathrm{mg}$ & 11.520 & $75.347,64$ & 0,25 \\
\hline Midazolam & solução injetável & $50 \mathrm{mg}$ & 45.650 & $74.828,70$ & 0,25 \\
\hline Lamivudina suspensão & solução oral & $10 \mathrm{mg} / \mathrm{mL}$ & 1.577 & $72.167,08$ & 0,24 \\
\hline Gliconato de cálcio $10 \%$ & solução injetável & $10 \mathrm{~mL}$ & 87.100 & $71.998,00$ & 0,24 \\
\hline Ertapenem sódico & pó liófilo injetável & $1 \mathrm{~g}$ & 392 & $71.121,84$ & 0,24 \\
\hline Cloridrato de gencitabina & pó liófilo injetável & $200 \mathrm{mg}$ & 660 & $70.488,00$ & 0,23 \\
\hline Granisetrona & solução injetável & $3 \mathrm{mg}$ & 3.404 & $70.417,44$ & 0,23 \\
\hline Indinavir & cápsula gelatinosa dura & $400 \mathrm{mg}$ & 60.120 & $70.345,92$ & 0,23 \\
\hline
\end{tabular}




\begin{tabular}{|c|c|c|c|c|c|}
\hline & & & \multicolumn{3}{|c|}{ Continuação } \\
\hline Nome do Medicamento & Forma Farmacêutica & Concentração & $\begin{array}{c}\text { Quantidade } \\
\text { Recebida (unidades) }\end{array}$ & $\begin{array}{c}\text { Valor } \\
\text { Total (R\$) }\end{array}$ & $\begin{array}{c}\% \text { do } \\
\text { Gasto Total }\end{array}$ \\
\hline Agonista de GNRH de uso diário & pó liófilo injetável & - & 203 & $70.266,00$ & 0,23 \\
\hline Solução fisiológica isotônica & solução injetável & $10 \mathrm{~mL}$ & 585.600 & $69.735,30$ & 0,23 \\
\hline Omeprazol & pó liófilo injetável & $40 \mathrm{mg}$ & 33.650 & $67.461,52$ & 0,22 \\
\hline Solução de glicose $5 \%$ & solução injetável GV & $1 \mathrm{~L}$ & 37.400 & $66.812,00$ & 0,22 \\
\hline Carboplatina & solução injetável & $450 \mathrm{mg}$ & 345 & $66.505,00$ & 0,22 \\
\hline Olanzapina & comprimido revestido & $10 \mathrm{mg}$ & 6.188 & $66.246,32$ & 0,22 \\
\hline Citarabina & solução injetável & $1 \mathrm{~g}$ & 790 & $66.128,95$ & 0,22 \\
\hline Ac. Mucopolissacarideo polissulfurico & pomada & $40 \mathrm{~g}$ & 6.060 & $65.979,50$ & 0,22 \\
\hline Cefazolina & pó liófilo injetável & $1 \mathrm{~g}$ & 71.950 & $64.564,80$ & 0,22 \\
\hline Poliestirenosulfonato de calcio & pó para solução oral & $30 \mathrm{~g}$ & 4.640 & $62.170,60$ & 0,21 \\
\hline Hematina & pó liófilo injetável & $300 \mathrm{mg}$ & 9 & $61.965,00$ & 0,21 \\
\hline Amprenavir & cápsula gelatinosa mole & $150 \mathrm{mg}$ & 29.760 & $61.008,00$ & 0,20 \\
\hline Água para injeção & solução injetável GV & $100 \mathrm{~mL}$ & 35.050 & $60.710,00$ & 0,20 \\
\hline Nevirapina & suspensão oral & $50 \mathrm{mg} / 5 \mathrm{~mL}$ & 652 & $60.358,92$ & 0,20 \\
\hline Imunoglobulina humana endovenosa & pó liófilo injetável & $2,5 \mathrm{~g}$ & 124 & $59.458,00$ & 0,20 \\
\hline Imatinib & comprimido revestido & $100 \mathrm{mg}$ & 1.440 & $59.040,00$ & 0,20 \\
\hline Sirolimus solução oral & solução oral & $1 \mathrm{mg} / \mathrm{mL}$ & 52 & $57.784,22$ & 0,19 \\
\hline Topotecan & pó liófilo injetável & $4 \mathrm{mg}$ & 77 & $57.024,00$ & 0,19 \\
\hline Abacavir & comprimido revestido & $300 \mathrm{mg}$ & 12.960 & $55.834,25$ & 0,19 \\
\hline Nor-adrenalina & solução injetável & $1 \mathrm{mg}$ base $/ 1 \mathrm{~mL}$ & 32.100 & $55.535,00$ & 0,18 \\
\hline Zidovudina & cápsula gelatinosa dura & $100 \mathrm{mg}$ & 165.240 & $54.644,01$ & 0,18 \\
\hline Sevoflurano & solução para inalação & $250 \mathrm{~mL}$ & 122 & $54.452,40$ & 0,18 \\
\hline Bicalutamida & comprimido revestido & $50 \mathrm{mg}$ & 21.015 & $53.816,80$ & 0,18 \\
\hline Cloridrato de irinotecam & solução injetável & $100 \mathrm{mg}$ & 502 & $53.715,42$ & 0,18 \\
\hline Esponja hemostática de celulose oxidada & outros & $5,5 \times 7,5 \mathrm{~cm}$ & 564 & $53.163,60$ & 0,18 \\
\hline Aprotinina & solução injetável & $500.000 \mathrm{UI}$ & 412 & $52.324,00$ & 0,17 \\
\hline Cetoprofeno & pó liófilo injetável & $100 \mathrm{mg}$ & 39.750 & $52.281,50$ & 0,17 \\
\hline Polivitaminas para adultos & solução injetável & ---- & 3.380 & $51.004,20$ & 0,17 \\
\hline Fosamprenavir cálcico & comprimido revestido & $700 \mathrm{mg}$ & 6.900 & $50.182,10$ & 0,17 \\
\hline
\end{tabular}




\begin{tabular}{|c|c|c|c|c|c|}
\hline & & & \multicolumn{3}{|c|}{ Continuação } \\
\hline Nome do Medicamento & Forma Farmacêutica & Concentração & $\begin{array}{c}\text { Quantidade } \\
\text { Recebida (unidades) }\end{array}$ & $\begin{array}{c}\text { Valor } \\
\text { Total (R\$) }\end{array}$ & $\begin{array}{c}\% \text { do } \\
\text { Gasto Total }\end{array}$ \\
\hline Milrinona lactato & solução injetável & $20 \mathrm{mg}$ & 540 & $49.608,00$ & 0,17 \\
\hline Emulsão lipídica 20\% & emulsão injetável GV & $500 \mathrm{~mL}$ & 980 & $47.940,00$ & 0,16 \\
\hline Didanosina (liberação prolongada) & cápsula gelatinosa dura & $400 \mathrm{mg}$ & 13.950 & $47.603,07$ & 0,16 \\
\hline Contraste $\mathrm{p} /$ uro/radiologia vascular & solução injetável & $20 \mathrm{~mL}$ & 4.050 & $47.365,00$ & 0,16 \\
\hline Alemtuzumab & solução injetável & $30 \mathrm{mg}$ & 36 & $47.181,24$ & 0,16 \\
\hline Isoflurano & solução para inalação & $100 \mathrm{~mL}$ & 1.125 & $46.059,30$ & 0,15 \\
\hline Nevirapina & comprimido simples & $200 \mathrm{mg}$ & 54.600 & $45.318,00$ & 0,15 \\
\hline Ciclofosfamida & pó liófilo injetável & $1 \mathrm{~g}$ & 1.940 & $45.229,72$ & 0,15 \\
\hline Fludarabina & pó liófilo injetável & $50 \mathrm{mg}$ & 90 & $44.136,00$ & 0,15 \\
\hline Globulina antilinfocitaria & pó liófilo injetável & $100 \mathrm{mg}$ & 160 & $43.358,40$ & 0,14 \\
\hline Solução glicofisiológica 5\% & solução injetável GV & $1 \mathrm{~L}$ & 17.952 & $43.152,97$ & 0,14 \\
\hline Bromoprida & solução injetável & $10 \mathrm{mg}$ & 51.509 & $42.151,26$ & 0,14 \\
\hline Amoxicilina + clavulanato & pó liófilo injetável & $1 \mathrm{~g}$ & 9.400 & $42.100,00$ & 0,14 \\
\hline Imunoglobulina anti-hepatite B & solução injetável & $1000 \mathrm{UI}$ & 15 & $41.250,00$ & 0,14 \\
\hline Fentanila & solução injetável & $0,50 \mathrm{mg}$ & 28.850 & $40.656,70$ & 0,14 \\
\hline Caspofungina & pó liófilo injetável & $50 \mathrm{mg}$ & 25 & $38.832,35$ & 0,13 \\
\hline Abciximab & solução injetável & $10 \mathrm{mg}$ & 28 & $37.104,40$ & 0,12 \\
\hline Propofol & emulsão injetável & $200 \mathrm{mg}$ & 18.630 & $37.073,70$ & 0,12 \\
\hline Carboximetilcelulose sódica 0,5\% & pó liófilo injetável & $15 \mathrm{~mL}$ & 205 & $37.073,50$ & 0,12 \\
\hline Carmustina & solução injetável & $100 \mathrm{mg}$ & 205 & $37.073,50$ & 0,12 \\
\hline Solução p/ preservação de órgãos sólidos & solução injetável GV & $1 \mathrm{~L}$ & 32 & $36.800,00$ & 0,12 \\
\hline Estavudina & cápsula gelatinosa dura & $40 \mathrm{mg}$ & 65.340 & $34.630,22$ & 0,12 \\
\hline Atracurio besilato & solução injetável & $25 \mathrm{mg}$ & 14.025 & $32.193,75$ & 0,11 \\
\hline Metilprednisolona & pó liófilo injetável & $500 \mathrm{mg}$ & 2.850 & $32.084,50$ & 0,11 \\
\hline Solução de glicose $5 \%$ & solução injetável GV & $500 \mathrm{~mL}$ & 22.400 & $32.032,00$ & 0,11 \\
\hline Ciprofloxacina & solução injetável GV & $200 \mathrm{mg}$ & 18.250 & $31.645,00$ & 0,11 \\
\hline Cloridrato de daunorrubicina & pó liófilo injetável & $20 \mathrm{mg}$ & 515 & $31.635,15$ & 0,11 \\
\hline Anfotericina B & pó liófilo injetável & $50 \mathrm{mg}$ & 3.400 & $31.382,16$ & 0,10 \\
\hline Etoposido & solução injetável & $100 \mathrm{mg}$ & 1.010 & $31.309,00$ & 0,10 \\
\hline
\end{tabular}




\begin{tabular}{|c|c|c|c|c|c|}
\hline & & & \multicolumn{3}{|c|}{ Continuação } \\
\hline Nome do Medicamento & Forma Farmacêutica & Concentração & $\begin{array}{c}\text { Quantidade } \\
\text { Recebida (unidades) }\end{array}$ & $\begin{array}{c}\text { Valor } \\
\text { Total (R\$) }\end{array}$ & $\begin{array}{c}\% \text { do } \\
\text { Gasto Total }\end{array}$ \\
\hline Heparina sódica subcutânea & solução injetável & $5000 \mathrm{UI}$ & 83.400 & $31.249,04$ & 0,10 \\
\hline Solução p/ hemodiálise (cálcio 3,5 meq/l) & solução injetável GV & $5 \mathrm{~L}$ & 7.203 & $30.932,76$ & 0,10 \\
\hline Solução p/ diálise peritoneal + glicose $1,5 \%$ & solução injetável GV & $5 \mathrm{~L}$ & 1.524 & $30.189,00$ & 0,10 \\
\hline Sulfato de bleomicina & solução injetável & $15 \mathrm{mg}$ & 340 & $29.969,40$ & 0,10 \\
\hline Temozolamida & cápsula gelatinosa dura & $20 \mathrm{mg}$ & 3.565 & $28.776,50$ & 0,10 \\
\hline Oxacilina & pó liófilo injetável & $500 \mathrm{mg}$ & 50.250 & $28.700,25$ & 0,10 \\
\hline Corticorelina & pó liófilo injetável & $100 \mathrm{mcg}$ & 18 & $27.985,03$ & 0,09 \\
\hline Dexametasona (ação prolongada) & solução injetável & $20 \mathrm{mg}$ & 3.780 & $27.027,00$ & 0,09 \\
\hline Polimixina & pó liófilo injetável & - & 1.100 & $26.122,80$ & 0,09 \\
\hline Hidroxiuréia & cápsula gelatinosa dura & $500 \mathrm{mg}$ & 28.200 & $25.380,00$ & 0,08 \\
\hline \multicolumn{6}{|l|}{ Curva C } \\
\hline Solução de microelementos p/ adulto & solução injetável & $2 \mathrm{~mL}$ & 4.600 & $25.320,00$ & 0,08 \\
\hline Bevacizumab & pó liófilo injetável & $400 \mathrm{mg}$ & 6 & $25.248,66$ & 0,08 \\
\hline Imunoglobulina anti-rho & pó liófilo injetável & $300 \mathrm{mcg}$ & 255 & $24.973,50$ & 0,08 \\
\hline Sufentanila IV & solução injetável & $50 \mathrm{mcg}$ & 3.025 & $23.768,80$ & 0,08 \\
\hline Clindamicina & solução injetável & $600 \mathrm{mg}$ & 24.700 & $23.269,20$ & 0,08 \\
\hline Clonidina & solução injetável & $150 \mathrm{mcg}$ & 7.000 & $23.222,98$ & 0,08 \\
\hline Amoxicilina + clavulanato & pó liófilo injetável & $500 \mathrm{mg}$ & 2.800 & $22.930,00$ & 0,08 \\
\hline Zidovudina & pó liófilo injetável & $50 \mathrm{mg} / 5 \mathrm{~mL}$ & 1.876 & $22.830,61$ & 0,08 \\
\hline Aciclovir & pó liófilo injetável & $250 \mathrm{mg}$ & 6.750 & $22.540,00$ & 0,08 \\
\hline Ciclosporina & solução injetável & $250 \mathrm{mg}$ & 370 & $22.005,30$ & 0,07 \\
\hline Solução pronta p/ hidratação & solução oral & $500 \mathrm{~mL}$ & 2.476 & $21.850,54$ & 0,07 \\
\hline Ceftazidima injetável & pó liófilo injetável & $1 \mathrm{~g}$ & 9.310 & $21.072,90$ & 0,07 \\
\hline Óleo de silicone p/ oftalmologia & solução oftálmica & $10 \mathrm{~mL}$ & 150 & $21.018,00$ & 0,07 \\
\hline Didanosina & cápsula gelatinosa dura & $250 \mathrm{mg}$ & 8.310 & $21.016,90$ & 0,07 \\
\hline Salbutamol & solução para inalação & $10 \mathrm{Ml}$ & 2.550 & $20.984,00$ & 0,07 \\
\hline Dipirona & solução injetável & $1 \mathrm{~g}$ & 106.350 & $20.769,05$ & 0,07 \\
\hline Fibrinolisina + desoxiribon.+ cloranf. & pomada & $30 \mathrm{~g}$ & 1.620 & $20.429,31$ & 0,07 \\
\hline Heparina sódica IV & solução injetável & $25000 \mathrm{UI}$ & 13.525 & $20.418,75$ & 0,07 \\
\hline
\end{tabular}




\begin{tabular}{|c|c|c|c|c|c|}
\hline & & & \multicolumn{3}{|c|}{ Conclusão } \\
\hline Nome do Medicamento & Forma Farmacêutica & Concentração & $\begin{array}{c}\text { Quantidade } \\
\text { Recebida (unidades) }\end{array}$ & $\begin{array}{c}\text { Valor } \\
\text { Total }(R \$)\end{array}$ & $\begin{array}{c}\% \text { do } \\
\text { Gasto Total }\end{array}$ \\
\hline $\begin{array}{l}\text { Ifosfamida } \\
\ldots\end{array}$ & pó liófilo injetável & $1 \mathrm{~g}$ & 755 & $20.130,24$ & 0,07 \\
\hline Primaquina comprimido & comprimido simples & $5 \mathrm{mg}$ & 120 & 1,61 & 0,000005 \\
\hline Levamisol comprimido & comprimido simples & $80 \mathrm{mg}$ & 1 & 1,41 & 0,000005 \\
\hline
\end{tabular}


Tabela 36 - Distribuição dos medicamentos adquiridos pelo HCFMRP-USP em curva ABC de demanda quantitativa, 2006

\begin{tabular}{|c|c|c|c|c|c|}
\hline Nome do Medicamento & Forma Farmacêutica & Concentração & $\begin{array}{l}\text { Quantidade } \\
\text { Recebida } \\
\text { (unidades) }\end{array}$ & $\begin{array}{c}\text { Valor } \\
\text { Total (R\$) }\end{array}$ & $\begin{array}{l}\% \text { do } \\
\text { Gasto } \\
\text { Total }\end{array}$ \\
\hline \multicolumn{6}{|l|}{ Curva A } \\
\hline Isoflurano & pó liófilo injetável & $240 \mathrm{~mL}$ & 705.670 & $13.123,69$ & 4,87 \\
\hline Solução fisiológica isotônica & solução injetável & $20 \mathrm{~mL}$ & 622.200 & $102.022,56$ & 4,29 \\
\hline Sevelamer & comprimido revestido & $800 \mathrm{mg}$ & 566.640 & $2.611 .077,30$ & 3,91 \\
\hline Solução fisiológica isotônica & solução injetável & $10 \mathrm{~mL}$ & 508.200 & $58.676,00$ & 3,51 \\
\hline Zidovudina + lamivudina & comprimido simples & $300 \mathrm{mg}+150 \mathrm{mg}$ & 507.480 & $642.977,17$ & 3,50 \\
\hline Lopinavir + ritonavir & cápsula gelatinosa dura & $133,3 \mathrm{mg}+33,3 \mathrm{mg}$ & 461.340 & $1.065 .030,85$ & 3,18 \\
\hline Etomidato & solução injetável & $20 \mathrm{mg}$ & 380.280 & $8.705,58$ & 2,63 \\
\hline Nelfinavir & comprimido simples & $250 \mathrm{mg}$ & 375.030 & $390.152,47$ & 2,59 \\
\hline Lamivudina & comprimido simples & $150 \mathrm{mg}$ & 233.280 & $160.132,66$ & 1,61 \\
\hline Solução fisiológica isotônica & solução injetável & $100 \mathrm{~mL}$ & 216.940 & $285.791,80$ & 1,50 \\
\hline Efavirenz & comprimido simples & $600 \mathrm{mg}$ & 178.350 & $635.457,72$ & 1,23 \\
\hline Tamoxifeno & comprimido simples & $10 \mathrm{mg}$ & 171.490 & $24.537,30$ & 1,18 \\
\hline Captopril & comprimido simples & $25 \mathrm{mg}$ & 141.040 & $5.286,02$ & 0,97 \\
\hline Calcitriol & cápsula gelatinosa dura & $0,25 \mathrm{mcg}$ & 140.370 & $16.309,89$ & 0,97 \\
\hline Ribavirina & cápsula gelatinosa dura & $250 \mathrm{mg}$ & 133.260 & $18.730,08$ & 0,92 \\
\hline Micofenolato mofetil & comprimido simples & $500 \mathrm{mg}$ & 130.800 & $383.824,00$ & 0,90 \\
\hline Enzimas pancreáticas & cápsula gelatinosa dura & $4500 \mathrm{UI}$ & 127.000 & $142.881,51$ & 0,88 \\
\hline Olanzapina & comprimido simples & 10 mg & 124.404 & $1.265 .048,40$ & 0,86 \\
\hline Tacrolimus & cápsula gelatinosa dura & $1 \mathrm{mg}$ & 119.400 & $534.050,00$ & 0,82 \\
\hline Risperidona & comprimido simples & $2 \mathrm{mg}$ & 116.200 & $10.349,52$ & 0,80 \\
\hline Dipirona & comprimido simples & $1 \mathrm{~g}$ & 115.750 & $26.900,80$ & 0,80 \\
\hline Solução de cloreto de sódio $20 \%$ & solução injetável & $10 \mathrm{~mL}$ & 114.750 & $14.881,65$ & 0,79 \\
\hline Sulfametoxazol+ trimetoprima & comprimido simples & & 113.500 & $5.756,90$ & 0,78 \\
\hline Azatioprina & comprimido simples & $50 \mathrm{mg}$ & 113.000 & $24.050,86$ & 0,78 \\
\hline Sinvastatina & comprimido simples & $20 \mathrm{mg}$ & 112.320 & $7.161,18$ & 0,78 \\
\hline Gliconato de cálcio $10 \%$ & solução injetável & $10 \mathrm{~mL}$ & 106.600 & $88.567,00$ & 0,74 \\
\hline Lamotrigina & comprimido simples & $100 \mathrm{mg}$ & 105.800 & $24.390,00$ & 0,73 \\
\hline
\end{tabular}


Continuação

\begin{tabular}{|c|c|c|c|c|c|}
\hline Nome do Medicamento & Forma Farmacêutica & Concentração & $\begin{array}{l}\text { Quantidade } \\
\text { Recebida } \\
\text { (unidades) }\end{array}$ & $\begin{array}{c}\text { Valor } \\
\text { Total (R\$) }\end{array}$ & $\begin{array}{l}\% \text { do } \\
\text { Gasto } \\
\text { Total } \\
\end{array}$ \\
\hline Ritonavir & cápsula gelatinosa dura & $100 \mathrm{mg}$ & 103.992 & $134.696,34$ & 0,72 \\
\hline Solução fisiológica isotônica & solução injetável & $1 \mathrm{~L}$ & 103.074 & $195.308,10$ & 0,71 \\
\hline Topiramato & comprimido simples & $100 \mathrm{mg}$ & 101.460 & $274.226,60$ & 0,70 \\
\hline Estavudina & cápsula gelatinosa dura & $40 \mathrm{mg}$ & 97.260 & $51.547,73$ & 0,67 \\
\hline Levodopa + benserazida & comprimido simples & $200 \mathrm{mg}+50 \mathrm{mg}$ & 94.170 & $105.470,40$ & 0,65 \\
\hline Saquinavir & cápsula gelatinosa dura & $200 \mathrm{mg}$ & 93.180 & $145.196,07$ & 0,64 \\
\hline Sulfasalazina & comprimido simples & $500 \mathrm{mg}$ & 92.360 & $24.429,22$ & 0,64 \\
\hline Sinvastatina & comprimido simples & $10 \mathrm{mg}$ & 89.730 & $6.453,78$ & 0,62 \\
\hline Mesalazina & comprimido simples & $400 \mathrm{mg}$ & 88.230 & $22.933,17$ & 0,61 \\
\hline Atorvastatina & comprimido simples & $10 \mathrm{mg}$ & 87.610 & $212.906,14$ & 0,60 \\
\hline Bromocriptina & comprimido simples & $2,5 \mathrm{mg}$ & 87.192 & $77.361,76$ & 0,60 \\
\hline Clozapina & comprimido simples & $100 \mathrm{mg}$ & 83.880 & $156.190,30$ & 0,58 \\
\hline Heparina sódica subcutânea & solução injetável & $5000 \mathrm{UI}$ & 80.800 & $34.687,08$ & 0,56 \\
\hline Isotretinoina & cápsula gelatinosa dura & $20 \mathrm{mg}$ & 79.710 & $30.546,00$ & 0,55 \\
\hline Indinavir & cápsula gelatinosa dura & $400 \mathrm{mg}$ & 76.500 & $90.045,68$ & 0,53 \\
\hline Água para injeção & solução injetável & $10 \mathrm{~mL}$ & 72.750 & $5.961,80$ & 0,50 \\
\hline Solução de cloreto de potássio 19,1\% & solução injetável & $10 \mathrm{~mL}$ & 71.600 & $9.057,62$ & 0,49 \\
\hline Cefalotina & pó liófilo injetável & $1 \mathrm{~g}$ & 67.250 & $81.938,30$ & 0,46 \\
\hline Aciclovir & comprimido simples & $200 \mathrm{mg}$ & 64.830 & $6.213,62$ & 0,45 \\
\hline Alendronato sódico & comprimido simples & $10 \mathrm{mg}$ & 64.710 & $2.588,40$ & 0,45 \\
\hline Tenofovir & comprimido revestido & $300 \mathrm{mg}$ & 63.780 & $777.251,89$ & 0,44 \\
\hline Prednisona & comprimido simples & $20 \mathrm{mg}$ & 63.200 & $3.289,44$ & 0,44 \\
\hline Água para injeção & solução injetável & $20 \mathrm{~mL}$ & 61.100 & $10.244,50$ & 0,42 \\
\hline Ranitidina & comprimido simples & $150 \mathrm{mg}$ & 61.000 & $2.374,25$ & 0,42 \\
\hline Carbamazepina & comprimido simples & $200 \mathrm{mg}$ & 59.580 & $4.069,56$ & 0,41 \\
\hline Omeprazol & cápsula gelatinosa dura & $20 \mathrm{mg}$ & 59.050 & $4.077,98$ & 0,41 \\
\hline Ranitidina & solução injetável & $50 \mathrm{mg}$ & 57.700 & $11.035,60$ & 0,40 \\
\hline Nevirapina & comprimido simples & $200 \mathrm{mg}$ & 57.540 & $47.758,20$ & 0,40 \\
\hline
\end{tabular}


Continuação

\begin{tabular}{|c|c|c|c|c|c|}
\hline Nome do Medicamento & Forma Farmacêutica & Concentração & $\begin{array}{l}\text { Quantidade } \\
\text { Recebida } \\
\text { (unidades) }\end{array}$ & $\begin{array}{c}\text { Valor } \\
\text { Total (R\$) }\end{array}$ & $\begin{array}{c}\% \text { do } \\
\text { Gasto } \\
\text { Total } \\
\end{array}$ \\
\hline Furosemida & solução injetável & $20 \mathrm{mg}$ & 57.150 & $11.140,60$ & 0,39 \\
\hline Acitretina & cápsula gelatinosa dura & $10 \mathrm{mg}$ & 56.400 & $122.388,00$ & 0,39 \\
\hline Sulfato de atropina & solução injetável & $0,25 \mathrm{mg}$ & 55.950 & $11.382,57$ & 0,39 \\
\hline Atorvastatina & comprimido simples & $20 \mathrm{mg}$ & 54.960 & $238.860,56$ & 0,38 \\
\hline Solução fisiológica isotônica & solução injetável & $250 \mathrm{~mL}$ & 54.850 & $65.989,50$ & 0,38 \\
\hline Tramadol & solução injetável & $100 \mathrm{mg}$ & 54.798 & $34.264,28$ & 0,38 \\
\hline Amantadina & comprimido simples & $100 \mathrm{mg}$ & 54.640 & $23.015,30$ & 0,38 \\
\hline Amprenavir & cápsula gelatinosa dura & $150 \mathrm{mg}$ & 53.520 & $109.370,49$ & 0,37 \\
\hline Bromoprida & solução injetável & $10 \mathrm{mg}$ & 52.602 & $46.459,02$ & 0,36 \\
\hline \multicolumn{6}{|l|}{ Curva B } \\
\hline Fluconazol & cápsula gelatinosa dura & $100 \mathrm{mg}$ & 51.752 & $9.440,62$ & 0,36 \\
\hline Atazanavir & cápsula gelatinosa dura & $150 \mathrm{mg}$ & 51.600 & $349.547,40$ & 0,36 \\
\hline Enzimas pancreáticas & cápsula gelatinosa dura & 20000 UI & 50.600 & $210.666,00$ & 0,35 \\
\hline Ciclosporina microemulsão & cápsula gelatinosa dura & 50 mg & 48.400 & $80.289,33$ & 0,33 \\
\hline Nor-adrenalina & solução injetável & $1 \mathrm{mg}$ & 47.810 & $102.120,00$ & 0,33 \\
\hline Água para injeção & solução injetável & $100 \mathrm{~mL}$ & 47.150 & $78.386,50$ & 0,33 \\
\hline Cetoprofeno IV & pó liófilo injetável & $100 \mathrm{mg}$ & 46.700 & $101.410,00$ & 0,32 \\
\hline Topiramato & comprimido simples & $25 \mathrm{mg}$ & 46.140 & $31.867,60$ & 0,32 \\
\hline Solução de ringer+lactato de sodio & solução injetável & $500 \mathrm{~mL}$ & 45.990 & $64.601,90$ & 0,32 \\
\hline Solução fisiológica isotônica & solução injetável & $500 \mathrm{~mL}$ & 45.630 & $69.574,36$ & 0,31 \\
\hline Oxacilina & pó liófilo injetável & $500 \mathrm{mg}$ & 45.450 & $29.425,05$ & 0,31 \\
\hline Morfina & comprimido simples & $10 \mathrm{mg}$ & 45.230 & $3.175,43$ & 0,31 \\
\hline Midazolam & solução injetável & $50 \mathrm{mg}$ & 44.830 & $87.825,64$ & 0,31 \\
\hline Micofenolato sódico & comprimido simples & $360 \mathrm{mg}$ & 44.640 & $280.014,72$ & 0,31 \\
\hline Pramipexol & comprimido simples & $0,25 \mathrm{mg}$ & 43.980 & $71.664,00$ & 0,30 \\
\hline Ácido acetilsalicilico & comprimido simples & $100 \mathrm{mg}$ & 43.259 & $2.669,91$ & 0,30 \\
\hline Vigabatrina & comprimido simples & $500 \mathrm{mg}$ & 42.240 & $69.375,60$ & 0,29 \\
\hline Eritropoetina humana recombinante & solução injetável & $4000 \mathrm{UI}$ & 42.026 & $216.433,71$ & 0,29 \\
\hline Hidroxiuréia & cápsula gelatinosa dura & $500 \mathrm{mg}$ & 42.000 & $36.828,20$ & 0,29 \\
\hline
\end{tabular}


Continuação

\begin{tabular}{|c|c|c|c|c|c|}
\hline Nome do Medicamento & Forma Farmacêutica & Concentração & $\begin{array}{l}\text { Quantidade } \\
\text { Recebida } \\
\text { (unidades) }\end{array}$ & $\begin{array}{c}\text { Valor } \\
\text { Total }(\mathrm{R} \$)\end{array}$ & $\begin{array}{l}\% \text { do } \\
\text { Gasto } \\
\text { Total }\end{array}$ \\
\hline Efavirenz & comprimido simples & $200 \mathrm{mg}$ & 41.220 & $62.565,03$ & 0,28 \\
\hline Topiramato & comprimido simples & $50 \mathrm{mg}$ & 40.560 & $58.000,80$ & 0,28 \\
\hline Ciclosporina microemulsão & cápsula gelatinosa dura & $100 \mathrm{mg}$ & 40.350 & $112.094,12$ & 0,28 \\
\hline Fenitoina & comprimido simples & $100 \mathrm{mg}$ & 39.750 & $2.058,62$ & 0,27 \\
\hline Cefepime & pó liófilo injetável & $1 \mathrm{~g}$ & 38.850 & $238.170,68$ & 0,27 \\
\hline Biperideno & comprimido simples & $2 \mathrm{mg}$ & 37.650 & $2.098,08$ & 0,26 \\
\hline Quetiapina & comprimido simples & $100 \mathrm{mg}$ & 37.492 & $174.691,51$ & 0,26 \\
\hline Clonidina & comprimido simples & $150 \mathrm{mcg}$ & 36.600 & $4.437,60$ & 0,25 \\
\hline Bezafibrato & dragea & $200 \mathrm{mg}$ & 36.100 & $8.313,15$ & 0,25 \\
\hline Fentanila & solução injetável & $0,5 \mathrm{mg}$ & 36.050 & $67.707,20$ & 0,25 \\
\hline Água para injeção & solução injetável & $1 \mathrm{~L}$ & 35.350 & $108.020,00$ & 0,24 \\
\hline Levodopa + carbidopa & comprimido simples & $250 \mathrm{mg}+25 \mathrm{mg}$ & 35.000 & $5.988,90$ & 0,24 \\
\hline Solução de glicose $50 \%$ & solução injetável & $20 \mathrm{~mL}$ & 34.550 & $9.203,60$ & 0,24 \\
\hline Vancomicina & solução injetável & $500 \mathrm{mg}$ & 32.590 & $135.083,80$ & 0,22 \\
\hline Solução de glicose $5 \%$ & solução injetável & $1 \mathrm{~L}$ & 32.144 & $68.273,20$ & 0,22 \\
\hline Ciclosporina microemulsão & cápsula gelatinosa dura & $25 \mathrm{mg}$ & 32.100 & $23.185,92$ & 0,22 \\
\hline Estavudina & cápsula gelatinosa dura & $30 \mathrm{mg}$ & 31.620 & $8.959,41$ & 0,22 \\
\hline Paracetamol & comprimido simples & $500 \mathrm{mg}$ & 31.100 & $1.746,08$ & 0,21 \\
\hline Entacapone & comprimido simples & $200 \mathrm{mg}$ & 31.080 & $80.186,40$ & 0,21 \\
\hline Quetiapina & comprimido simples & $200 \mathrm{mg}$ & 30.716 & $254.119,60$ & 0,21 \\
\hline Leflunomide & comprimido simples & $20 \mathrm{mg}$ & 29.880 & $179.280,00$ & 0,21 \\
\hline Rivastigmina & cápsula gelatinosa dura & $4,5 \mathrm{mg}$ & 28.420 & $102.889,66$ & 0,20 \\
\hline Dinitrato de isossorbida & comprimido simples & $10 \mathrm{mg}$ & 27.930 & $1.524,44$ & 0,19 \\
\hline Amlodipina & comprimido simples & $5 \mathrm{mg}$ & 27.400 & $1.814,02$ & 0,19 \\
\hline Propofol & solução injetável & $200 \mathrm{mg}$ & 27.170 & $84.871,00$ & 0,19 \\
\hline Imipenema+cilastatina IV & pó liófilo injetável & $500 \mathrm{mg}$ & 26.990 & $883.135,00$ & 0,19 \\
\hline Complexo B & comprimido simples & & 26.529 & $2.342,37$ & 0,18 \\
\hline Sulfato de magnésio (6\%) & solução injetável & $1 \mathrm{meq} / \mathrm{Ml}$ & 26.520 & $7.008,72$ & 0,18 \\
\hline Sulfato ferroso & comprimido simples & $200 \mathrm{mg}$ a $300 \mathrm{mg}$ & 26.220 & $1.732,35$ & 0,18 \\
\hline
\end{tabular}


Continuação

\begin{tabular}{|c|c|c|c|c|c|}
\hline Nome do Medicamento & Forma Farmacêutica & Concentração & $\begin{array}{l}\text { Quantidade } \\
\text { Recebida } \\
\text { (unidades) }\end{array}$ & $\begin{array}{c}\text { Valor } \\
\text { Total }(\mathrm{R} \$)\end{array}$ & $\begin{array}{l}\% \text { do } \\
\text { Gasto } \\
\text { Total }\end{array}$ \\
\hline Propranolol & comprimido simples & $40 \mathrm{mg}$ & 26.000 & 681,60 & 0,18 \\
\hline Fluoxetina & cápsula gelatinosa dura & $20 \mathrm{mg}$ & 25.984 & $2.105,10$ & 0,18 \\
\hline Ácido valpróico & comprimido simples & $250 \mathrm{mg}$ & 25.900 & $4.797,16$ & 0,18 \\
\hline Enzimas pancreáticas & cápsula gelatinosa dura & $12000 \mathrm{UI}$ & 25.700 & $78.463,00$ & 0,18 \\
\hline Pramipexol & comprimido simples & $1 \mathrm{mg}$ & 25.620 & $127.506,60$ & 0,18 \\
\hline Ceftriaxona & pó liófilo injetável & $1 \mathrm{~g}$ & 25.600 & $35.080,40$ & 0,18 \\
\hline Rivastigmina & cápsula gelatinosa dura & $3 \mathrm{mg}$ & 25.424 & $79.934,66$ & 0,18 \\
\hline Capsulas gelatinosas $n^{\circ} 3$, coloridas & material de embalagem & & 25.000 & 230,80 & 0,17 \\
\hline Neostigmina & solução injetável & $0,5 \mathrm{mg}$ & 25.000 & $14.835,58$ & 0,17 \\
\hline Tramadol & cápsula gelatinosa dura & $50 \mathrm{mg}$ & 24.560 & $3.582,25$ & 0,17 \\
\hline Rivastigmina & cápsula gelatinosa dura & $6 \mathrm{mg}$ & 24.360 & $91.087,36$ & 0,17 \\
\hline Sirolimus & drágea & $1 \mathrm{mg}$ & 24.360 & $367.227,00$ & 0,17 \\
\hline Imatinib & comprimido simples & $100 \mathrm{mg}$ & 24.300 & $923.400,00$ & 0,17 \\
\hline Carbonato de cálcio & comprimido mastigável & $500 \mathrm{mg}$ & 24.296 & $2.917,24$ & 0,17 \\
\hline Adrenalina & solução injetável & $1 \mathrm{mg}$ & 24.000 & $5.866,25$ & 0,17 \\
\hline Solução de glicose $5 \%$ & solução injetável & $500 \mathrm{~mL}$ & 23.610 & $36.378,90$ & 0,16 \\
\hline Clindamicina & solução injetável & $4 \mathrm{~mL}$ & 23.600 & $29.257,78$ & 0,16 \\
\hline Lorazepam & comprimido simples & $2 \mathrm{mg}$ & 23.540 & $1.812,79$ & 0,16 \\
\hline Furosemida & comprimido simples & $40 \mathrm{mg}$ & 23.400 & 817,90 & 0,16 \\
\hline Amitriptilina & comprimido simples & $25 \mathrm{mg}$ & 23.315 & $8.991,15$ & 0,16 \\
\hline Atazanavir & cápsula gelatinosa dura & $200 \mathrm{mg}$ & 23.100 & $156.641,26$ & 0,16 \\
\hline Sulfadiazina & comprimido simples & $500 \mathrm{mg}$ & 23.000 & $1.379,98$ & 0,16 \\
\hline Ciprofloxacina & comprimido simples & $500 \mathrm{mg}$ & 22.050 & $2.585,39$ & 0,15 \\
\hline Mercaptopurina & comprimido simples & $50 \mathrm{mg}$ & 22.050 & $53.449,72$ & 0,15 \\
\hline Ondansetrona & solução injetável & $8 \mathrm{mg}$ & 21.550 & $15.710,28$ & 0,15 \\
\hline Cetoprofeno & cápsula gelatinosa dura & $50 \mathrm{mg}$ & 21.504 & $2.953,67$ & 0,15 \\
\hline Rivastigmina & cápsula gelatinosa dura & $1,5 \mathrm{mg}$ & 21.084 & $59.404,24$ & 0,15 \\
\hline Donepezil & comprimido revestido & $10 \mathrm{mg}$ & 20.972 & $223.482,84$ & 0,14 \\
\hline Enoxaparina & solução injetável & $40 \mathrm{mg}$ & 20.900 & $364.832,60$ & 0,14 \\
\hline
\end{tabular}


Continuação

\begin{tabular}{|c|c|c|c|c|c|}
\hline Nome do Medicamento & Forma Farmacêutica & Concentração & $\begin{array}{l}\text { Quantidade } \\
\text { Recebida } \\
\text { (unidades) }\end{array}$ & $\begin{array}{c}\text { Valor } \\
\text { Total (R\$) }\end{array}$ & $\begin{array}{l}\% \text { do } \\
\text { Gasto } \\
\text { Total }\end{array}$ \\
\hline Dexclorfeniramina & comprimido simples & $2 \mathrm{mg}$ & 20.600 & $3.530,30$ & 0,14 \\
\hline Clindamicina & cápsula gelatinosa dura & $300 \mathrm{mg}$ & 20.520 & $5.724,88$ & 0,14 \\
\hline Zidovudina & cápsula gelatinosa dura & $100 \mathrm{mg}$ & 20.000 & $6.362,83$ & 0,14 \\
\hline Metronidazol & solução injetável & $500 \mathrm{mg}$ & 19.910 & $10.627,16$ & 0,14 \\
\hline Ciprofibrato & comprimido simples & $100 \mathrm{mg}$ & 19.170 & $13.984,23$ & 0,13 \\
\hline Meropenem IV & pó liófilo injetável & $500 \mathrm{mg}$ & 19.130 & $497.270,00$ & 0,13 \\
\hline Solução de glicose $5 \%$ & solução injetável & $100 \mathrm{~mL}$ & 18.800 & $26.832,00$ & 0,13 \\
\hline Solução glicofisiológica 5\% & solução injetável & $1 \mathrm{~L}$ & 18.704 & $39.419,92$ & 0,13 \\
\hline Letrozol & comprimido simples & $2,5 \mathrm{~g}$ & 18.592 & $210.227,64$ & 0,13 \\
\hline Bezafibrato (liberação lenta) & comprimido revestido & $400 \mathrm{mg}$ & 18.150 & $23.130,24$ & 0,13 \\
\hline Diazepam & comprimido simples & $10 \mathrm{mg}$ & 18.100 & 217,10 & 0,12 \\
\hline Levodopa + benserazida & cápsula gelatinosa dura & $100 \mathrm{mg}+25 \mathrm{mg}$ & 17.910 & $14.420,40$ & 0,12 \\
\hline Bicalutamida & comprimido simples & $50 \mathrm{mg}$ & 17.892 & $58.238,32$ & 0,12 \\
\hline Nifedipina (retard ) & comprimido simples & $20 \mathrm{mg}$ & 17.830 & $2.463,03$ & 0,12 \\
\hline Dexametasona & solução injetável & $10 \mathrm{mg}$ & 17.802 & $8.805,60$ & 0,12 \\
\hline Etambutol & comprimido simples & $400 \mathrm{mg}$ & 17.230 & $1.688,37$ & 0,12 \\
\hline Bicarbonato de sódio & solução injetável & $10 \mathrm{~mL}$ & 17.200 & $5.710,56$ & 0,12 \\
\hline Isoniazida + rifampicina & comprimido simples & $200 \mathrm{mg}+300 \mathrm{mg}$ & 17.200 & $2.476,93$ & 0,12 \\
\hline Baclofeno & comprimido simples & $10 \mathrm{mg}$ & 17.140 & $1.447,42$ & 0,12 \\
\hline Selegilina & comprimido simples & $5 \mathrm{mg}$ & 17.140 & $4.537,71$ & 0,12 \\
\hline Hidroclorotiazida & comprimido simples & $50 \mathrm{mg}$ & 17.110 & 838,50 & 0,12 \\
\hline Espironolactona & comprimido simples & $25 \mathrm{mg}$ & 16.890 & $1.551,10$ & 0,12 \\
\hline Solução de glicose $5 \%$ & solução injetável & $250 \mathrm{~mL}$ & 16.374 & $19.756,99$ & 0,11 \\
\hline Dexametasona & comprimido simples & $4 \mathrm{mg}$ & 16.370 & $1.541,82$ & 0,11 \\
\hline Amoxicilina + clavulanato & pó liófilo injetável & $1 \mathrm{~g}$ & 16.220 & $162.217,40$ & 0,11 \\
\hline Deferoxamina mesilato & pó liófilo injetável & $500 \mathrm{mg}$ & 15.920 & $366.734,34$ & 0,11 \\
\hline Pirimetamina & comprimido simples & $25 \mathrm{mg}$ & 15.900 & 732,68 & 0,11 \\
\hline Hidrocortisona succinato & pó liófilo injetável & $100 \mathrm{mg}$ & 15.850 & $16.599,75$ & 0,11 \\
\hline Didanosina (liberação prolongada) & comprimido revestido & $400 \mathrm{mg}$ & 15.450 & $58.315,65$ & 0,11 \\
\hline
\end{tabular}


Continuação

\begin{tabular}{|c|c|c|c|c|c|}
\hline Nome do Medicamento & Forma Farmacêutica & Concentração & $\begin{array}{l}\text { Quantidade } \\
\text { Recebida } \\
\text { (unidades) }\end{array}$ & $\begin{array}{c}\text { Valor } \\
\text { Total }(\mathrm{R} \$)\end{array}$ & $\begin{array}{l}\% \text { do } \\
\text { Gasto } \\
\text { Total }\end{array}$ \\
\hline Midazolam & solução injetável & $5 \mathrm{mg}$ & 15.390 & $10.801,22$ & 0,11 \\
\hline Midazolam & solução injetável & $15 \mathrm{mg}$ & 14.950 & $13.110,94$ & 0,10 \\
\hline Galantamina & comprimido simples & $8 \mathrm{mg}$ & 14.600 & $55.484,00$ & 0,10 \\
\hline Metformina & comprimido simples & $500 \mathrm{mg}$ & 14.525 & $1.341,61$ & 0,10 \\
\hline Pirazinamida & comprimido simples & $500 \mathrm{mg}$ & 14.500 & $1.759,28$ & 0,10 \\
\hline Gentamicina & solução injetável & $40 \mathrm{mg}$ & 14.440 & $24.919,60$ & 0,10 \\
\hline Olanzapina & comprimido simples & $5 \mathrm{mg}$ & 14.392 & $73.750,60$ & 0,10 \\
\hline Capecitabina & comprimido simples & $500 \mathrm{mg}$ & 14.296 & $186.620,00$ & 0,10 \\
\hline Fenitoina & solução injetável & $250 \mathrm{mg}$ & 14.100 & $9.697,16$ & 0,10 \\
\hline Dexclorfeniramina & solução injetável & $5 \mathrm{mg}$ & 13.880 & $4.789,40$ & 0,10 \\
\hline Enalapril & comprimido simples & $5 \mathrm{mg}$ & 13.670 & $2.531,43$ & 0,09 \\
\hline Dornase alfa & solução injetável & $2,5 \mathrm{mg}$ & 13.620 & $960.482,40$ & 0,09 \\
\hline Dopamina & solução injetável & $50 \mathrm{mg}$ & 13.600 & $6.312,00$ & 0,09 \\
\hline Galantamina & comprimido simples & $4 \mathrm{mg}$ & 13.146 & $43.187,27$ & 0,09 \\
\hline Tiroxina & comprimido simples & $50 \mathrm{mcg}$ & 13.110 & $1.132,13$ & 0,09 \\
\hline Somatotrofina & pó liófilo injetável & $4 \mathrm{UI}$ & 13.066 & $187.575,35$ & 0,09 \\
\hline Ciprofloxacina & solução injetável & $100 \mathrm{~mL}$ & 13.030 & $32.796,90$ & 0,09 \\
\hline Ácido ursodesoxicolico & comprimido simples & $50 \mathrm{mg}$ & 12.960 & $9.333,76$ & 0,09 \\
\hline Donepezil & comprimido revestido & $5 \mathrm{mg}$ & 12.768 & $114.656,64$ & 0,09 \\
\hline Raloxifeno & comprimido simples & $60 \mathrm{mg}$ & 12.768 & $42.934,08$ & 0,09 \\
\hline Paracetamol + codeína & comprimido simples & $500 \mathrm{mg}+30 \mathrm{mg}$ & 12.684 & $5.983,23$ & 0,09 \\
\hline Tacrolimus & cápsula gelatinosa dura & $5 \mathrm{mg}$ & 12.650 & $282.262,50$ & 0,09 \\
\hline Dipirona & solução oral & $20 \mathrm{~mL}$ & 12.552 & $13.973,92$ & 0,09 \\
\hline Ácido folinico & comprimido simples & $15 \mathrm{mg}$ & 12.510 & $5.265,86$ & 0,09 \\
\hline Alopurinol & comprimido simples & $100 \mathrm{mg}$ & 12.320 & $1.216,96$ & 0,09 \\
\hline Lidocaina 2\% & solução injetável & $20 \mathrm{~mL}$ & 12.320 & $9.616,72$ & 0,09 \\
\hline Ácido fólico & comprimido simples & $5 \mathrm{mg}$ & 12.300 & $2.498,60$ & 0,08 \\
\hline Atracurio besilato & solução injetável & $25 \mathrm{mg}$ & 12.300 & $42.344,00$ & 0,08 \\
\hline Amiodarona & comprimido simples & $200 \mathrm{mg}$ & 12.210 & $1.422,62$ & 0,08 \\
\hline
\end{tabular}


Continuação

\begin{tabular}{|c|c|c|c|c|c|}
\hline Nome do Medicamento & Forma Farmacêutica & Concentração & $\begin{array}{l}\text { Quantidade } \\
\text { Recebida } \\
\text { (unidades) }\end{array}$ & $\begin{array}{c}\text { Valor } \\
\text { Total }(\mathrm{R} \$)\end{array}$ & $\begin{array}{l}\% \text { do } \\
\text { Gasto } \\
\text { Total } \\
\end{array}$ \\
\hline Varfarina sódica & comprimido simples & $5 \mathrm{mg}$ & 12.120 & $2.211,69$ & 0,08 \\
\hline Abacavir & comprimido revestido & $300 \mathrm{mg}$ & 11.940 & $66.520,47$ & 0,08 \\
\hline Surfactante exógeno natural & solução injetável & ----- & 11.700 & $35.204,40$ & 0,08 \\
\hline Morfina (liberação lenta) & comprimido revestido & $30 \mathrm{mg}$ & 11.620 & $8.905,21$ & 0,08 \\
\hline Sinvastatina & comprimido simples & $40 \mathrm{mg}$ & 11.370 & $1.687,08$ & 0,08 \\
\hline Nalbufina & solução injetável & $10 \mathrm{mg}$ & 11.360 & $81.396,40$ & 0,08 \\
\hline Heparina sódica IV & solução injetável & $25000 \mathrm{UI}$ & 11.250 & $18.585,18$ & 0,08 \\
\hline Diclofenaco sódico & comprimido simples & 50 mg & 11.200 & 773,15 & 0,08 \\
\hline Contraste $\mathrm{p} /$ angiografia cerebral & solução injetável & $50 \mathrm{~mL}$ & 11.100 & $345.380,00$ & 0,08 \\
\hline Lidocaina $1 \%$ & solução injetável & $20 \mathrm{~mL}$ & 10.970 & $10.566,75$ & 0,08 \\
\hline Metoclopramida & solução injetável & $10 \mathrm{mg}$ & 10.840 & $2.085,70$ & 0,07 \\
\hline Vitaminas ADEK & comprimido simples & ----- & 10.680 & $6.133,99$ & 0,07 \\
\hline Nimodipina & comprimido simples & $30 \mathrm{mg}$ & 10.668 & $3.575,87$ & 0,07 \\
\hline Eritropoetina humana recombinante & solução injetável & $3000 \mathrm{UI}$ & 10.656 & $35.093,16$ & 0,07 \\
\hline Carvedilol & comprimido simples & $6,25 \mathrm{mg}$ & 10.648 & $2.206,89$ & 0,07 \\
\hline Lidocaína 2\% & gel & $30 \mathrm{~mL}$ & 10.410 & $9.871,50$ & 0,07 \\
\hline Ziprasidona & cápsula gelatinosa dura & $80 \mathrm{mg}$ & 10.410 & $100.344,00$ & 0,07 \\
\hline Risperidona & comprimido simples & $1 \mathrm{mg}$ & 10.400 & 442,40 & 0,07 \\
\hline \multicolumn{6}{|l|}{ Curva C } \\
\hline Hidralazina & comprimido simples & $50 \mathrm{mg}$ & $10.300,00$ & $1.614,55$ & 0,07 \\
\hline Itraconazol & cápsula gelatinosa dura & $100 \mathrm{mg}$ & $10.260,00$ & $5.009,43$ & 0,07 \\
\hline Bromoprida & comprimido simples & $10 \mathrm{mg}$ & $10.239,00$ & $1.940,01$ & 0,07 \\
\hline Amiodarona & solução injetável & $150 \mathrm{mg}$ & $10.100,00$ & $5.919,60$ & 0,07 \\
\hline Álcool a $70 \%$ & comprimido simples & $1 \mathrm{~L}$ & $10.080,00$ & $22.286,88$ & 0,07 \\
\hline Loperamida & comprimido simples & $2 \mathrm{mg}$ & $10.000,00$ & $1.034,07$ & 0,07 \\
\hline Fenobarbital & comprimido simples & $100 \mathrm{mg}$ & $10.000,00$ & 192,60 & 0,07 \\
\hline Cápsulas gelatinosas $n^{\circ} 0$, coloridas & material de embalagem & ---- & $10.000,00$ & 91,90 & 0,07 \\
\hline Cápsulas gelatinosas $n^{\circ} 2$, coloridas & material de embalagem & ----- & $10.000,00$ & 88,40 & 0,07 \\
\hline Metildopa & comprimido simples & $250 \mathrm{mg}$ & $9.940,00$ & $1.579,74$ & 0,07 \\
\hline
\end{tabular}


Continuação

\begin{tabular}{|c|c|c|c|c|c|}
\hline Nome do Medicamento & Forma Farmacêutica & Concentração & $\begin{array}{l}\text { Quantidade } \\
\text { Recebida } \\
\text { (unidades) }\end{array}$ & $\begin{array}{c}\text { Valor } \\
\text { Total (R\$) }\end{array}$ & $\begin{array}{l}\% \text { do } \\
\text { Gasto } \\
\text { Total }\end{array}$ \\
\hline Imunoglobulina de coelho anti-timocitos hum. & pó liófilo injetável & $25 \mathrm{mg}$ & $9.820,00$ & $286.675,00$ & 0,07 \\
\hline Hidroxietilamida solução $6 \%$ & solução injetável & $500 \mathrm{~mL}$ & $9.800,00$ & $327.896,00$ & 0,07 \\
\hline Metronidazol & comprimido simples & $400 \mathrm{mg}$ & $9.800,00$ & 811,40 & 0,07 \\
\hline Amicacina & solução injetável & $500 \mathrm{mg}$ & $9.700,00$ & $6.786,44$ & 0,07 \\
\hline Imatinib & comprimido simples & $400 \mathrm{mg}$ & $9.690,00$ & $9.690,00$ & 0,07 \\
\hline Dexclorfeniramina & comprimido revestido & $6 \mathrm{mg}$ & $9.612,00$ & $5.947,72$ & 0,07 \\
\hline Imipramina & comprimido simples & $25 \mathrm{mg}$ & $9.600,00$ & 333,60 & 0,07 \\
\hline Ondansetrona & solução injetável & $4 \mathrm{mg}$ & $9.350,00$ & $3.181,22$ & 0,06 \\
\hline Bicarbonato de sódio $8,4 \%$ & solução injetável & $5 \mathrm{~L}$ & $9.302,00$ & $36.201,30$ & 0,06 \\
\hline Ferro elementar IV & solução injetável & $100 \mathrm{mg}$ & $9.250,00$ & $52.352,95$ & 0,06 \\
\hline \multicolumn{6}{|l|}{... } \\
\hline Vitamina B12 & solução injetável & $1000 \mathrm{mcg}$ & 1 & 2,80 & 0,00001 \\
\hline Levamisol & comprimido simples & $80 \mathrm{mg}$ & 1 & 1,47 & 0,00001 \\
\hline
\end{tabular}


Tabela 37 - Distribuição dos medicamentos adquiridos pelo HCFMRP-USP em Curva ABC de demanda quantitativa, 2007

\begin{tabular}{|c|c|c|c|c|c|}
\hline Nome do Medicamento & Forma Farmacêutica & Concentração & $\begin{array}{l}\text { Quantidade } \\
\text { Recebida } \\
\text { (unidades) }\end{array}$ & $\begin{array}{c}\text { Valor } \\
\text { Total (R\$) }\end{array}$ & $\begin{array}{l}\% \text { do } \\
\text { Gasto } \\
\text { Total }\end{array}$ \\
\hline \multicolumn{6}{|l|}{ Curva A } \\
\hline Solução fisiológica isotônica & solução injetável & $10 \mathrm{~mL}$ & 585.600 & $69.735,30$ & 7,16 \\
\hline Zidovudina & comprimido simples & $300 \mathrm{mg}+150 \mathrm{mg}$ & 468.480 & $637.805,06$ & 5,72 \\
\hline Solução fisiológica isotônica & solução injetável & $20 \mathrm{~mL}$ & 467.900 & $83.727,00$ & 5,72 \\
\hline Lopinavir + ritonavir & cápsula gelatinosa dura & $133,3 \mathrm{mg}+33,3 \mathrm{mg}$ & 439.920 & $599.911,18$ & 5,38 \\
\hline Lamivudina & comprimido simples & $150 \mathrm{mg}$ & 259.860 & $179.019,41$ & 3,18 \\
\hline Solução fisiológica isotônica & solução injetável & $100 \mathrm{~mL}$ & 186.410 & $198.629,90$ & 2,28 \\
\hline Efavirenz & comprimido simples & $600 \mathrm{mg}$ & 183.570 & $506.448,27$ & 2,24 \\
\hline Zidovudina & cápsula gelatinosa dura & $100 \mathrm{mg}$ & 165.240 & $54.644,01$ & 2,02 \\
\hline Nelfinavir & comprimido simples & $250 \mathrm{mg}$ & 148.500 & $149.901,93$ & 1,81 \\
\hline Tenofovir & comprimido simples & $300 \mathrm{mg}$ & 114.620 & $8.627,59$ & 1,40 \\
\hline Solução fisiológica isotônica & solução injetável & $1 \mathrm{~L}$ & 111.854 & $206.684,58$ & 1,37 \\
\hline Dipirona & solução injetável & $1 \mathrm{~g}$ & 106.350 & $20.769,05$ & 1,30 \\
\hline Solução de cloreto de sódio $20 \%$ & solução injetável & $10 \mathrm{~mL}$ & 95.600 & $13.053,00$ & 1,17 \\
\hline Omeprazol & cápsula gelatinosa dura & $20 \mathrm{mg}$ & 93.360 & $2.891,53$ & 1,14 \\
\hline Gliconato de cálcio $10 \%$ & solução injetável & $10 \mathrm{Ml}$ & 87.100 & $71.998,00$ & 1,06 \\
\hline Heparina sódica subcutânea & solução injetável & $5000 \mathrm{UI}$ & 83.400 & $31.249,04$ & 1,02 \\
\hline Ritonavir & cápsula gelatinosa dura & $100 \mathrm{mg}$ & 82.740 & $107.746,33$ & 1,01 \\
\hline Saquinavir & cápsula gelatinosa dura & $200 \mathrm{mg}$ & 82.260 & $124.638,57$ & 1,01 \\
\hline Captopril & comprimido simples & $25 \mathrm{mg}$ & 80.000 & $1.120,00$ & 0,98 \\
\hline Água para injeção & solução injetável & $10 \mathrm{~mL}$ & 75.700 & $7.467,50$ & 0,93 \\
\hline Atazanavir & cápsula gelatinosa dura & $150 \mathrm{mg}$ & 73.140 & $419.835,59$ & 0,89 \\
\hline Cefazolina & pó liófilo injetável & $1 \mathrm{~g}$ & 71.950 & $64.564,80$ & 0,88 \\
\hline Carbamazepina & comprimido simples & $200 \mathrm{mg}$ & 71.500 & $2.154,10$ & 0,87 \\
\hline Solução fisiológica isotônica & solução injetável & $250 \mathrm{~mL}$ & 69.692 & $92.715,61$ & 0,85 \\
\hline Estavudina & cápsula gelatinosa dura & $40 \mathrm{mg}$ & 65.340 & $34.630,22$ & 0,80 \\
\hline Lopinavir + ritonavir & comprimido revestido & $200 \mathrm{mg}+50 \mathrm{mg}$ & 64.800 & $110.373,96$ & 0,79 \\
\hline Solução fisiológica isotônica & solução injetável & $500 \mathrm{~mL}$ & 64.210 & $83.995,05$ & 0,78 \\
\hline
\end{tabular}


Continuação

\begin{tabular}{|c|c|c|c|c|c|}
\hline Nome do Medicamento & Forma Farmacêutica & Concentração & $\begin{array}{l}\text { Quantidade } \\
\text { Recebida } \\
\text { (unidades) }\end{array}$ & $\begin{array}{c}\text { Valor } \\
\text { Total (R\$) }\end{array}$ & $\begin{array}{c}\% \text { do } \\
\text { Gasto } \\
\text { Total } \\
\end{array}$ \\
\hline Solução de ringer + lactato de sódio & solução injetável & $500 \mathrm{~mL}$ & 61.610 & $89.813,10$ & 0,75 \\
\hline Prednisona & comprimido simples & $20 \mathrm{mg}$ & 61.100 & $2.555,67$ & 0,75 \\
\hline Indinavir & cápsula gelatinosa dura & $400 \mathrm{mg}$ & 60.120 & $70.345,92$ & 0,73 \\
\hline Nevirapina & comprimido simples & $200 \mathrm{mg}$ & 54.600 & $45.318,00$ & 0,67 \\
\hline Água para injeção & solução injetável & $20 \mathrm{~mL}$ & 52.700 & $7.378,00$ & 0,64 \\
\hline Fluconazol & cápsula gelatinosa dura & $100 \mathrm{mg}$ & 51.600 & $7.385,53$ & 0,63 \\
\hline Bromoprida & solução oral & $10 \mathrm{mg}$ & 51.509 & $42.151,26$ & 0,63 \\
\hline Oxacilina & pó liófilo injetável & $500 \mathrm{mg}$ & 50.250 & $28.700,25$ & 0,61 \\
\hline Tramadol & solução injetável & $100 \mathrm{mg}$ & 49.998 & $18.701,28$ & 0,61 \\
\hline Solução de cloreto de potássio 19,1\% & solução injetável & $10 \mathrm{~mL}$ & 48.200 & $6.872,13$ & 0,59 \\
\hline Terlipressina & pó liófilo injetável & $1 \mathrm{mg}$ & 45.750 & $8.271,35$ & 0,56 \\
\hline Midazolam & solução injetável & $50 \mathrm{mg}$ & 45.650 & $74.828,70$ & 0,56 \\
\hline Cápsulas gelatinosas $n^{\circ} 3$, coloridas & material de embalagem & & 40.000 & 384,60 & 0,49 \\
\hline Furosemida & solução injetável & $20 \mathrm{mg}$ & 39.800 & $7.268,00$ & 0,49 \\
\hline Cetoprofeno IV & pó liófilo injetável & 100 mg & 39.750 & $52.281,50$ & 0,49 \\
\hline Água para injeção embalagem & solução injetável & $1000 \mathrm{~mL}$ & 38.790 & $128.223,00$ & 0,47 \\
\hline Solução de glicose $50 \%$ & solução injetável & $20 \mathrm{~mL}$ & 37.500 & $8.982,00$ & 0,46 \\
\hline Solução de glicose 5\% & solução injetável & $1 \mathrm{~L}$ & 37.400 & $66.812,00$ & 0,46 \\
\hline Cefepime & pó liófilo injetável & $1 \mathrm{~g}$ & 37.210 & $136.406,80$ & 0,45 \\
\hline Sinvastatina & comprimido simples & $10 \mathrm{mg}$ & 36.392 & $1.601,24$ & 0,44 \\
\hline \multicolumn{6}{|l|}{ Curva B } \\
\hline Fenitoina & comprimido simples & 100 mg & 35.500 & $1.384,00$ & 0,43 \\
\hline Clonidina & comprimido simples & $150 \mathrm{mcg}$ & 35.310 & $4.209,89$ & 0,43 \\
\hline Água para injeção & solução injetável & $100 \mathrm{~mL}$ & 35.050 & $60.710,00$ & 0,43 \\
\hline Adrenalina & solução injetável & $1 \mathrm{mg}$ & 34.900 & $8.263,85$ & 0,43 \\
\hline Omeprazol & pó liófilo injetável & $40 \mathrm{mg}$ & 33.650 & $67.461,52$ & 0,41 \\
\hline Nor-adrenalina & solução injetável & $1 \mathrm{mg}$ & 32.100 & $55.535,00$ & 0,39 \\
\hline Paracetamol & comprimido simples & $500 \mathrm{mg}$ & 30.000 & 674,50 & 0,37 \\
\hline Amprenavir & cápsula gelatinosa dura & $150 \mathrm{mg}$ & 29.760 & $61.008,00$ & 0,36 \\
\hline
\end{tabular}


Continuação

\begin{tabular}{|c|c|c|c|c|c|}
\hline Nome do Medicamento & Forma Farmacêutica & Concentração & $\begin{array}{l}\text { Quantidade } \\
\text { Recebida } \\
\text { (unidades) }\end{array}$ & $\begin{array}{c}\text { Valor } \\
\text { Total (R\$) }\end{array}$ & $\begin{array}{l}\% \text { do } \\
\text { Gasto } \\
\text { Total }\end{array}$ \\
\hline Vancomicina & pó liófilo injetável & $500 \mathrm{mg}$ & 29.225 & $95.622,25$ & 0,36 \\
\hline Fentanila & solução injetável & $0,50 \mathrm{mg}$ & 28.850 & $40.656,70$ & 0,35 \\
\hline Hidroxiuréia & cápsula gelatinosa dura & $500 \mathrm{mg}$ & 28.200 & $25.380,00$ & 0,34 \\
\hline Estavudina & cápsula gelatinosa dura & $30 \mathrm{mg}$ & 28.020 & $7.943,67$ & 0,34 \\
\hline Dexametasona & comprimido simples & $4 \mathrm{mg}$ & 28.010 & $2.465,90$ & 0,34 \\
\hline Ácido acetilsalicilico & comprimido simples & $100 \mathrm{mg}$ & 28.000 & $1.130,00$ & 0,34 \\
\hline Imipenema+cilastatina IV & pó liófilo injetável & $500 \mathrm{mg}$ & 27.560 & $551.214,50$ & 0,34 \\
\hline Ranitidina & solução injetável & $50 \mathrm{mg}$ & 27.400 & $5.043,00$ & 0,33 \\
\hline Temozolamida & cápsula gelatinosa dura & $100 \mathrm{mg}$ & 26.100 & $1.578,00$ & 0,32 \\
\hline Complexo B & comprimido simples & ---- & 25.008 & 913,29 & 0,31 \\
\hline Clindamicina & solução injetável & $4 \mathrm{~mL}$ & 24.700 & $23.269,20$ & 0,30 \\
\hline Aciclovir & comprimido simples & $200 \mathrm{mg}$ & 24.000 & $1.517,56$ & 0,29 \\
\hline Dexametasona & solução injetável & $10 \mathrm{mg}$ & 22.600 & $8.750,00$ & 0,28 \\
\hline Letrozol & comprimido simples & $2,5 \mathrm{mg}$ & 22.456 & $259.434,00$ & 0,27 \\
\hline Solução de glicose $5 \%$ & solução injetável & $500 \mathrm{~mL}$ & 22.400 & $32.032,00$ & 0,27 \\
\hline Alopurinol & comprimido simples & $100 \mathrm{mg}$ & 22.200 & $1.508,50$ & 0,27 \\
\hline Enoxaparina & solução injetável & $40 \mathrm{mg}$ & 21.850 & $404.896,00$ & 0,27 \\
\hline Neostigmina & solução injetável & $0,5 \mathrm{mg}$ & 21.800 & $12.766,00$ & 0,27 \\
\hline Atazanavir & cápsula gelatinosa dura & $200 \mathrm{mg}$ & 21.720 & $134.960,83$ & 0,27 \\
\hline Bicalutamida & comprimido simples & $50 \mathrm{mg}$ & 21.015 & $53.816,80$ & 0,26 \\
\hline Capecitabina & comprimido simples & $500 \mathrm{mg}$ & 20.804 & $275.294,40$ & 0,25 \\
\hline Enalapril & comprimido simples & $5 \mathrm{mg}$ & 20.781 & $3.343,66$ & 0,25 \\
\hline Meropenem IV & pó liófilo injetável & $500 \mathrm{mg}$ & 20.500 & $377.900,00$ & 0,25 \\
\hline Ácido folinico & comprimido simples & $15 \mathrm{mg}$ & 20.460 & $6.279,86$ & 0,25 \\
\hline Tramadol & comprimido simples & $50 \mathrm{mg}$ & 20.000 & $1.300,00$ & 0,24 \\
\hline Ondansetrona & solução injetável & $8 \mathrm{mg}$ & 19.750 & $12.479,44$ & 0,24 \\
\hline Hidrocortisona succinato & pó liófilo injetável & $100 \mathrm{mg}$ & 19.000 & $15.361,35$ & 0,23 \\
\hline Imatinib & comprimido simples & $400 \mathrm{mg}$ & 18.840 & $3.103 .500,00$ & 0,23 \\
\hline Propofol & emulsão injetável & $200 \mathrm{mg}$ & 18.630 & $37.073,70$ & 0,23 \\
\hline
\end{tabular}


Continuação

\begin{tabular}{|c|c|c|c|c|c|}
\hline Nome do Medicamento & Forma Farmacêutica & Concentração & $\begin{array}{l}\text { Quantidade } \\
\text { Recebida } \\
\text { (unidades) }\end{array}$ & $\begin{array}{c}\text { Valor } \\
\text { Total (R\$) }\end{array}$ & $\begin{array}{l}\% \text { do } \\
\text { Gasto } \\
\text { Total }\end{array}$ \\
\hline Propranolol & comprimido simples & $40 \mathrm{mg}$ & 18.500 & 366,30 & 0,23 \\
\hline Ciprofloxacina & solução injetável & $100 \mathrm{Ml}$ & 18.250 & $31.645,00$ & 0,22 \\
\hline Solução glicofisiológica & solução injetável & $1 \mathrm{~L}$ & 17.952 & $43.152,97$ & 0,22 \\
\hline Dexclorfeniramina & comprimido simples & $2 \mathrm{mg}$ & 17.540 & $2.294,92$ & 0,21 \\
\hline Metronidazol & solução injetável & $500 \mathrm{mg}$ & 17.440 & $11.809,60$ & 0,21 \\
\hline Amlodipina & comprimido simples & $5 \mathrm{mg}$ & 17.220 & $3.201,60$ & 0,21 \\
\hline Furosemida & comprimido simples & $40 \mathrm{mg}$ & 17.210 & 409,30 & 0,21 \\
\hline Ceftriaxona injetável IV & pó liófilo injetável & $1 \mathrm{~g}$ & 17.100 & $19.007,00$ & 0,21 \\
\hline Carbonato de cálcio & comprimido mastigável & $500 \mathrm{mg}$ & 16.520 & $1.756,08$ & 0,20 \\
\hline Lorazepam & comprimido simples & $2 \mathrm{mg}$ & 16.200 & 723,20 & 0,20 \\
\hline Bicarbonato de sódio $8,4 \%$ & solução injetável & $5 \mathrm{~L}$ & 16.075 & $76.169,43$ & 0,20 \\
\hline Ocitocina & solução injetável & $5 \mathrm{UI}$ & 16.000 & $7.996,80$ & 0,20 \\
\hline Nifedipina (retard) & comprimido simples & $20 \mathrm{mg}$ & 15.430 & $5.423,40$ & 0,19 \\
\hline Ácido fólico & comprimido simples & $5 \mathrm{mg}$ & 15.306 & $1.346,29$ & 0,19 \\
\hline Clindamicina & cápsula gelatinosa dura & $300 \mathrm{mg}$ & 15.248 & $3.953,11$ & 0,19 \\
\hline Dexclorfeniramina & comprimido revestido & $6 \mathrm{mg}$ & 15.156 & $9.555,81$ & 0,19 \\
\hline Contraste $\mathrm{p} /$ angiografia cerebral & solução injetável & $50 \mathrm{~mL}$ & 15.150 & $806.250,00$ & 0,19 \\
\hline Cápsulas gelatinosas $n^{\circ} 0$, coloridas & material de embalagem & ---- & 15.000 & 134,85 & 0,18 \\
\hline Cápsulas gelatinosas $n^{\circ} 2$, coloridas & material de embalagem & ---- & 15.000 & 134,85 & 0,18 \\
\hline Nalbufina & solução injetável & $10 \mathrm{mg}$ & 14.800 & $117.801,92$ & 0,18 \\
\hline Diazepam & comprimido simples & $10 \mathrm{mg}$ & 14.400 & 203,20 & 0,18 \\
\hline Pirazinamida & comprimido simples & $500 \mathrm{mg}$ & 14.150 & $1.719,69$ & 0,17 \\
\hline Bromoprida & comprimido simples & $10 \mathrm{mg}$ & 14.068 & $1.626,06$ & 0,17 \\
\hline Atracurio besilato & cápsula gelatinosa dura & $25 \mathrm{mg}$ & 14.025 & $32.193,75$ & 0,17 \\
\hline Didanosina (liberação prolongada) & comprimido simples & $400 \mathrm{mg}$ & 13.950 & $47.603,07$ & 0,17 \\
\hline Paracetamol + codeina & comprimido simples & $500 \mathrm{mg}+30 \mathrm{mg}$ & 13.764 & $4.603,86$ & 0,17 \\
\hline Itraconazol & cápsula gelatinosa dura & $100 \mathrm{mg}$ & 13.726 & $3.974,09$ & 0,17 \\
\hline Solução de glicose 5\% & solução injetável & $100 \mathrm{~mL}$ & 13.674 & $16.866,36$ & 0,17 \\
\hline Fenitoina & solução injetável & $250 \mathrm{mg}$ & 13.600 & $7.764,35$ & 0,17 \\
\hline
\end{tabular}


Continuação

\begin{tabular}{|c|c|c|c|c|c|}
\hline Nome do Medicamento & Forma Farmacêutica & Concentração & $\begin{array}{l}\text { Quantidade } \\
\text { Recebida } \\
\text { (unidades) }\end{array}$ & $\begin{array}{c}\text { Valor } \\
\text { Total (R\$) }\end{array}$ & $\begin{array}{c}\% \text { do } \\
\text { Gasto } \\
\text { Total }\end{array}$ \\
\hline Solução de glicose $5 \%$ & solução injetável & $250 \mathrm{~mL}$ & 13.590 & $18.546,00$ & 0,17 \\
\hline Ondansetrona & solução injetável & $4 \mathrm{mg}$ & 13.556 & $5.212,42$ & 0,17 \\
\hline Heparina sódica IV & solução injetável & $25000 \mathrm{UI}$ & 13.525 & $20.418,75$ & 0,17 \\
\hline Amitriptilina & comprimido simples & $25 \mathrm{mg}$ & 13.500 & 193,40 & 0,16 \\
\hline Lidocaína 2\% & solução injetável & $20 \mathrm{~mL}$ & 13.400 & $10.587,00$ & 0,16 \\
\hline Hidroclorotiazida & comprimido simples & $50 \mathrm{mg}$ & 13.300 & 703,85 & 0,16 \\
\hline Hidralazina & comprimido simples & $50 \mathrm{mg}$ & 13.000 & $2.242,65$ & 0,16 \\
\hline Abacavir & comprimido revestido & $300 \mathrm{mg}$ & 12.960 & $55.834,25$ & 0,16 \\
\hline Baclofeno & comprimido simples & $10 \mathrm{mg}$ & 12.465 & $1.465,20$ & 0,15 \\
\hline Bicarbonato de sódio $8,4 \%$ & solução injetável & $10 \mathrm{~mL}$ & 12.300 & $4.139,50$ & 0,15 \\
\hline Metoclopramida & solução injetável & $10 \mathrm{mg}$ & 12.000 & $2.052,00$ & 0,15 \\
\hline Dexclorfeniramina & comprimido simples & $5 \mathrm{mg}$ & 11.900 & $5.423,00$ & 0,15 \\
\hline Ciprofloxacina & comprimido simples & $500 \mathrm{mg}$ & 11.800 & $1.207,56$ & 0,14 \\
\hline Dopamina & solução injetável & $50 \mathrm{mg}$ & 11.800 & $5.066,00$ & 0,14 \\
\hline Midazolam & solução injetável & $5 \mathrm{mg}$ & 11.550 & $7.560,20$ & 0,14 \\
\hline Micofenolato sódico & comprimido simples & $360 \mathrm{mg}$ & 11.520 & $75.347,64$ & 0,14 \\
\hline Dipirona & comprimido simples & $500 \mathrm{mg}$ & 11.000 & 373,50 & 0,13 \\
\hline Gentamicina & solução injetável & $40 \mathrm{mg}$ & 10.930 & $17.271,10$ & 0,13 \\
\hline Dipirona & solução oral & $500 \mathrm{mg}$ & 10.880 & $11.791,55$ & 0,13 \\
\hline Vitamina C & solução injetável & $500 \mathrm{mg}$ & 10.860 & $3.114,10$ & 0,13 \\
\hline Etambutol & comprimido simples & $400 \mathrm{mg}$ & 10.840 & $1.098,24$ & 0,13 \\
\hline Lidocaína 1\% & solução injetável & $20 \mathrm{~mL}$ & 10.840 & $11.319,22$ & 0,13 \\
\hline Prednisona & comprimido simples & $5 \mathrm{mg}$ & 10.800 & 196,08 & 0,13 \\
\hline Gentamicina & solução injetável & $60 \mathrm{mg}$ & 10.700 & $2.848,34$ & 0,13 \\
\hline Pirimetamina & comprimido simples & $25 \mathrm{mg}$ & 10.700 & 528,85 & 0,13 \\
\hline Lidocaína 2\% & gel & $30 \mathrm{~mL}$ & 10.560 & $8.146,98$ & 0,13 \\
\hline Bicarbonato de sódio & comprimido simples & $500 \mathrm{mg}$ & 10.477 & $3.133,53$ & 0,13 \\
\hline Temozolamida & cápsula gelatinosa dura & $5 \mathrm{mg}$ & 10.047 & $3.929,54$ & 0,12 \\
\hline Metformina & comprimido simples & $500 \mathrm{mg}$ & 9.990 & 875,39 & 0,12 \\
\hline
\end{tabular}


Continuação

\begin{tabular}{|c|c|c|c|c|c|}
\hline Nome do Medicamento & Forma Farmacêutica & Concentração & $\begin{array}{l}\text { Quantidade } \\
\text { Recebida } \\
\text { (unidades) }\end{array}$ & $\begin{array}{c}\text { Valor } \\
\text { Total (R\$) }\end{array}$ & $\begin{array}{l}\% \text { do } \\
\text { Gasto } \\
\text { Total }\end{array}$ \\
\hline Ácido valpróico & comprimido simples & $250 \mathrm{mg}$ & 9.900 & $2.133,00$ & 0,12 \\
\hline Espironolactona & comprimido simples & $25 \mathrm{mg}$ & 9.900 & 661,50 & 0,12 \\
\hline Metoprolol & comprimido simples & $100 \mathrm{mg}$ & 9.900 & $4.303,75$ & 0,12 \\
\hline Dinitrato de isossorbida & comprimido simples & $10 \mathrm{mg}$ & 9.790 & 422,50 & 0,12 \\
\hline Piridostigmina & comprimido simples & $60 \mathrm{mg}$ & 9.600 & $2.852,52$ & 0,12 \\
\hline Ácido ursodesoxicolico & comprimido simples & $50 \mathrm{mg}$ & 9.500 & $7.691,40$ & 0,12 \\
\hline Amoxicilina + clavulanato & pó liófilo injetável & $1 \mathrm{~g}$ & 9.400 & $42.100,00$ & 0,11 \\
\hline Ceftazidima & pó liófilo injetável & $1 \mathrm{~g}$ & 9.310 & $21.072,90$ & 0,11 \\
\hline Fluoxetina & cápsula gelatinosa dura & $20 \mathrm{mg}$ & 9.250 & 303,54 & 0,11 \\
\hline Varfarina & comprimido simples & $5 \mathrm{mg}$ & 9.240 & 790,56 & 0,11 \\
\hline Claritromicina & comprimido simples & $500 \mathrm{mg}$ & 9.054 & $7.787,82$ & 0,11 \\
\hline Petidina & solução injetável & $100 \mathrm{mg}$ & 8.800 & $4.044,72$ & 0,11 \\
\hline Enalapril & comprimido simples & $20 \mathrm{mg}$ & 8.744 & $2.432,30$ & 0,11 \\
\hline Midazolam & solução injetável & $15 \mathrm{mg}$ & 8.600 & $5.484,00$ & 0,11 \\
\hline Carvedilol & comprimido simples & $6,25 \mathrm{mg}$ & 8.512 & $1.319,36$ & 0,10 \\
\hline Diclofenaco sódico & comprimido simples & 50 mg & 8.500 & 303,00 & 0,10 \\
\hline Didanosina (liberação prolongada) & comprimido simples & $250 \mathrm{mg}$ & 8.310 & $21.016,90$ & 0,10 \\
\hline Cetoprofeno & cápsula gelatinosa dura & $50 \mathrm{mg}$ & 8.280 & 596,16 & 0,10 \\
\hline Bisacodil & comprimido revestido & $5 \mathrm{mg}$ & 8.200 & $1.312,00$ & 0,10 \\
\hline Óleo mineral & solução tópica & $100 \mathrm{~mL}$ & 7.784 & $9.815,12$ & 0,10 \\
\hline Albumina humana & solução injetável & $50 \mathrm{~mL}$ & 7.575 & $692.403,00$ & 0,09 \\
\hline Fenobarbital & comprimido simples & $100 \mathrm{mg}$ & 7.500 & 162,30 & 0,09 \\
\hline Hidroxietilamida & solução injetável & $500 \mathrm{~mL}$ & 7.379 & $245.481,50$ & 0,09 \\
\hline Enoxaparina & solução injetável & $60 \mathrm{mg}$ & 7.220 & $190.749,50$ & 0,09 \\
\hline Cefalexina & cápsula gelatinosa dura & $500 \mathrm{mg}$ & 7.208 & 959,62 & 0,09 \\
\hline Solução p/ hemodiálise (cálcio 3,5 meq/l) & solução injetável & $5 \mathrm{~L}$ & 7.203 & $30.932,76$ & 0,09 \\
\hline Amiodarona & solução injetável & $150 \mathrm{mg}$ & 7.200 & $3.670,00$ & 0,09 \\
\hline Amiodarona & comprimido simples & $200 \mathrm{mg}$ & 7.100 & 528,40 & 0,09 \\
\hline Ampicilina & pó liófilo injetável & $500 \mathrm{mg}$ & 7.000 & $3.936,60$ & 0,09 \\
\hline
\end{tabular}


Continuação

\begin{tabular}{|c|c|c|c|c|c|}
\hline Nome do Medicamento & Forma Farmacêutica & Concentração & $\begin{array}{l}\text { Quantidade } \\
\text { Recebida } \\
\text { (unidades) }\end{array}$ & $\begin{array}{c}\text { Valor } \\
\text { Total (R\$) }\end{array}$ & $\begin{array}{c}\% \text { do } \\
\text { Gasto } \\
\text { Total } \\
\end{array}$ \\
\hline Clonidina & solução injetável & $150 \mathrm{mcg}$ & 7.000 & $23.222,98$ & 0,09 \\
\hline Isoniazida + rifampicina & comprimido simples & $200 \mathrm{mg}+300 \mathrm{mg}$ & 7.000 & $1.134,01$ & 0,09 \\
\hline Fentanila & solução injetável & $0,10 \mathrm{mg}$ & 6.900 & $4.995,00$ & 0,08 \\
\hline Fosamprenavir calcico & comprimido simples & $700 \mathrm{mg}$ & 6.900 & $50.182,10$ & 0,08 \\
\hline Fenobarbital sódico IV & solução injetável & $200 \mathrm{mg}$ & 6.850 & $3.920,25$ & 0,08 \\
\hline $\mathrm{N}$-acetilcisteina $10 \%$ & solução injetável & $3 \mathrm{~mL}$ & 6.800 & $4.558,00$ & 0,08 \\
\hline Aciclovir & solução injetável & $250 \mathrm{mg}$ & 6.750 & $22.540,00$ & 0,08 \\
\hline Brometo de ipratropio & solução nasal & $20 \mathrm{~mL}$ & 6.660 & $5.414,30$ & 0,08 \\
\hline Efavirenz & cápsula gelatinosa dura & $200 \mathrm{mg}$ & 6.570 & $7.686,48$ & 0,08 \\
\hline \multicolumn{6}{|l|}{ Curva C } \\
\hline Metildopa & comprimido simples & $250 \mathrm{mg}$ & 6.560 & 664,59 & 0,08 \\
\hline Diazepam & comprimido simples & $5 \mathrm{mg}$ & 6.500 & 132,65 & 0,08 \\
\hline Atenolol & comprimido simples & $100 \mathrm{mg}$ & 6.304 & 178,6 & 0,08 \\
\hline Contraste $\mathrm{p} /$ uro/radiologia vascular & solução injetável & $50 \mathrm{~mL}$ & 6.300 & 155300 & 0,08 \\
\hline Acetato de ciproterona & comprimido simples & $50 \mathrm{mg}$ & 6.230 & 2741,2 & 0,08 \\
\hline Dimeticona & solução oral & $75 \mathrm{mg} / \mathrm{mL}$ & 6.190 & 3139,42 & 0,08 \\
\hline Olanzapina & comprimido simples & $10 \mathrm{mg}$ & 6.188 & 66246,32 & 0,08 \\
\hline Ac. Mucopolissacarideo polissulfurico & pomada & $40 \mathrm{~g}$ & 6.060 & 65979,5 & 0,07 \\
\hline Clozapina & comprimido simples & $100 \mathrm{mg}$ & 6.054 & 11496,06 & 0,07 \\
\hline Filgrastima & pó liófilo injetável & $300 \mathrm{mcg}$ & 6.024 & 83131,2 & 0,07 \\
\hline Diltiazem, cloridrato & comprimido simples & $60 \mathrm{mg}$ & 5.940 & 524,94 & 0,07 \\
\hline Calcitriol & cápsula gelatinosa dura & $0,25 \mathrm{mcg}$ & 5.882 & 407,45 & 0,07 \\
\hline Metotrexato sódico & comprimido simples & $2,5 \mathrm{mg}$ & 5.808 & 2117,04 & 0,07 \\
\hline Propatilnitrato & comprimido simples & $10 \mathrm{mg}$ & 5.700 & 1146 & 0,07 \\
\hline Bupivacaina pesada $0,5 \%$ & solução injetável & $4 \mathrm{~mL}$ & 5.600 & 8292 & 0,07 \\
\hline Clonazepam & comprimido simples & $2 \mathrm{mg}$ & 5.600 & 125,8 & 0,07 \\
\hline Amicacina & solução injetável & $500 \mathrm{mg}$ & 5.550 & 2636,25 & 0,07 \\
\hline Lidocaina 2\% & gel & $1,8 \mathrm{Ml}$ & 5.550 & 1358,25 & 0,07 \\
\hline Nistatina & suspensão oral & $100000 \mathrm{UI} / \mathrm{mL}$ & 5.450 & 7235,8 & 0,07 \\
\hline
\end{tabular}




\begin{tabular}{|c|c|c|c|c|c|}
\hline Nome do Medicamento & Forma Farmacêutica & Concentração & $\begin{array}{l}\text { Quantidade } \\
\text { Recebida } \\
\text { (unidades) }\end{array}$ & $\begin{array}{c}\text { Valor } \\
\text { Total (R\$) }\end{array}$ & $\begin{array}{l}\% \text { do } \\
\text { Gasto } \\
\text { Total }\end{array}$ \\
\hline Clopidogrel & comprimido revestido & $75 \mathrm{mg}$ & 5.376 & 11456,76 & 0,07 \\
\hline \multicolumn{6}{|l|}{... } \\
\hline Dexclorfeniramina & solução oral & $2 \mathrm{mg} / 5 \mathrm{~mL}$ & 1 & 2,87 & 0,00001 \\
\hline Levamisol & comprimido simples & $80 \mathrm{mg}$ & 1 & 1,41 & 0,00001 \\
\hline
\end{tabular}




\section{APÊNDICE B}

\section{Adjuvantes produtos sólidos}

Uma formulação excipiente é constituída pela mistura de componentes com diferentes funções (ALDERBORN, 2005; ANSEL; POPOVICH; ALLEN Jr, 2000; PECK et all, 1989; BANDELIN, 1989):

a) Diluentes: dão o volume necessário para a formulação, proporcionando comprimidos com dimensões adequadas, especialmente quando o princípio ativo é empregado em pequenas concentrações. Normalmente são empregados mais de um diluente na proporção de $30-50 \%$ do peso do princípio ativo. Os diluentes mais comuns são celulose, celulose microcristalina, amido, amido pré-gelatinizado, lactose, lactose monohidratada.

b) Aglutinante: promovem a adesão das partículas no processo de granulação e permite a formação de comprimidos com resistência mecânica adequada. A quantidade empregada varia de $8-10 \%$ em relação ao peso do princípio ativo. Normalmente emprega-se polivinilpirrolidona (PVP K30), gelatina, goma arábica, carboximetilcelulose (CMC).

c) Lubrificante: melhora as propriedades de fluxo da formulação, importantes para o processo de compressão. A quantidade empregada não deve ser superior a $3 \%$ do peso do princípio ativo. Tem função lubrificante o talco, a sílica, o estearato de magnésio e o ácido esteárico.

d) Tensoativo: compõem apenas $1 \%$ da formulação. $O$ tensoativo mais utilizado é o polissorbato.

e) Desintegrante: garantem que o comprimido, quando em contato com líquidos desintegre em partículas menores e promova a dissolução do fármaco de maneira mais rápida. Empregados na quantidade de $3-5 \%$ do peso do princípio ativo, somente quando é necessário utilizar mais que $10 \%$ de aglutinante. São desintegrantes o amido glicolato de sódio, o ácido tartárico + bicarbonato de sódio e o manitol.

f) Líquido de umedecimento: empregados no processo de formação dos grânulos quando os comprimidos são produzidos pela via úmida. A quantidade varia de 10$20 \%$ em relação ao peso da formulação total (princípio ativo + excipiente). Não 
participa do peso final do comprimido, pois o líquido evapora no processo de secagem. Comumente é empregada uma mistura de água purificada e álcool etílico. g) Outros adjuvantes: podem ser adicionados à formulação excipiente outros adjuvantes como corretivo de $\mathrm{pH}$, corantes e flavorizantes.

Para os comprimidos revestidos é preciso, após a compressão, aplicar uma solução de revestimento. Os revestimentos podem ser empregados para proteger o comprimido, por exemplo, no caso de princípio ativo sensível à luz ou umidade; para mascarar sabor e para facilitar a deglutição. Neste caso, emprega-se o revestimento por película, a seco ou drageamento, sendo o primeiro a técnica mais moderna e mais empregada atualmente. Quando se deseja modificar as propriedades de liberação do fármaco a partir da forma farmacêutica, gerando as chamadas formas de liberação modificada empregam-se os revestimentos funcionais (HOGAN, J., 2005).

Quando se deseja dar brilho aos comprimidos revestidos é utilizada cera de abelha ou carnaúba. 


\section{Adjuvantes produtos estéreis}

Os adjuvantes que compõem uma solução injetável são (BILLANY, 2005):

a) Solvente: o principal constituinte das soluções parenterais é o solvente, normalmente água, que deve ter qualidade de água para injetáveis. A quantidade de solvente utilizada corresponde ao volume final desejado para a formulação;

b) Co-solventes: empregados quando é preciso aumentar a solubilidade do fármaco na água. Para tal finalidade o mais comum é utilizar uma mistura de etanol e água. Outros co-solventes são sorbitol em água, glicerina e propilenoglicol;

c) Controle do $\mathrm{pH}$ : grande parte dos fármacos é ácido ou base fraca, portanto sua solubilidade em água pode ser influenciada pelo $\mathrm{pH}$ do sistema. Além disso, é importante o controle do $\mathrm{pH}$ em soluções injetáveis já que extremos de $\mathrm{pH}$ podem causar dor, irritação e até mesmo danos ao tecido. Para redução do pH da solução utiliza-se ácido cítrico, ácido clorídrico, ácido fosfórico ou ácido tartárico. Já para aumentá-lo pode ser empregado bicarbonato de sódio.

d) Tensoativos: os tensoativos são adicionados à solução para aumentar a solubilidade de fármacos insolúveis ou pouco solúveis em água. Polissorbatos, macrogol, óleo de rícino polioxietilado são adjuvantes com propriedades tensoativas.

e) Agentes isotonizantes: soluções injetáveis para aplicação nas mucosas devem ser isotônicas em relação ao fluido tissular para evitar dor e irritação. Normalmente utiliza-se cloreto de sódio ou dextrose. 


\section{APÊNDICE C}

\section{Controle de qualidade}

Testes realizados para controle de qualidade físico-químico e microbiológico em matéria-prima, água purificada e de qualidade injetável, produtos sólidos, produtos injetáveis e área asséptica ou capela de fluxo laminar segundo parâmetros determinados na Farmacopéia Brasileira e na Farmacopéia Americana (Farm. bras., 1996; USP, 1999).

\subsection{Controle de qualidade físico-químico}

Tabela 38 - Testes realizados no controle de qualidade físico-químico de matéria-prima

\begin{tabular}{lc}
\hline \multicolumn{1}{c}{ Teste } & Equipamento (s) \\
\hline Identificação & espectrofotômetro UV/VIS \\
HPLC & espectrofotômetro UV/VIS \\
Doseamento & HPLC \\
$\begin{array}{l}\text { Impurezas ou Produtos de } \\
\text { Degradação* }\end{array}$ & espectrofotômetro UV/VIS \\
Ponto de fusão & HPLC \\
\hline${ }^{*}$ quando especificado na monografia (USP24, 1999) &
\end{tabular}

Tabela 39 - Testes realizados no controle de qualidade físico-químico de água purificada e água de qualidade injetável

\begin{tabular}{lc}
\hline \multicolumn{1}{c}{ Teste } & Equipamento (s) \\
\hline $\mathrm{pH}$ & $\mathrm{pHmetro}$ \\
Condutividade & condutivímetro \\
Teor de oxigênio & medidor de oxigênio dissolvido \\
\hline
\end{tabular}


Tabela 40 - Testes realizados no controle de qualidade físico-químico de produtos sólidos (comprimido simples e comprimidos revestidos)

\begin{tabular}{lc}
\hline \multicolumn{1}{c}{ Teste } & Equipamento (s) \\
\hline Identificação & espectrofotômetro UV/VIS \\
HPLC & espectrofotômetro UV/VIS \\
HPLC & espectrofotômetro UV/VIS \\
Impurezas ou Produtos de Degradação* & HPLC \\
Uniformidade de conteúdo** & espectrofotômetro UV/VIS \\
& HPLC \\
Dureza & durômetro \\
Desintegração & desintegrador \\
Teste de dissolução & dissolutor \\
\hline${ }^{*}$ quando especificado na monografia (USP24, 1999); ${ }^{* *}$ comprimidos cujo teor de substância \\
ativa é inferior a 50mg/unidade, quando corresponde a menos de $50 \%$ do peso da unidade e \\
para todos os comprimidos revestidos e sólidos estéreis de dose única.
\end{tabular}

Tabela 41 - Testes realizados no controle de qualidade físico-químico de produtos sólidos exigidos apenas para comprimidos simples

\begin{tabular}{lc}
\hline \multicolumn{1}{c}{ Teste } & Equipamento (s) \\
\hline Umidade* $^{*}$ & dessecador \\
Variação de peso/ Peso médio & balança analítica \\
Friabilidade & friabilômetro \\
\hline${ }^{*}$ quando especificado na monografia $(U S P 24,1999)$ &
\end{tabular}

* quando especificado na monografia (USP24, 1999)

Tabela 42 - Testes realizados no controle de qualidade físico-químico de produtos injetáveis (soluções e pós liófilos injetáveis)

\begin{tabular}{lc}
\hline \multicolumn{1}{c}{ Teste } & Equipamento (s) \\
\hline Identificação & espectrofotômetro UV/VIS \\
Hoseamento & HPLC \\
espectrofotômetro UV/VIS \\
HPLC \\
espectrofotômetro UV/VIS \\
HPLC
\end{tabular}

* quando especificado na monografia (USP24, 1999)

Tabela 43 - Testes realizados no controle de qualidade de produtos injetáveis exigidos apenas para soluções injetáveis

\begin{tabular}{lc}
\hline \multicolumn{1}{c}{ Teste } & Equipamento (s) \\
\hline Teste de material particulado & aparelho revisor \\
Volume médio/Variação de volume & visual \\
$\mathrm{pH}$ & pHmetro \\
\hline
\end{tabular}


Tabela 44 - Testes realizados no controle de qualidade físico-químico de produtos injetáveis exigidos apenas para pós liófilos injetáveis

\begin{tabular}{lc}
\hline \multicolumn{1}{c}{ Teste } & Equipamento (s) \\
\hline Umidade & dessecador \\
Variação de peso/ Peso médio & balança analítica \\
Uniformidade de conteúdo & espectrofotômetro UV/VIS \\
& HPLC \\
\hline
\end{tabular}

Tabela 45 - Equipamentos de apoio ao setor de controle de qualidade físicoquímico

\begin{tabular}{lc}
\hline \multicolumn{1}{c}{ Teste } & Equipamento (s) \\
\hline Armazenamento de água purificada & barrilete de PVC 50L \\
Armazenamento e Análise dos dados & computador \\
Conservação de substâncias termosessíveis & geladeira \\
Controle de umidade e temperatura & termo/higrometrodigital \\
Esterilização e Secagem de vidrarias & estufa esterilização e secagem \\
Pesagem de reagentes & balança semi-analítica \\
& balança analítica \\
Produção de água para HPLC & sistema de água MiliQ \\
Outros & utensílios e vidrarias \\
\hline
\end{tabular}

\subsection{Controle de qualidade microbiológico}

Tabela 46 - Testes realizados no controle de qualidade microbiológico de qualidade microbiológico de matéria-prima

\begin{tabular}{lc}
\hline \multicolumn{1}{c}{ Teste } & Equipamento (s) \\
\hline Contagem de microrganismos viáveis & estufa \\
Teste LAL & fluxolaminar vertical \\
& fluxolaminar vertical \\
\hline
\end{tabular}

Tabela 47 - Testes realizados no controle de qualidade microbiológico de água purificada e água de qualidade injetável

\begin{tabular}{lc}
\hline \multicolumn{1}{c}{ Teste } & Equipamento (s) \\
\hline Contagem de microrganismos viáveis & estufa \\
Teste LAL & fluxolaminar vertical \\
fluxolaminar vertical
\end{tabular}


Tabela 48 - Testes realizados no controle de qualidade microbiológico de produtos sólidos (comprimidos revestidos e comprimidos simples)

\begin{tabular}{cc}
\hline Teste & Equipamento (s) \\
\hline Contagem de microrganismos viáveis & estufa \\
& fluxolaminar vertical \\
\hline
\end{tabular}

Tabela 49 - Testes realizados no controle de qualidade microbiológico de produtos injetáveis (soluções e pós liófilos injetáveis)

\begin{tabular}{ll}
\hline \multicolumn{1}{c}{ Teste } & Equipamento (s) \\
\hline Teste de esterilidade & estufa bacteriológica \\
& fluxolaminar vertical \\
Teste LAL & fluxolaminar vertical \\
\hline
\end{tabular}

Tabela 50 - Testes realizados no controle de qualidade microbiológico ambiental da área asséptica ou capela de fluxo laminar

\begin{tabular}{lc}
\hline \multicolumn{1}{c}{ Teste } & Equipamento (s) \\
\hline Contagem de partículas & aparelho para contagem de partículas \\
Contagem de microganismos viáveis & estufa bacteriológica \\
& fluxolaminar vertical \\
\hline
\end{tabular}

Tabela 51 - Equipamentos de apoio ao setor de controle de qualidade microbiológico

\begin{tabular}{ll}
\hline Teste & Equipamento (s) \\
\hline Armazenamento de água purificada & barrilete de PVC 50L \\
Armazenamento e Análise dos dados & $\begin{array}{l}\text { computador } \\
\text { geladeira } \\
\text { Conservação de substâncias termosessíveis }-20^{\circ} \mathrm{C}\end{array}$ \\
freezer & termo/higrometrodigital \\
Esterilização e Secagem de vidrarias & $\begin{array}{l}\text { estufa esterilização e secagem } \\
\text { balança semi-analítica }\end{array}$ \\
Pesagem de reagentes & $\begin{array}{l}\text { balança analítica } \\
\text { autoclave }\end{array}$ \\
Preparo de meios de cultura & $\begin{array}{l}\text { agitador magnético com } \\
\text { aquecimento } \\
\text { sistema de água MiliQ } \\
\text { utensílios e vidrarias }\end{array}$ \\
\hline
\end{tabular}




\section{APÊNDICE D}

\section{Levantamento dos custos variáveis de produção - CVP}

a) mão-de-obra diretamente relacionada ao processo produtivo:

Tabela 52 - Valores de salários e encargos referentes à mão de obra diretamente relacionada ao processo produtivo*

\begin{tabular}{lccc}
\hline & Farmacêutico & Técnico & Auxiliar \\
\hline Salário & $1.340,75$ & 906 & 500 \\
$13^{\circ}$ (Provisão Mensal) & 111,73 & 75,5 & 41,67 \\
Férias (Provisão Mensal) & 145,25 & 98,15 & 54,17 \\
Total & $\mathbf{1 . 5 9 7 , 7 3}$ & $\mathbf{1 . 0 7 9 , 6 5}$ & $\mathbf{5 9 5 , 8 3}$ \\
INSS & 460,15 & 310,94 & 171,6 \\
FGTS & 127,82 & 129,56 & 71,5 \\
Prov. Multa (50\%) & 63,91 & 64,78 & 35,75 \\
Total Tributos & $\mathbf{6 5 1 , 8 7}$ & $\mathbf{4 4 0 , 5}$ & $\mathbf{2 4 3 , 1}$ \\
Total & $\mathbf{2 . 2 4 9 , 6 0}$ & $\mathbf{1 . 5 8 4 , 9 3}$ & $\mathbf{8 7 4 , 6 8}$ \\
\hline
\end{tabular}

* valores referentes a janeiro de 2009

b) matéria-prima (formulação excipiente, princípio ativo e material de embalagem) e material de consumo:

Os custos com a matéria-prima foram obtidos com base na média dos valores dos princípios ativos, acrescido do excipiente e embalagem do medicamento. A fim de evitar distorções no cálculo do princípio ativo optou-se por utilizar à média, pois os custos dessa matéria-prima são variáveis.

Não foi possível obter os valores dos princípios ativos de todos os medicamentos selecionados para o estudo, devido à grande variedade e a dificuldade de conseguir cotações com as empresas distribuidoras. A média foi feita entre os valores de alguns princípios ativos para os quais foi obtido o valor de mercado. Para o estudo de viabilidade foram considerados somente os de menor valor. A exclusão dos princípios ativos de maior valor não implica em erro no cálculo, uma vez que a quantidade de princípio ativo considerada não é usual em formulações farmacêuticas com estas substâncias, que normalmente estão presentes em concentrações de microgramas. 
Tabela 53 - Valor dos princípios ativos utilizados para o cálculo do valor de matéria-prima*

\begin{tabular}{cc}
\hline Principio Ativo & Custo/Kg (R\$) \\
\hline 1- Omeprazol & 60 \\
2- Diazepan & 300 \\
3- Fluoxetiana & 130 \\
4- Amitriptilina & 200 \\
5- Lorazepan & 2.700 \\
6- Atenolol & 120 \\
7- Fenobarbital & 100 \\
8- Propanolol & 20 \\
9- Gabapentina & 300 \\
10- Nortriptilina & 360 \\
11- Ramipril & $6.000,00$ \\
12- Residronato & $15.000,00$ \\
13- Fludrocortisona & $140.000,00$ \\
14- Tibolona & $55.000,00$ \\
15- Diassereina & $2.000,00$ \\
16- Tacrolimus & $568.000,00$ \\
* valores referentes a janeiro de 2009
\end{tabular}

Utilizou-se como padrão $250 \mathrm{mg}$ de princípio ativo, para o cálculo de viabilidade considerou-se o valor médio dos dez primeiros princípios ativos, que equivale a $\mathrm{R} \$ 429,00$ por quilo.

Outras variações utilizaram a média de todos os valores de princípio ativo cotados, equivalente a $R \$ 49.393,13$ por quilo e a média excluindo o tacrolimus, $\mathrm{R} \$ 14.819,33$ e a média somente dos princípios ativos de maior valor (11 a 16) $\mathrm{R} \$ 131.000,00$.

Incluindo a formulação excipiente e a embalagem, o custo médio total de uma unidade de produto sólido foi $R \$ 0,26$ e de injetável $R \$ 0,90$.

c) material de consumo:

Os filtros utilizados no processo de clarificação e esterilização dos medicamentos injetáveis devem ser trocados a cada lote de produção, portanto, foram considerados como material de consumo. No caso, quantidade mensal consumida são 20 unidades de cada, já que foi considerada a produção de um lote por dia.

Cada unidade de filtro para clarificação custa $R \$ 453,47$ e de filtro para esterilização $\mathrm{R} \$ 511,18$.

d) energia consumida pelos equipamentos durante o processo de produção: 
Tabela 54 - Consumo mensal de energia elétrica dos equipamentos do setor de produtos sólidos*

\begin{tabular}{lccc}
\hline Equipamento & Consumo KWH/mês & Consumo MWH/mês & Total (R\$) \\
\hline Balança & 8,316000 & 0,008316 & 1,530144 \\
Misturador em V & 16,632000 & 0,016632 & 3,060288 \\
Granulador & 24,948000 & 0,024948 & 4,590432 \\
Estufa & 88,704000 & 0,088704 & 16,321536 \\
Granulador & 0,498960 & 0,000499 & 0,091809 \\
Misturador em V & 8,316000 & 0,008316 & 1,530144 \\
Compressora & 26,825806 & 0,026826 & 4,935948 \\
Drageadeira & 33,264000 & 0,033264 & 6,120576 \\
Embaladora & 46,200000 & 0,046200 & 8,500800 \\
\hline Valor Total & & & 46,68 \\
\hline Valor da Tarifa & &
\end{tabular}

Tabela 55 - Consumo mensal de energia elétrica dos equipamentos do setor de produtos injetáveis*

\begin{tabular}{lccc}
\hline \multicolumn{1}{c}{ Equipamento } & Consumo KWH/mês & Consumo MWH/mês & Total (R\$) \\
\hline Balança (produtos & 166,320000 & 0,166320 & 30,602880 \\
injetáveis) & 17,000000 & 0,017000 & 3,128000 \\
Reator & 10,000000 & 0,010000 & 1,840000 \\
Envasadora & 324,000000 & 0,324000 & 59,616000 \\
Freezer - $35^{\circ} \mathrm{C}$ & 468,000000 & 0,468000 & 86,112000 \\
Liofilizador & 20,000000 & 0,020000 & 3,680000 \\
Autoclave & 400,000000 & 0,400000 & 73,600000 \\
Fluxo Laminar & 684,000000 & 0,684000 & 125,856000 \\
Estufa & & & 384,43 \\
\hline Valor Total
\end{tabular}

$*$ valores referentes a janeiro de 2009 


\section{Levantamento dos custos de implantação e do valor residual}

Os custos do projeto básico e da construção infra-estrutura foram fornecidos por empresa especializada na construção de áreas destinadas a empresas farmacêuticas e outras do setor saúde, os valores correspondem ao custo por metro quadrado. Para almoxarifado, controle de qualidade, produção de água e produção de medicamentos sólidos estão incluídos infra-estrutura de bancada, pisos, móveis, capela (controle de qualidade físico-químico), sistema de exaustão (produção de sólidos) etc. $\mathrm{O}$ custo por $\mathrm{m}^{2}$ para a área destinada a produção de injetáveis inclui infra-estrutura de bancada, pisos, portas, forro, exaustão, HVAC e outros, todos de acordo com as exigências específicas de área limpa. Não estão dimensionados nem quantificados neste cálculo todo o processo de tratamento dos resíduos gerados nos laboratórios (esgoto, lixo sólido e líquido, gases). Também não estão inclusos custos de estacionamentos, vias de acesso, obras como fundações e terraplanagem, tampouco as respectivas áreas. Estes custos não foram considerados, pois já integram o complexo hospitalar.

Para os sanitários foi considerado o valor do metro quadrado para construção civil no Estado de São Paulo.

Tabela 56 - Valor de construção da infra-estrutura da farmácia semi-industrial para produção de medicamentos hospitalares*

\begin{tabular}{|c|c|c|c|}
\hline DESCRIÇÃO & $\begin{array}{c}\text { VALOR } \\
\text { UNITARIO (R\$) }\end{array}$ & $\begin{array}{c}\text { QUANTIDADE } \\
\left(\mathrm{m}^{2}\right)\end{array}$ & VALOR TOTAL (R\$) \\
\hline Projeto básico & 420,00 & 153 & $64.260,00$ \\
\hline Almoxarifado matéria-prima & $2.500,00$ & 20 & $50.000,00$ \\
\hline Produção de água & $2.500,00$ & 8 & $20.000,00$ \\
\hline Produção de sólidos & $4.500,00$ & 40 & $180.000,00$ \\
\hline Produção de estéreis & $6.200,00$ & 40 & $248.000,00$ \\
\hline Controle de qualidade físico-químico & $2.500,00$ & 10 & $25.000,00$ \\
\hline Controle de qualidade microbiológico & $2.500,00$ & 10 & $25.000,00$ \\
\hline Almoxarifado produto acabado & $2.500,00$ & 15 & $37.500,00$ \\
\hline Sanitários & $2.000,00$ & 10 & $20.000,00$ \\
\hline TOTAL & & & $669.760,00$ \\
\hline
\end{tabular}

* valores referentes a janeiro de 2009

Todos os equipamentos selecionados tanto para as diferentes etapas de produção quanto para o controle de qualidade e produção de água foram cotados 
em empresas fabricantes ou fornecedoras os valores obtidos incluídos como custo de implantação do projeto. As cotações referem-se a valores de janeiro de 2009.

Tabela 57 - Valor dos equipamentos da unidade de produção de água purificada e água de qualidade injetável*

\begin{tabular}{lccc}
\hline \multicolumn{1}{c}{ EQUIPAMENTO } & $\begin{array}{c}\text { VALOR } \\
\text { UNITÁRIO }\end{array}$ & QUANTIDADE & VALOR TOTAL \\
\hline Água purificada & & & \\
Sistema de purificação de água 4 fases 10L/h & $2.500,00$ & 1 & $2.500,00$ \\
Barrilete de PVC 50L & 273,33 & 5 & $1.366,65$ \\
Água injetável & & & \\
Sistema de purificação de água 4 fases 10L/h & $2.500,00$ & 1 & $2.500,00$ \\
Sistema de purificação de água 4 fases 10L/h & $2.500,00$ & 1 & $2.500,00$ \\
Barrilete de PVC 50L & 273,33 & 5 & $1.366,65$ \\
Medidor de ph, oxigênio dissolvido e condutividade & $11.635,00$ & 1 & $11.635,00$ \\
TOTAL & & & $\mathbf{2 5 . 7 3 4 , 9 5}$ \\
\hline
\end{tabular}

${ }^{*}$ valores referentes a janeiro de 2009

Tabela 58 - Valor dos equipamentos da unidade de controle de qualidade físicoquímico*

\begin{tabular}{lccc}
\hline \multicolumn{1}{c}{ EQUIPAMENTO } & VALOR UNITARIO & QUANTIDADE & VALOR TOTAL \\
\hline Dissolutor & $26.368,33$ & 1 & $26.368,33$ \\
Durômetro & $16.611,15$ & 1 & $16.611,15$ \\
Friabilômetro & $7.272,99$ & 1 & $7.272,99$ \\
Desintegrador & $11.328,51$ & 1 & $11.328,51$ \\
Phmetro & 545,00 & 1 & 545,00 \\
Eletrodo pH simples & 173,25 & 1 & 173,25 \\
Espectrofotômetro & $30.675,00$ & 1 & $30.675,00$ \\
HPLC analítico & $116.700,00$ & 1 & $116.700,00$ \\
Ponto de fusão & 800,00 & 1 & 800,00 \\
Balança c/ capela & $2.692,00$ & 1 & $2.692,00$ \\
Balança analítica & $4.133,00$ & 1 & $4.133,00$ \\
Barrilete de PVC 50L & 273,33 & 1 & 273,33 \\
Termo/higrometrodigital s/ sensor & 96,57 & 1 & 96,57 \\
Utensílios e Vidrarias & $5.000,00$ & 1 & $5.000,00$ \\
Estufa Esterilização e Secagem & $1.616,00$ & 1 & $1.616,00$ \\
Computador & $3.500,00$ & 1 & $3.500,00$ \\
Geladeira & $1.200,00$ & 1 & $1.200,00$ \\
Sistema de água miliq & $46.680,00$ & 1 & $46.680,00$ \\
Condutivímetro & 646,00 & 1 & 646,00 \\
TOTAL & & & $\mathbf{2 7 6 . 3 1 1 , 1 3}$ \\
\hline
\end{tabular}

* valores referentes a janeiro de 2009 
Tabela 59 - Valor dos equipamentos da unidade de controle de qualidade microbiológico*

\begin{tabular}{lccc}
\hline \multicolumn{1}{c}{ EQUIPAMENTO } & VALOR UNITARIO & QUANTIDADE & VALOR TOTAL \\
\hline Estufa Bacteriológica & $1.736,00$ & 1 & $1.736,00$ \\
Estufa esterilização e secagem & $1.616,00$ & 1 & $1.616,00$ \\
Câmara de Fluxo Laminar Vertical & $24.200,00$ & 1 & $24.200,00$ \\
Utensílios e vidrarias & $5.000,00$ & 1 & $5.000,00$ \\
Balança c/ capela semi-analítica & $2.692,00$ & 1 & $2.692,00$ \\
Agitador magnético com aquecimento & 620,00 & 1 & 620,00 \\
Freezer - 20 C & $1.500,00$ & 1 & $1.500,00$ \\
Geladeira & $1.200,00$ & 1 & $1.200,00$ \\
Computador & $3.500,00$ & 1 & $3.500,00$ \\
Termo/higrometrodigital s/ sensor & 96,57 & 1 & 96,57 \\
TOTAL & & & $\mathbf{4 2 . 1 6 0 , 5 7}$ \\
\hline
\end{tabular}

* valores referentes a janeiro de 2009

Tabela 60 - Valor dos equipamentos da unidade de produção de medicamentos sólidos*

\begin{tabular}{lccc}
\hline \multicolumn{1}{c}{ EQUIPAMENTO } & VALOR UNITARIO & QUANTIDADE & VALOR TOTAL \\
\hline Balança capacidade 10Kg & 945,00 & 1 & 945,00 \\
Misturador em V & $19.600,00$ & 1 & $19.600,00$ \\
Granulador & $24.850,00$ & 1 & $24.850,00$ \\
Estufa & $45.500,00$ & 1 & $45.500,00$ \\
Compressora & $54.500,00$ & 1 & $54.500,00$ \\
Drageadeira & $22.500,00$ & 1 & $22.500,00$ \\
Embaladora & $46.880,00$ & 1 & $46.880,00$ \\
TOTAL & & & $\mathbf{2 1 4 . 7 7 5 , 0 0}$ \\
\hline
\end{tabular}

* valores referentes a janeiro de 2009

Tabela 61 - Valor dos equipamentos da unidade de produção de medicamentos injetáveis*

\begin{tabular}{lccc}
\hline \multicolumn{1}{c}{ EQUIPAMENTO } & VALOR UNITÁRIO & QUANTIDADE & VALOR TOTAL \\
\hline Estufa esterilização e secagem & $1.616,00$ & 1 & $1.616,00$ \\
Autoclave & $4.265,00$ & 1 & $4.265,00$ \\
Balança & 945,00 & 1 & 945,00 \\
Reator 50L (aquecimento e agitação) & $9.860,00$ & 1 & $9.860,00$ \\
Filtro 0,4 um & 1,00 & 1 & 1,00 \\
Filtro 0,22 um & 1,00 & 1 & 1,00 \\
Envasadeira de ampolas & $60.000,00$ & 1 & $60.000,00$ \\
Freezer -35 C & $8.500,00$ & 1 & $8.500,00$ \\
Liofilizador de bandejas & $25.000,00$ & 1 & $25.000,00$ \\
Câmara de Fluxo Laminar Vertical & $30.000,00$ & 1 & $30.000,00$ \\
Etiquetadora & $1.538,00$ & 1 & $1.538,00$ \\
TOTAL & & & $\mathbf{1 4 1 . 7 2 6 , 0 0}$ \\
\hline
\end{tabular}

* valores referentes a janeiro de 2009 
Os filtros estão considerados como zero por serem empregados um para cada lote produzido, portanto, são custos variáveis de produção.

Como os equipamentos de maior porte são fabricados em aço, o valor residual foi calculado considerando o peso do equipamento e o seu valor como sucata em aço. Para equipamentos muito leves ou feitos de material plástico não foi considerado valor residual.

Tabela 62 - Valor residual dos equipamentos considerando sua venda como sucata de aço*

\begin{tabular}{|c|c|c|c|}
\hline & $\begin{array}{l}\text { PESO } \\
(\mathrm{Kg})\end{array}$ & $\begin{array}{c}\text { PREÇO } \\
\text { AÇO (R\$) }\end{array}$ & $\begin{array}{c}\text { VENDA } \\
\text { SUCATA (R\$) }\end{array}$ \\
\hline \multicolumn{4}{|l|}{ Injetáveis } \\
\hline Autoclave & 160 & 0,16 & 25,6 \\
\hline Balança & 2,63 & 0,16 & 0,4208 \\
\hline Reator para líquidos $50 \mathrm{~L}$ com aquecimento e agitação & 120 & 0,16 & 19,2 \\
\hline Envasadeira de ampolas & 160 & 0,16 & 25,6 \\
\hline freezer $-35^{\circ} \mathrm{C}$ & 20 & 0,16 & 3,2 \\
\hline Liofilizador de bandejas & 60 & 0,16 & 9,6 \\
\hline Câmara Fluxo Laminar & 25 & 0,16 & 4 \\
\hline \multicolumn{4}{|l|}{ Sólidos } \\
\hline Balança & 2,63 & 0,16 & 0,42 \\
\hline Misturador em V & 60,00 & 0,16 & 9,60 \\
\hline Granulador & 90,00 & 0,16 & 14,40 \\
\hline Estufa & 35,00 & 0,16 & 5,60 \\
\hline Compressora & 160,00 & 0,16 & 25,60 \\
\hline Drageadeira & 65,00 & 0,16 & 10,40 \\
\hline Embaladora & 90,00 & 0,16 & 14,40 \\
\hline \multicolumn{4}{|l|}{ Controle de qualidade } \\
\hline Dissolutor & 20 & 0,16 & 3,2 \\
\hline Durômetro & 10 & 0,16 & 1,6 \\
\hline Friabilômetro & 10 & 0,16 & 1,6 \\
\hline Desintegrador & 30 & 0,16 & 4,8 \\
\hline Espectrofotômetro & 30 & 0,16 & 4,8 \\
\hline HPLC analítico & 20 & 0,16 & 3,2 \\
\hline Estufa Esterilização e Secagem & 50 & 0,16 & 8 \\
\hline Geladeira & 20 & 0,16 & 3,2 \\
\hline Estufa Bacteriológica & 50 & 0,16 & 8 \\
\hline Estufa Esterilização e Secagem & 50 & 0,16 & 8 \\
\hline Câmara de Fluxo Laminar Vertical & 25 & 0,16 & 4 \\
\hline Câmara Fluxo Laminar & 25 & 0,16 & 4 \\
\hline Agitador magnético com aquecimento & 3 & 0,16 & 0,48 \\
\hline Freezer - $20 \mathrm{C}$ & 20 & 0,16 & 3,2 \\
\hline Geladeira & 20 & 0,16 & 3,2 \\
\hline Total & & & 229,32 \\
\hline
\end{tabular}

* valores referentes a janeiro de 2009 
Anexos 


\section{ANEXO}

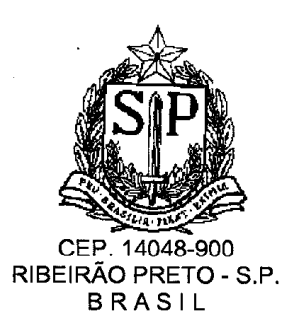

HOSPITAL DAS CLÍNICAS DA FACULDADE DE MEDICINA DE RIBEIRÃO PRETO DA UNIVERSIDADE DE SÃO PAULO

CAMPUS UNIVERSITÁRIO - MONTE ALEGRE FONE: 602-1000 - FAX (016) 633-1144

Ribeirão Preto, 27 de abril de 2005

Oficio $\mathrm{n}^{\circ} 1159 / 2005$

CEP/SPC

Ref.: Processo HCRP n ${ }^{\circ} 2107 / 2005$

Prezada Senhora:

O trabalho intitulado "ESTUDO DA

VIABILIDADE FARMACOECONÔMICA DA PRODUÇÃO SEMIINDUSTRIAL DE MEDICAMENTOS EM HOSPITAL DE GRANDE

PORTE", foi analisado pelo Comitê de Ética em Pesquisa, em sua $200^{a}$ Reunião Ordinária realizada em 25/04/2005, e como este estudo tratase de casuística onde não envolve seres humanos, não há necessidade de submetê-lo à avaliação específica do Comitê de Ética.

Aproveito a oportunidade para apresentar a Vossa Senhoria protestos de estima e consideração.

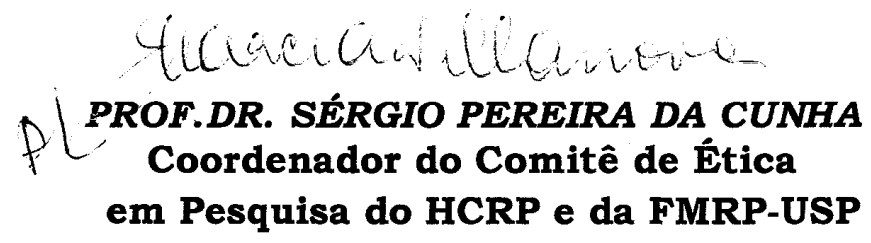

Ilustríssima Senhora

CAMILA ALVES AREDA(Orientanda)

PROF. DR. OSVALDO DE FREITAS(Orientador)

Faculdade de Ciências Farmacêuticas - USP - Depto. de Ciências

Farmacêuticas

Em mãos 